\title{
Análisis Teórico-Experimental del Canal Radio en Microceldas y Entornos Especiales para Sistemas de Comunicaciones Móviles de Banda Ancha
}

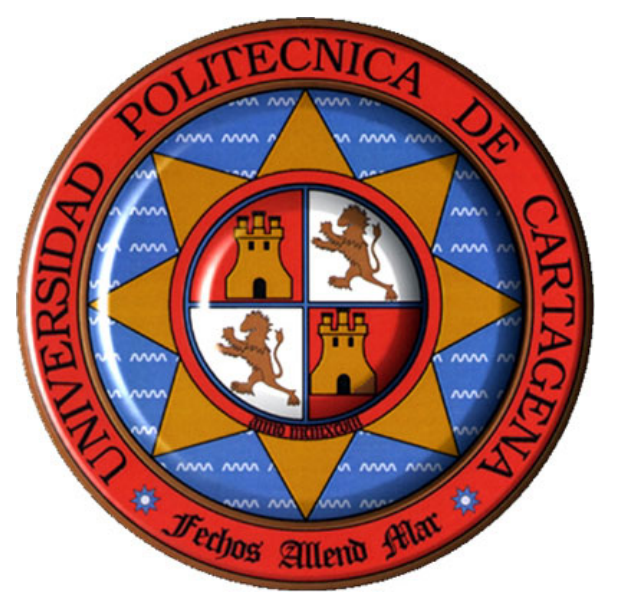

Universidad Politécnica de Cartagena Departamento de Tecnologías de la Información y las Comunicaciones

José María Molina García-Pardo

Director

Dr. D. Leandro Juan Llácer 



\section{AUTORIZACIÓN DEL DIRECTOR/A DE LA TESIS}

D. Leandro Juan Llácer Profesor Doctor del área de Teoría de la Señal y las Comunicaciones en el Departamento de Tecnologías de la Información y las Comunicaciones

\section{A U T O R I Z A:}

La presentación de la Tesis Doctoral titulada “ANÁLISIS TEÓRICO-EXPERIMENTAL DEL CANAL RADIO EN MICROCELDAS Y ENTORNOS ESPECIALES PARA SISTEMAS DE COMUNICACIONES MÓVILES DE BANDA ANCHA”, realizada por D. José María Molina García-Pardo, bajo mi dirección y supervisión, en el Departamento de Tecnologías de la Información y las Comunicaciones

, y que presenta para la obtención del grado de Doctor por la Universidad Politécnica de Cartagena.

En Cartagena, a de de

EL DIRECTOR DE TESIS

Fdo.: Leandro Juan Llácer 

UNIVERSIDAD POLITÉCNICA DE CARTAGENA

Comisión de Doctorado

\section{AUTORIZACIÓN DEL DEPARTAMENTO RESPONSABLE}

$D^{a}$. Bárbara Álvarez Torres Directora del Departamento Tecnologías de la Información y las Comunicaciones

\section{N F O R M A:}

Que la Tesis Doctoral titulada "ANÁLISIS TEÓRICO-EXPERIMENTAL DEL CANAL RADIO EN MICROCELDAS Y ENTORNOS ESPECIALES PARA SISTEMAS DE COMUNICACIONES MÓVILES DE BANDA ANCHA", ha sido realizada por D. José María Molina García-Pardo bajo la dirección y supervisión de D. Leandro Juan Yacer y que el Departamento ha dado su conformidad para que sea presentada ante la Comisión de Doctorado.

En Cartagena, a de de

LA DIRECTORA DEL DEPARTAMENTO

Fdo.: Bárbara Álvarez Torres 

A mi familia 



\section{AGRADECIMIENTOS}

Quiero expresar mi gratitud a Leandro Juan Llácer, director de la tesis, por su labor desempeñada en el desarrollo de la misma y demostrarme que al final todo llega.

Quisiera agradecer a mis compañeros y amigos del área de Teoría de la Señal y las Comunicaciones y al resto del departamento Tecnologías de la Información y las Comunicaciones por haberme acompañado estos años, y entre todos compartir la difícil tarea de levantar una escuela.

A mis amigos de Cartagena, Valencia, Newcastle upon Tyne y Torre de la Horadada, por los grandes momentos que hemos pasado juntos.

A mi familia, mis padres y mi hermana, que siempre están ahí.

Y por último, pero no menos importante, a Marta, por su cariño y su apoyo en todo momento. 



\section{Índice}

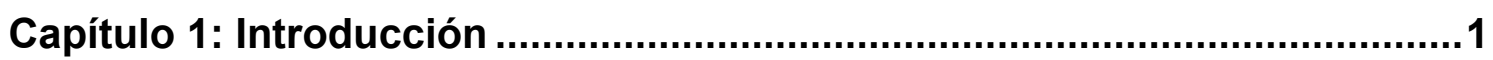

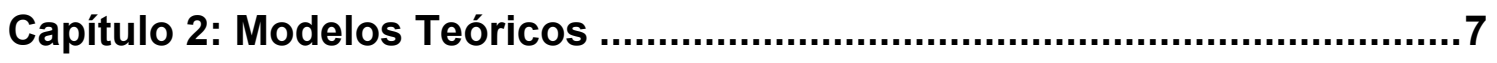

2.1 Lanzado de rayos para sistemas de banda ancha ..................................

2.1.1 Función UTD de banda ancha ....................................................10

2.1.2 Transformación de la respuesta en frecuencia al Perfil de Retardo..11

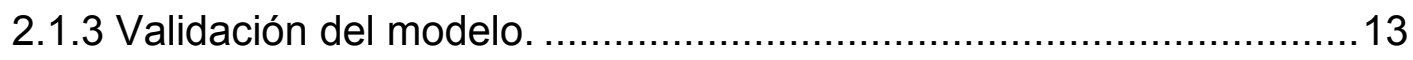

2.2 Lanzado de rayos para sistemas MIMO ………...............................14

2.3 Herramienta para cálculo de la capacidad MIMO mediante el lanzado de

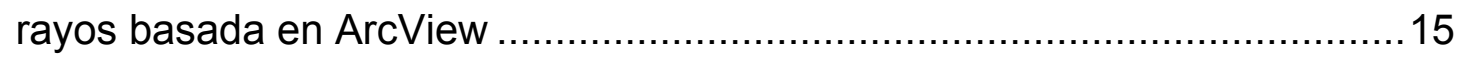

2.3.1 Descripción de la herramienta....................................................16

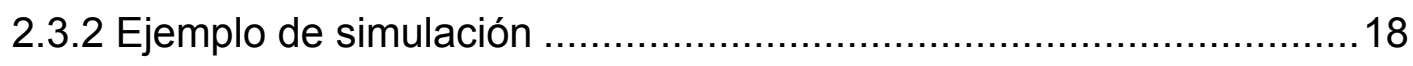

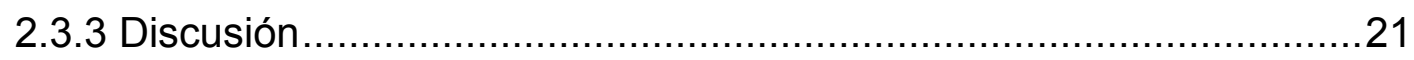

2.4 Modelo paramétrico basado en el trazado de rayos para MIMO ............21

2.4.1 Revisión del modelo de onda plana ..............................................22 
2.4.2 Modelo paramétrico: contribuciones......................................23

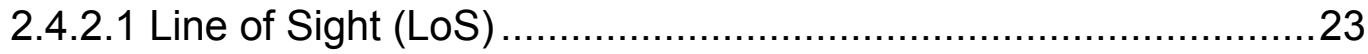

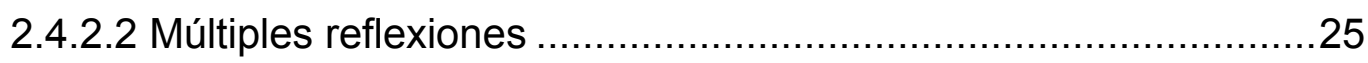

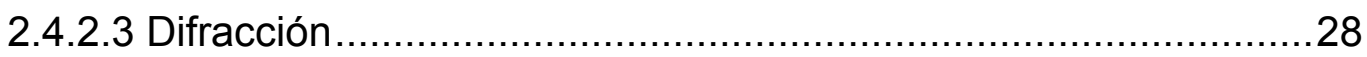

2.4.2.4 Modelo de banda ancha y de banda estrecha ........................ 30

Capítulo 3: Propagación en Túneles ........................................................31

3.1 Resultados teóricos para túneles y sistemas SISO ..............................32

3.1.1 Dispersión espacial en la transición de entrada a un túnel ...............32

3.1.1.1 Entorno de propagación ................................................. 33

3.1.1.2 Modelo de propagación ............................................... 34

3.1.1.3 Resultados................................................................. 34

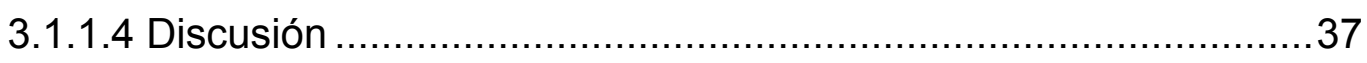

3.1.2 Cálculo de la zona de excitación para diversos túneles ..................37

3.1.2.1 Entorno de propagación .................................................... 37

3.1.2.2 Modelo de propagación .....................................................38

3.1.2.3 Definición de la zona de excitación.......................................38

3.1.2.4 Resultados............................................................... 40

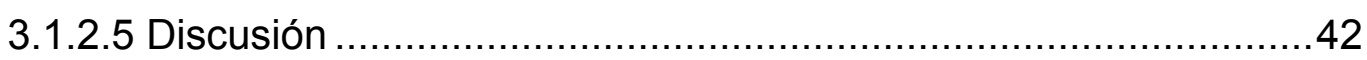

3.2 Medidas SISO en un túnel pequeño .............................................42

3.2.1 Entorno de propagación ..................................................43

3.2.2 Sistema de medidas ...........................................................4

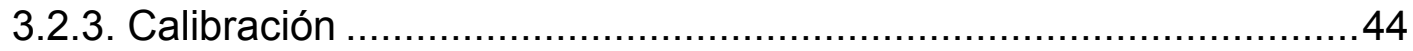

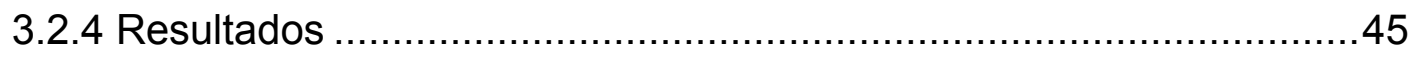

3.2.4.1 Pérdidas de propagación ................................................. 45

3.2.4.2. Perfil de retardo ........................................................... 47

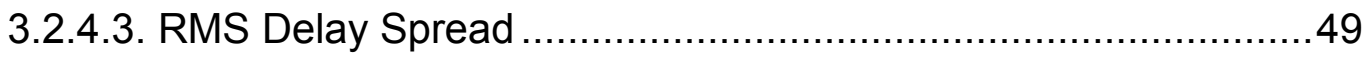

3.2.4.4 Ancho de banda de coherencia ............................................50

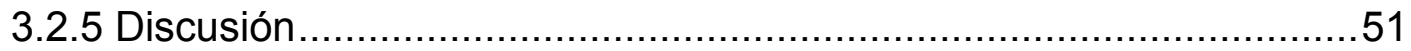

3.3 Resultados teóricos para túneles y sistemas MIMO ............................51

3.3.1. Entorno de propagación .................................................52

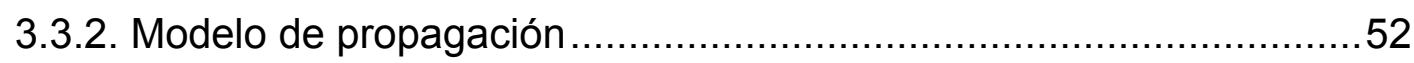

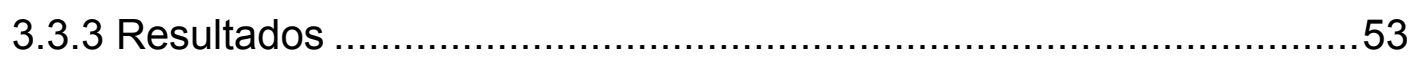

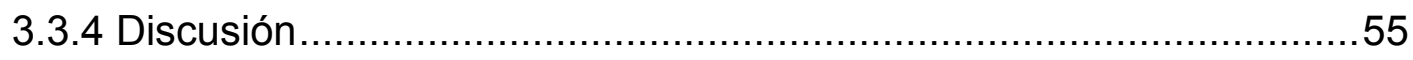


Capítulo 4: Propagación en Microceldas

4.1 Dispersión temporal teórica en cruces de cuatro esquinas y de cuatro chaflanes .58

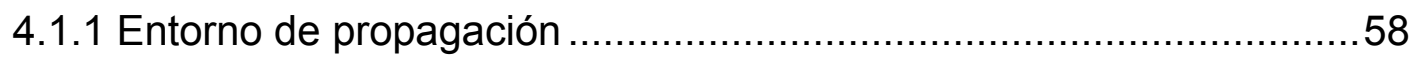

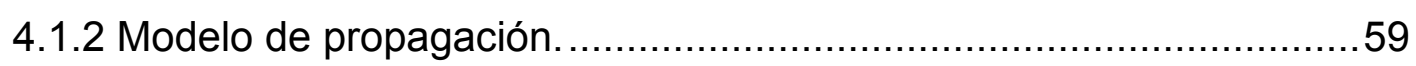

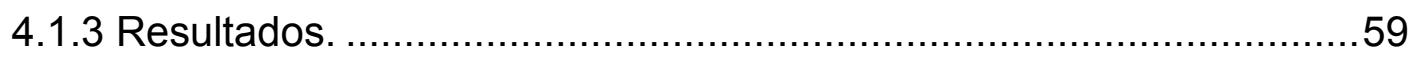

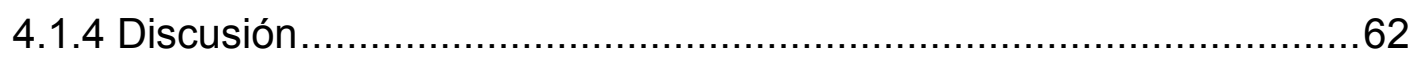

4.2 Medidas SISO en cruces de cuatro esquinas y cuatro chaflanes ............63 63

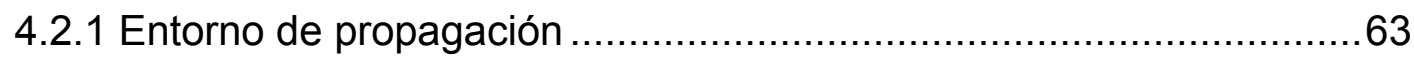

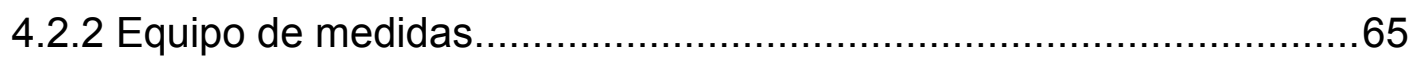

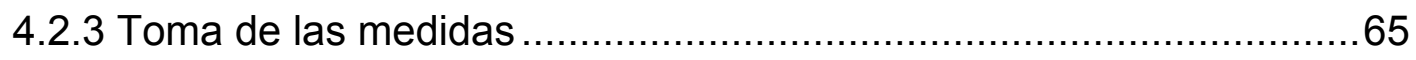

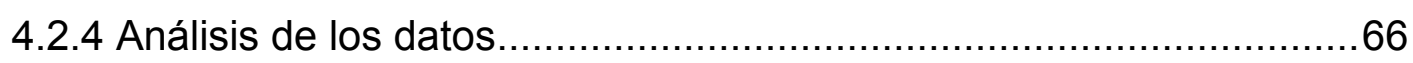

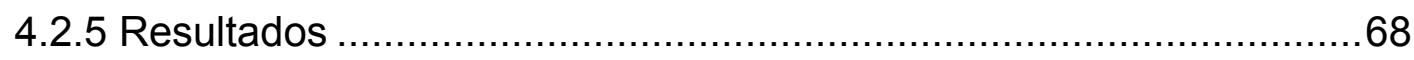

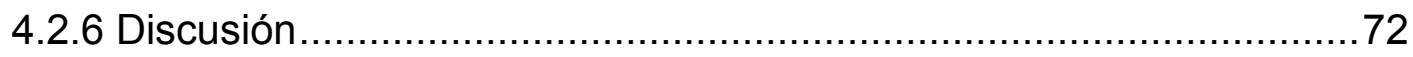

4.3 Simulaciones MIMO en cruces de cuatro esquinas y cuatro chaflanes ...73

4.3.1 Entorno de propagación ......................................................... 73

4.3.2 Modelo de propagación.................................................. 74

4.3.3 Capacidad según la orientación de los arrays..............................75

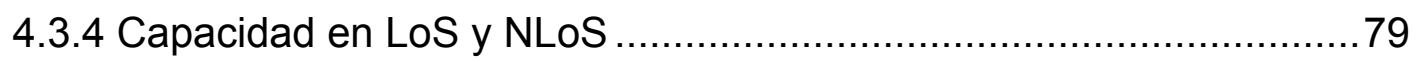

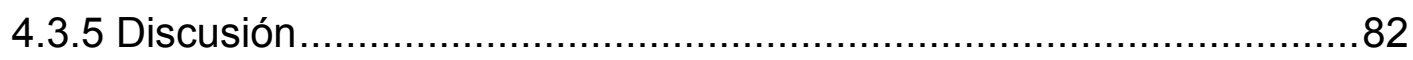

4.4 Modelo paramétrico MIMO. .................................................... 83

4.4.1 Simulaciones de entornos simples .......................................... 83

4.4.2 Simulaciones de un entorno microcelular real............................... 88

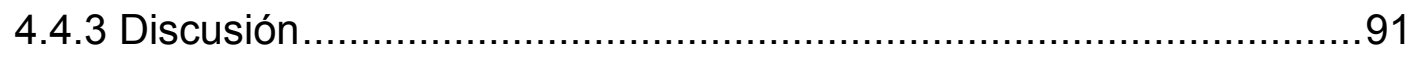

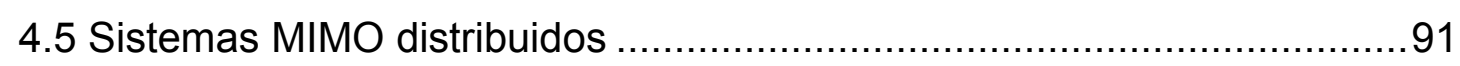

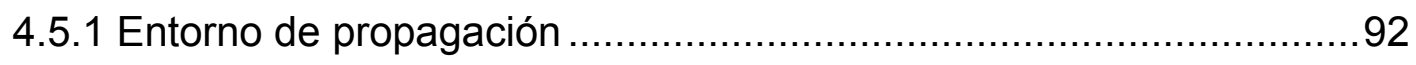

4.5.2 Modelos de propagación .................................................93

4.5.3 Capacidad en entorno abierto con un sistema distribuido.................93

4.5.4 Capacidad en entorno urbano con un sistema distribuido.................96

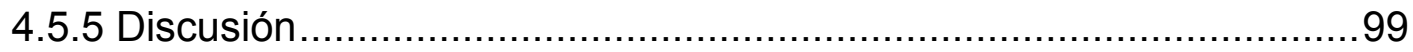

Capítulo 5: Sistema de Medidas para Canales MIMO.................................101

5.1 Descripción del equipo de medidas ............................................. 102

5.1.1 Analizador de redes multipuerto ENA ..................................103 


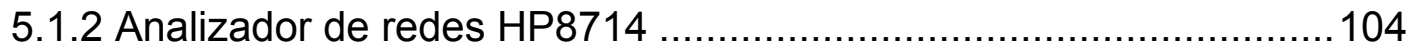

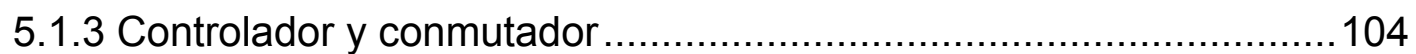

5.1.4 GPS Thunderbolt Disciplined Clock Start Kit y antena BULLET III .105

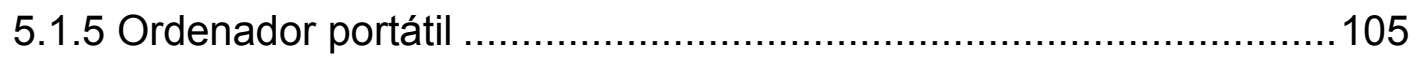

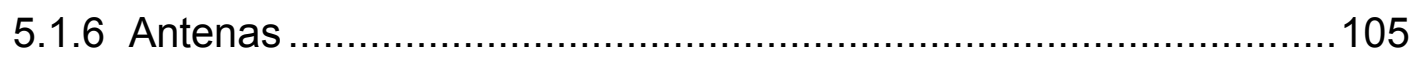

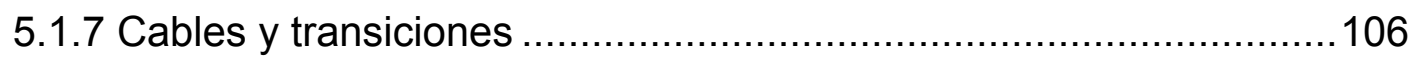

5.1.8 Baterías y convertidores de corriente ........................................106

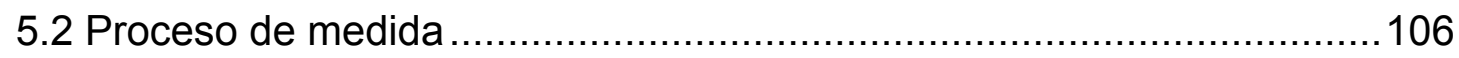

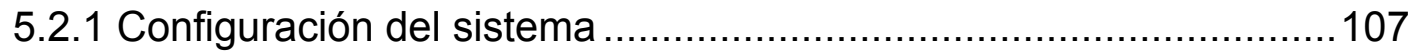

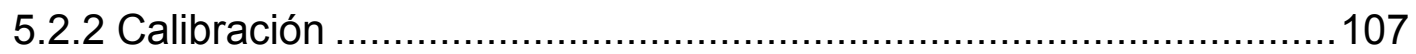

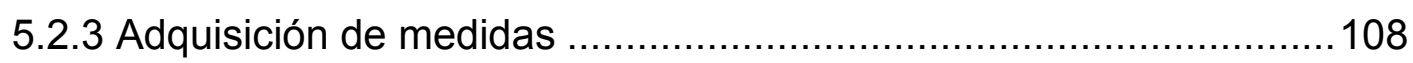

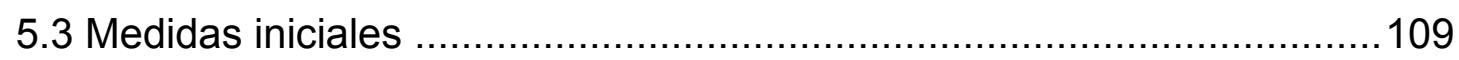

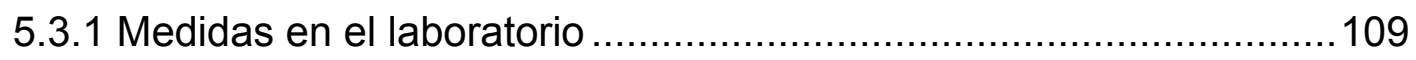

5.3.2 Medidas en el patio de la universidad ........................................110

5.3.3 Nuevas medidas en el laboratorio ...............................................112

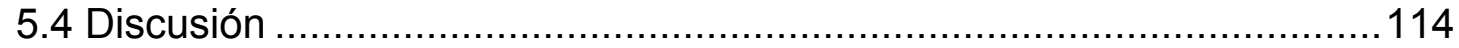

Capítulo 6: Conclusiones ......................................................................117

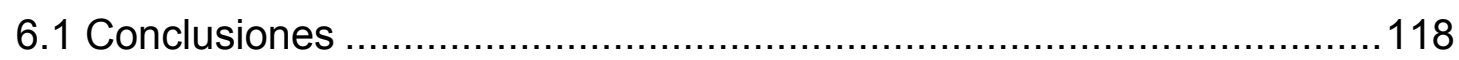

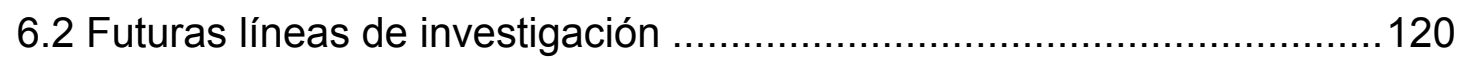

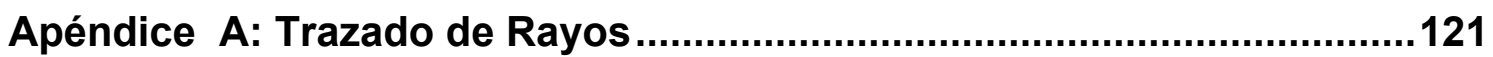

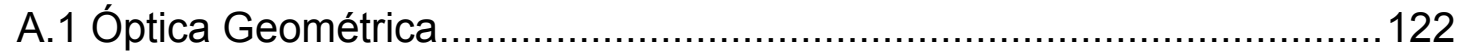

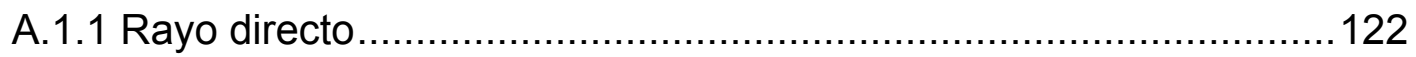

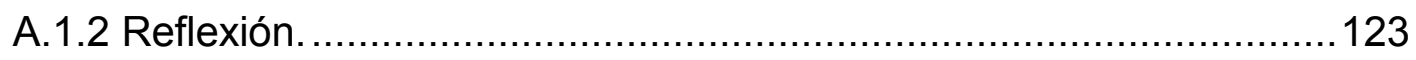

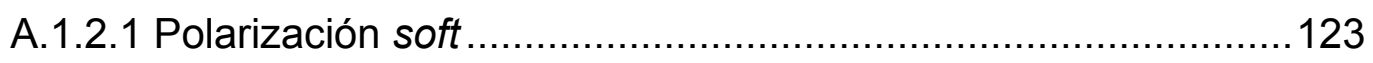

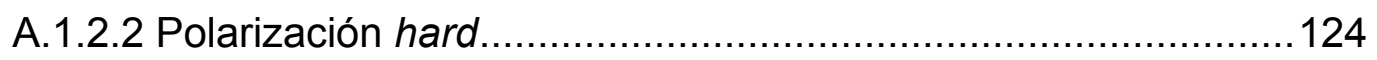

A.1.2.3 Campo eléctrico definido por un rayo reflejado .......................125

A.2 Teoría Uniforme de la Difracción ........................................................125

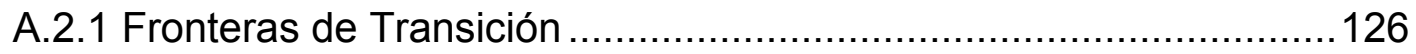

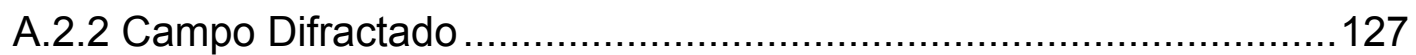

A.2.3 El Coeficiente Diádico de Difracción ..........................................128

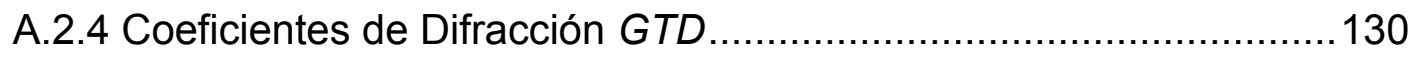

A.2.5 Difracción UTD en una cuña de paredes de conductividad finita....131 
A.2.6 Campo eléctrico definido por un rayo difractado......................... 132

A.3 Resumen de las diferentes contribuciones del trazador ......................133

Apéndice B: Caracterización del Canal Radio ........................................135

B.1 Desvanecimiento lento del canal (Large-Scale Fading) .......................136

B.2 Desvanecimiento rápido del canal (Small-Scale fading)......................137

B.3 Ergodicidad, estacionariedad en sentido amplio y dispersores incorrelados ............................................................................... 139

B.4 Parámetros del canal radioeléctrico .............................................. 140

B.4.1 Perdidas de propagación ................................................. 140

B.4.2 Retardo medio y dispersión del retardo ....................................141

B.4.3 Ancho de banda de coherencia .......................................... 142

B.4.4 Tiempo de coherencia .................................................. 142

B.4.5 Doppler medio y dispersión Doppler ......................................143

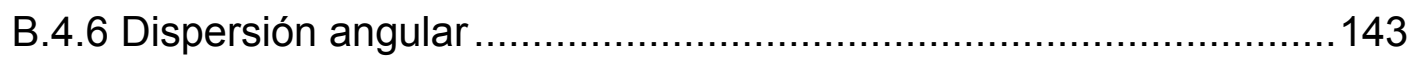

Apéndice C: Equipo de Medidas de Banda Ancha....................................145

C.1 Técnicas en el dominio de la frecuencia .......................................146

C.2 Sistema de medidas basado en un analizador de redes ...................... 147

C.2.1 Analizador de redes........................................................ 148

C.2.2 Cables y conectores ..................................................... 148

C.2.3 Amplificadores .............................................................. 149

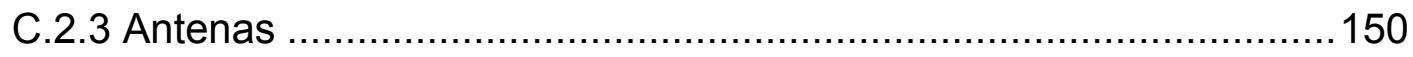

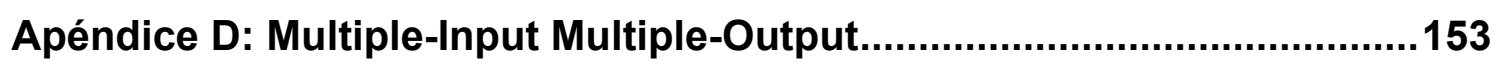

D.1 Nociones básicas de Teoría de la Información ................................154

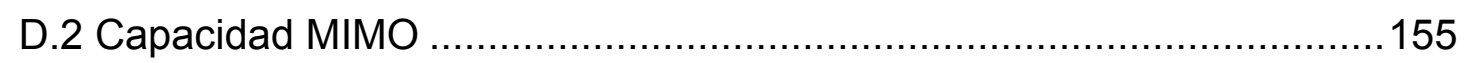

D.3 Ganancia de Array, de diversidad y de multiplexado ........................157

D.4 Capacidad Ergódica y Outage .................................................. 158

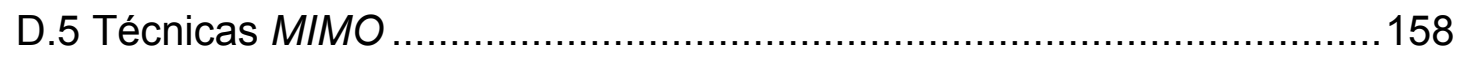

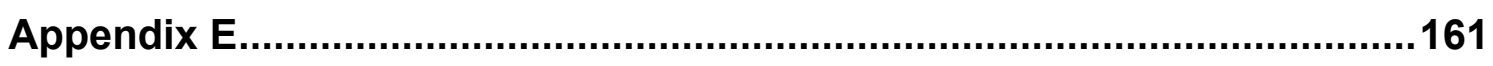

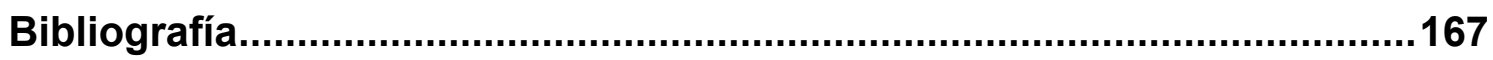




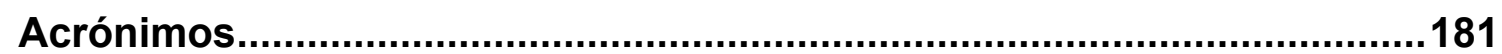

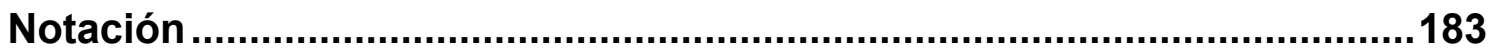




\section{Capítulo 1}

\section{Introducción}

Las comunicaciones inalámbricas forman parte de la vida diaria de la sociedad en la que vivimos. La comunicación a cualquier hora y desde cualquier lugar se ha convertido en requisito indispensable de calidad de las mismas. Además de esto, se ha incrementado la necesidad del intercambio de datos; cuando antes lo único que se requería eran simples conversaciones de voz, ahora son las transmisiones de datos a alta velocidad. Este aumento requiere sistemas avanzados de telecomunicaciones que permitan poder afrontar estas necesidades.

La demanda de transferencia de grandes volúmenes de información vía radio hace necesario dirigir los esfuerzos hacia soluciones que aumenten la capacidad utilizando los escasos recursos radio. También está tomando mucha importancia la posibilidad de comunicación desde cualquier ubicación y en cualquier instante. La comunicación desde el interior de túneles, centros comerciales y en medios de transporte 
entre otros lugares empieza a ser un nuevo requisito de diseño en los sistemas modernos de telecomunicaciones.

Una de las tecnologías que permite aumentar la capacidad del bucle radio es la de comunicaciones de banda ancha, cuya capacidad es proporcional al ancho de banda utilizado. El análisis de estos sistemas se complica con respecto a los sistemas tradicionales, ya que surgen nuevos parámetros que caracterizan su comportamiento (apéndice B).

Otra forma de aumentar la capacidad consiste en el uso de múltiples antenas a ambos lados del enlace de la comunicación. De esta forma es posible alcanzar eficiencias espectrales (bits/sg/Hz) impensables para sistemas convencionales. Esto es posible siempre y cuando se garantice que las señales que llegan y salen de los diversos elementos radiantes estén lo suficientemente decorreladas. Esta nueva tecnología se denominada en inglés MIMO (Múltiple-Input Múltiple-Output) (apéndice D).

El desarrollo de estos sistemas de comunicaciones móviles pasa por disponer de modelos teóricos que tengan en cuenta los principales mecanismos de propagación en los distintos tipos de entornos. Estos modelos de propagación pueden proceder bien del análisis de los datos recogidos en campañas de medidas, o bien de modelos más complejos que resuelven el problema electromagnético desde un punto de vista teórico. Estos últimos buscan soluciones aproximadas que sean fáciles de implementar, y suelen dar lugar a resultados cuya solución es compromiso entre el tiempo de cálculo y precisión. En esta tesis se ha utilizado el modelo de trazado de rayos basado en la Óptica Geométrica $(G O)$ y la Teoría Uniforme de la Difracción (UTD) (apéndice A).

Por otra parte, la medida del canal radio es esencial para el estudio del mismo, ya que permite tanto la obtención de datos necesarios para la implementación de modelos como la verificación de estos.

El objetivo principal de esta tesis es el estudio tanto teórico como experimental del canal radio en entornos microcelulares y especiales como túneles. Teórico, desde el punto de vista de desarrollar modelos eficientes de canal para sistemas de banda ancha y sistemas $M I M O$, y experimental, desde el punto de vista de la toma de medidas reales en estos entornos y la comparación con los modelos teóricos.

Para cumplir dichos objetivos se presenta a continuación el contenido de cada uno de los capítulos y apéndices en los que se ha dividido esta tesis.

En el capítulo 2 se desarrollan los modelos teóricos utilizados en la presente tesis. Primeramente se presentan dos modelos basados en el trazado de rayos: un modelo 
de banda ancha para sistemas SISO (Single-Input Single-Output) y otro para sistemas MIMO. Ambos modelos se han desarrollado e implementado a partir de una herramienta de trazado de rayos de banda estrecha programada en un proyecto de fin de carrera en la Universidad Politécnica de Valencia [Rod99]. También se presenta un modelo basado en el trazado de rayos, el cual, a partir de una simple simulación con una antena en cada lado del enlace (SISO), reconstruye el canal MIMO para cualquier configuración de antenas.

El capítulo 3 se centra en el estudio de la propagación en túneles. Estos son entornos cerrados donde la naturaleza de los fenómenos físicos que permiten la propagación de las ondas es diferente al de espacio libre, existe un fenómeno de guiado. En este capítulo se analiza teórica y experimentalmente la propagación en túneles. El análisis teórico se realiza tanto para sistemas SISO como MIMO. También se presentan y analizan los resultados de una campaña de medidas en un túnel cercano a la Universidad Politécnica de Cartagena.

Por otro lado, el capítulo 4 estudia en detalle la propagación en entornos microcelulares. Primeramente estudia cómo se comporta el canal radio en los cruces de cuatro esquinas y los cruces de cuatro chaflanes. En el capítulo se estudia teóricamente la dispersión temporal y la capacidad $M I M O$, y se analiza una campaña de medidas tomadas en cruces de este tipo en la ciudad de Valencia. También se analizan las ventajas de los sistemas distribuidos en entornos abierto y urbano. Estos sistemas utilizan más de una estación base simultáneamente para incrementar la diversidad y las prestaciones del sistema. Por último, el modelo desarrollado en el capítulo 2, que reconstruye la respuesta del canal MIMO a partir de una respuesta SISO, es analizado en detalle en entornos simples, y también en un entorno realista microcelular correspondiente a una zona de la ciudad de Murcia.

En el capítulo 5 se presenta un sistema de medidas para el canal MIMO por un coste y tiempo razonable. Está basado en el barrido de la respuesta frecuencial mediante dos analizadores de redes.

Por último, en el capítulo 6 se ofrecen las conclusiones generales de la tesis así como las futuras líneas de investigación a las que puede dar lugar este trabajo.

Además de los seis capítulos de los que consta la tesis, se han anexado cuatro apéndices que completan el entendimiento total del contenido de la misma. El apéndice A describe el trazado de rayos. Éste es un modelo determinista que se emplea para la predicción de la respuesta del canal radio y se fundamenta en la aplicación de la Óptica 
Geométrica $(G O)$ y la Teoría Uniforme de la Difracción (UTD). En el apéndice B se repasan los conceptos fundamentales de la caracterización del canal radio. En el apéndice $\mathrm{C}$ se describe un sistema de medidas de banda ancha para canales SISO basado en el análisis del dominio frecuencial de la respuesta del canal, que se ha utilizado en diversos trabajos de esta tesis. Y por último el apéndice D presenta los conceptos fundamentales de los sistemas MIMO.

El contenido de esta tesis ha dado lugar a 3 publicaciones en revistas internacionales, 6 congresos internacionales, 3 comunicaciones en COST 273 y 5 congresos nacionales.

Un trabajo del capítulo 2 ha sido publicado en:

Rubén Hibernón Fernández, José María Molina García-Pardo, y Leandro Juan-Llácer, "Herramienta para Análisis de Canales MIMO en Microceldas Basada en GIS", XIX Simposium Nacional de la Unión Cientifica Internacional de Radio, Barcelona, Septiembre 2004.

Los trabajos del capítulo 3 han sido publicados en:

José Maria Molina Garcia-Pardo and Leandro Juan-Llácer,"Path Loss, Delay Spread and Angular Spread at $2.1 \mathrm{GHz}$ while entering Tunnels", COST 273 TD(02) 043, Espoo, Finland 2002/May/30-31.

José María Molina García-Pardo, José Victor Rodríguez Rodríguez, and Leandro Juan-Llácer, "Angular Spread at $2.1 \mathrm{GHz}$ while entering Tunnels", Microwave and Optical Technology Letters, vol. 37, no. 3, May 2003.

José María Molina García-Pardo, José Victor Rodríguez Rodríguez y Leandro Juan-Llácer, "Cálculo de la Zona de Excitación para diversos túneles a la frecuencia de $2.1 \mathrm{GHz}$ ", XVII Simposium Nacional de la Unión Cientifica Internacional de Radio, Alcalá de Henáres, Madrid, Septiembre 2002.

José Maria Molina Garcia-Pardo, Jose Victor Rodriguez and Leandro JuanLlácer, "Measurements and Characterization of the Wide Band Complex Channel Transfer Function in a Small Tunnel", COST 273 TD(03)016 Barcelona, Spain 2003/January.

Jose-Maria Molina-García-Pardo, Jose-Victor Rodríguez, and Leandro Juan-Llacer, "Wide-Band Measurements and Characterization at $2.1 \mathrm{GHz}$ While Entering in a Small Tunnel", IEEE Transaction on Vehicular Technology, vol. 53, no. 6, November 2004.

José María Molina García-Pardo, José Victor Rodríguez Rodríguez y Leandro Juan-Llácer, "Capacidad MIMO en la Transición de entrada a un Túnel”, XVIII Simposium Nacional de la Unión Científica Internacional de Radio, A Coruña, 10-12 Septiembre 2003. 
José-María Molina-García-Pardo, José-Víctor Rodríguez and Leandro JuanLlácer, "MIMO Capacity at $2.1 \mathrm{GHz}$ While Entering Tunnels", IEEE Vehicular Technology Conference Fall, Los Ángeles, September 2004.

Los trabajos del capítulo 4 han sido publicados en:

Jose-Maria Molina-Garcia-Pardo and Leandro Juan-Llácer, "Time Delay Spread at $2.1 \mathrm{GHz}$ around Regular and Chaflane Street Corners for Microcellular Communications", The 13th IEEE International Symposium on Personal, Indoor and Mobile Radio Communications, vol. 3, pp. 1200-1202, Lisbon, 15-18 September 2002.

Jose-Maria Molina-Garcia-Pardo, Vicent-Miquel Rodrigo-Peñarrocha and Leandro Juan-Llacer "Wideband Radio Communication Measurements at 450, 900, 1800 and $2400 \mathrm{MHz}$ at Regular and Chaflane Street Corners", IEEE Antennas and Propagation Conference, Ohio, June 2003.

Jose-Maria Molina-Garcia-Pardo, Vicent-Miquel Rodrigo-Peñarrocha and Leandro Juan-Llacer "Characterization at 450, 900, 1800 and $2400 \mathrm{MHz}$ of Regular and Chaflane Street Corners by Measurements", accepted for publication in IEEE Transactions on Antennas and Propagation.

Jose-Maria Molina-Garcia-Pardo, Jose-Victor Rodriguez, Leandro JuanLlacer, "Evaluation of MIMO capacity in regular and chaflane street corners for microcellular communications", The 14th IEEE International Symposium on Personal, Indoor and Mobile Radio Communications, 2003. PIMRC 2003, vol. 2, pp 1511-1515, Beijing, China, September, 2003.

José-María Molina-García-Pardo, José-Víctor Rodríguez and Leandro JuanLlácer, "Modelo MIMO Paramétrico para Simulaciones utilizando el Trazado de Rayos", XIX Simposium Nacional de la Unión Científica Internacional de Radio, Barcelona, Septiembre 2004.

José-María Molina-García-Pardo, José-Victor Rodríguez and Leandro JuanLlácer, "Parametric MIMO Model for Ray Tracing/Launching Simulations", IEEE Vehicular Technology Conference Fall, Los Ángeles, September 2004.

José-María Molina-García-Pardo, Domingo Pardo-Quiles, José Víctor Rodríguez and Leandro Juan-Llácer, "A Distributed MIMO Scheme for Urban Street Microcells", 15th IEEE International Symposium on Personal, Indoor and Mobile Radio Communications, Barcelona, September 2004.

Los trabajos del capítulo 5 han sido publicados en:

Javier Celdrán-Blaya, José María Molina Garcia-Pardo, y Leandro JuanLlácer, "Sistema de medidas MIMO basado en dos analizadores de redes", XIX Simposium Nacional de la Unión Científica Internacional de Radio, Barcelona, Septiembre 2004.

Jose-María Molina-García-Pardo, Javier Celdrán-Blaya, Jose-Victor Rodríguez y Leandro Juan-Llácer, “A MIMO Measurement System Based on Two Network Analyzers", COST 273 TD(04)106, Gothenburg, Sweden, 2004/June/09-10. 



\section{Capítulo 2}

\section{Modelos Teóricos}

La calidad de los sistemas de radiocomunicaciones depende estrechamente del entorno de propagación. La propagación en los distintos tipos de entorno (rural, urbano, suburbano, túneles entre otros) ha sido objeto de estudio, con el fin de desarrollar modelos que ayuden a entender, diseñar y planificar nuevos sistemas de comunicaciones [Cos99] [Cos01]. Estos modelos se suelen clasificar atendiendo a su naturaleza en: empíricos, deterministas y semiempíricos o semideterministas [Cat99]:

- Los modelos empíricos realizan campañas masivas de medidas, y a partir de los datos obtenidos en éstas, describen el canal móvil a través de ecuaciones (normalmente curvas de regresión) y tablas. Son simples, rápidos, fáciles de utilizar y no requieren una descripción minuciosa del entorno. Sin embargo, su rango de aplicación se reduce a entornos similares a aquellos en los que se tomaron las medidas [Hat80] [Cos91]. 
- Los modelos deterministas predicen la respuesta del canal radio a partir de las ecuaciones de Maxwell o aproximaciones de éstas. Para estos modelos, es requisito fundamental el conocimiento del entorno específico de propagación bajo estudio, y suelen ser bastante lentos. Uno de estos modelos es el trazado de rayos, y utiliza aproximaciones de las ecuaciones de Maxwell basadas en Óptica Geométrica $(G O)$ y La Teoría Uniforme de la Difracción (UTD) [Bal89] (ver apéndice A). Estos modelos simplifican el problema de la propagación sustituyendo los frentes de onda por tubos de rayos; una vez hecha esta simplificación, aplican modelos de difracción, reflexión y transmisión a estos rayos para explicar los fenómenos físicos que se producen en cada uno de estos mecanismos de propagación [Bal89]. Para que esta aproximación sea válida, los obstáculos deberán tener dimensiones mayores a la longitud de onda de la señal bajo estudio.

- Semideterministas o semiempíricos: Están a caballo entre los deterministas y los empíricos. Necesitan información del entorno pero no tan detallada como los deterministas. Son relativamente fáciles y rápidos de aplicar [Ike84] [Ber94].

De entre todos estos modelos, la investigación de esta tesis se ha centrado en el modelado determinista del canal radio mediante el trazado de rayos. En el apéndice A se resume la teoría del trazado de rayos, que fue implementada en un trazador de rayos por Jorge Luis Rodríguez en su proyecto final de carrera en la Universidad Politécnica de Valencia [Rod99]. Parte del trabajo realizado en esta tesis utiliza como elemento de partida los programas desarrollados en aquel proyecto final de carrera, programados en el lenguaje de programación $\mathrm{C}++$.

En este capítulo se describen los modelos que se han utilizado en la presente tesis para analizar teóricamente el canal radio. Primeramente se presentan dos modelos, uno para analizar canales de banda ancha y otro para analizar canales $M I M O$, ambos basados en el trazado de rayos. Para este último modelo se ha programado una herramienta basada en un Sistema de Información Geográfica $(G I S)$ que ofrece una interfaz gráfica muy sencilla para visualizar los resultados [Hib04]. Este capítulo finaliza con un modelo que reconstruye el canal MIMO a partir de una simple realización SISO del canal para cualquier configuración de antenas en el transmisor y en el receptor. 


\subsection{Lanzado de rayos para sistemas de banda ancha}

Los canales radioeléctricos, dependiendo del ancho de banda que utilicen, se clasifican en canales de banda estrecha y banda ancha (ver apéndice B). La UTD se ha utilizado casi siempre para modelar canales de banda estrecha, aunque Luebbers et al., en [Lue89], desarrollaron un modelo de banda ancha basado en UTD para predecir las características de banda ancha de un canal en entornos rurales. Por otro lado Zhang et al., en [Zha97], hicieron lo mismo en un entorno urbano. Ambos estudios asumían secuencias pseudoaleatorias para la transmisión de la señal [Rap96], y propusieron un modelo matemático para que, a partir de múltiples simulaciones en banda estrecha, se pudiese reconstruir la respuesta temporal del canal de banda ancha. Aparte del estudio teórico, en [Lue89] se tomaron medidas en un entorno rural y se contrastaron con las simulaciones, obteniéndose resultados satisfactorios.

Luebbers utilizó un modelo a dos rayos sobre tierra plana [Lue89] y Zhang [Zhang97] un modelo del tipo Walfish-Bertoni [Ber94]. Este último es un modelo urbano donde se tiene en cuenta las pérdidas de espacio libre, las pérdidas por difracción múltiple debido a la propagación por encima de los edificios, la última difracción y la reflexión en el edificio posterior (figura 2.1).

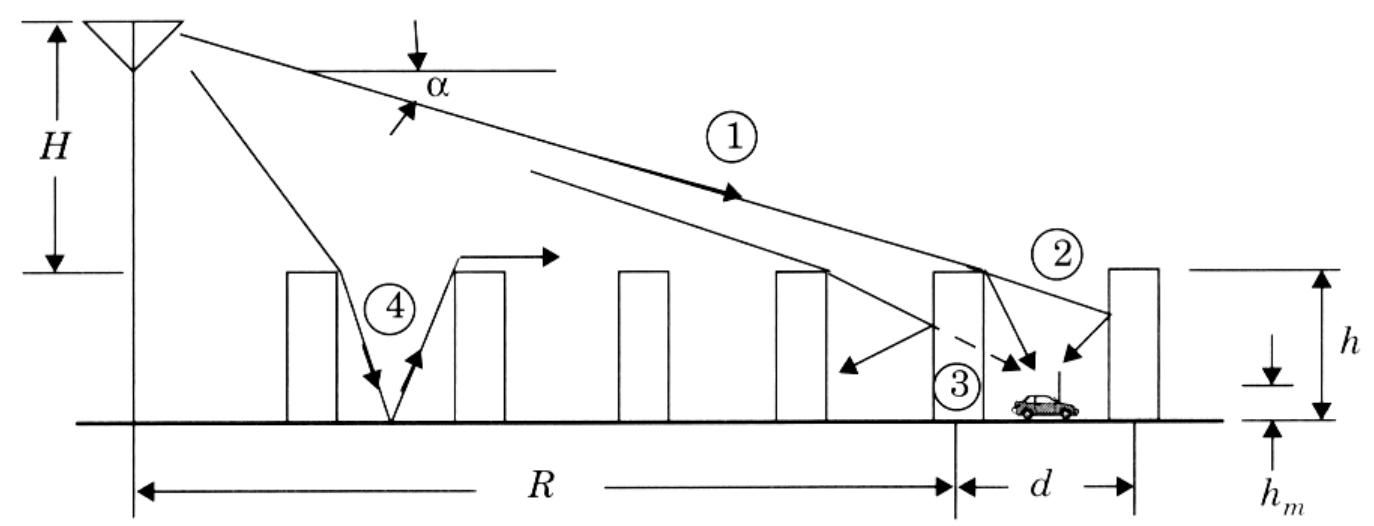

Figura 2.1: Geometría de propagación propuesta por Walfish y Bertoni en [Wal88].

El trazador de [Rod99] trabaja a una sola frecuencia, es decir, sirve únicamente para simular entornos donde el canal pueda considerarse de banda estrecha. Se ha trabajado en el trazador para que a partir de una frecuencia central, barra el espectro radioeléctrico sobre un conjunto de frecuencias seleccionadas. En los siguientes puntos se resume el modelo matemático necesario para poder, a partir de $N$ simulaciones de banda estrecha, modelizar un canal de banda ancha. 


\subsubsection{Función UTD de banda ancha}

El trazado de rayos de banda ancha se ha implementado mediante la discretización de la respuesta en frecuencia del canal. Se divide el ancho de banda total en $N$ canales, y en cada uno de ellos la respuesta del canal se considera plana (ver figura 2.2). Entonces, se calcula para cada una de estas bandas la respuesta en banda estrecha correspondiente. La ventaja que se tiene al simular el canal de esta forma es la comparación directa de resultados con los obtenidos mediante un sistema de medidas como el del apéndice C, basado en la medida de la respuesta frecuencial del canal con un analizador de redes. En el caso de [Lue89], como su sistema de medida estaba basado en códigos pseudoaleatorios, su modelo de canal tenía en cuenta este tipo de señal transmitida.

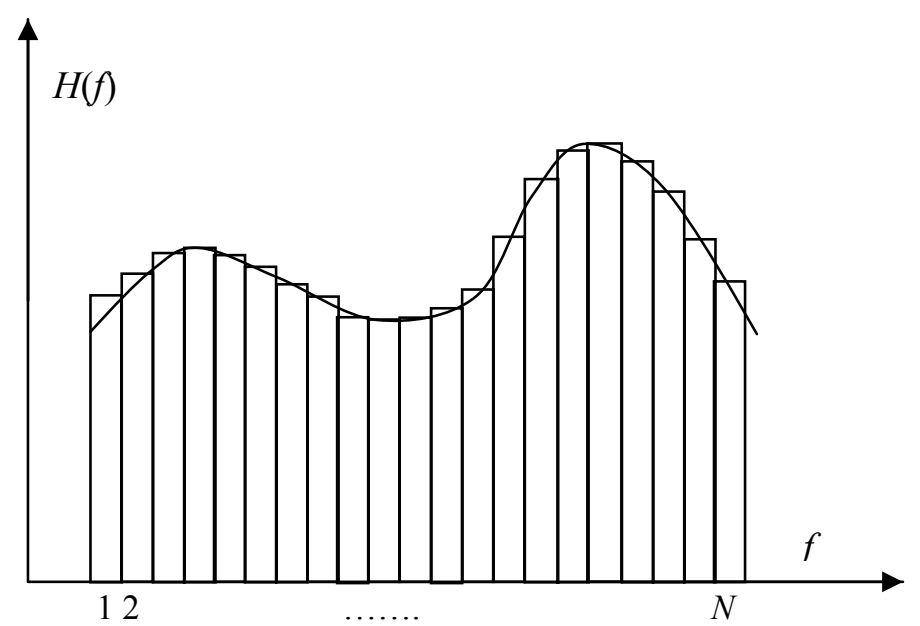

Figura 2.2: Discretización de la respuesta frecuencial de un canal en $N$ canales banda estrecha.

De acuerdo con el apéndice A, se han tenido en cuenta las siguientes contribuciones para el estudio del canal: rayo directo, rayos reflejados, rayos difractados y combinaciones de los dos últimos.

El campo eléctrico recibido en la antena receptora a una cierta frecuencia $f$ es para el rayo directo:

$$
E_{\text {directo }}(f)=\frac{E_{0}}{r} e^{-j k r}
$$

donde $E_{0}$ es una constante que depende del transmisor, $k$ es la longitud de onda, y $r$ es la distancia que recorre la onda entre las dos antenas. El campo originado por rayos reflejados es: 


$$
E_{\text {reflejado }}(f)=R \frac{E_{0}}{r_{2}} e^{-j k r_{2}}
$$

donde $R$ es el coeficiente acumulado de reflexión (apéndice A) y $r_{2}$ la distancia total recorrida por la rayo entre el transmisor y el receptor. Para los rayos difractados:

$$
E_{\text {difractado }}(f)=\frac{E_{0}}{s^{\prime}} e^{-j k s^{\prime}} D \sqrt{\frac{s^{\prime}}{s\left(s+s^{\prime}\right)}} e^{-j k s}
$$

donde $D, s^{\prime}, s$ están definidos también en el apéndice A. Y, por último para los rayos reflejados y difractados:

$$
E_{\text {difractado-reflejado }}(f)=\frac{E_{0}}{s^{\prime}} e^{-j k s^{\prime}} D R \sqrt{\frac{s^{\prime}}{s\left(s+s^{\prime}\right)}} e^{-j k s}
$$

De tal forma que la función de transferencia total a la frecuencia $f$ queda:

$$
H^{+}(f)=\frac{\lambda}{4 \pi} \sum_{i=1}^{4}\left[\sum_{j=1}^{n_{i}} \frac{E_{i j}(f)}{E_{0}}\right]
$$

donde $E_{i j}(f)$ es el campo generado en el receptor por cada uno de los rayos, donde $i$ representa el tipo de contribución y $n_{i}$ representa el número de rayos de esa clase. Si se hace que $f=f_{0}$, se tendrá la respuesta de banda estrecha correspondiente a esa frecuencia. Una vez que se ha repetido el proceso para cada frecuencia, la parte positiva $H^{+}(f)$ de la función de transferencia $H(f)$ se aproxima a:

$$
H^{+}(f)=\sum_{n=1}^{N} H^{+}\left(f_{n}\right) \partial\left(f-f_{n}\right)
$$

La igualdad es exacta en el límite cuando $N$ tiende a infinito, es decir, se tendría un espectro continuo.

\subsubsection{Transformación de la respuesta en frecuencia al Perfil de Retado}

Hasta el momento se ha obtenido la respuesta $H^{+}(f)$. La respuesta total paso banda de un canal se define como:

$$
H(f)=H^{+}(f)+H^{-}(f)
$$

donde $H^{+}(f)$ y $H^{-}(f)$ son la parte positiva y negativa del espectro respectivamente. Con la ecuación (2.7) se obtiene la respuesta en banda ancha de un canal dado en un instante de tiempo. Durante la medida del canal radio, es necesario garantizar que este 
cumpla la condición de canal WSSUS (ver apéndice B). La parte negativa del espectro se obtiene para canales reales mediante la relación:

$$
H^{-}(-f)=\left(H^{+}(f)\right)^{*}
$$

Las respuestas paso-bajo del canal, tanto de la parte positiva como de la negativa del espectro, vienen dadas por:

$$
\begin{aligned}
& H_{L}{ }^{+}(f)=H^{+}\left(f-f_{0}\right) \\
& H_{L}{ }^{-}(f)=H^{-}\left(f+f_{0}\right)
\end{aligned}
$$

Un equivalente paso bajo, tiene una parte en fase y otra en cuadratura expresadas por:

$$
\begin{aligned}
& H_{I}(f)=\frac{H_{L}{ }^{+}(f)+H_{L}{ }^{-}(f)}{2} \\
& H_{Q}(f)=\frac{H_{L}{ }^{-}(f)-H_{L}{ }^{+}(f)}{2}
\end{aligned}
$$

La respuesta compleja instantánea $h(t)$ se define finalmente mediante las componentes en fase y cuadratura de la respuesta en banda base [Zha97]:

$$
h(t)=E(t) \cos \left[2 \pi f_{0}(t)+\theta(t)\right]
$$

donde $E(t)$ y $\theta(t)$ se definen como:

$$
\begin{aligned}
& E(t)=\sqrt{h_{Q}^{2}(t)+h_{I}^{2}(t)} \\
& \theta(t)=\tan ^{-1}\left(h_{Q}(t) / h_{I}(t)\right)
\end{aligned}
$$

El Power Delay Profie (PDP, apéndice B), se define como el cuadrado de la envolvente de la respuesta paso banda (2.12), es decir, la potencia instantánea recibida. Sustituyendo (2.10) y (2.9) en la ecuación de la envolvente de la respuesta de canal (2.12), previamente transformadas en dominio temporal mediante la transformada de inversa de Fourier, se obtiene que el PDP:

$$
|E(t)|^{2}=\frac{\left|h_{L}{ }^{+}(t)\right|^{2}+\left|h_{L}{ }^{-}(t)\right|^{2}}{2}=\left|h_{L}{ }^{+}(t)\right|^{2}
$$

es decir que calculando la Inverse Discrete Fourier Transfer (IDFT) del equivalente paso bajo positivo de la respuesta del canal obtendremos el PDP. Dicho de otra forma, después 
de simular o medir un entorno, y de obtener (2.6), si se calcula su IDFT se tendrá el perfil de retardo:

$$
P(\tau)=\mid D F T^{-1}\left(\left.H_{L}^{+}(f)\right|^{2}\right.
$$

Se suele utilizar un enventanado para reducir la amplitud de lóbulos secundarios y para suavizar la respuesta temporal, y se suele rellenar también con ceros la respuesta frecuencial hasta una potencia de 2 para que la transformada de Fourier sea más eficiente (además de la consecuente interpolación temporal). Este proceso se hace multiplicando por una ventana (Hanning, Hamming, Bartlett, Blackman, etc.), los $N$ puntos que tenemos en frecuencia. Si este valor no es una potencia de 2, se rellenará con ceros hasta tener una respuesta de duración $M$. Sin embargo, al realizar estas operaciones, el valor del $P D P$ hay que modificarlo ya que se ha variado su energía. El valor corregido de potencia recibida queda en escala logarítmica como:

$$
\hat{P}(\tau)=10 \log _{10}\left[\frac{P(\tau)}{K^{2}}\right]
$$

donde $K$ es la transforma inversa de Fourier de una ventana de $N$ puntos que ha sido rellenada con ceros hasta un número de puntos $M$. De esta forma la elección de los valores de $M, N$ y el tipo de ventana no influyen en el valor absoluto del PDP.

\subsubsection{Validación del modelo}

El modelo ha sido validado con el artículo de [Zha97]. Se ha simulado el entorno de la figura 2.1, que ha sido obtenido del artículo [Wal88]. Se han utilizado los mismos parámetros que en el artículo de Zhang: $R=1000 \mathrm{~m}, H+h=50 \mathrm{~m}, h=10 \mathrm{~m}, h_{\mathrm{m}}=1.6 \mathrm{~m}, d$ $=60 \mathrm{~m}$, y la distancia del móvil al edificio anterior es de $5 \mathrm{~m}$.

La figura 2.3 muestra el $P D P$ recibido en el receptor de la figura 2.2. La transmisión se hace a $2.154 \mathrm{GHz}$ y con un ancho de banda de $200 \mathrm{MHz}$. Para la simulación se han obtenido $1601(N)$ puntos en frecuencia. Se ha utilizado una ventana del tipo Hanning y se ha completado la respuesta en frecuencia hasta 2048 puntos $(M)$. 


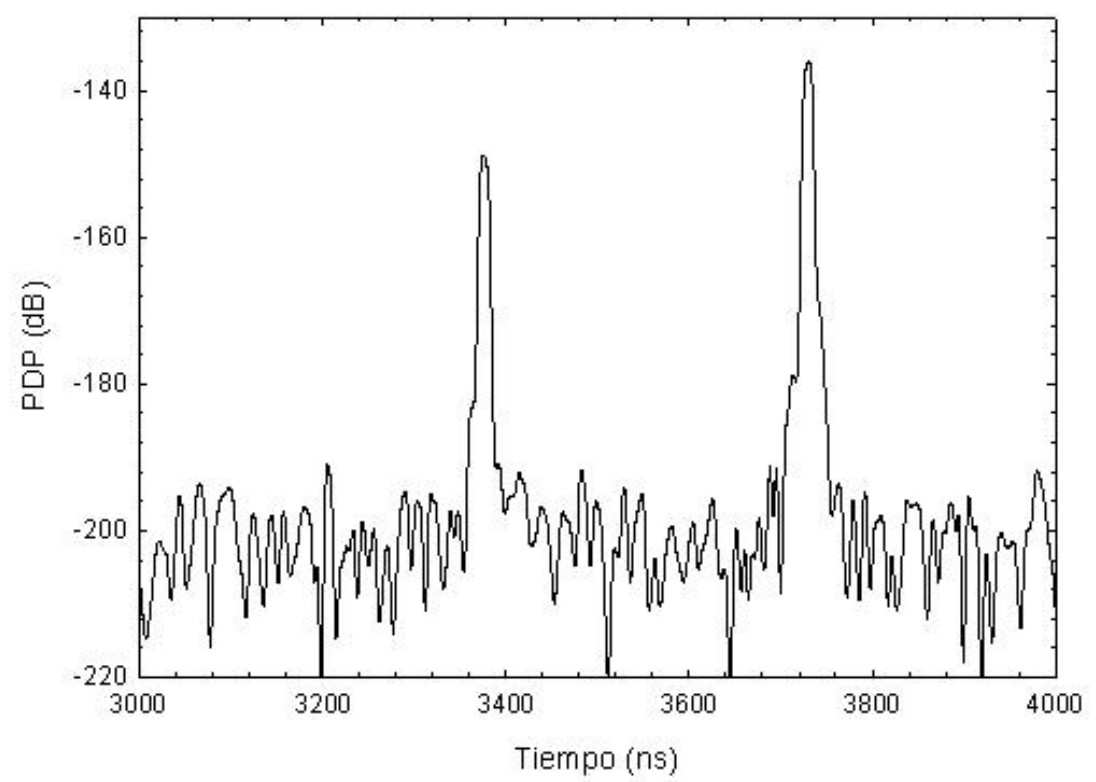

Figura 2.3: Power Delay Profile correspondiente al perfil de la figura 2.1 en el rango temporal 3000-4000 ns.

Se observan dos contribuciones que caen exactamente en los mismos tiempos que en el artículo. Si se comparan las amplitudes del resultado de la figura 2.3 con las del artículo [Zha97], también se observa que no son exactamente iguales. Esto es debido a que en el modelo del artículo se ha tenido en cuenta la difracción múltiple sobre edificios, algo que no se hizo con el trazado de rayos. El trazador de rayos tiene en cuenta difracciones simples y dobles. Si se tiene en cuenta esa contribución de energía, el nivel de ambas contribuciones coincidiría hasta los niveles de potencia del artículo.

\subsection{Lanzado de rayos para sistemas MIMO}

El trazado de rayos también puede utilizarse como modelo determinista para analizar canales $M I M O$. Como ejemplos de uso del trazado de rayos en interiores tenemos [Ger01] y [Bur02]. En este último se analiza la capacidad en un pasillo de oficinas mediante la teoría de las imágenes. Algunos ejemplos en exteriores son: en [Dri99] se analiza la capacidad en una calle, en [Kry02] se analiza la capacidad en un entorno abierto con un modelo a dos rayos, en [Lin01] se estudia la difracción de los edificios y en [Chu00] se estudia la capacidad en un entorno de interiores y otro de exteriores con el software WiSE [For95].

En un sistema $M I M O$ formado por $M$ antenas transmisoras y $N$ antenas receptoras, la respuesta del canal se puede caracterizar mediante una matriz $\mathbf{G}$ de dimensiones $M \mathrm{x} N$, 
donde el elemento $G(m, n)$ representa el campo generado en la antena $n$ por la antena transmisora $m$. Entre cada par de antenas se realiza el trazado de rayos para calcular el campo generado por la antena transmisora $m$ en la antena receptora $n$, dando lugar a una matriz de transferencia $\mathbf{G}$. El rayo directo entre la antena $m$ y $n$ se obtiene con:

$$
\mathbf{E}_{\text {directo }}(n, m)=\frac{E_{o}}{r(n, m)} e^{-j k r(n, m)}
$$

donde $r(n, m)$ es la distancia entre las antenas $n$ y $m$. Los rayos reflejados se calculan como:

$$
\mathbf{E}_{\text {reflejado }}(n, m)=\sum_{i} R_{i} \frac{E_{0}}{r_{i}} e^{-j k r_{i}}
$$

donde $R$ es el coeficiente acumulado de reflexión (apéndice A). Los rayos difractados como:

$$
\mathbf{E}_{\text {difractado }}(n, m)=\sum_{i} \frac{E_{0}}{s_{i}{ }^{\prime}} e^{-j k s_{i}{ }^{\prime}} D_{i} \sqrt{\frac{s_{i}{ }^{\prime}}{s_{i}\left(s_{i}+s_{i}{ }^{\prime}\right)}} e^{-j k s_{i}}
$$

donde los parámetros $D_{\mathrm{i}}, s_{\mathrm{i}}$ ' y $s_{\mathrm{i}}$ se definen en el apéndice A. Al igual que antes también se puede tener combinación entre rayos reflejados y difractados, y se calcularía como:

$$
\mathbf{E}_{\text {difractado-reflejado }}(n, m)=\sum_{i} \frac{E_{0}}{s_{i}{ }^{\prime}} e^{-j k s_{i}{ }^{\prime}} D_{i} R_{i} \sqrt{\frac{s_{i}{ }^{\prime}}{s_{i}\left(s_{i}+s^{\prime}{ }_{i}\right)}} e^{-j k s_{i}}
$$

de tal forma que el elemento $\mathbf{G}(n, m)$ quedaría:

$$
\mathbf{G}(n, m)=\frac{\lambda}{4 \pi} \sum_{i=1}^{4}\left[\sum_{j=1}^{n_{i}} \frac{\mathbf{E}_{i j}(n, m)}{E_{0}}\right]
$$

donde $\mathbf{E}_{i j}(n, m)$ es el campo generado en el receptor $m$, por la antena $n$, por cada uno de los rayos, donde $i$ representa el tipo de contribución y $n_{i}$ representa el número de rayos de esa clase. Este modelo se ha programado en el lenguaje de programación $\mathrm{C}++$.

\subsection{Herramienta para cálculo de la capacidad MIMO mediante el lanzado de rayos basada en ArcView}

Se ha programado una herramienta basada en un Sistema de Información Geográfico (GIS) que utiliza el modelo del apartado anterior [Hib04]. El programa permite obtener la capacidad en un recorrido o en un área dada para un receptor móvil, obteniendo así una herramienta de simulación de sistemas MIMO. Además del cálculo de la 
capacidad, permite la visualización de las contribuciones más importantes que alcanzan al receptor, proporcionando así una herramienta visual y didáctica.

\subsubsection{Descripción de la herramienta}

La herramienta trabaja sobre un entorno GIS, lo que permite una gran versatilidad. Es capaz de cargar directamente archivos de AutoCad (extensión dxf) permitiendo simular un entorno de propagación real, donde se coloca el transmisor y se calcula la capacidad en las posiciones elegidas para receptor.

En la figura 2.4 se muestran los pasos que se siguen en una simulación realizada con esta herramienta. Se han programado en Visual Basic todos los menús para la introducción de datos y llamadas a otros programas, como son: el trazado de rayos (programa anterior) y el cálculo de la capacidad, así como la lectura de los resultados dados por dichos programas. En primer lugar se solicita al usuario, mediante formularios, la información necesaria para realizar el lanzado de rayos. A partir de los resultados obtenidos por el trazador se calcula la capacidad en cada punto por medio de otro programa en el que se apoya también la herramienta (Matlab). Una vez finalizado el cálculo de estas capacidades se pasa a la visualización de los resultados. El intercambio de información entre estos programas se realiza a través de ficheros de texto.

Esta herramienta permite el cálculo de la capacidad en un punto, en un recorrido o en un área. Una vez cargado el entorno de propagación se elige la posición del transmisor y del receptor, pudiendo observar su posición en el dibujo.

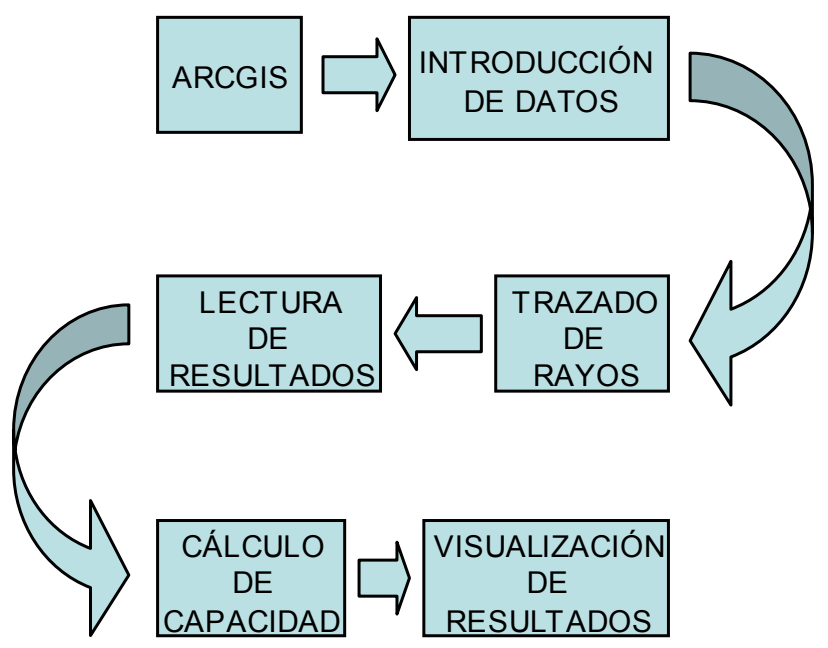

Figura 2.4: Pasos de una simulación de la herramienta. 
Para la ubicación de las antenas se utilizan coordenadas UTM (Universal Transverse Mercator). Para facilitar el cálculo de la posición individual de las antenas de cada array, se han incluido funciones que ayudan a realizar dicho cálculo. Así, se puede elegir las coordenadas del primer elemento de las antenas de dos maneras: introduciendo las coordenadas manualmente o pinchando con el ratón directamente sobre el plano, eligiendo así la posición visualmente. El usuario puede elegir entre varias configuraciones de los arrays, tales como: lineal, circular y planar, creándose automáticamente las coordenadas de cada uno de los elementos introduciendo los datos necesarios. Estas coordenadas son tridimensionales, y tienen la posibilidad de modificarse, pudiendo así obtener cualquier tipo de configuración definida por el usuario, incluso pudiendo cambiar la altura de cada uno de los elementos independientemente.

Para el cálculo de la respuesta del canal, la herramienta se apoya en el trazador de rayos (apartado 2.2). Éste tiene en cuenta todo tipo de parámetros radioeléctricos y condiciones del entorno, como la conductividad de las paredes $(\sigma)$, permitividad relativa $\left(\varepsilon_{r}\right)$, polarización etc. Además, se pueden elegir los diagramas de radiación de las antenas como por ejemplo: omnidireccional, dipolo $\lambda / 2$ vertical y dipolo $\lambda / 2$ horizontal, etc. Otras de las opciones que permite el trazador son elegir el número de rayos lanzados desde cada elemento del transmisor, el número máximo de reflexiones de los rayos reflejados, si debe tener en cuenta el rayo directo y las reflexiones en el suelo, si se quiere tener en cuenta la difracción, en cuyo caso se tiene que especificar el número máximo de reflexiones de los rayos difractados y la separación angular de los rayos que se lanzan desde la esquina donde se produce la difracción. También se puede indicar si las paredes son conductoras, si se desea tener en cuenta la doble difracción y si el trazador debe tomar las esquinas difractoras como aristas ideales (knife edge).

Los resultados radioeléctricos se pueden calcular fundamentalmente de dos formas. La primera se ha denominado "perfil de retardo", y en ella se obtiene información de todos los rayos que impactan en cada elemento, pudiendo visualizar el rayo directo, los rayos reflejados una vez y los rayos difractados en las esquinas. La otra opción se denomina "perfil de potencias", y en ella se obtiene información sobre el campo eléctrico, las pérdidas, el número de rayos que han impactado, etc. pudiendo así calcular la capacidad en un recorrido o en un área. Si se desea calcular la capacidad en un recorrido se tendrá que indicar el número de posiciones del receptor y la distancia entre receptores o la posición final; esta posición se puede indicar pinchando directamente en el plano o 
introduciendo las coordenadas manualmente. Si por el contrario se quiere calcular la capacidad en un área se tendrá que indicar la distancia entre receptores contiguos y las coordenadas del rectángulo, tarea que se puede hacer también directamente sobre el plano o introduciendo los datos manualmente.

Todas las opciones anteriormente mencionadas se pueden introducir de forma sencilla desde formularios programados en Visual Basic. Con estas opciones se puede controlar el coste computacional de la simulación, teniendo que encontrar el compromiso entre exactitud en el cálculo y tiempo de simulación. Estas opciones se recogen en un fichero de texto que es leído por el trazador.

El trazador está programado en lenguaje $\mathrm{C}$, lo cual le da una gran potencia y rapidez de cálculo. El trazado de rayos realizado es en dos dimensiones, sin embargo, tiene en cuenta la altura de cada uno de los elementos del transmisor, los elementos del receptor, esquinas difractoras y paredes para el cálculo de los rayos reflejados en el suelo.

Los resultados del trazador se dan en un fichero de texto, a partir del cual se calcula la capacidad. Esta tarea la realiza un programa realizado en $M A T L A B$, debido a su sencillez a la hora de hacer cálculos con matrices. Este programa devuelve las capacidades calculadas en cada punto en un fichero de texto que es leído por la herramienta, mostrando finalmente la capacidad en el recorrido o en el área deseada.

\subsubsection{Ejemplo de simulación}

Se ha realizado una simulación en una zona de la ciudad de Murcia. La frecuencia de trabajo es $2.1 \mathrm{GHz}$, la permitividad relativa $\left(\varepsilon_{\mathrm{r}}\right) 5$ y la conductividad de las paredes $(\sigma)$ $10^{-2} \mathrm{~S} / \mathrm{m}$. Se ha considerado que la $S N R$ media en las antenas receptoras es de $20 \mathrm{~dB}$. El transmisor consiste en un array de 5 elementos isotrópicos polarizados verticalmente, separados una distancia de $3 \lambda$ entre sí. El receptor es un array lineal de 3 elementos isotrópicos polarizados verticalmente separados $\lambda$. Las opciones que se han considerado para el trazado de rayos han sido 10 reflexiones como máximo, y 2 reflexiones después de cada difracción.

En la figura 2.5 se puede observar la situación del transmisor, y el recorrido que describe el receptor. La distancia mínima entre ambos es de unos 40 metros y la distancia entre los puntos donde se calcula la capacidad es de un metro. El receptor recorre una línea de 80 metros a lo largo de la calle siendo el sentido de su marcha hacia abajo en el 
plano. El array del transmisor es perpendicular al del receptor, que a su vez es perpendicular a la dirección del recorrido descrito por éste.

Uno de los resultados que se puede obtener es la capacidad en función de la posición, gráfica que se puede observar en la parte inferior derecha de la figura 2.5. Se puede ver así la capacidad de transmisión máxima en cada punto de este recorrido. En este caso la capacidad varía entre 11 y $21 \mathrm{bps} / \mathrm{Hz}$, situación que se da cuando el receptor ha recorrido unos 30 y 40 metros respectivamente.

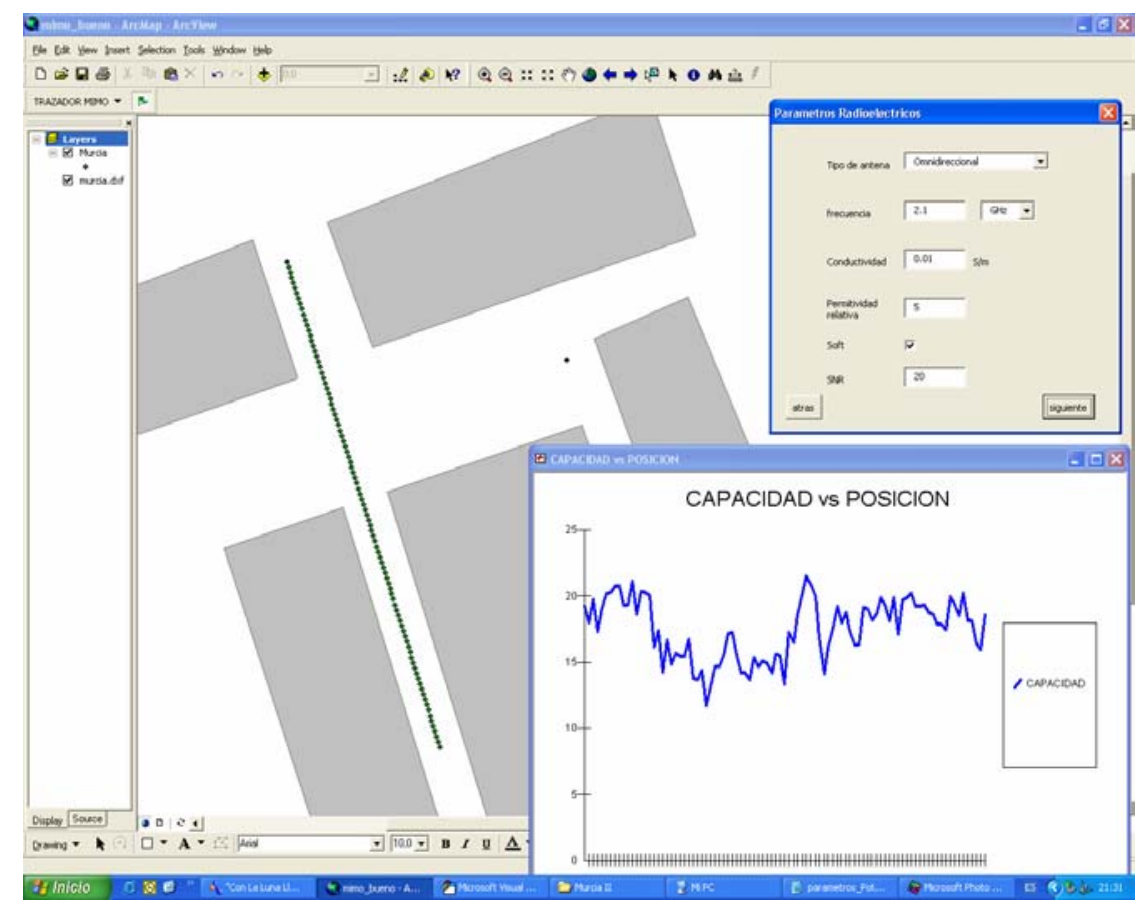

Figura. 2.5: Aspecto de la herramienta de simulación de canales MIMO. Cálculo de la capacidad en un recorrido.

También permite el cálculo de la capacidad en un área determinada. En la figura 2.6 se muestra el resultado de una simulación en la que se puede ver cómo varía la capacidad en función de la posición con la misma configuración que antes, pero sobre el área rodeada por el rectángulo. Se obtiene en este caso una visualización de dicha variación sobre el plano en una escala de colores, que en función de la intensidad da el valor de la capacidad. Esta escala aparece en la parte izquierda de la figura, siendo el valor mínimo de 9,51 bps/Hz y el máximo de 21,23 bps/Hz. En este caso también se muestra el histograma de las capacidades calculadas en el área, gráfica que se puede observar en la parte inferior derecha de la figura. 


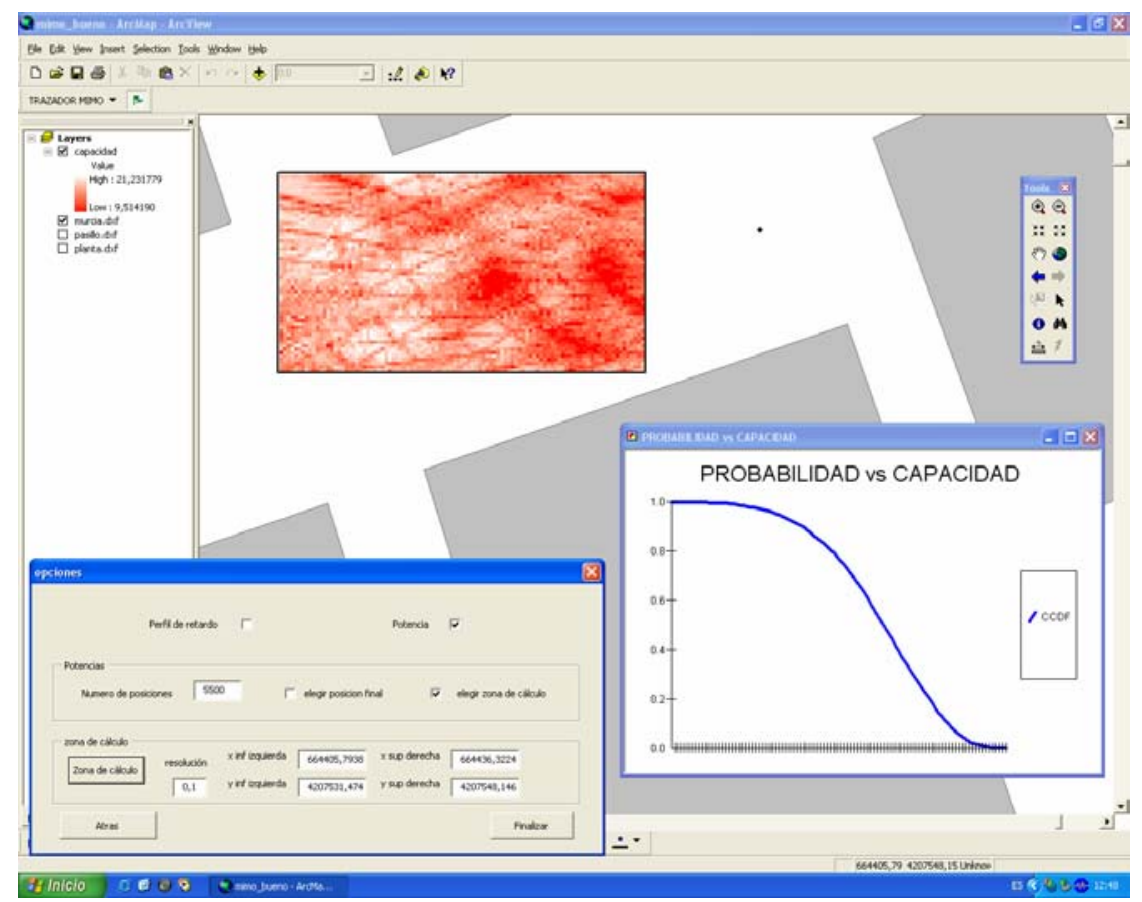

Figura 2.6: Cálculo de la capacidad en un área.

Por último, otro resultado que se puede obtener de una simulación es una visualización de las contribuciones que llegan a un receptor desde un transmisor. En la figura 2.7 se puede ver el trazado de rayos realizado. En azul se muestra el rayo directo, en rojo los reflejados una vez y en verde los difractados en las esquinas. Se obtiene así una visión real de la propagación de los rayos, distancia recorrida por cada uno, ángulo de llegada, existencia de rayo directo, etc.

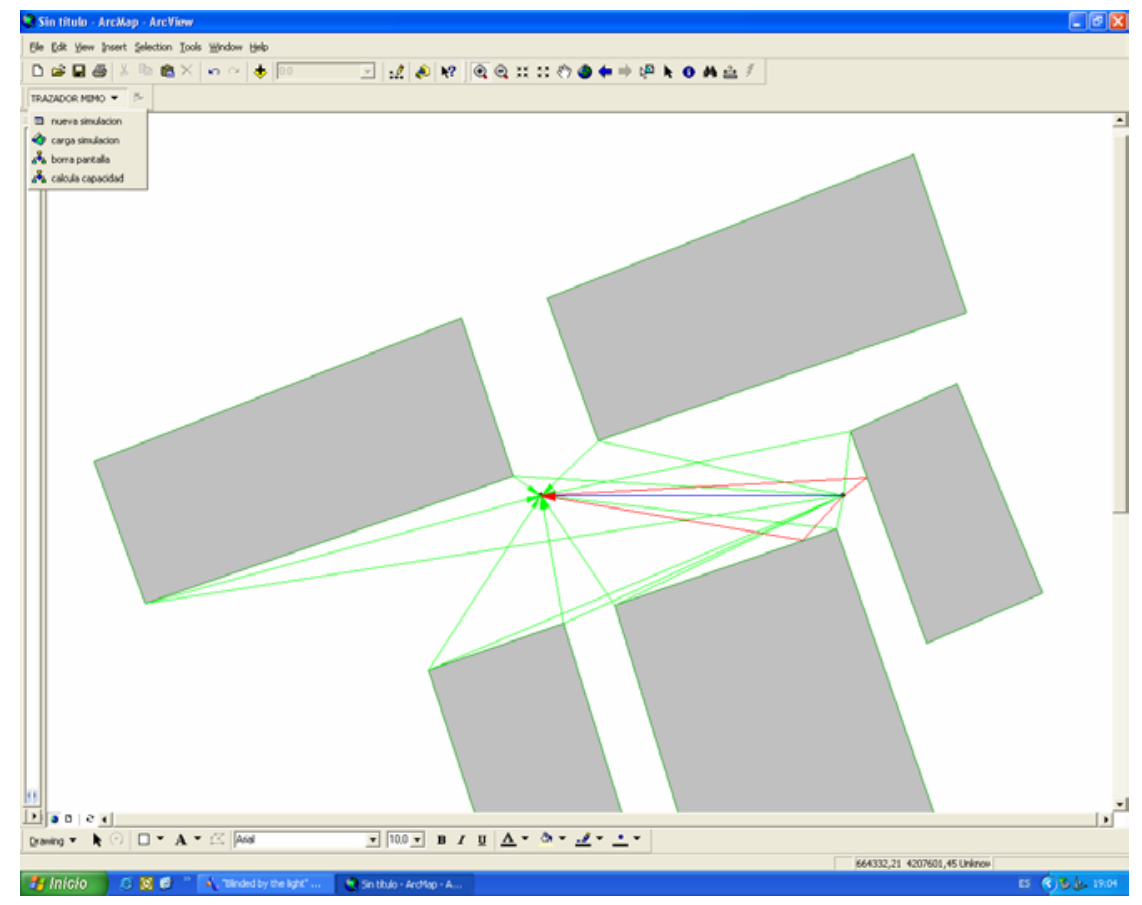

Figura 2.7: Visualización en la herramienta de los diferentes tipos de rayos. 


\subsubsection{Discusión}

Se ha presentado una aplicación desarrollada sobre un entorno GIS que es capaz de analizar un canal MIMO mediante el trazado de rayos. Es un software que consigue una fácil visualización de los resultados. Puede ser utilizada para el análisis del canal radio de sistemas MIMO, ya que permite el cálculo de capacidades en entornos reales, como microceldas. También puede utilizarse para labores docentes, ya que la herramienta es muy didáctica.

\subsection{Modelo paramétrico basado en el trazado de rayos sistemas MIMO}

El trazado de rayos utilizado en sistemas MIMO plantea el problema de que el coste computacional es muy elevado para predecir los campos recibidos por un array cuando otro transmite. Para un sistema $M I M O N x M$, el número de operaciones se multiplica por $N x M$ para cada punto donde se quiere calcular la capacidad con respecto a un sistema SISO (que ya de por si es bastante elevado).

Algunas aproximaciones, para disminuir este alto coste computacional, reconstruyen el campo en el entorno cercano a ambos arrays. Siempre asumen que el número y la procedencia de las contribuciones no van a cambiar significativamente en la cercanía de los arrays. En [Mol02] y [Jia02] estiman a partir de medidas los parámetros del canal doble-direccional [Ste01] para, mediante la hipótesis de onda plana $(P W)$, reconstruir la matriz MIMO. En [Con03] y [Gal03] se presentan dos simuladores, que reconstruyen el canal MIMO asumiendo un modelo de onda plana. En [Jia02b] se demuestra que para distancias cortas es necesario suponer propagación esférica en la reconstrucción del campo eléctrico. En [Ham02], se utiliza propagación esférica en las reflexiones para reconstruir el canal MIMO mediante medidas.

Aquí se presenta un modelo paramétrico $(P M)$ que utilizado conjuntamente con el trazado de rayos, permite reconstruir el canal $M I M O$ con bastante exactitud a partir de una sola simulación SISO. 


\subsubsection{Revisión del modelo de onda plana}

Es el modelo más simple para reconstruir el campo eléctrico en el entorno cercano del transmisor $(T X)$ y del receptor $(R X)$. Se asume que la distancia entre $T X$ y $R X$ es muy grande, que el número de contribuciones no cambia entre las antenas de un mismo array y que tampoco cambia la procedencia de éstas. El campo se reconstruye estimando la diferencia de fase de cada contribución con respecto a una antena referencia [Tho01]. La figura 2.8 representa un ejemplo en dos dimensiones donde una contribución sale de la antena transmisora con un ángulo de salida $\varphi_{\mathrm{tx}}$, y se recibe con un ángulo de llegada $\varphi_{\mathrm{rx}}$.
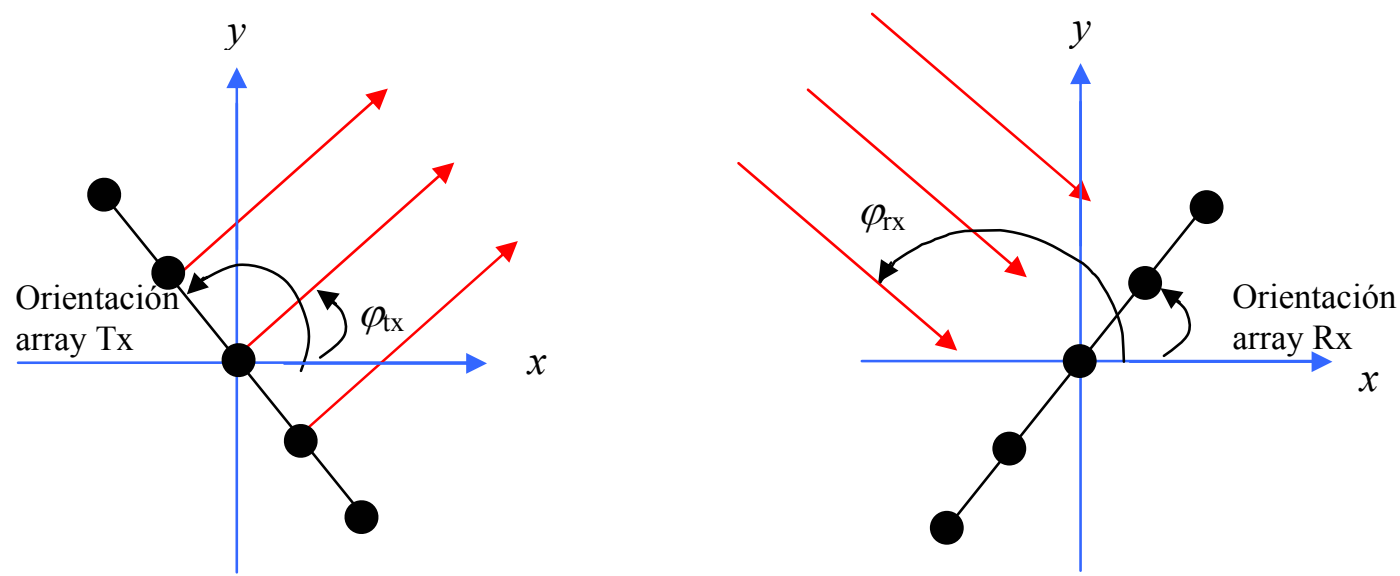

Figura 2.8: Modelo de onda plana. Una contribución en transmisión que sale con ángulo de salida $\varphi_{\mathrm{tx}} \mathrm{y}$ que llega con ángulo de llegada $\varphi_{\mathrm{rx}}$.

Los parámetros de un canal SISO (Single-Input Single-Output) doble-direccional para la contribución $k$-ésima consisten en una amplitud compleja $\left(G_{\mathrm{SISO}}(k)\right)$, un ángulo de salida $\left(\varphi_{\mathrm{tx}}(k)\right)$, un ángulo de llegada $\left(\varphi_{\mathrm{rx}}(k)\right)$ y un tiempo de llegada $\left(\tau_{\mathrm{k}}\right)$ [Ste01]. La matriz MIMO correspondiente a la contribución $k$-ésima se reconstruye en un array linear uniforme (Uniform Linear Array) como:

$$
\begin{aligned}
& \mathbf{G}_{M I M O}^{P W}(\mathrm{k})=G_{S I S O}(\mathrm{k}) \boldsymbol{\Theta} r x(\mathrm{k})(\boldsymbol{\Theta} t x(\mathrm{k}))^{T}
\end{aligned}
$$

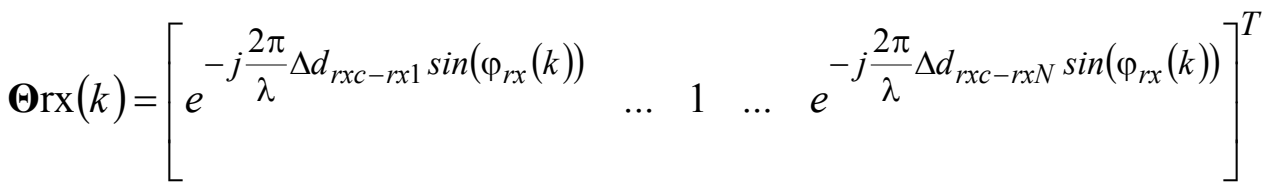

$$
\begin{aligned}
& \boldsymbol{\Theta t x}(k)=\left[\begin{array}{lllll}
e^{-j \frac{2 \pi}{\lambda} \Delta d_{t x c-t x 1} \sin \left(\varphi_{t x}(k)\right)} & \ldots & 1 & \ldots & e^{-j \frac{2 \pi}{\lambda} \Delta d_{t x c-t x N} \sin \left(\varphi_{t x}(k)\right)}
\end{array}\right]^{T}
\end{aligned}
$$


donde $\boldsymbol{\Theta} r x(k)$ es la steering matrix en recepción, $\Theta t x(k)$ la steering matrix en transmisión, $\Delta d_{\text {rxc-rxi }}$ es la distancia entre el elemento central del array en recepción y el elemento $i$ ésimo del mismo array, $\Delta d_{\mathrm{txc}-\mathrm{txi}}$ es la distancia entre el elemento central del array en transmisión y el $i^{\text {ésimo }}$ elemento del mismo array, y $\lambda$ la longitud de onda. En [Tho01], se puede encontrar la formulación para otras geometrías de array tales como los arrays uniformes rectangulares (Uniform Rectangular Array) y los arrays uniformes circulares (Circular Uniform Beam Array). El canal MIMO de banda estrecha reconstruido por $P W$ puede obtenerse como:

$$
\mathbf{G}_{\mathrm{MIMO} \_\mathrm{NB}}^{\mathrm{PW}}=\sum_{k} \mathbf{G}_{\mathrm{MIMO}}^{\mathrm{PW}}(\mathrm{k})
$$

y el canal de banda ancha $M I M O$ reconstruido por $P W$ :

$$
\mathbf{G}_{\mathrm{MIMO} \_\mathrm{WB}}^{\mathrm{PW}}(t)=\sum_{k} \mathbf{G}_{\mathrm{MIMO}}^{\mathrm{PW}}(k) \delta\left(t-\tau_{k}\right)
$$

\subsubsection{Modelo paramétrico: contribuciones}

La idea principal del modelo paramétrico $(P M)$ es el estudio de los diferentes mecanismos que ocurren en el canal radio para cada contribución. Como en $P W$, se asume que el número de contribuciones no varía en las antenas de cada array. Este modelo tiene en cuenta distancias cortas, mientras que $P M$ asumía que la distancia entre transmisor y receptor era suficientemente alta como para suponer incidencia de onda plana. El modelo contempla las siguientes contribuciones: Rayo directo (LoS), múltiples reflexiones y la difracción.

\subsubsection{Line of Sight (LoS)}

La reconstrucción más sencilla es la de la componente de visión directa LoS. En una simulación se conocen las posiciones exactas de las antenas transmisoras y receptoras (son parámetros de entrada). Desde el elemento central de cada arrays $\overrightarrow{x_{c}}\left(t x_{c}\right.$ para el transmisor y $\overrightarrow{r x_{c}}$ para el receptor, que son los centros de las antenas utilizadas en la simulación SISO), se define un vector por cada antena tanto en el transmisor como en el receptor $\overrightarrow{r_{i}}$. La posición exacta de cada elemento se puede obtener como: 


$$
\overrightarrow{x_{i}}=\overrightarrow{x_{c}}+\overrightarrow{r_{i}}
$$

Esta expresión sirve tanto para los elementos del transmisor como para el receptor, y permite simular cualquier geometría de array. Se define $\mathrm{R}_{\mathrm{n}, \mathrm{m}}$ como la distancia entre la antena transmisora m y la antena receptora $\mathrm{n}$. La distancia entre las antenas SISO se puede obtener a partir del tiempo de propagación: $R_{L O S}=v \cdot \tau_{L O S}$, donde $v$ es la velocidad de propagación en el medio y $\tau_{L O S}$ el retardo de la contribución LoS. Entonces, la matriz $M I M O-\mathrm{LoS}$ se reconstruye con:

$$
\mathbf{G}_{\mathrm{MIMO}}^{\mathrm{LoS}}=G_{\mathrm{SISO}}^{\mathrm{LoS}}\left[\begin{array}{ccc}
e^{-j \frac{2 \pi}{\lambda}\left(R_{1,1}-R_{L O S}\right)} & \ldots & e^{-j \frac{2 \pi}{\lambda}\left(R_{1, M}-R_{L O S}\right)} \\
e^{-j \frac{2 \pi}{\lambda}\left(R_{N, 1}-R_{L O S}\right)} & \ldots & e^{-j \frac{2 \pi}{\lambda}\left(R_{N, M}-R_{L O S}\right)}
\end{array}\right]
$$

Figure 2.9: Modelo LoS para una antena trasmisora y dos receptoras.

En [Jia02b] se hace un estudio en esta línea. La figura 2.9 muestra una situación genérica con una antena transmisora y dos antenas receptoras. La diferencia de caminos de los frentes de onda que llegan a cada antena es $\Delta R=R_{0}-R_{1}$. Inspeccionando la figura, $\mathrm{y}$ utilizando el teorema del seno se puede escribir:

$$
\begin{aligned}
& \frac{\operatorname{sen}(\beta)}{d}=\frac{\operatorname{sen}\left(\frac{\pi}{2}-\alpha\right)}{R_{1}}=\frac{\operatorname{sen}\left(\pi-\left(\frac{\pi}{2}-\alpha+\beta\right)\right)}{R_{0}} \\
& \frac{\operatorname{sen}(\beta)}{d}=\frac{\cos (\alpha)}{R_{1}}=\frac{\cos (\beta-\alpha)}{R_{0}}
\end{aligned}
$$

Las distancias $R_{0}$ y $R_{1}$ se pueden relacionar con los ángulos de la figura de la siguiente manera: 


$$
\begin{aligned}
& R_{0}=d \frac{\cos (\beta-\alpha)}{\operatorname{sen}(\beta)} \\
& R_{1}=d \frac{\cos (\alpha)}{\operatorname{sen}(\beta)}
\end{aligned}
$$

$Y$ si se define entonces la diferencia de caminos $\Delta R$ como la diferencia entre esas dos distancias $\left(R_{0}\right.$ y $\left.R_{1}\right)$ :

$$
\Delta R=\frac{d}{\operatorname{sen}(\beta)}[\cos (\beta-\alpha)-\cos (\alpha)]
$$

Cuando se tiene un frente de ondas plano, se asume que ambas contribuciones llegan paralelas, lo que quiere decir que $\beta$ tiende a cero. Tomando el límite cuando $\beta$ tiende a cero de esa diferencia de distancias se obtiene:

$$
\begin{aligned}
& \lim _{\beta \rightarrow 0} \frac{d}{\operatorname{sen}(\beta)}[\cos (\beta-\alpha)-\cos (\alpha)]=\frac{0}{0} \\
& \lim _{\beta \rightarrow 0} \frac{\frac{\partial}{\partial \beta}(d[\cos (\beta-\alpha)-\cos (\alpha)])}{\frac{\partial}{\partial \beta}(\operatorname{sen}(\beta))}=d \frac{\operatorname{sen}(\alpha)}{\cos (0)}=d \operatorname{sen}(\alpha)
\end{aligned}
$$

Es decir, se demuestra que cuando la distancia es grande entre el transmisor y el receptor, el modelo $P M$ es equivalente al $P W$. Lo que quiere decir que $P W$ es un caso particular de $P M$. Además, esta demostración sirve también para múltiples reflexiones si aplicamos la teoría de las imágenes para resolver las distancias.

\subsubsection{Múltiples reflexiones}

El problema de las múltiples reflexiones se resuelve de forma sencilla aplicando la teoría de las imágenes. Consiste en construir la imagen especular de uno de los arrays de antenas cada vez que en un rayo se produce el fenómeno de la reflexión. La nueva posición central del array en el plano imagen $\left(\overrightarrow{t x_{c}}\right)$ se puede determinar utilizando: 


$$
\overrightarrow{t x_{c}^{\prime}}=r x_{c}+\tau \mathrm{v}\left(\cos \left(\varphi_{r x}\right) \hat{x}+\sin \left(\varphi_{r x}\right) \hat{y}\right)
$$
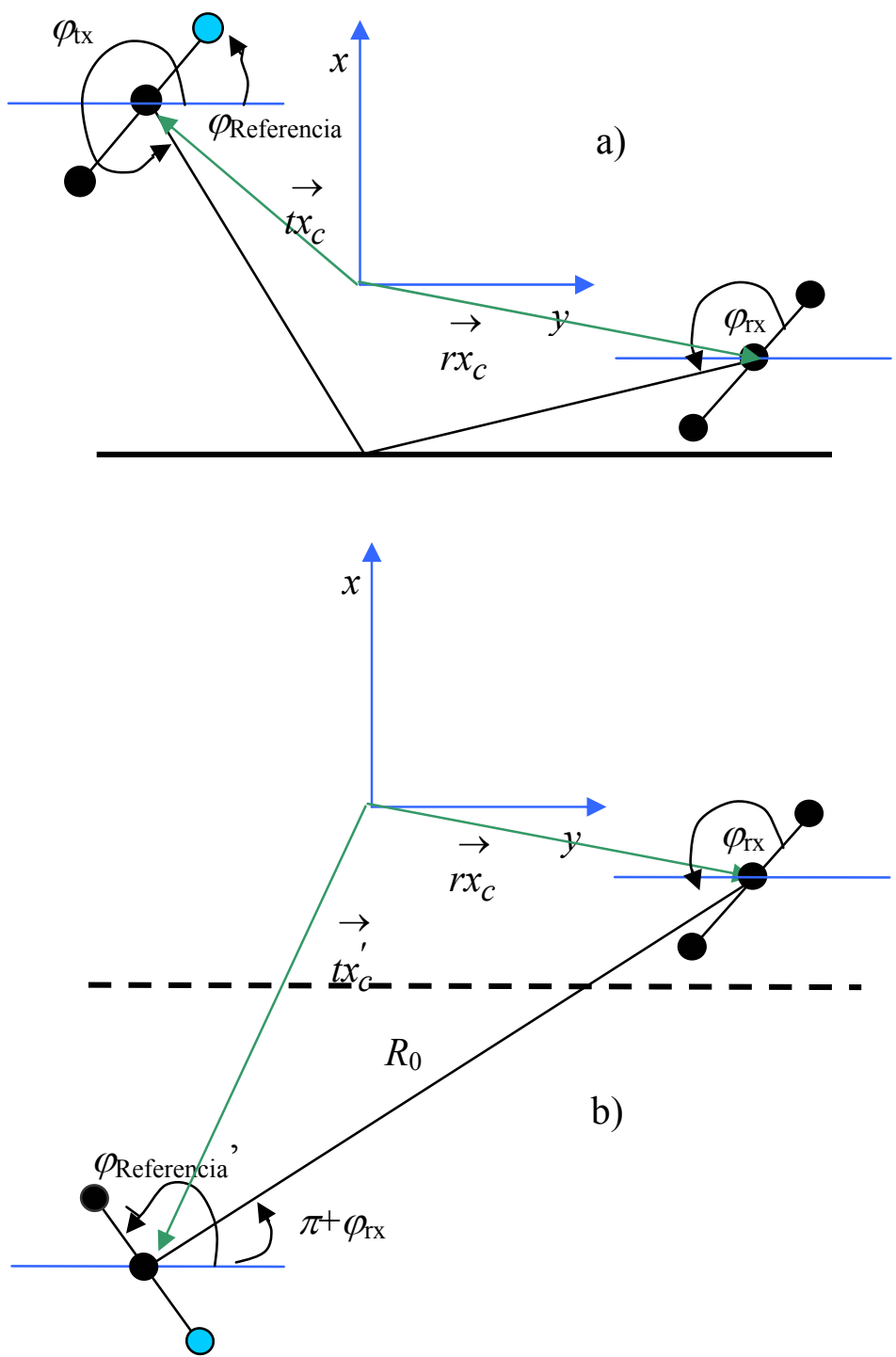

Figura 2.10: a) Una reflexión para un sistema $M I M O 3 \times 3$ y b) su imagen.

donde $\overrightarrow{r x_{c}}$ es la posición central del receptor, $\tau$ el retardo del rayo que llega al receptor, $v$ la velocidad de la luz en el medio y $\varphi_{\mathrm{rx}}$ el ángulo de llegada del mismo. La figura 2.10.a muestra el diagrama de un sistema $M I M O 3 \times 3$ en el que se produce una reflexión. Suponiendo que se fija la posición del receptor, el problema se reduce a calcular la nueva posición de todas las antenas transmisoras en el nuevo plano imagen.

Cuando se produce una reflexión, las posiciones de los elementos sobre los que se va a aplicar la teoría de las imágenes han variado, y para el caso concreto de un ULA se produce una rotación. Para obtener el ángulo de rotación se necesita tomar una referencia. 
En la figura 2.10.a se ha marcado el primer elemento de azul. En la figura 2.10.b, se presenta la imagen del sistema de la figura 2.10.a. El transmisor ha rotado de tal forma que el nuevo ángulo referencia $\varphi_{\text {Referencia' }}$ se puede relacionar con $\varphi_{\text {Referencia }}$ mediante una rotación dada por:

$$
\text { rotacion }=\left(\pi+\varphi_{r x}\right)+(-1)^{\text {Numero de reflexiones }}\left(\varphi_{\text {referencia }}-\varphi_{t x}\right)-\varphi_{\text {referencia }}
$$

Una vez en el nuevo sistema de referencia imagen, las distancias entre las antenas puede calcularse tal y como se hizo para el caso $\operatorname{LoS}$ : como la distancia euclídea entre ellas $\left(R_{n, m}\right)$. Es importante saber si el número de reflexiones es par o impar. La diferencia está en que cada vez que se produce una reflexión, la rotación tiene sentido contrario. Esto se ve reflejado en (2.30). La matriz MIMO de múltiples reflexiones se puede escribir como:

$$
\begin{aligned}
& \mathbf{G}_{\text {MIMO }}^{\text {Múltiples reflexiones }}(k)=G_{\text {SISO }}^{\text {Múltiples reflexiones }}(k) . \\
& {\left[\begin{array}{ccc}
e^{-j \frac{2 \pi}{\lambda}\left(R_{1,1}(k)-R_{0}(k)\right)} & & e^{-j \frac{2 \pi}{\lambda}\left(R_{1, M}(k)-R_{0}(k)\right)} \\
\ldots & \ldots & \\
e^{-j \frac{2 \pi}{\lambda}\left(R_{N, 1}(k)-R_{0}(k)\right)} & \ldots & e^{-j \frac{2 \pi}{\lambda}\left(R_{N, M}(k)-R_{0}(k)\right)}
\end{array}\right]}
\end{aligned}
$$

Es fácil observar que esta rotación también sirve también para el caso $L o S$, en cuyo caso la rotación vale cero, y (2.32) es equivalente a (2.25). Existe un problema añadido, y es que el coeficiente de reflexión depende del ángulo de incidencia. En un sistema de múltiples antenas, generalmente el ángulo de incidencia cambia de una antena a otra. Se distinguen dos polarizaciones: hard y soft (apéndice A). Para polarización soft, pequeños incrementos/decrementos del ángulo de incidencia no influyen demasiado en el resultado si lo consideramos constante, y la matriz se puede reconstruir con (2.32). Sin embargo, para el caso de polarización hard y estar entorno al ángulo de Brewster, se produce un salto de $\pi$ radianes en la fase.

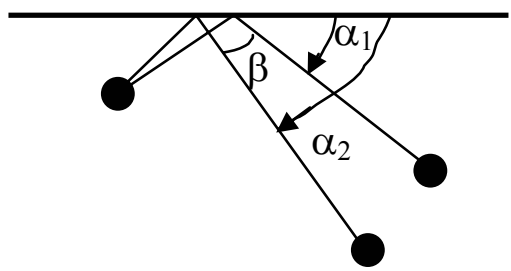

Figura 2.11: Ángulo de incidencia en una pared para un sistema de múltiples antenas.

En la figura 2.11 se puede observar como el ángulo de incidencia varía para rayos que salen de antenas diferentes $\left(\alpha_{1}\right.$ es diferente a $\left.\alpha_{2}\right)$. En el caso de una reflexión, el 
problema de la corrección de fase tiene solución. $G_{\mathrm{SISO}}$ contiene la información relativa al desfase por propagación y al desfase causado por la reflexión. El desfase debido a la

propagación es $\exp \left(-j \frac{2 \pi}{\lambda} R_{O}\right)$, con lo cual puede substraerse de $G_{\text {SISO }}$ para obtener el desfase de la reflexión, y consecuentemente el ángulo de incidencia. La diferencia entre los ángulos de incidencias se obtiene geométricamente de la figura 2.11, así que haciendo los cálculos oportunos se podrá corregir la fase para cada combinación de rayos. En el capítulo 4 se verá que, incluso en los peores casos, no merece la pena corregir este error ya que es muy pequeño. Esto se debe a que en torno al ángulo de Brewster la mayoría de la energía se transmite, y cualquier otra contribución será mucho mayor que ésta.

\subsubsection{Difracción}

El fenómeno de la difracción ocurre cuando una onda incide sobre una superficie afilada. La figura 2.12 muestra un sistema MIMO $3 \times 3$ con una esquina difractora. En [Lin01] una esquina difractora es analizada como un keyhole. Un keyhole [Chi02] o también llamado pin-hole [Ge00] se refiere al fenómeno que se produce en canales que aun teniendo las antenas incorreladas en transmisión y en recepción (suficientemente separadas y con dispersión angular alta), la matriz $\mathbf{H}$ tiene un solo grado de libertad, o lo que es lo mismo, rango 1. En estas circunstancias, no hay ningún incremento de capacidad por el uso de múltiples antenas.

En [Lin01] se asume que coefiente de difracción (apéndice A) es constante para todos los ángulos de incidencia ( $\left.\phi^{\prime}\right)$, ángulos de salida $(\phi)$, distancias entre los transmisores y la esquina difractora $\left(s^{\prime}\right)$, y distancia entre la esquina difractora y los receptores $(s)$. Sin embargo, esta hipótesis es muy restrictiva, ya que el coeficiente de difracción no es constante ante variaciones de estos parámetros, con lo que esa afirmación ya no es correcta. 


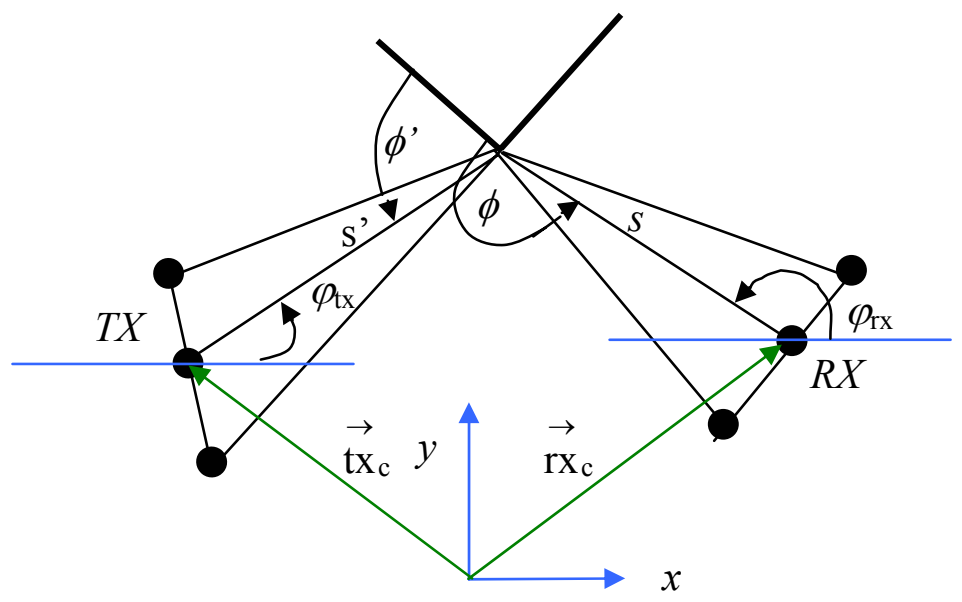

Figura 2.12: Difracción de un sistema $M I M O 3 \times 3$ a través de una esquina.

Este modelo paramétrico resuelve el problema de la reconstrucción a partir de los parámetros $s$ y $s^{\prime}, \phi$ y $\phi '$ de la simulación SISO. El algoritmo de trazado de rayos debe proveer esta información. El coeficiente de difracción puede entonces recalcularse para cada par de antenas. Para la antena transmisora $\mathrm{m}$ y la antena receptora $\mathrm{n}$ los parámetros calculados son: $s_{\mathrm{txm}}^{\prime}$ y $s_{\mathrm{rxn}}, \phi_{\mathrm{txn}} \mathrm{y} \phi_{\mathrm{rxm}}^{\prime}$. Definimos $\psi\left(\mathrm{s}, \mathrm{s}^{\prime}, \phi^{\prime}, \phi\right)$ como:

$$
\psi\left(s, s^{\prime}, \phi^{\prime}, \phi\right)=D\left(s, s^{\prime}, \phi^{\prime}, \phi\right) e^{-j k\left(s+s^{\prime}\right)} \sqrt{\frac{1}{s s^{\prime}\left(s+s^{\prime}\right)}}
$$

donde $D$ es el coeficiente de difracción [Ba189]. De este modo, la matriz correspondiente a la difracción se puede expresar como:

$$
\begin{aligned}
& \left.\mathbf{G}_{M I M O}^{\text {Diffracted }}=\frac{G_{S I S O}^{\text {Diffracted }}}{\psi\left(s_{r x c}, s_{t x c}^{\prime}, \phi_{r x c}, \phi_{t x c}^{\prime}\right.}\right) . \\
& {\left[\begin{array}{ccc}
\psi\left(s_{r x 1}, s_{t x 1}^{\prime}, \phi_{r x 1}, \phi_{t x 1}^{\prime}\right) & \ldots & \psi\left(s_{r x 1}, s_{t x M}^{\prime}, \phi_{r x 1}, \phi_{t x M}^{\prime}\right) \\
\ldots & \ldots & \ldots \\
\psi\left(s_{r x N}, s_{t x 1}^{\prime}, \phi_{r x N}, \phi_{t x 1}^{\prime}\right) & \ldots & \psi\left(s_{r x N}, s_{t x M}^{\prime}, \phi_{r x N}, \phi_{t x M}^{\prime}\right)
\end{array}\right]}
\end{aligned}
$$

El caso anterior es válido cuando no existen reflexiones. Si hay reflexiones antes o después de la difracción, las esquinas se pueden resituar utilizando nuevamente la teoría de las imágenes desde el transmisor y desde el receptor. Las nuevas posiciones de las esquinas difractoras quedan como:

$$
\begin{aligned}
& \underset{\text { corner_tx }}{\rightarrow}=\overrightarrow{t x}_{c}+s^{\prime}\left(\cos \left(\varphi_{t x}\right) \hat{x}+\sin \left(\varphi_{t r x}\right) \hat{y}\right) \\
& \stackrel{\rightarrow}{\text { corner_rx }_{-} x^{\prime}}=\overrightarrow{r x_{c}}+s^{\prime}\left(\cos \left(\varphi_{r x}\right) \hat{x}+\sin \left(\varphi_{r x}\right) \hat{y}\right)
\end{aligned}
$$


Cuidado especial debe tenerse con el número de reflexiones. Si este número es impar, los signos de los ángulos $\phi$ y $\phi$ 'cambian.

\subsubsection{Modelo de banda ancha y de banda estrecha}

Hasta el momento, se han definido las contribuciones $L o S$, las múltiplemente reflejadas y las difractadas. Una vez que todas las matrices se han reconstruido para todas las contribuciones, el modelo MIMO PM de banda estrecha se obtiene como:

$$
\mathbf{G}_{\text {MIMO_NB }}^{\text {PM }}=\sum_{k} \mathbf{G}_{\text {MIMO }}^{\text {PM }}(k)
$$

y el modelo $M I M O P M$ de banda ancha como:

$$
\mathbf{G}_{\mathrm{MIMO} \_\mathrm{WB}}^{\mathrm{PM}}(t)=\sum_{k} \mathbf{G}_{\mathrm{MIMO}}^{\mathrm{PM}}(k) \delta\left(t-\tau_{k}\right)
$$




\section{Capítulo 3}

\section{Propagación en Túneles}

Hoy en día, se observa un aumento de las necesidades de comunicación en entornos especiales, como es el caso de los túneles. Esta comunicación debe ser continua, fiable y de alta capacidad, así que es muy importante predecir qué es lo que ocurre en cada uno de estos entornos. Los túneles son entornos cerrados donde la naturaleza de los fenómenos físicos que permiten la propagación de las ondas es diferente al de otros entornos como pueden ser las microceldas o macroceldas. Una primera forma de transmitir información en el interior de un túnel consiste en utilizar cables radiantes que se colocan a lo largo de éste [De191][Lie99]. Otra forma consiste en el uso de antenas en el exterior del túnel y cerca de la entrada [Der78], y que se llama propagación natural.

El análisis del comportamiento radioeléctrico en el interior de un túnel (generado por un transmisor) puede realizarse de diversas formas. La primera de ellas es considerar al túnel como una guía-onda con pérdidas de forma rectangular [Ems75] [Laa76] [Chi78] 
[Chi82] [Zha98b], o cilíndrica [Yam85] [Hol00], y hacer un análisis modal. El problema que presenta este análisis es que resulta sencillo para estructuras simples (rectángulo, cilindro), pero muy complicado si se aumenta la complejidad de la geometría del túnel.

Otra forma de realizar el análisis es mediante las técnicas de trazado de rayos. Éstas simplifican el estudio de estructuras más complejas, siempre y cuando se conozca la geometría del entorno. Estas técnicas para el análisis de túneles se han utilizado durante más de tres décadas [Mah74]. En [Hwa98] y [Zha98c] se desarrolla un modelo para el análisis mediante trazado de rayos de túneles rectos, y en [Lam98] se estudian túneles curvos.

También se ha modelado la propagación en el interior de túneles mediante campañas de medidas. En [Zhe99] se estudian túneles trapezoidales. En [Zha98c] se utiliza un analizador de redes para medir la respuesta del canal de banda ancha. En [Lie00] se analiza la influencia de tráfico en un túnel y en [Zha01] se toman medidas en una mina de carbón para presentar un modelo híbrido de propagación.

En la propagación en el interior de los túneles, se observa una zona de transición a partir de la entrada del túnel llamada zona de excitación [Mar94][Lie98], que es posteriormente investigada en [Mar01]. Esta zona se encuentra en un espacio que comprende desde la entrada del túnel hasta una cierta distancia que depende de la geometría del túnel y de la posición de la antena transmisora con respecto a éste.

En este capítulo se recogen los resultados más importantes del estudio de la propagación en túneles. Utilizando el trazado de rayos, se estudia la dispersión angular en la entrada del túnel [Mol02a,Mol03a], la longitud de la zona de excitación [Mol02b] y la capacidad de un sistema MIMO en este entorno [Mol03c,Mol04b]. También se presenta una campaña de medidas de banda ancha realizada en un pequeño túnel cercano a la Universidad Politécnica de Cartagena [Mol03b,Mol04a].

\subsection{Resultados teóricos para túneles y sistemas SISO}

\subsubsection{Dispersión espacial en la transición de entrada a un túnel}

Para el diseño de los futuros sistemas de comunicaciones, es muy importante conocer el comportamiento de los distintos parámetros radioeléctricos. En el caso de la propagación en túneles, en [Mar94] se analizan las pérdidas básicas de propagación y se relacionan con la zona de excitación. Se observa que las pérdidas son mayores en esta zona, y a partir de ésta, la constante de atenuación disminuye notablemente. En [Mar01] se 
observa que esta distancia depende del ángulo formado por el transmisor y el eje longitudinal del túnel, aumentando las pérdidas conforme aumenta este ángulo. También en el mismo estudio se observó que el RMS delay spread presenta un máximo al final de dicha zona de excitación, y es proporcional a la inclinación del transmisor. Utilizando el trazador del apéndice $\mathrm{A}$, se han estudiado las pérdidas básicas de propagación, el $R M S$ delay spread y el RMS angular spread [Mol02a,Mo103a].

\subsubsection{Entorno de propagación}

Las figuras 3.1 y 3.2 representan una vista isométrica y en planta del túnel simulado en [Mar01]. El túnel tiene 5.3 metros de altura y 8.5 metros de ancho. A cuatro metros de altura, y a una distancia de 100 metros de la entrada se sitúa el transmisor. El receptor de 2 metros de altura, realiza un recorrido hacia el interior del túnel a una distancia de 2.125 metros de la pared del mismo.

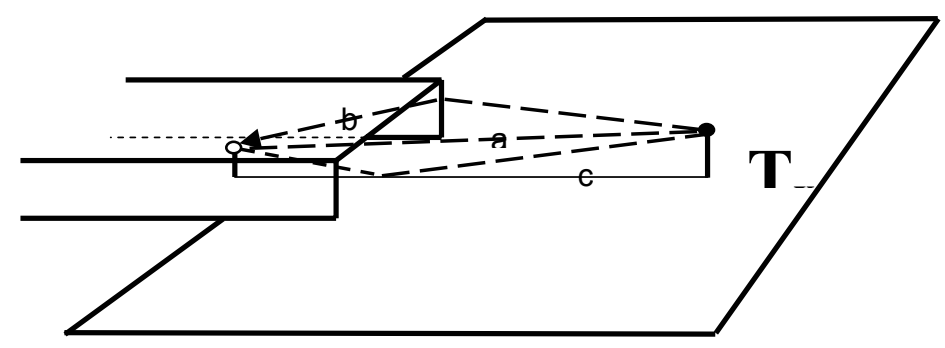

Figura 3.1: Vista tridimensional de un túnel ideal de sección rectangular con el transmisor situado en el exterior y el receptor situado en el interior. También se muestran las componentes $\operatorname{LoS}(\mathrm{a})$, difracción en la pared (b) y reflexión en suelo (c).

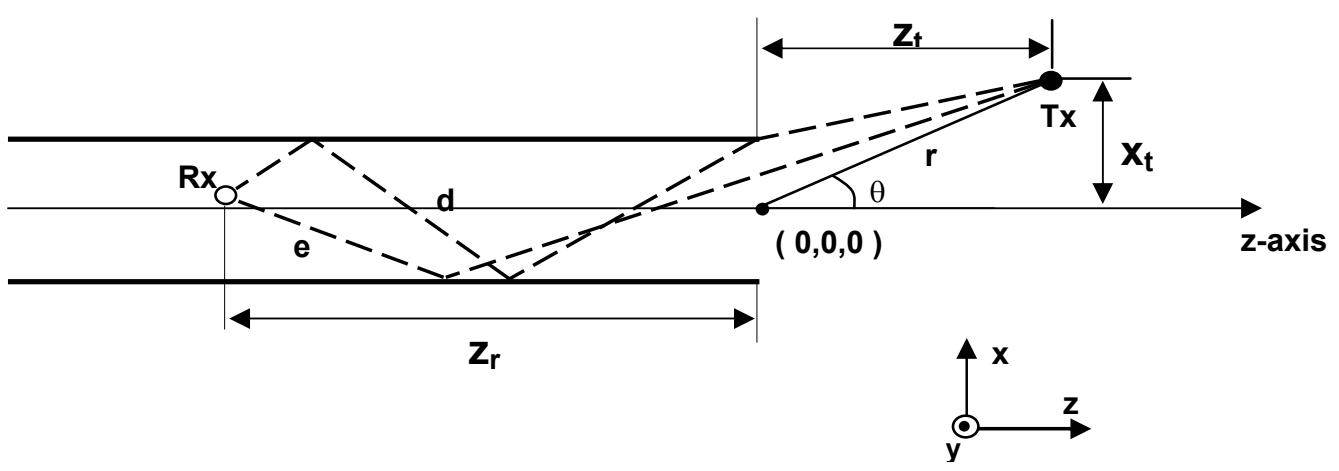

Figura 3.2: Vista en planta del túnel y el sistema de coordenadas. Se muestran las componentes múltiplemente reflejadas en las paredes laterales (e), y las difractadas y luego reflejadas en las paredes (d). 


\subsubsection{Modelo de propagación}

Para hacer el estudio se han realizado simulaciones a la frecuencia de 2.1 GHz. Las simulaciones han tenido en cuenta las siguientes contribuciones:

- Rayo directo, figura 3.1 rayo (a).

- Difracción en las esquinas de la entrada, figura 3.1 rayo (b).

- Reflexión en el suelo para el rayo LoS, figura 3.1 rayo (c).

- Reflexiones múltiples tras la difracción en las esquinas de la entrada, figura 3.2 rayo $(\mathrm{d})$.

- Reflexiones múltiples en las paredes, figura 3.2 rayo (e).

El número máximo de reflexiones en las paredes se ha fijado a 10 [Mar01]. Para todas las simulaciones, se han utilizado antenas isotrópicas polarizadas verticalmente. Los parámetros radioeléctricos utilizados han sido $\sigma=0.01 \mathrm{~S} / \mathrm{m}$, y $\varepsilon_{\mathrm{r}}=5$. La difracción de las esquinas se ha calculado tomando aristas afiladas (Knife Edge). El receptor realiza un recorrido de 1100 metros desde el transmisor hacia el interior del túnel. El factor de propagación $(P F)$ (proporcional a la inversa de las pérdidas básicas de propagación) se ha calculado como:

$$
P F(d B)=20 \log _{10}\left(\frac{\left|E_{\mathrm{TOT}}\right|}{\left|E_{0}\right|}\right)
$$

donde $E_{0}$ es una constante que depende del transmisor y $E_{\mathrm{TOT}}$ es el campo total recibido en la antena. El RMS delay spread y el RMS angular spread se han calculado utilizando (B.11) y (B.18).

\subsubsection{Resultados}

Para todas las simulaciones, se han tomado tres ángulos $\theta: 15^{\circ}, 30^{\circ}$ y $45^{\circ}$. La figura 3.3 muestra el factor de propagación utilizando (3.1) en función de la distancia entre el transmisor y el receptor. La distancia indica el camino recorrido por el receptor sobre el eje z. La línea vertical a 100 metros hace referencia a la ubicación de la entrada del túnel, y las otras tres líneas verticales a las tres zonas de excitación para cada uno de los ángulos definidos en [Mar94]. Estas distancias son 388, 140 y 85 metros para $15^{\circ}, 30^{\circ}$ y $45^{\circ}$ respectivamente. 


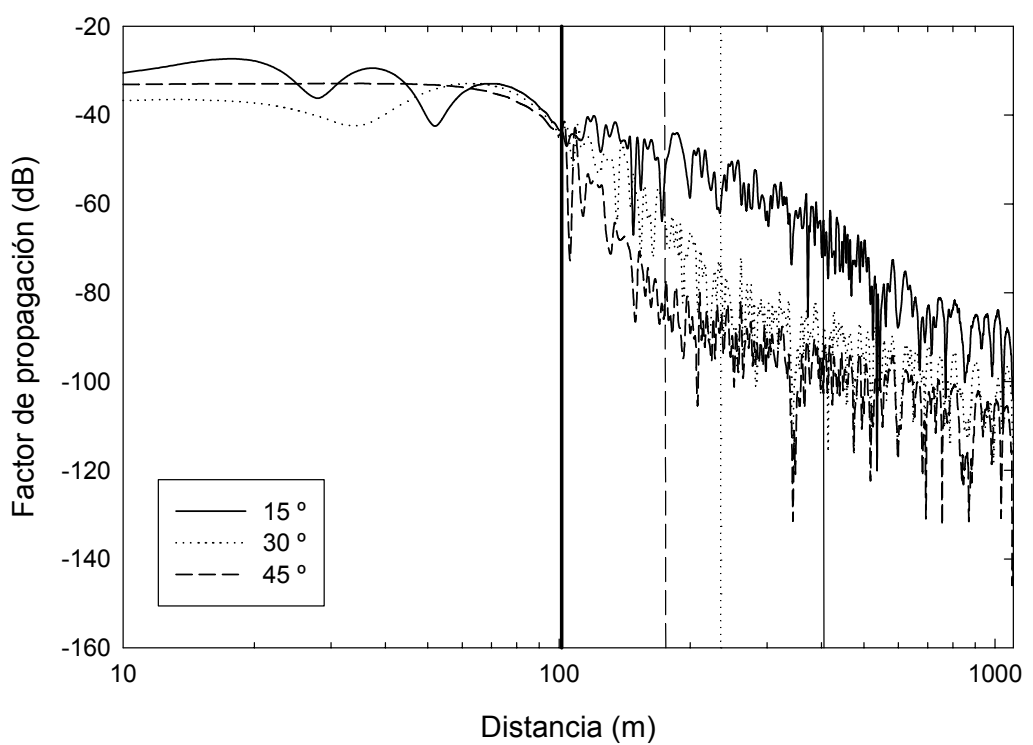

Figura. 3.3: Factor de propagación para un túnel recto de dimensiones $8.5 \mathrm{~m}$ x $5.3 \mathrm{~m}$.

En la figura 3.3 se observan tres pendientes para cada posición del transmisor. La primera entre el transmisor y la entrada del túnel. Una segunda llamada zona de excitación, donde la mayor parte de la potencia proviene de los múltiples rayos reflejados. Y por último una tercera pendiente, más suave que la anterior, donde dominan los rayos difractados y el efecto de guiado.

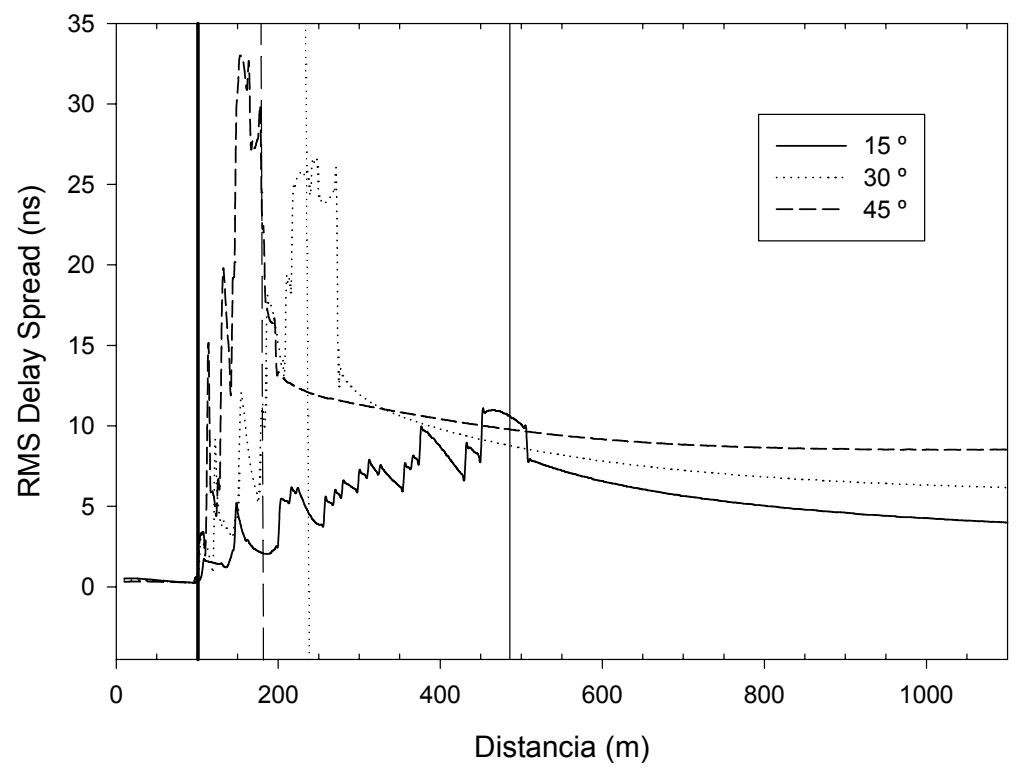

Figura. 3.4: RMS delay spread para un túnel recto de dimensiones $8.5 \mathrm{~m} \times 5.3 \mathrm{~m}$.

La figura 3.4 muestra el RMS delay spread para las tres posiciones del transmisor. Se observa que cuanto mayor es la inclinación del transmisor, mayor es el valor máximo 
del RMS delay spread. Éste aumenta desde $11 \mathrm{~ns}$ para $15^{\circ}$ de inclinación hasta $33 \mathrm{~ns}$ para $45^{\circ}$ de inclinación. Se observa una relación directa entre la zona de excitación y el $R M S$ delay spread. El valor máximo se encuentra siempre al final de la zona de excitación. En la tercera zona, se observa que los valores del delay spread no convergen a un valor único, sino que a un mayor ángulo del transmisor corresponde un valor mayor residual dispersión temporal al final del túnel.

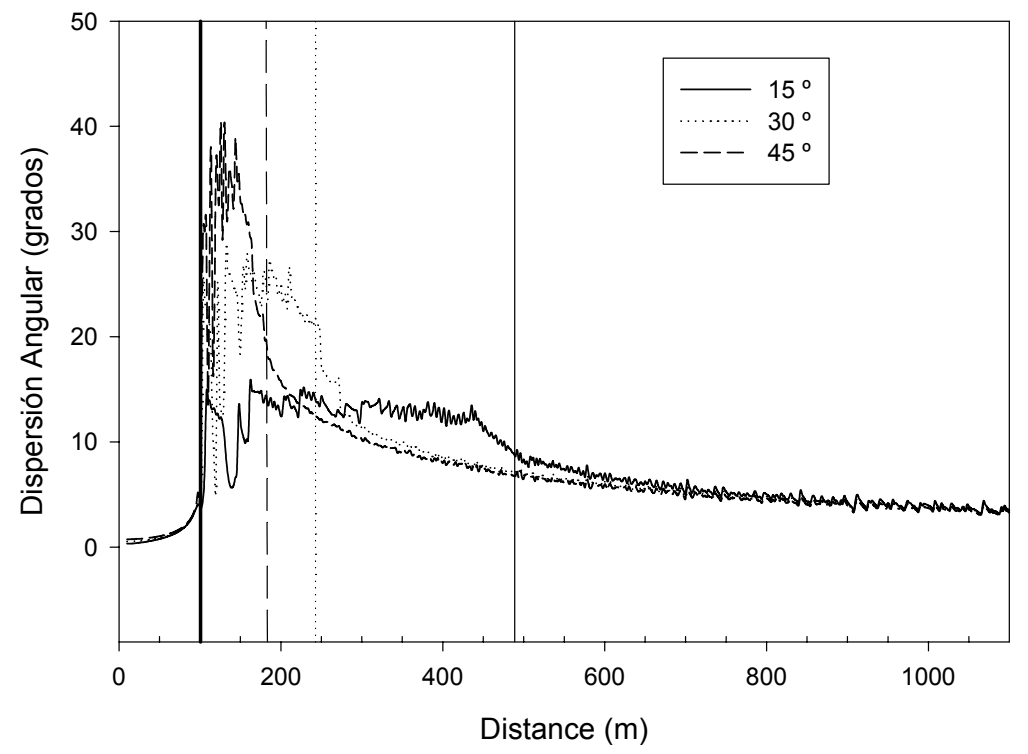

Figura 3.5: RMS angular spread para un túnel recto de dimensiones $8.5 \mathrm{~m} \times 5.3 \mathrm{~m}$.

Finalmente en la figura 3.5 se representa el RMS angular spread [Mol03a]. Vuelve a haber una relación directa entre la zona de excitación y este parámetro. Para valores elevados del ángulo del transmisor, se corresponden valores elevados del RMS angular spread. Para $45^{\circ}$ se tiene una dispersión angular de casi $40^{\circ}$, y para $15^{\circ}$ la dispersión se reduce a $13^{\circ}$. También se observa que el máximo se encuentra al principio de la zona de excitación, a diferencia del RMS delay spread que se produce al final. También se puede ver que en la tercera zona, sea cual sea la posición del transmisor, el RMS angular spread converge al mismo valor, que viene definido por la geometría del túnel. Al final de ésta, las contribuciones más importantes son las difractadas, que provienen de las dos esquinas de la entrada del túnel. 


\subsubsection{Discusión}

En este trabajo se ha utilizado el trazado de rayos para estudiar los diversos parámetros radioeléctricos en la transición de entrada a un túnel. Las pérdidas muestran la existencia de una región (segunda zona) antes de la zona de guiado (tercera zona) donde la pendiente es significativamente mayor que el resto. Esta zona se llama zona de excitación. También se estudiaron el RMS delay spread y el RMS angular spread. El primero de ellos alcanza su valor máximo al final de la zona de excitación, y toma valores de 33 ns y $11 \mathrm{~ns}$ para inclinaciones del transmisor de $45^{\circ}$ y $15^{\circ}$ respectivamente. El segundo alcanza su máximo en la entrada del túnel y toma valores de $40^{\circ}$ para una inclinación de $45^{\circ}$ y $13^{\circ}$ para una inclinación de $15^{\circ}$. A parte de esta particularidad, el RMS delay spread toma valores distintos en una tercera zona después de la zona de excitación, cuando el $R M S$ angular spread converge a un mismo valor independientemente de cuál sea la inclinación del transmisor.

\subsubsection{Cálculo de la zona de excitación para diversos túneles}

En el siguiente trabajo [Mol02b], se continúa con el estudio de la zona de excitación, tratando de relacionarla con la geometría de diferentes túneles rectangulares. Se emplearán dos métodos para identificar la longitud de esta zona.

\subsubsection{Entorno de propagación}

La figura 3.6 muestra la planta de un túnel genérico de anchura $2 D$. Fuera de éste se sitúa un transmisor de 4 metros de altura a una distancia $R$ de $100 \mathrm{~m}$, y ángulo $\varphi$ con respecto al eje longitudinal del mismo. El receptor de dos metros de altura se sitúa a una distancia d de la pared del túnel, es decir, en el centro de una de las dos vías de las que consta el túnel. Se define la $x$ (Zona de visión directa) como la distancia en el interior del túnel en la que existe visión directa entre transmisor y receptor.

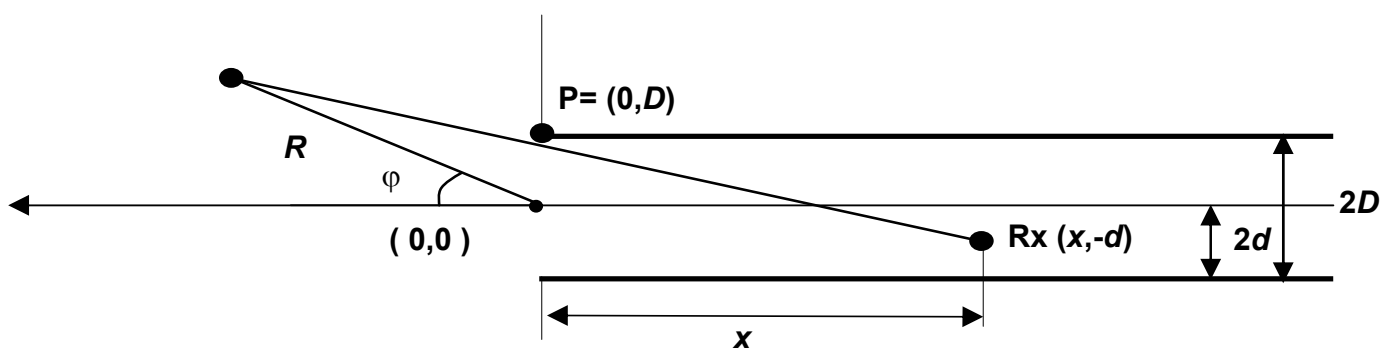

Figura 3.6: Planta de un túnel ideal de ancho en 2D. 


\subsubsection{Modelo de propagación}

Se ha utilizado de nuevo el trazador de rayos del apéndice $\mathrm{A}$, esta vez modificándolo para obtener por separado los rayos difractados y los reflejados. Se han tenido en cuenta las siguientes contribuciones:

- $\quad$ Rayo directo y su reflexión en el suelo.

- Difracción en las esquinas de la entrada.

- Reflexiones múltiples tras la difracción en las esquinas de la entrada.

- Reflexiones múltiples en las paredes interiores al túnel.

Se ha estudiado el número de reflexiones necesarias para obtener un resultado fiable, y se ha fijado en 10. Un número mayor de reflexiones supondría un coste computacional mucho más elevado y no proporcionaría una mejora en los resultados. Las simulaciones se han realizado a $2.1 \mathrm{GHz}$, con antenas isotrópicas verticalmente polarizadas. En cuanto a las paredes, se ha supuesto una conductividad de $\sigma=0.01 \mathrm{~S} / \mathrm{m}$ y una permitividad relativa $\varepsilon_{\mathrm{r}}=5$.

\subsubsection{Definición de la zona de excitación}

Para una transmisión en el interior de un túnel en situación de visión no directa (NLOS) se define la zona de excitación como la distancia que va desde la entrada del túnel hasta el punto en el que la energía de los rayos difractados supera a la de los reflejados en las paredes [Mar94]. Una primera forma de delimitar esta zona es estudiando la pendiente del factor de propagación (3.1). La figura 3.7 muestra el factor de propagación en el interior de un túnel de $8.5 \mathrm{~m}$ de ancho $(2 D)$ con respecto a la distancia entre transmisor y receptor. La inclinación del transmisor es de $30^{\circ}(\varphi)$, y la entrada túnel se encuentra a 50 metros del transmisor $(R)$. 


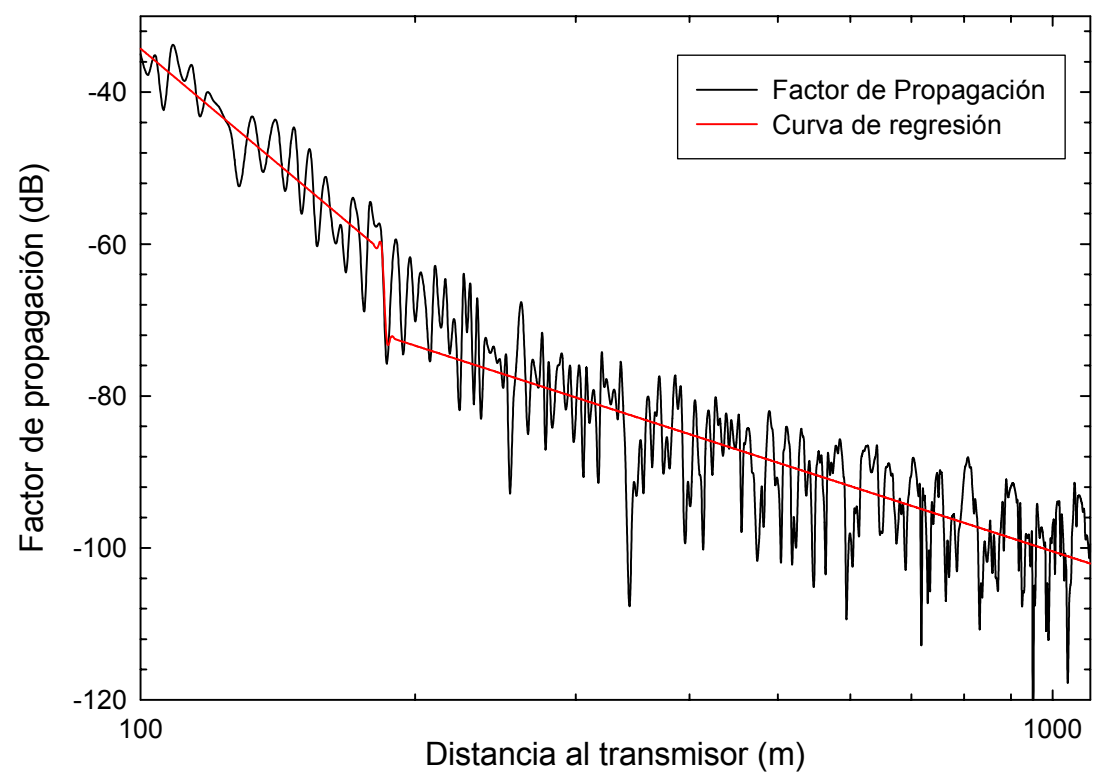

Figura 3.7: Factor de propagación en un túnel de $8.5 \mathrm{~m}$ de ancho.

Se observa que el comportamiento de estas pérdidas puede ser aproximado a dos rectas con pendientes diferentes, siendo la longitud de la primera la zona de excitación. Se ha utilizado el método de los mínimos cuadrados para calcular las dos rectas que mejor se ajustan al factor de propagación.

Además de esta primera solución, aplicando la definición inicial de la zona de excitación, se ha estudiado por separado la potencia de los rayos reflejados y los difractados. En la figura 3.8 está representado el factor de propagación debido a los rayos reflejados y a los difractados. Se observa que hay una distancia a partir de la cual la potencia de los difractados supera a la de los reflejados. De esta forma se puede delimitar la zona de excitación. También se observa que los rayos reflejados desaparecen a partir de una cierta distancia, debido a que se limita el número máximo de reflexiones. 


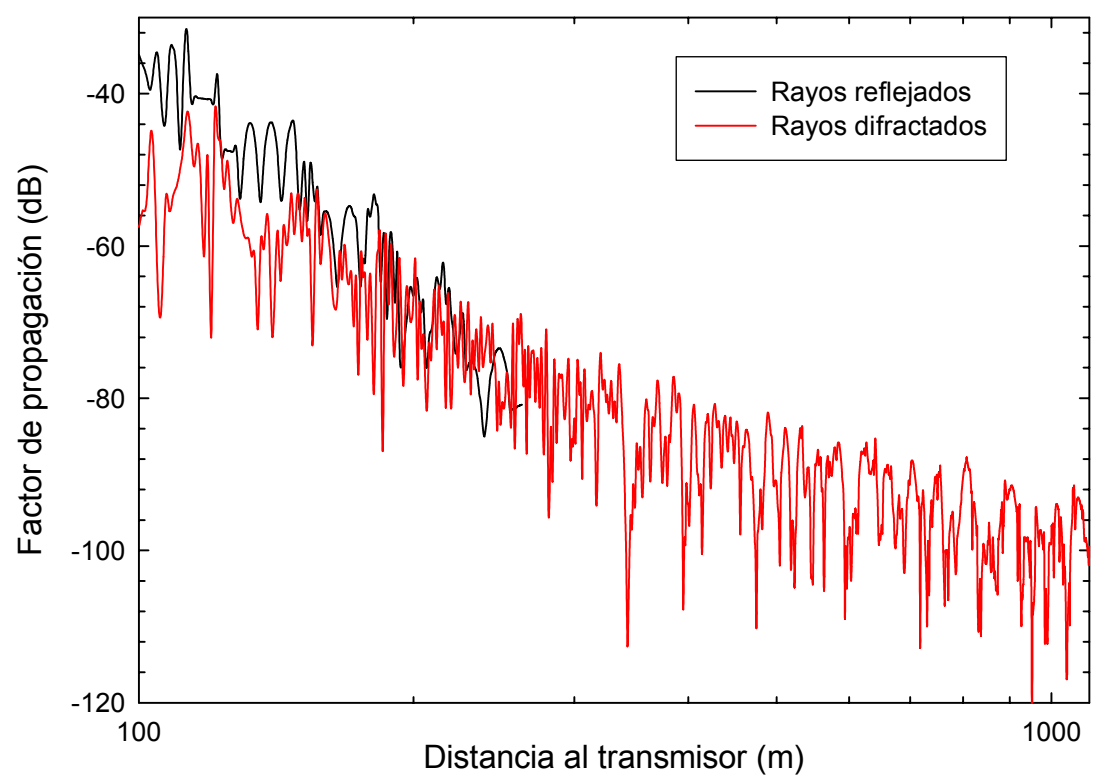

Figura 3.8: Factor de propagación correspondiente a las componentes reflejadas y difractadas en un túnel de $8.5 \mathrm{~m}$ de ancho.

\subsubsection{Resultados}

Se han realizado simulaciones en túneles de distintos anchos $(2 D): 7 \mathrm{~m}, 8.5 \mathrm{~m}, 10$ m y $13 \mathrm{~m}$, y para cada uno de éstos se han simulado ángulos del transmisor $(\varphi)$ entre $15^{\circ}$ y $70^{\circ}$. Se observó que si se expresa el valor obtenido de la zona de excitación con respecto a la dimensión $x$ de la figura 3.6, la longitud de la zona de excitación se ajusta bastante bien con una regresión lineal. Geométricamente se obtiene la relación entre $\varphi$ y $x$ :

$$
x=\frac{R \cdot \cos (\varphi)(D+d)}{R \cdot \sin (\varphi)-D}
$$

La dimensión $x$ es la distancia desde la entrada del túnel a partir de la cual se pierde la visión directa con el túnel. Si $R$ es mucho mayor que $D$, el valor de $x$ puede aproximarse a:

$$
x \approx \frac{(D+d)}{\tan (\varphi)}
$$




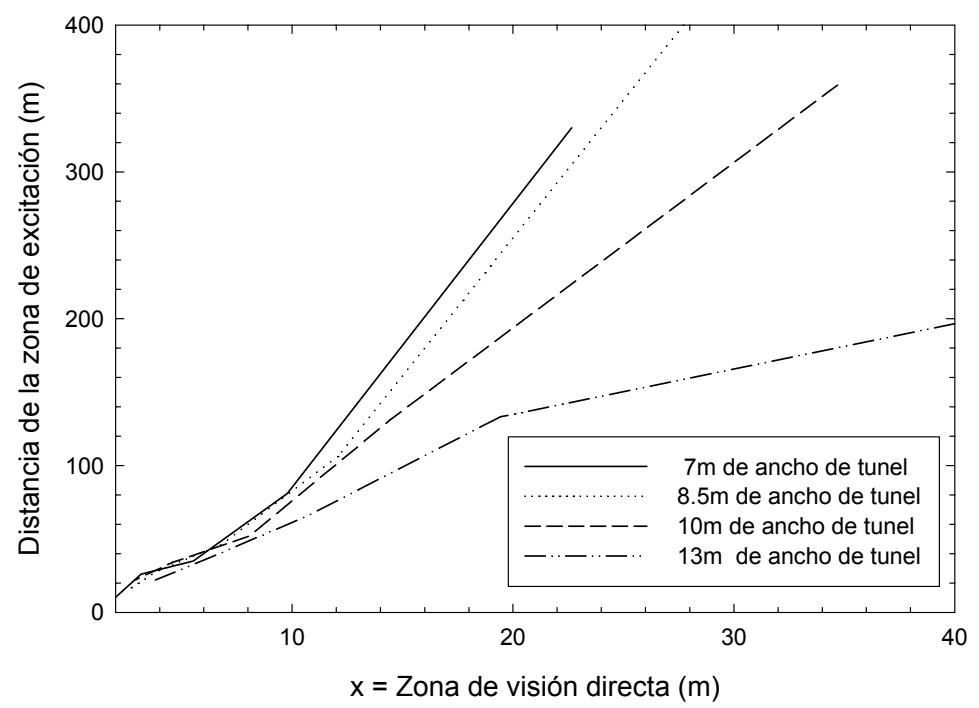

Figura 3.9: Zona de excitación calculada mediante la aproximación de las pérdidas con dos pendientes.

La figura 3.9 muestra la distancia de la zona de excitación frente a $x$ cuando se utiliza el método de las pendientes. Se observa que para los cuatro túneles, la relación entre $x$ con la zona de excitación es lineal. Esta línea tiene una pendiente que indica cuánto aumenta la zona de excitación con respecto a la distancia a partir de la cual el receptor deja de tener visión directa con el transmisor $(x)$. Así mismo, cuanto mayor sea la anchura del túnel, esta pendiente será más suave. Si se comparan estos resultados con respecto a los obtenidos calculando la zona de excitación mediante el cálculo de las energías de las reflexiones y difracciones, se observa que ambos son muy similares (figura 3.10). Esto indica que ambos métodos son equivalentes.

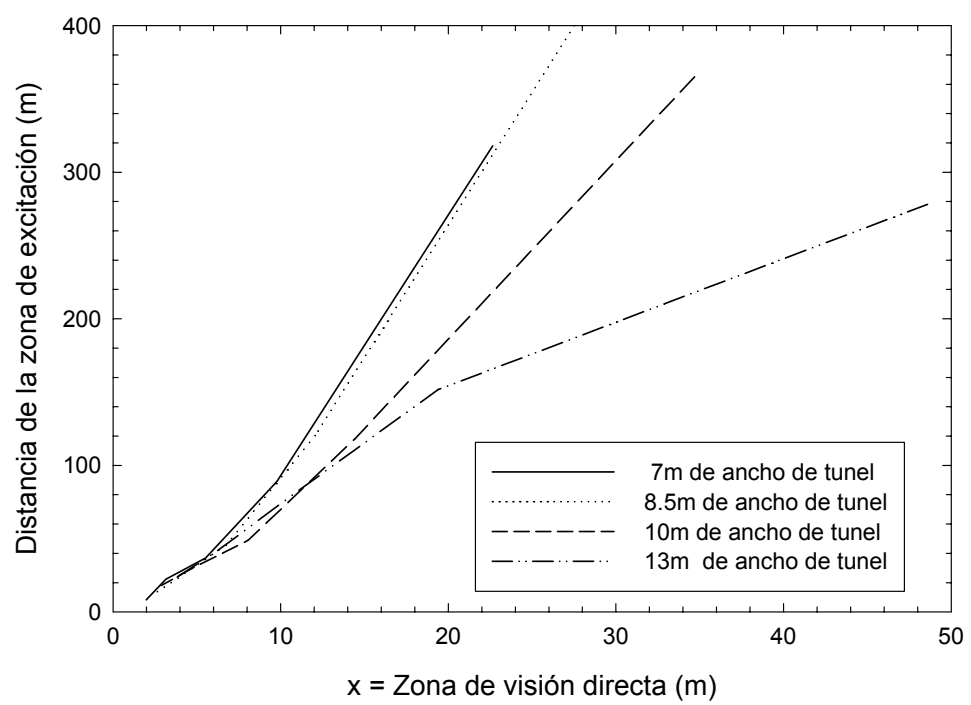

Figura 3.10: Zona de excitación calculada mediante el estudio de la potencia de las contribuciones reflejadas y la potencia de las contribuciones difractadas. 


\subsubsection{Discusión}

En este trabajo se ha estudiado la zona de excitación de túneles genéricos regulares mediante dos métodos. El primero de ellos, más matemático, aproxima las pérdidas de propagación a dos rectas y minimiza el error cuadrático medio entre los datos y las dos rectas de regresión. El segundo método, observa el comportamiento desde un punto de vista más físico. Se ha aplicado la definición de zona de excitación, en la que la energía de los rayos reflejados supera a la de los difractados.

Se concluye que los resultados de ambos métodos son satisfactorios y extremadamente similares. También se concluye que la pendiente disminuye con la anchura del túnel y que la relación entre el parámetro $x$ y la llamada zona de excitación es aproximadamente lineal.

\subsection{Medidas SISO en un túnel pequeño}

La caracterización de los distintos entornos de propagación es esencial para el diseño de sistemas de comunicaciones móviles. En los sistemas de tercera generación se buscan altas velocidades de transmisión en los diferentes entornos de propagación (rural, suburbano, edificios, túneles...) [Ca102][Rab01]. Por lo tanto, las características de banda ancha deben de ser analizadas para estos entornos. Por ejemplo, a partir de la dispersión del retardo se puede obtener la velocidad máxima de transmisión de información sin necesidad de ecualización [Rap96]. En concreto, en este punto se estudia la propagación en túneles pequeños, que son utilizados diariamente por un gran número de personas. Este trabajo se centra en el estudio de parámetros de banda ancha en un túnel pequeño para peatones en situación $N L O S$ [Mol03b,Mo104a]. 


\subsubsection{Entorno de propagación}

La figura 3.11 presenta una vista en planta del túnel en el que se realizó la campaña de medidas. El túnel está situado en el campus de la Universidad Politécnica de Cartagena, junto al Antiguo Hospital de Marina. En la figura 3.12 se observan dos fotografías del túnel bajo estudio, la primera de ellas tomada hacia el interior del mismo donde se encuentra la antena receptora. La segunda de ellas está tomada desde el transmisor hacia la entrada del túnel, donde la distancia es de 25 metros.

Es un túnel ligeramente curvo transitable solamente por personas. Para su análisis, ha sido aproximado por dos líneas rectas para poder realizar simulaciones. Mide 2.85 metros de alto, 2.5 metros de anchura en la entrada, 4.2 metros de anchura en el interior y 23 metros de largo.

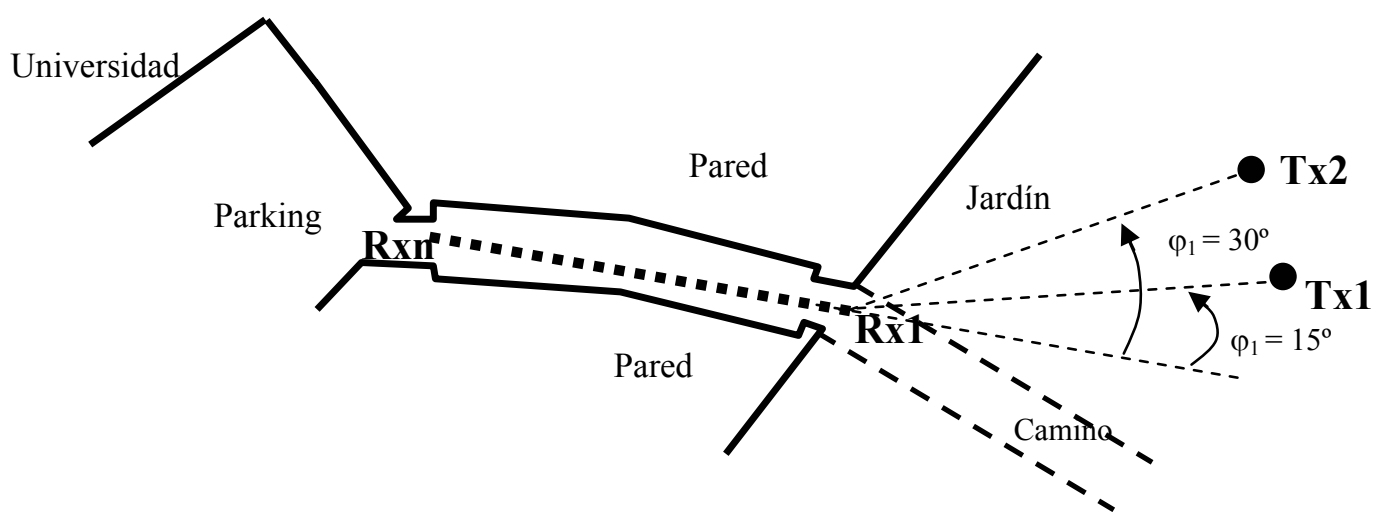

Figura 3.11: Vista en planta del túnel de la UPCT donde se realizó la campaña de medidas.
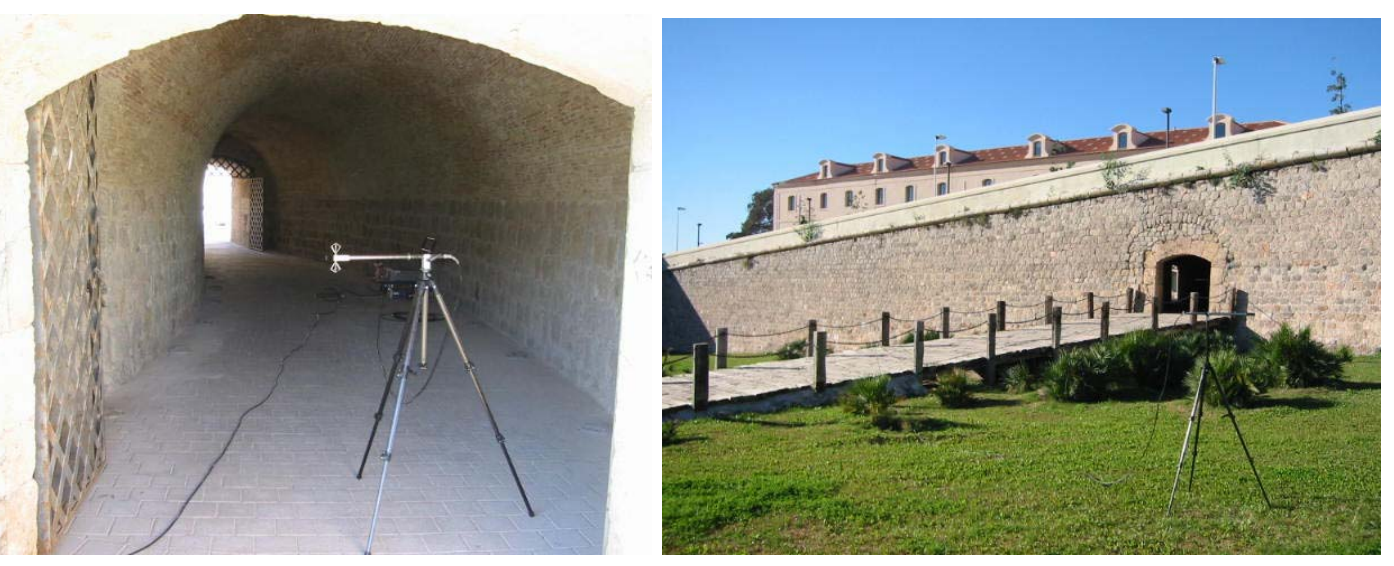

Figura 3.12: Fotografías del túnel bajo estudio de la Universidad Politécnica de Cartagena. 
Se seleccionaron dos posiciones para el transmisor que distaban 25 metros de la entrada. El receptor realiza un recorrido desde Rx1 hasta Rxn con separación entre receptores de un metro. La altura de los receptores es de 1.8 metros cada uno.

\subsubsection{Sistema de medidas}

Para realizar las medidas, se utilizó el equipo de medidas del apéndice C. El sistema está formado por un analizador de redes HP8714, un amplificador de $18 \mathrm{~dB}$, dos antenas de banda ancha bicónicas, cables y conectores (ver apéndice C). Los componentes se calibraron con el analizador de redes para eliminar el efecto de los mismos en las medidas. La respuesta en frecuencia de las antenas se calibró mediante un post-procesado de la información, utilizando el documento de calibración de las mismas.

El equipo se configuró de la siguiente manera: frecuencia central $\left(f_{0}\right) 2.1 \mathrm{GHz}$, ancho de banda total en las medidas $500 \mathrm{MHz}$ y número de puntos $(N)$ 1601. Con esta configuración se tiene una resolución temporal de 2 ns (0.6 metros), y una ventana temporal total de $3.2 \mu$ s (distancia máxima alrededor de un kilómetro). Durante la realización de las medidas el ancho de banda de frecuencia intermedia se fijó en $250 \mathrm{~Hz}$, además, para reducir en nivel de ruido, se tomó un factor de promediado de 8 . Con todo esto, el nivel máximo de potencia a la salida es de $0 \mathrm{dBm}$, y el nivel del ruido término $112 \mathrm{dBm}$. Es decir, se tienen más de 100 decibelios de rango dinámico teniendo en cuenta las pérdidas de la antena y cable en el receptor.

\subsubsection{Calibración}

Se tomaron medidas del sistema de medidas anterior en una cámara anecoica, configurando el sistema con los parámetros anteriormente mencionados. Las antenas se situaron a un metro de distancia. En la figura 3.13 se muestran los perfiles de retardo correspondientes a las medidas y a las simulaciones en banda ancha utilizando (2.15). Si se calculan las pérdidas de propagación (pathloss) a partir de los perfiles de retardo utilizando $(\hat{P}(\tau)$ definido en $(2.15))$ :

$$
\overline{\text { PathLoss }}=-10 \log _{10}\left(\sum_{i=1}^{M \wedge} \hat{P}\left(\tau_{i}\right)\right)
$$


se obtienen unas pérdidas de $38.05 \mathrm{~dB}$ para el perfil medido y $38.87 \mathrm{~dB}$ para el perfil simulado. Si se comparan estas pérdidas con las pérdidas en espacio libre dadas por la fórmula de Friis a 1 metro de distancia:

$$
\overline{\text { PathLoss }}=-20 \log _{10}\left(\frac{\lambda}{4 \pi R}\right)
$$

donde $\lambda$ es la longitud de onda y $R$ la distancia, para $R=1$ metro, se tiene que las pérdidas son de $38.88 \mathrm{~dB}$. Éstas son prácticamente idénticas a las pérdidas simuladas, como era de esperar.

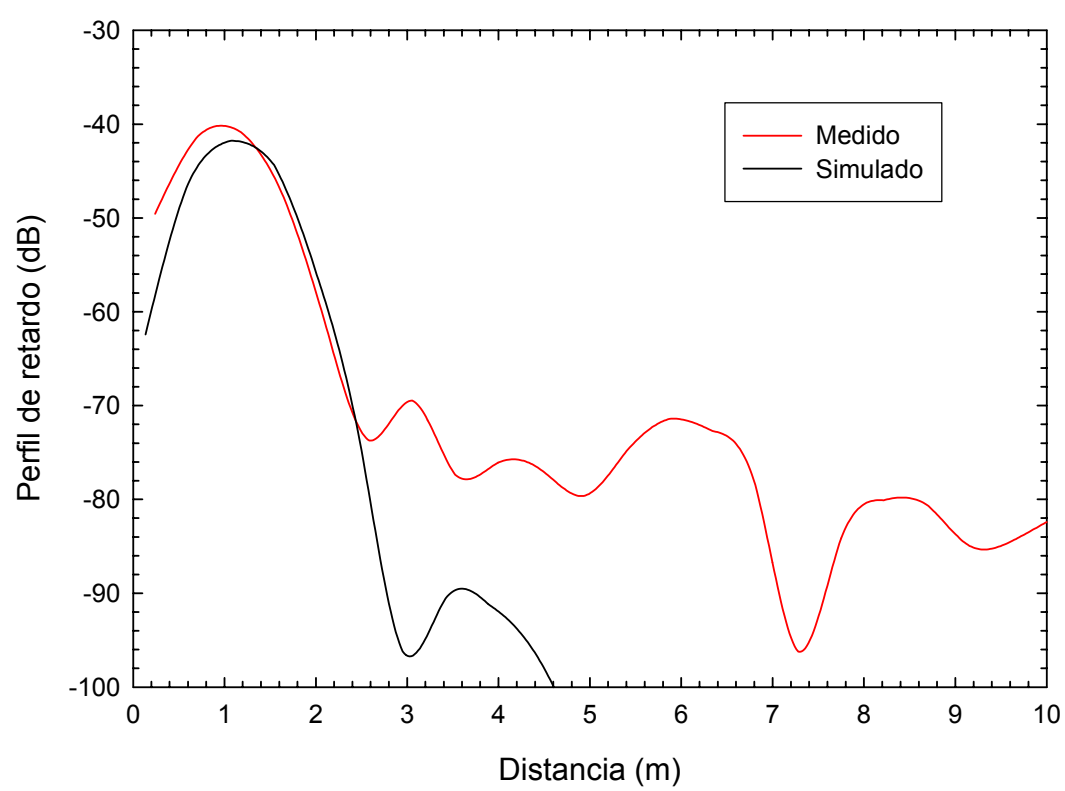

Figura 3.13: Medida y simulación en una cámara anecoica a 1 metro de distancia.

\subsubsection{Resultados}

Se han realizado varias campañas de medidas en el túnel de las figuras 3.11 y 3.12 para dos posiciones del transmisor. También se ha utilizado el modelo UTD de banda ancha explicado en el capítulo 2.1 para contrastar las medidas con resultados teóricos. Para las simulaciones, se ha tomado un número máximo de reflexiones igual a 10 [Mar01]. Los parámetros eléctricos se han ajustado a las medidas, tal y como se recomienda en [Riz97]. Se llegó a la conclusión de que $\sigma=10^{-2}$ y $\varepsilon_{r}=5$ eran óptimos.

\subsubsection{Pérdidas de propagación}

Las figuras 3.14 y 3.15 muestran las pérdidas básicas de propagación en el interior del túnel de la figura 3.11 para TX1 y TX2 respectivamente. En ambas figuras se 
encuentran las pérdidas medidas y simuladas en banda ancha que se han calculado utilizando (3.4). Para el caso de banda estrecha, se ha realizado una simulación a $2.1 \mathrm{GHz}$, y se han calculado las perdidas a partir de la expresión (3.1).

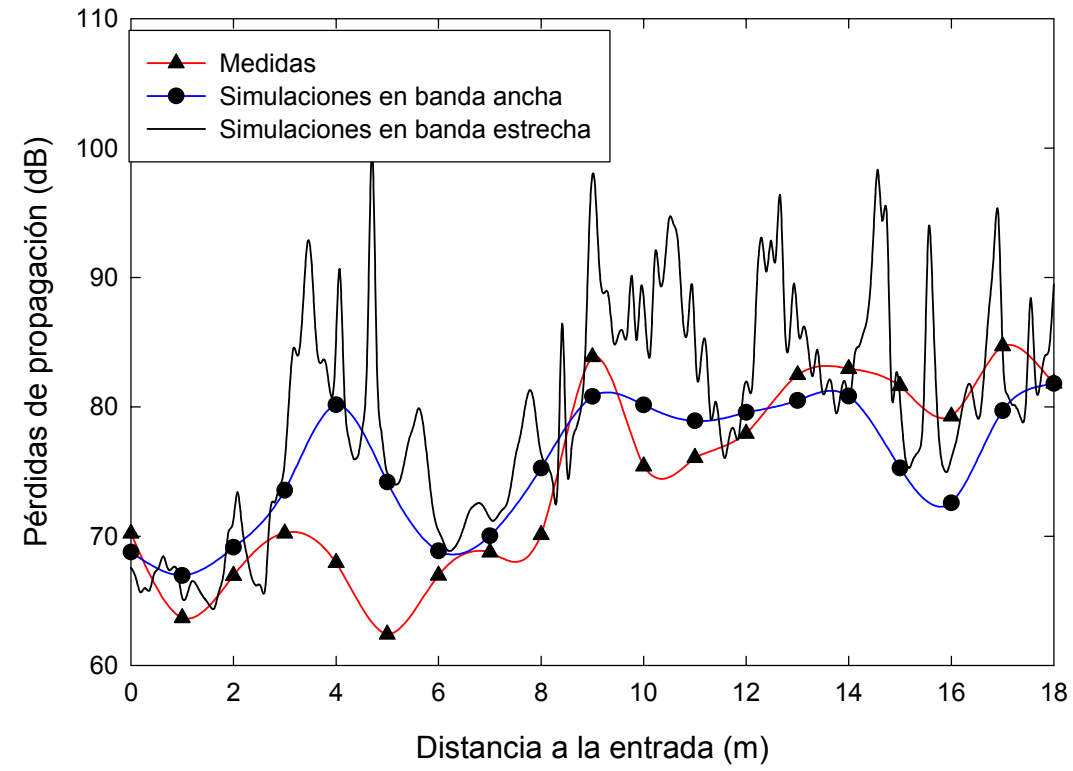

Figura 3.14: Pérdidas básicas de propagación en el interior del túnel de la figura 3.11 cuando transmite Tx1.

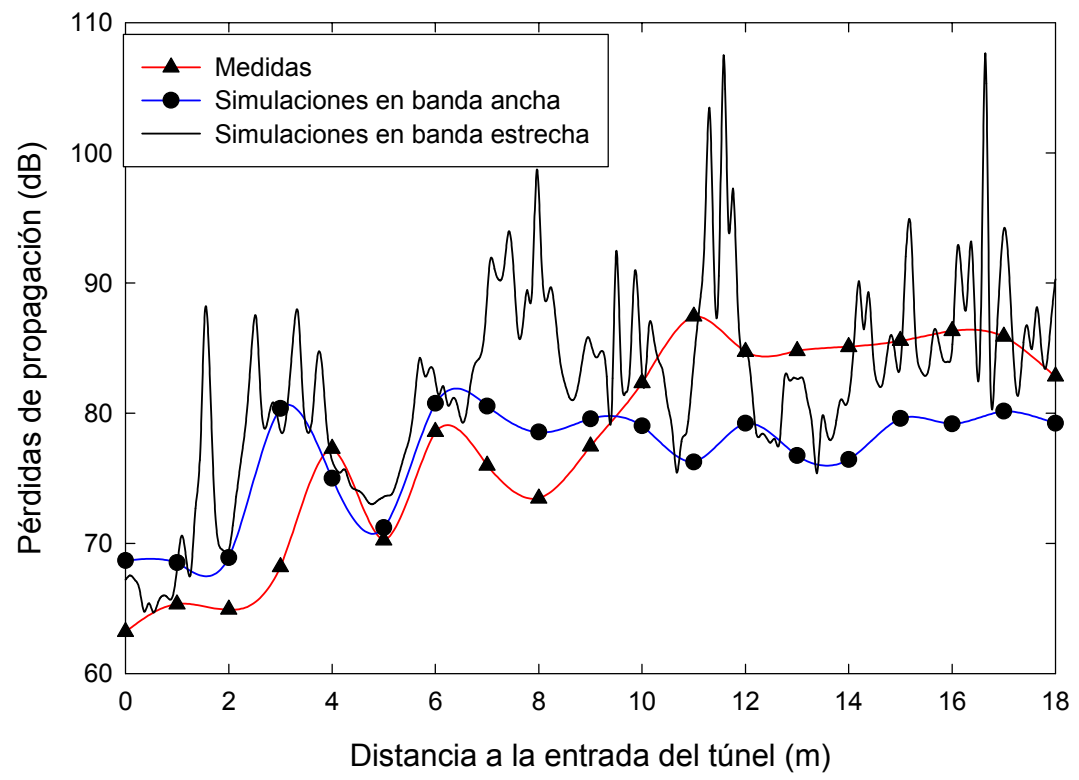

Figura 3.15: Pérdidas básicas de propagación en el interior del túnel de la figura 3.11 cuando transmite Tx2. 
Las medidas son muy similares a las simulaciones aun cuando sólo se ha tenido en cuenta la propagación en el plano horizontal (el lanzado de rayos es en dos dimensiones). En ambas figuras las pérdidas en la entrada oscilan alrededor de $67 \mathrm{~dB}$, que corresponde con unas pérdidas de espacio libre para una distancia de 25 metros, que es la distancia en ambos casos del transmisor a la entrada del túnel. A una mayor inclinación del transmisor corresponde una pendiente de pérdidas mayor, tal y como se observó en [Mar01]. Para el Tx1 las pérdidas aumentan hasta $80 \mathrm{~dB}$ al final del túnel, y para el Tx2 hasta $90 \mathrm{~dB}$. También se observa que ambas simulaciones de banda ancha y estrecha se comportan de forma similar.

\subsubsection{Perfil de retardo}

Las figuras $3.16,3.17$ y 3.18 presentan varios perfiles de retardo en decibelios utilizando el modelo de la sección 2.1.2 para las dos posiciones del transmisor: Tx1 y Tx2 (ver figura 3.11). La primera de ellas corresponde a una situación LoS, donde el receptor se encuentra en la entrada del túnel (Rx1). Esta posición es común para ambos transmisores ya que la distancia entre antenas es la misma, y la contribución con mayor energía es la del rayo directo. El máximo se encuentra a 83.7 ns, que corresponde a una distancia de 25 metros (distancia entre el transmisor y el receptor). Se detecta otra contribución a 200 ns, y puede que esto sea causado por la reflexión en algún edificio cercano.

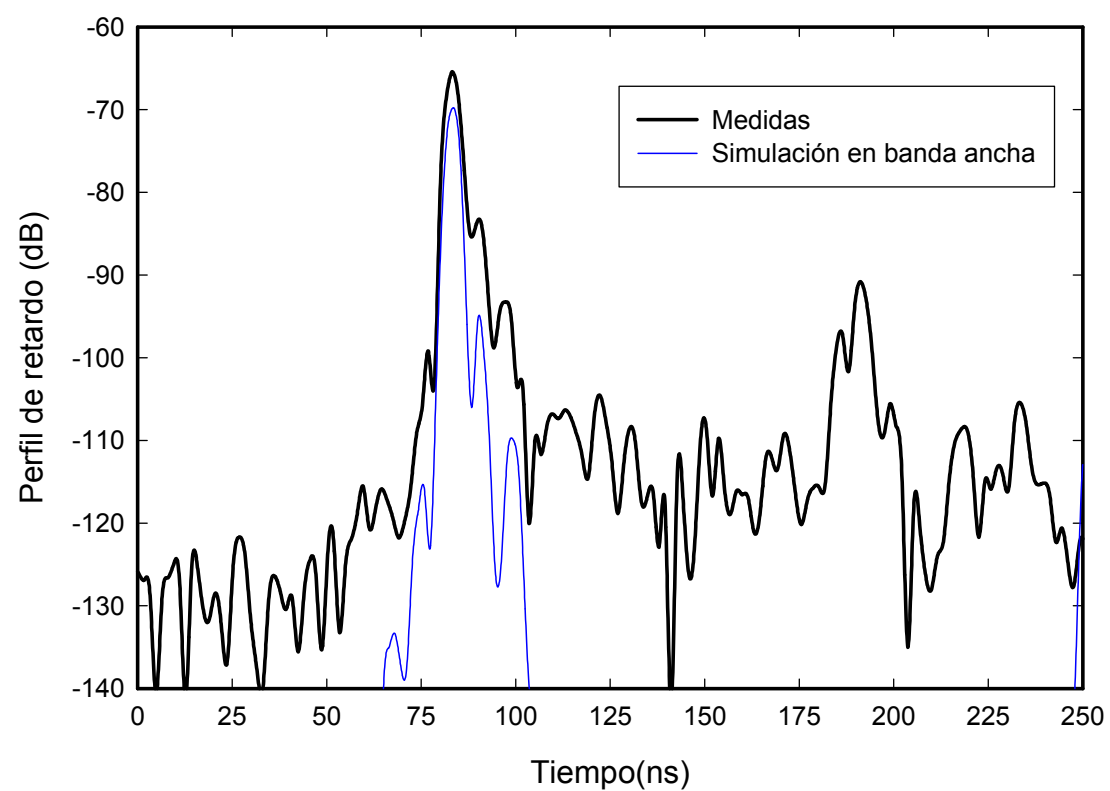

Figura 3.16: Perfil de retardo simulado y medido cuando el receptor se encuentra en la entrada del túnel. 
La siguiente figura, figura 3.17, muestra el perfil de retardo para un receptor situado a 14 metros de la entrada cuando se selecciona el Tx1. De nuevo, existe bastante similitud entre las medidas y las simulaciones de banda ancha. El primer pico se encuentra a los 130 ns, que corresponde a una reflexión en la pared. Este retardo corresponde con una distancia de 14 metros a partir de la entrada del túnel. Las siguientes contribuciones corresponden a contribuciones debidas a la reflexión y a la difracción en ambas entradas del túnel.

Por ultimo, la figura 3.18 muestra el perfil de retardo para un receptor situado a 16 metros de la entrada del túnel cuando se selecciona el transmisor Tx2. Una primera contribución aparece a los $143 \mathrm{~ns}$ (42.9 m), que corresponde con la distancia geométrica de la reflexión principal en la pared. Una segunda contribución a 50.4 metros corresponde a reflexiones en la entrada posterior del túnel. Este perfil de retardo es una situación clara de $N L o S$, es decir, un comportamiento exponencial negativo.

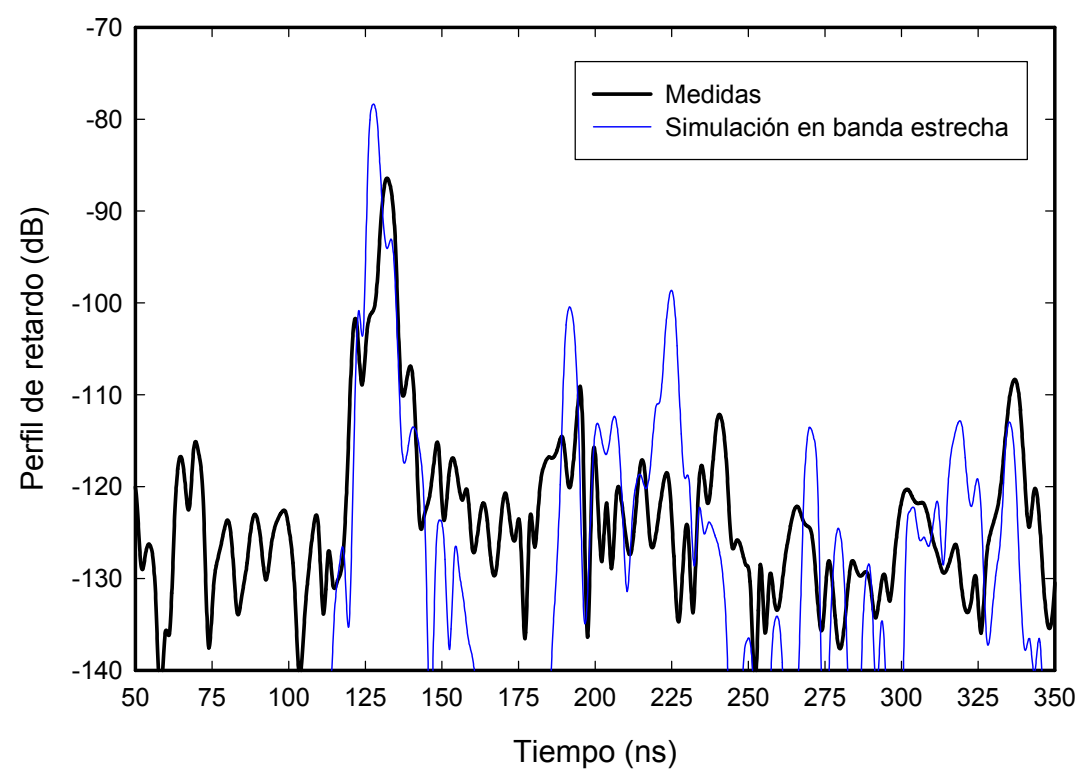

Figura 3.17: Perfil de retardo simulado y medido cuando el receptor se encuentra a 14 metros de la entrada y el transmisor es Tx1. 


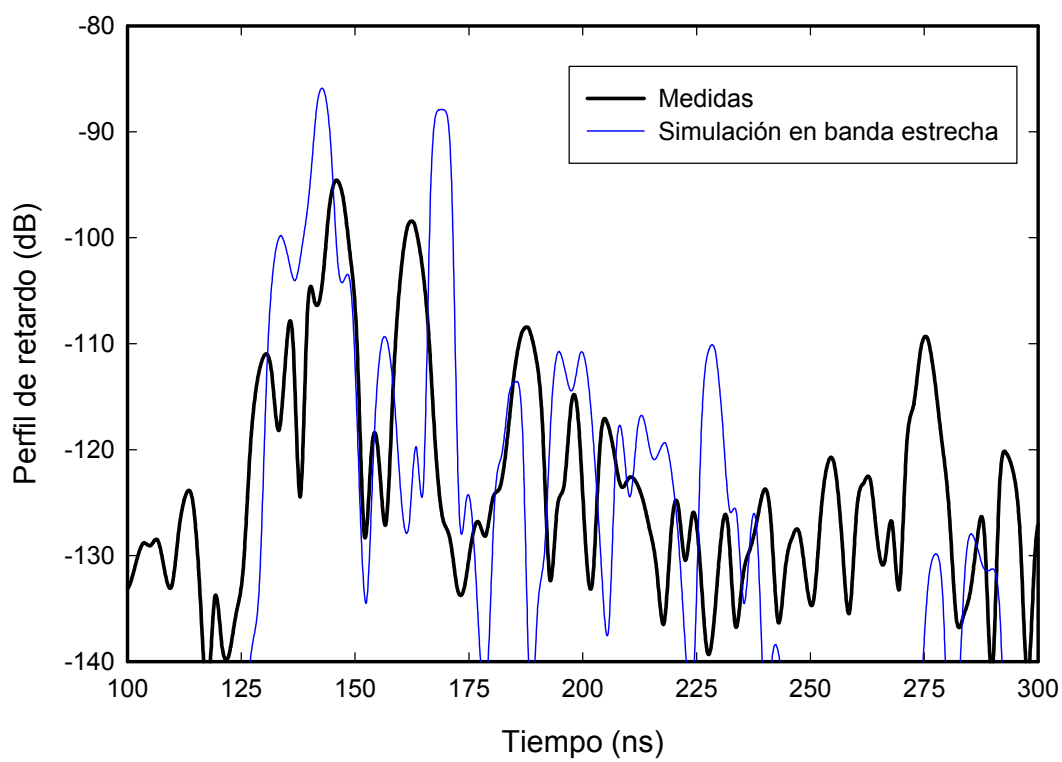

Figura 3.18: Perfil de retardo simulado y medido cuando el receptor se encuentra a 16 metros de la entrada y el transmisor es Tx2.

\subsubsection{RMS Delay Spread}

La figura 3.19 presenta la dispersión del retardo calculado con (B.11) en el interior del túnel cuando transmite Tx1. Para eliminar el ruido se ha tomado un umbral de $30 \mathrm{~dB}$ tanto para las simulaciones como para las medidas. En ambas se aprecia un incremento de la dispersión temporal en el medio del túnel. Este incremento define el final de la zona de excitación [Mar01], donde el RMS delay spread incrementa hasta casi $40 \mathrm{~ns}$. Se observa también que las simulaciones en banda ancha son más pesimistas que las de banda estrecha.

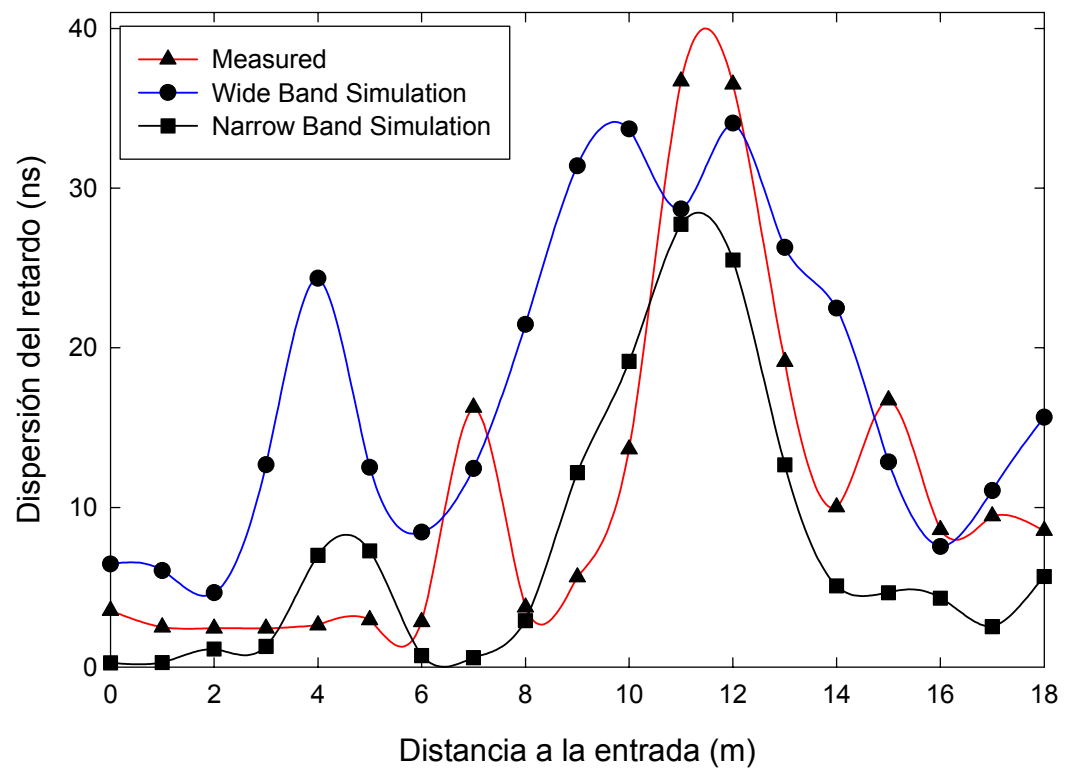

Figura 3.19: Dispersión del retardo en el interior del túnel cuando transmite Tx2. 


\subsubsection{Ancho de banda de coherencia}

Finalmente, las figuras 3.20 y 3.21 representan el ancho de banda de coherencia dentro del túnel para ambas posiciones del transmisor. El ancho de banda de coherencia se ha calculado a partir de la transformada de Fourier del perfil de retardo:

$$
\hat{P}(f)=\sum_{i=1}^{M}|\hat{P}(\tau)| e^{-j \cdot 2 \cdot \pi \cdot f \cdot i \cdot \Delta \tau}
$$

donde la función está definida entre $-B / 2$ y $B / 2$. El ancho de banda se puede dar a distintos niveles, y se ha elegido el ancho de banda a $-3 \mathrm{~dB}$ por ser el más utilizado en la literatura [Rap96]. La dispersión del retardo y el ancho de banda de coherencia se relacionan inversamente, como puede observarse inspeccionando las figuras. Para ambos transmisores, el ancho de banda simulado y medido en la entrada es de 125 y $110 \mathrm{MHz}$ respectivamente. En la entrada es similar sea cual sea la posición del transmisor ya que en ambos casos el receptor se encuentra en una clara situación de LoS y la distancia es la misma. Sin embargo, a una distancia de 7 metros de la entrada para el Tx1 y de 5 metros de la entrada para Tx2 el ancho de banda disminuye a 30MHz. De este resultado se deduce que existe un punto a partir del cual el ancho de banda decrece abruptamente, y depende de la posición del transmisor. La distancia desde la entrada del túnel hasta este punto es la zona de excitación. Esta distancia puede calcularse ahora mediante este parámetro, como antes se había hecho con las pérdidas [Mar94], dispersión temporal [Mar01] o con la dispersión del ángulo de llegada como se ha visto en el apartado 3.11.

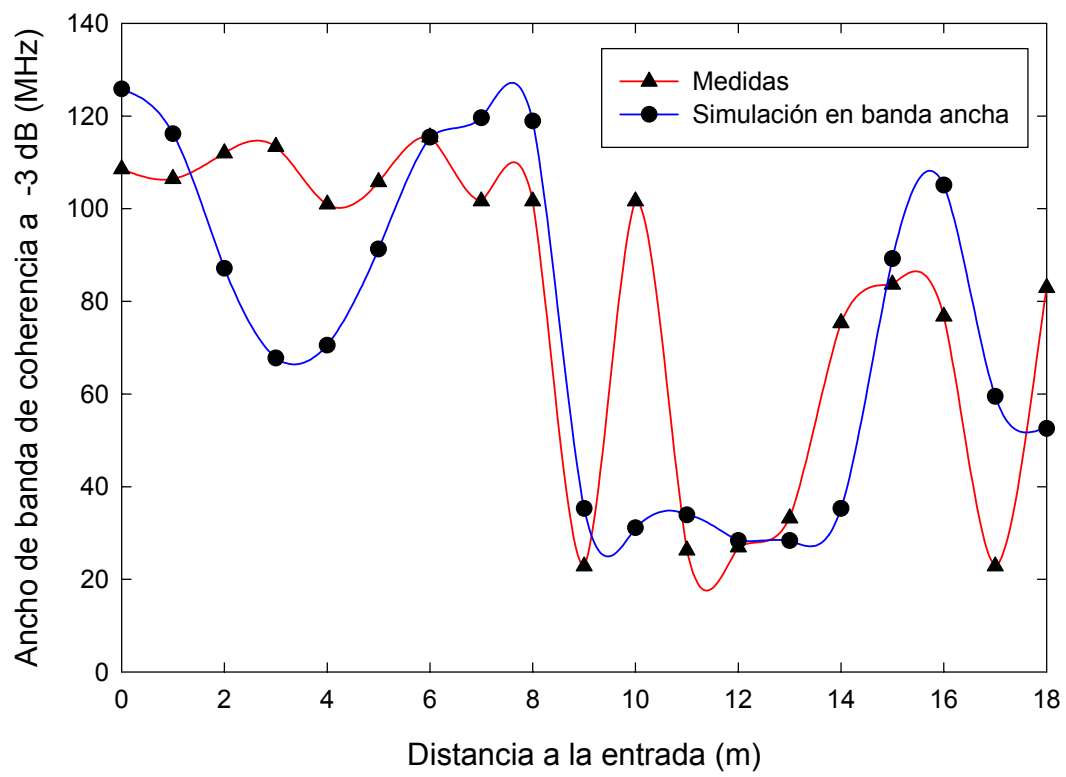

Figura 3.20: Ancho de banda de coherencia en el interior del túnel cuando transmite Tx1. 


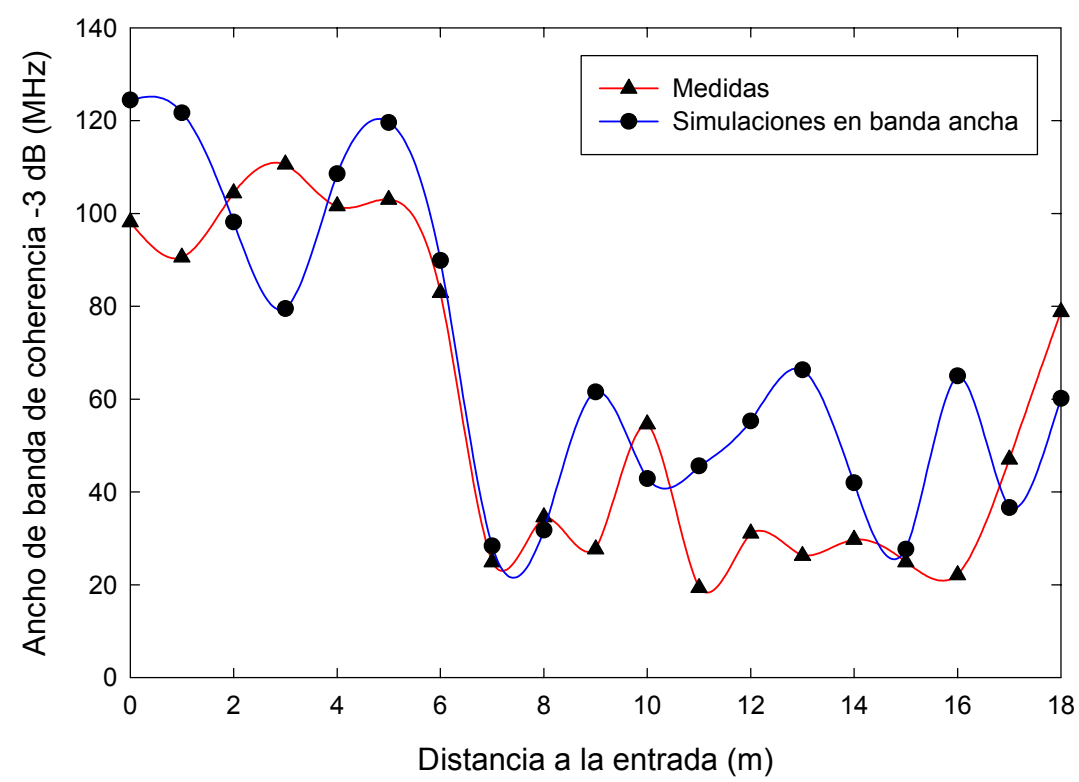

Figura 3.21: Ancho de banda de coherencia en el interior del túnel cuando transmite Tx2.

\subsubsection{Discusión}

Se ha aplicado el modelo de trazado de rayos de la sección 2.1.1 al túnel de la figura 3.11 para predecir la respuesta compleja de banda ancha del canal y se ha contrastado con medidas. Las respuestas frecuenciales se han enventanado, interpolado y transformado en el dominio temporal para obtener la respuesta al impulso. También se han ajustado los parámetros eléctricos de las simulaciones tal y como se recomienda en [Riz97]

El modelo de banda ancha predice bastante bien las pérdidas medias y el perfil de retardo, aun cuando solo se ha simulado en el plano horizontal. La dispersión del retardo es inferior a $40 \mathrm{~ns}$, y el ancho de banda de coherencia mayor a $30 \mathrm{MHz}$. Se ha encontrado la zona de excitación a partir del ancho de banda de coherencia a aproximadamente 7 y 5 metros de la entrada para $\mathrm{Tx} 1$ y $\mathrm{Tx} 2$ respectivamente.

\subsection{Resultados teóricos para túneles y sistemas MIMO}

Los sistemas MIMO (apéndice D) podrán ser de gran utilidad para aumentar la capacidad en entornos especiales como pueden ser los túneles. En este apartado se estudia la capacidad de los sistemas $M I M O$ en la transición de entrada y en el interior de los túneles, y se ha relacionado esta capacidad con la conocida zona de excitación de los mismos [Mol03c,Mol04b]. 


\subsubsection{Entorno de propagación}

La figura 3.22 muestra la planta de un túnel ideal utilizado en este estudio. El túnel tiene un ancho de 8.5 metros y una longitud muy grande comparada con el recorrido de la simulación. Fuera de éste, se sitúa un transmisor a 4 metros de altura, a una distancia de 25 metros y ángulo $\varphi$ de la entrada del mismo. El receptor, de 2 metros de altura, se sitúa en el centro del túnel y realiza un recorrido desde la entrada hasta una distancia de 3 kilómetros de la misma.

Tanto el transmisor como el receptor están formados por 8 antenas, separadas entre sí una distancia de $\lambda / 2$. Cada una de estas antenas tiene un patrón de radiación isotrópico. En el caso del transmisor, el array se orienta hacia la entrada del túnel de tal manera que su dirección de máxima radiación esté orientada a la entrada del túnel independientemente del ángulo con respecto a la entrada.

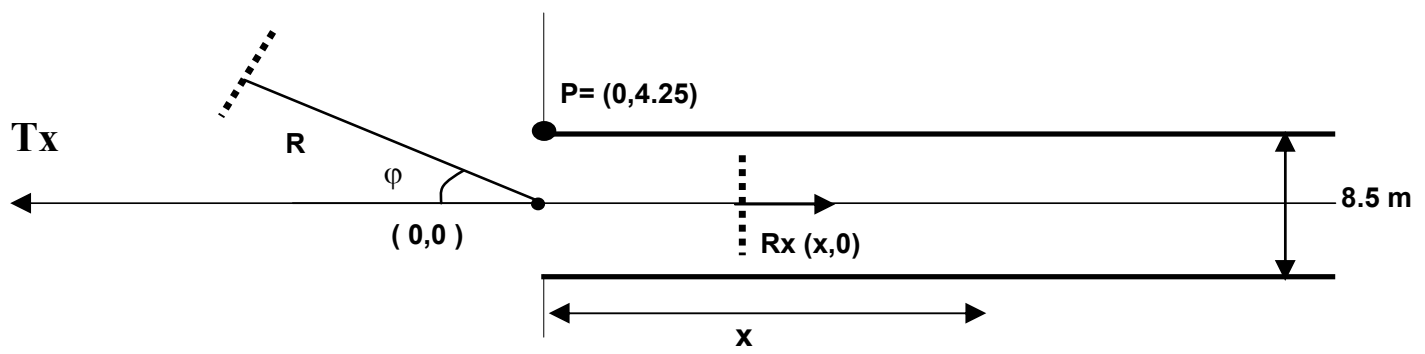

Figura 3.22: Planta de un túnel ideal.

\subsubsection{Modelo de propagación}

Para analizar el canal se ha utilizado el modelo que se explica en la sección 2.2. El número de antenas transmisoras y receptoras se ha tomado igual a 8. Para obtener la matriz de transferencia $\left(\mathbf{G}_{8 \times 8}\right)$, se han realizado $8 \times 8$ simulaciones en cada posición del receptor (3000). En cada punto, el coeficiente $\mathbf{G}(n, m)$ se obtiene como la suma coherente de todos los rayos recibidos en el receptor $m$ cuando la antena $n$ está transmitiendo (banda estrecha).

Se han tenido en cuenta las siguientes contribuciones:

- Rayo directo.

- Rayos múltiplemente reflejados.

- Rayos difractados.

- Rayos difractados y posteriormente múltiplemente reflejados. 


\subsubsection{Resultados}

Las simulaciones se han realizado para 4 ángulos distintos de transmisor, $\varphi=15$, $22,30 \mathrm{y} 45^{\circ}$. La frecuencia utilizada es $2.1 \mathrm{GHz}$, la permitividad relativa $\varepsilon_{\mathrm{r}}=5$, y la conductividad $\sigma=10^{-2}$. El número máximo de reflexiones se ha fijado en 50. En este caso se aumentó hasta 50 porque se vio que el valor de la capacidad era muy sensible al número de máximo de reflexiones. El primer resultado (figura 3.23) muestra la capacidad del sistema $8 \times 8$ en 3000 posiciones distintas desde la entrada del túnel equiespaciadas 1 metro, y para los cuatro ángulos del transmisor. El cálculo de la capacidad se hace utilizando (D.7)

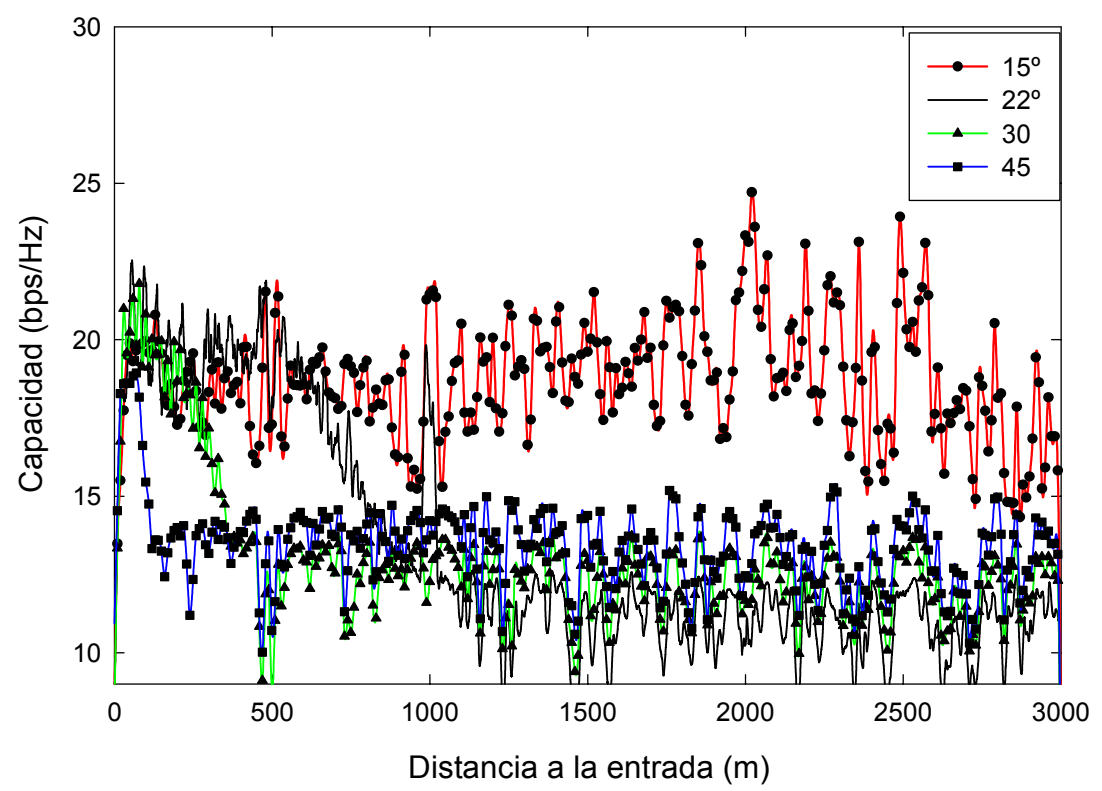

Figura 3.23: Capacidad en el interior del túnel para 4 inclinaciones distintas del transmisor.

Como se puede observar, se distinguen dos zonas en el comportamiento de la capacidad. Una primera zona donde la capacidad oscila en torno a $20 \mathrm{bps} / \mathrm{Hz}$. Esta zona tiene una longitud que depende de la inclinación del transmisor, de forma que a mayor inclinación, la distancia decrece. Esta distancia está directamente relacionada con la zona de excitación del túnel. Luego, la capacidad disminuye drásticamente debido a que la dispersión angular disminuye conforme aumenta la distancia a la entrada. Para un estudio más detallado del origen de esta disminución de capacidad, se obtienen las figuras 3.24 y 3.25 , donde se presenta la potencia de los valores propios de $\mathbf{G}$ en función de la distancia a la entrada del túnel para dos ángulos distintos. 
En ambos casos, se ve cómo dos de los autovalores permanecen con niveles de potencia altos, independientemente de la distancia a la entrada al túnel. Sin embargo, los 6 valores restantes, se atenúan fuertemente dependiendo de la inclinación del transmisor con respecto a la entrada del túnel. De este modo, al disminuir estas potencias, la capacidad sólo procede principalmente de 2 de los 8 posibles sub-canales del sistema.

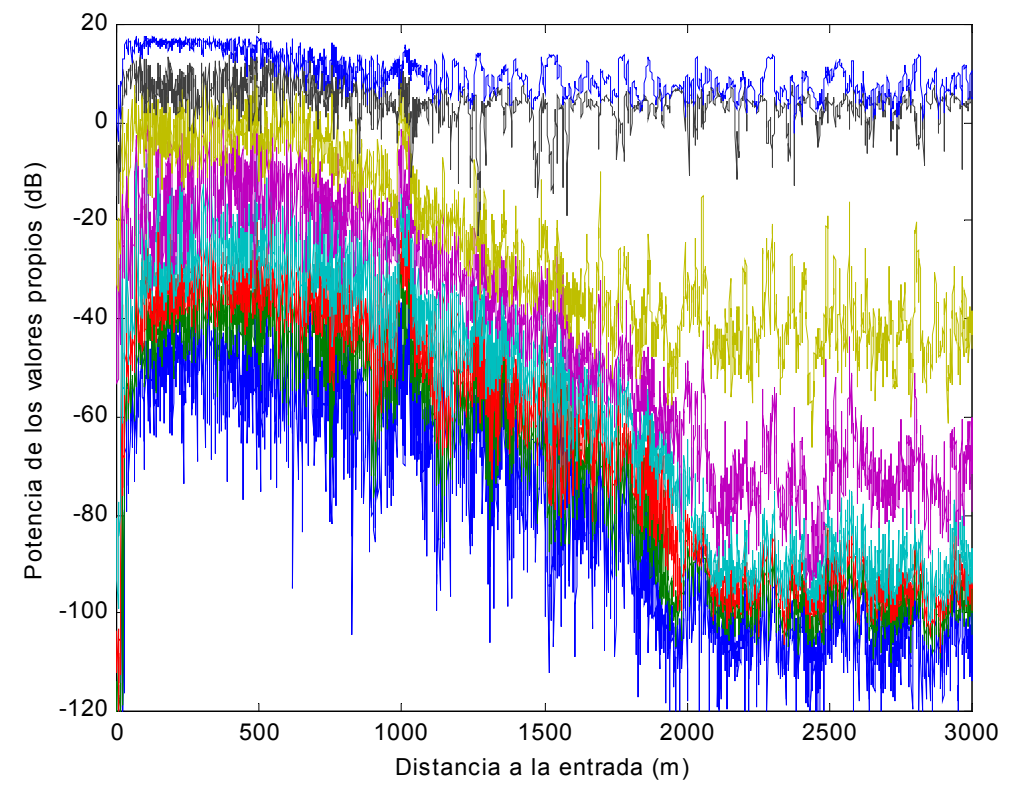

Figura 3.24: Potencia de los 8 valores propios en función de la distancia para $\varphi=22$.

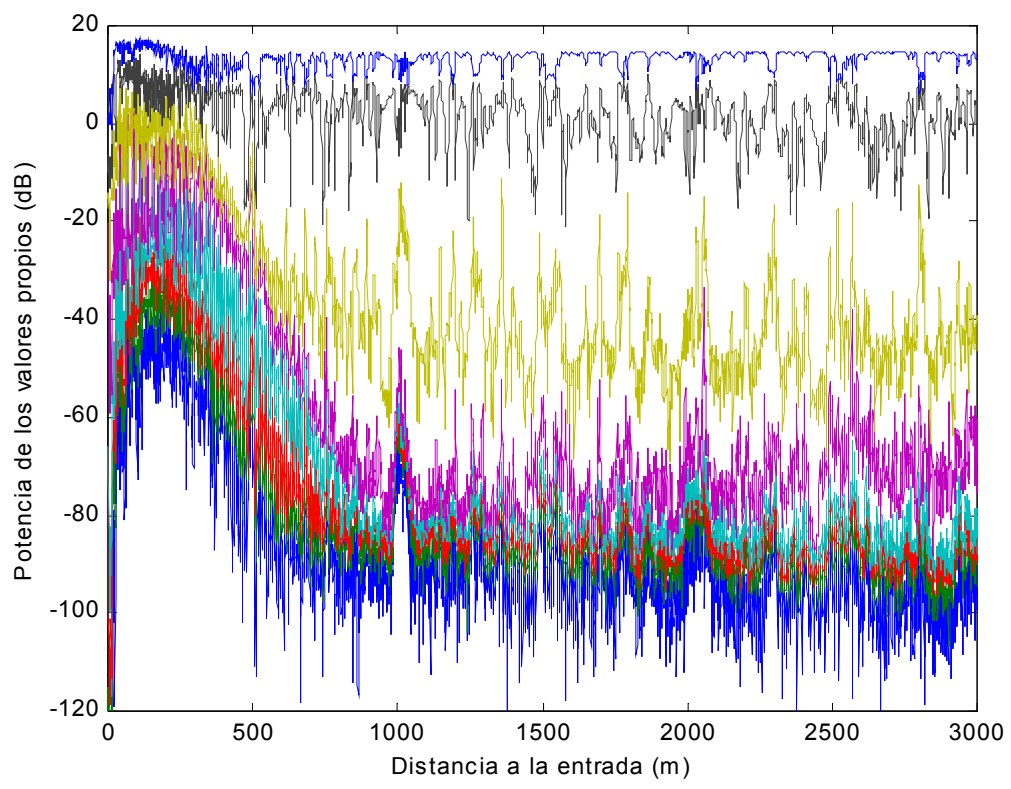

Figura 3.25: Potencia de los 8 valores propios en función de la distancia para $\varphi=30$. 


\subsubsection{Discusión}

En este trabajo se ha estudiado la capacidad de un sistema MIMO 8x8 en el interior de un túnel para 4 posiciones del transmisor. Para poder comparar las cuatro posiciones, se han orientado las antenas transmisoras hacia la entrada del túnel, y el receptor ha realizado un recorrido desde la entrada del túnel hasta una distancia de $3 \mathrm{Km}$.

Se ha observado que la capacidad toma un valor máximo a la entrada (20bps/Hz), donde la dispersión angular en el receptor es máxima. A medida que el receptor se separa de la entrada, existe una distancia a partir de la cual esta capacidad disminuye, y esta distancia está relacionada directamente con la zona de excitación del túnel. Por último, se han estudiado los valores propios de la matriz G para dos ángulos del transmisor, observando cuáles eran las causas de la disminución de la capacidad. 



\section{Capítulo 4}

\section{Propagación en Microceldas}

La planificación de los sistemas de comunicaciones móviles se hace siempre de forma celular, de modo que, garantizando una distancia mínima entre celdas iguales, se puedan reutilizar las frecuencias y aumentar la capacidad del sistema [Cat99]. Las microceldas nacen de la necesidad del aumento de la capacidad requerida en entornos urbanos. Se trata de celdas con radios que llegan hasta cientos de metros en entornos urbanos con alta densidad de tráfico, y en las que las antenas suelen situarse por debajo de los tejados de los edificios.

Bertoni presenta en [Ber94] modelos para microceldas basados en la difracción y los compara con campañas de medidas. También se han realizado extensas campañas de medidas para analizar este tipo de entornos en [Erc92] [Pap98].

Una técnica habitual que se utiliza para el estudio de las microceldas es el uso del trazado de rayos para modelar la propagación urbana [Rus91][Law94][Lee01] [Oes02]. En concreto, se ha estudiado con detalle la propagación en cruces de calles regulares (cuatro 
esquinas) [Fur89][Erc94][Riz97]. Para el caso de cruces con chaflanes, no existe en la literatura demasiada documentación [Rod01].

También se trabaja en modelos estadísticos que predigan el comportamiento del canal en microceldas [Hoe92][Cre95][Fu198][Bar02][Fu102] [Hum03]. En [Ert98] se encuentra un buen resumen de todos los modelos estadísticos que además tienen en cuenta variaciones espaciales.

Este capítulo trata de la propagación en microceldas. Se estudia teóricamente la dispersión temporal [Mol02c] y la capacidad $M I M O$ en cruces de cuatro esquinas y cuatro chaflanes [Mol03e]. Se presentan los resultados del análisis de unas medidas de banda ancha realizadas en la ciudad de Valencia [Mo103d,Mol04c]. También se aplica el modelo paramétrico descrito en el apartado 2.4 a un entorno microcelular [Mol04d,Mol04e], y se estudian las prestaciones de los sistemas distribuidos cuando se utiliza MIMO tanto en un entorno abierto como en microceldas[Mol04f].

\subsection{Dispersión temporal teórica en cruces de cuatro esquinas y de cuatro chaflanes}

La calidad de una comunicación radio depende estrechamente del entorno de propagación, que puede variar desde entornos rurales hasta picocélulas [Ber00][Cos01]. La propagación en cruces de cuatro esquinas ha sido estudiada con detalle, pero no así la propagación en cruces con cuatro chaflanes. Aquí se va a estudiar el comportamiento de la dispersión del retardo en cruces de cuatro esquinas y de chaflanes, y así se analizarán las diferencias y similitudes entre ambos tipos de entornos [Mol02c].

\subsubsection{Entorno de propagación}

La figura 4.1 presenta planos de dos entornos microcelulares de la ciudad de Valencia, uno es un cruce de cuatro esquinas y el otro un cruce con cuatro chaflanes. El primero tiene una anchura de calle de 17.5 metros y 18 metros. El cruce con chaflanes tiene unas dimensiones similares al de cuatro esquinas para facilitar la comparación, y el ángulo de los chaflanes es de $135^{\circ}$. En ambos entornos el transmisor se sitúa 70 metros a la izquierda del cruce, y el receptor realiza un recorrido desde P1 hasta el centro del cruce, y luego gira hacia arriba y continúa. En la figura 4.1 se señalan dos puntos por entorno: P1 y P2. Estos están igualmente posicionados, de tal forma que el primero es una clara situación de $L o S$, y el segundo $N L o S$. 

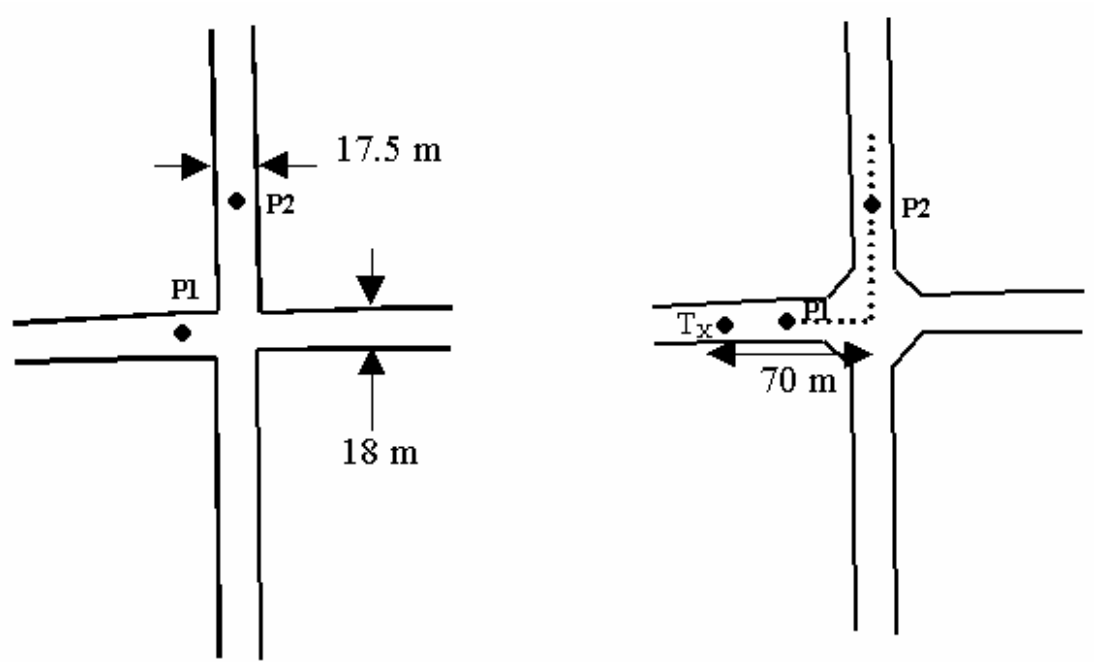

Figura 4.1: Geometría de (a) un cruce de cuatro esquinas y (b) un cruce de cuatro chaflanes.

\subsubsection{Modelo de propagación}

Se ha utilizado el trazador de rayos explicado en el apéndice A, y se han tenido en cuenta las siguientes contribuciones:

- Rayo directo.

- Rayos reflejados en las paredes.

- Difracción en las esquinas del cruce.

- Reflexiones múltiples tras la difracción en las esquinas.

Además, se le ha añadido a cada contribución su reflexión correspondiente en el suelo.

\subsubsection{Resultados}

Las simulaciones se han realizado con los parámetros dados en [Riz97]: permitividad $\varepsilon_{\mathrm{r}}=15 \mathrm{y}$ conductividad $\sigma=7 \mathrm{~S} / \mathrm{m}$. La frecuencia central es de $2.1 \mathrm{GHz}$, y las antenas son isotrópicas y verticalmente polarizadas. El transmisor tiene una altura de 10 metros y el receptor una de 1.8 metros. 


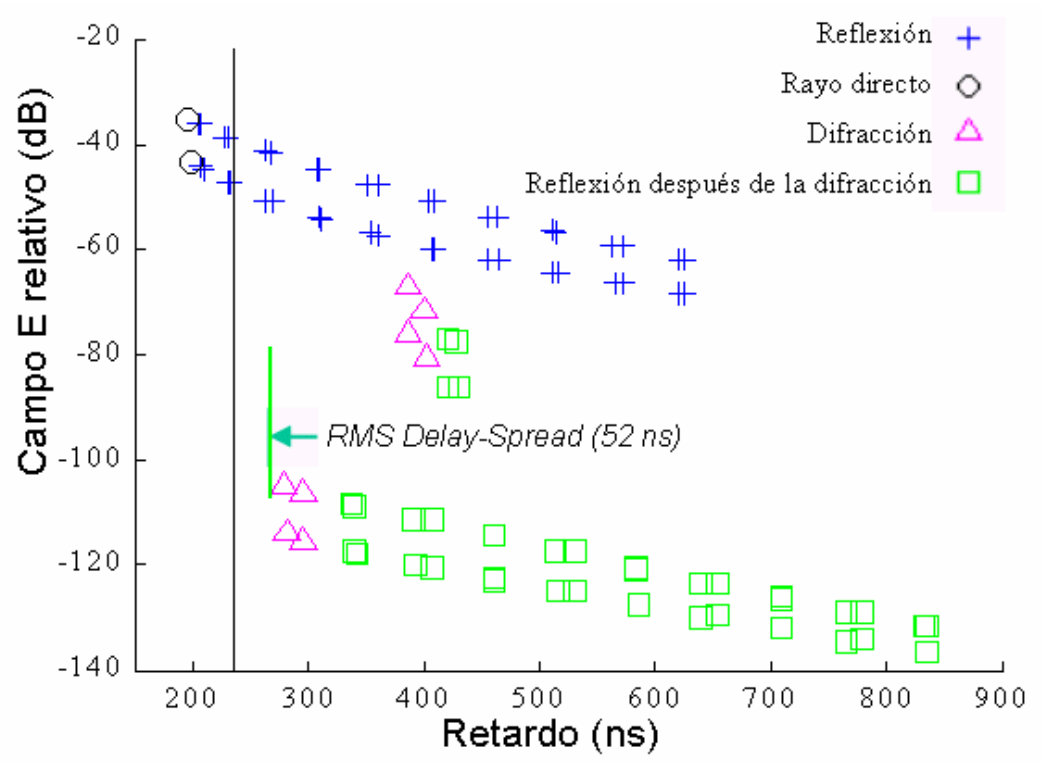

Figura 4.2: Perfil de retardo en P1 para el cruce de cuatro esquinas de la figura 4.1.

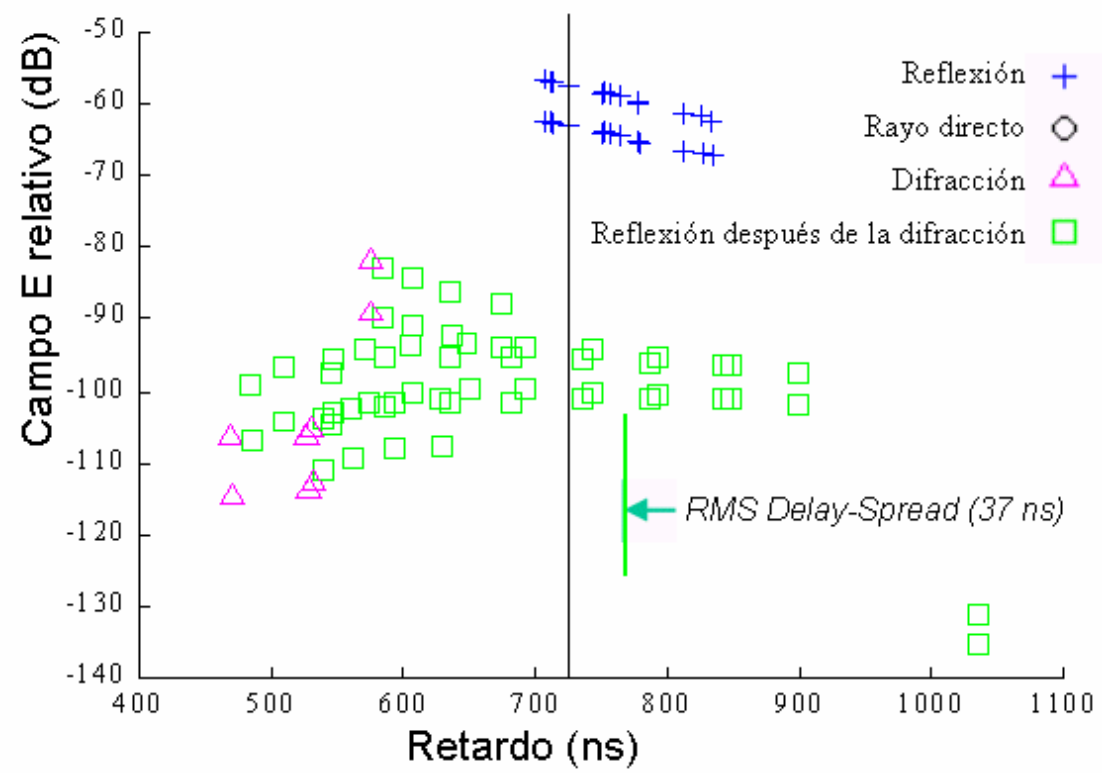

Figura 4.3: Perfil de retardo en P2 para el cruce de cuatro esquinas de la figura 4.1.

Para el cruce de cuatro esquinas, se simularon los perfiles de retardo correspondientes a los puntos P1 y P2 de la figura 4.1. Las figuras 4.2 y 4.3 muestran estos perfiles de retardo. Se observa que los retardos individuales y el retardo medio son mayores para el caso de P2, ya que el punto está más distante del transmisor. Sin embargo, la dispersión del retardo ( $R M S$ delay spread) disminuye de 52 a 37 ns después de torcer la esquina. 
Las figuras 4.4 y 4.5 muestran el perfil de retardo para los puntos P1 y P2 del cruce con cuatro chaflanes de la figura 4.1. De nuevo el retardo medio es superior en P2 que en P1, pero ahora la dispersión del retardo ha aumentado de 52 a 77 ns. Esto es debido a que en P2 para el caso de los chaflanes, llegan más contribuciones causadas por las reflexiones de los chaflanes aumentando la dispersión temporal.

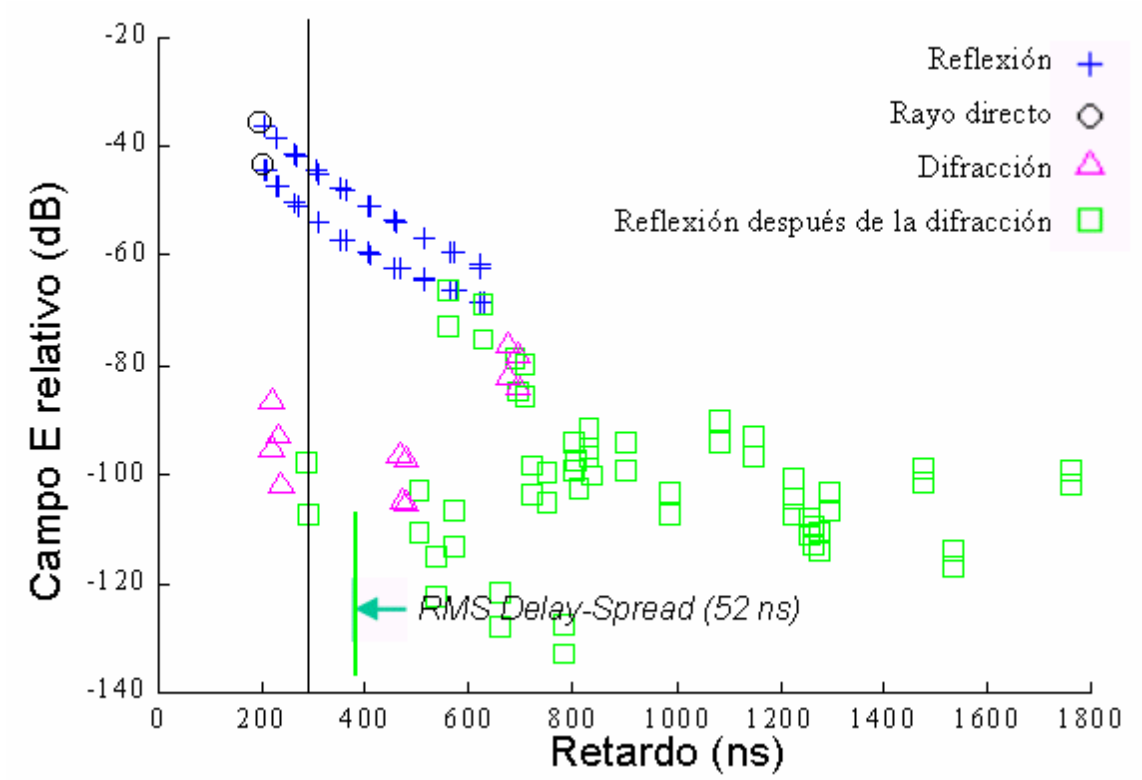

Figura 4.4: Perfil de retardo en P1 para el cruce con chaflanes de la figura 4.1.

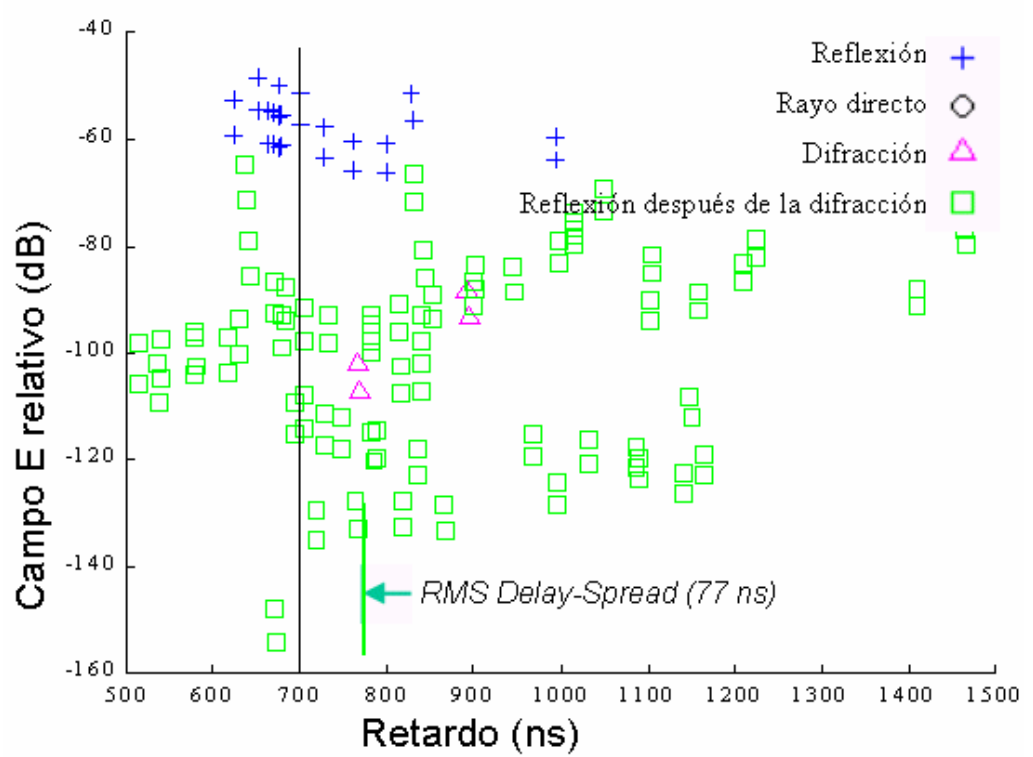

Figura 4.5: Perfil de retardo en P2 para el cruce con chaflanes de la figura 4.1. 
Resulta entonces interesante conocer el comportamiento del RMS delay spread para cada uno de los dos entornos. Se ha simulado un recorrido en cada entorno de la figura 4.1. Para permitir una comparación fiel, los recorridos son iguales, y tienen un primer recorrido hacia el cruce, para después girar arriba hacia posiciones $N L o S$. Se ha marcado con una línea de puntos la posición donde el receptor realiza el giro. La figura 4.6 muestra los resultados para ambos entornos. Se observa que para los primeros puntos, ambos entornos producen un RMS delay spread parecido, sin embargo cuando nos acercamos a la intersección este parámetro se incrementa sustancialmente para los chaflanes aumentando hasta $120 \mathrm{~ns}$.

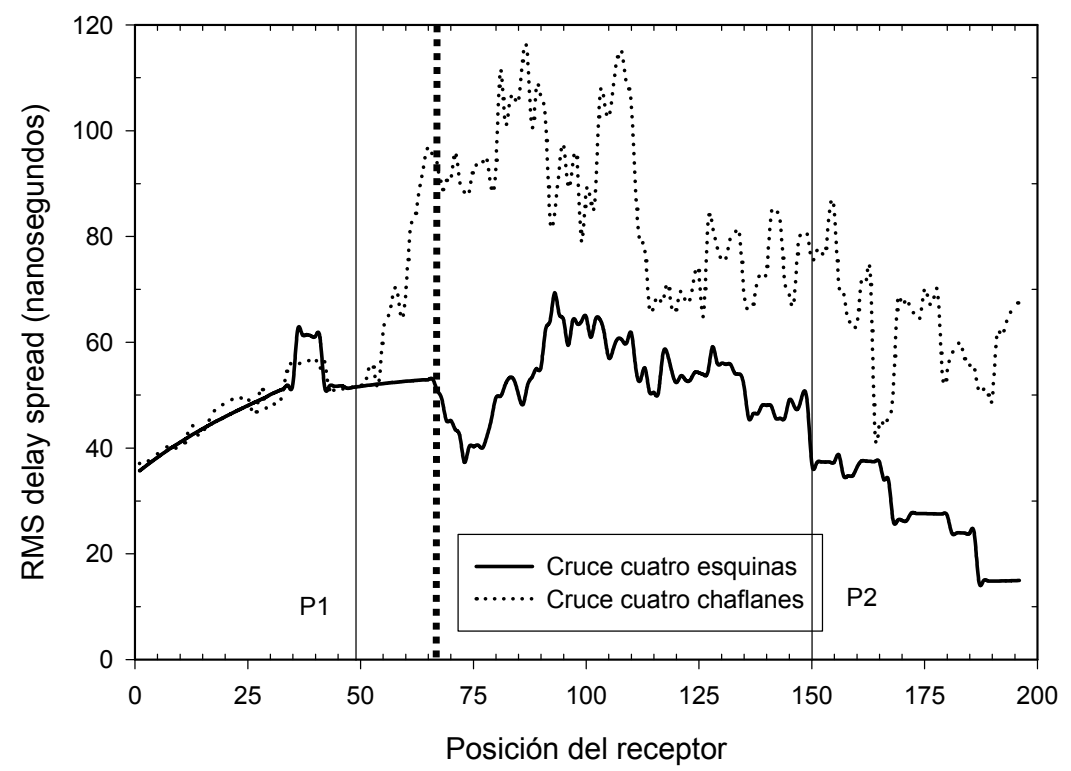

Figura 4.6: RMS delay spread en función de la posición del receptor. La línea vertical de puntos indica el cambio de dirección en el recorrido.

\subsubsection{Discusión}

Se ha utilizado la Teoría Uniforme de la Difracción (UTD) junto con la Óptica Geométrica (GO) para estudiar el comportamiento radioeléctrico en dos entornos microcelulares: un cruce con cuatro esquinas y otro con chaflanes. Se ha estudiado la dispersión del retardo y se observa que éste toma valores superiores en los cruces con chaflanes. Esto es debido a que a los chaflanes llegan muchas más contribuciones reflejadas que hacen incrementar el número y la energía de las mismas. 


\subsection{Medidas SISO en cruces de cuatro esquinas y cuatro chaflanes}

La respuesta del canal radio ha sido analizada con medidas y modelos teóricos para multitud de entornos y rangos de frecuencias [Pap98][Kiv99]. En concreto, resulta muy interesante conocer la dispersión del retardo, el ancho de banda de coherencia, la correlación en frecuencia y las líneas de retardo equivalentes para el diseño de sistemas inalámbricos. En este trabajo se han realizado medidas de banda ancha en dos tipos de entornos microcelulares: cruces de cuatro esquinas y cruces de cuatro chaflanes [Mol03d,Mol04c].

\subsubsection{Entorno de propagación}

El objetivo del trabajo es comparar dos entornos típicos microcelulares de las ciudades europeas: los cruces de cuatro esquinas y los cruces con cuatro chaflanes. En la figura 4.7 se observan dos planos de la ciudad de Valencia donde se observa que las intersecciones suelen ser de uno u otro tipo.
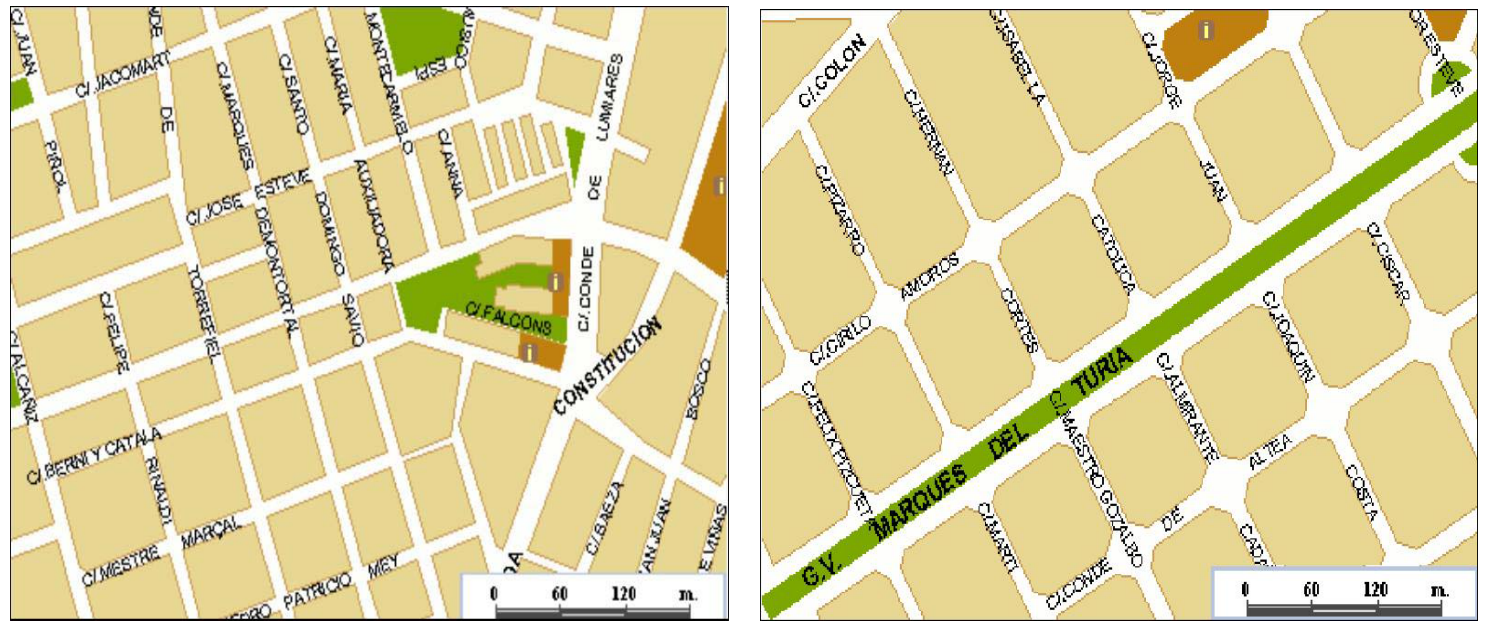

Figura 4.7: Planos de la ciudad de Valencia, (a) estructura de cruces con cuatro esquinas, y (b) estructura con cruces con cuatro chaflanes.

Para las medidas se eligieron el cruce de cuatro esquinas entre la calle G. Lluch y la calle Mariano Merenciano (fotos de la figura 4.8), y el cruce de cuatro chaflanes entre la calle Isabel la Católica y la calle Ciril Amorós (fotos de la figura 4.9). Las medidas fueron tomadas en el proyecto final de carrera de Alan Gooding [Goo00]. 

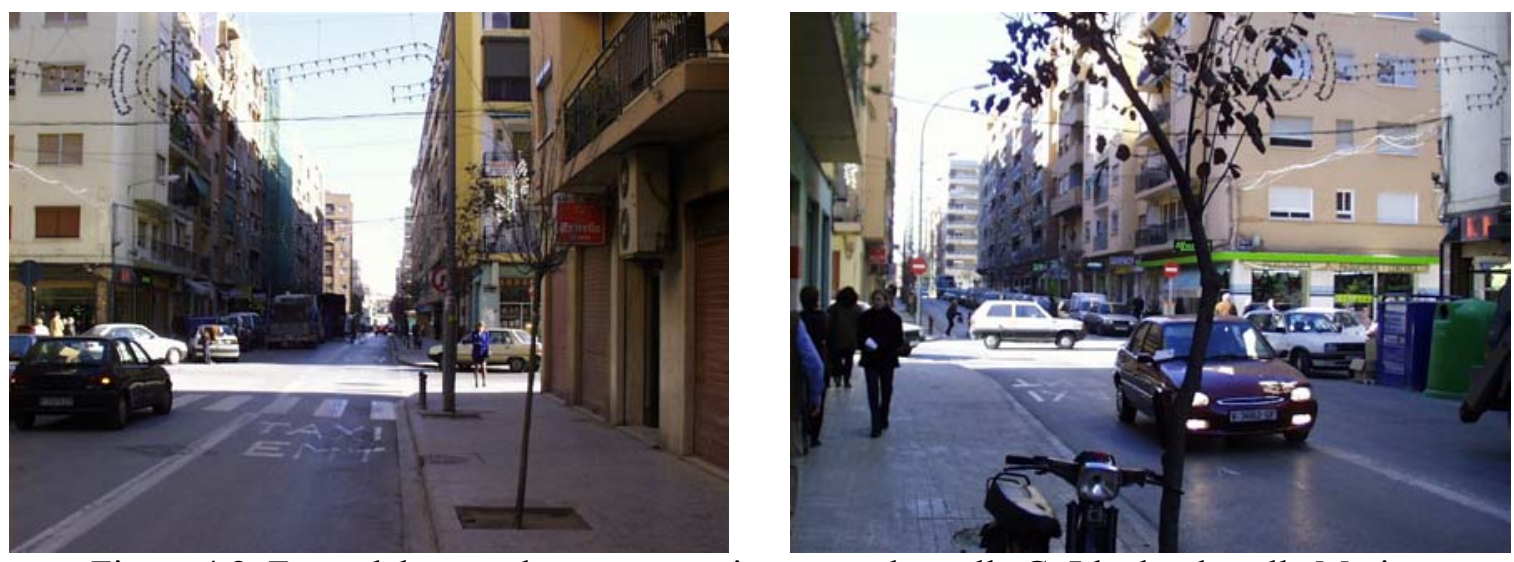

Figura 4.8: Fotos del cruce de cuatro esquinas entre las calle G. Lluch y la calle Mariano Merenciano en Valencia.
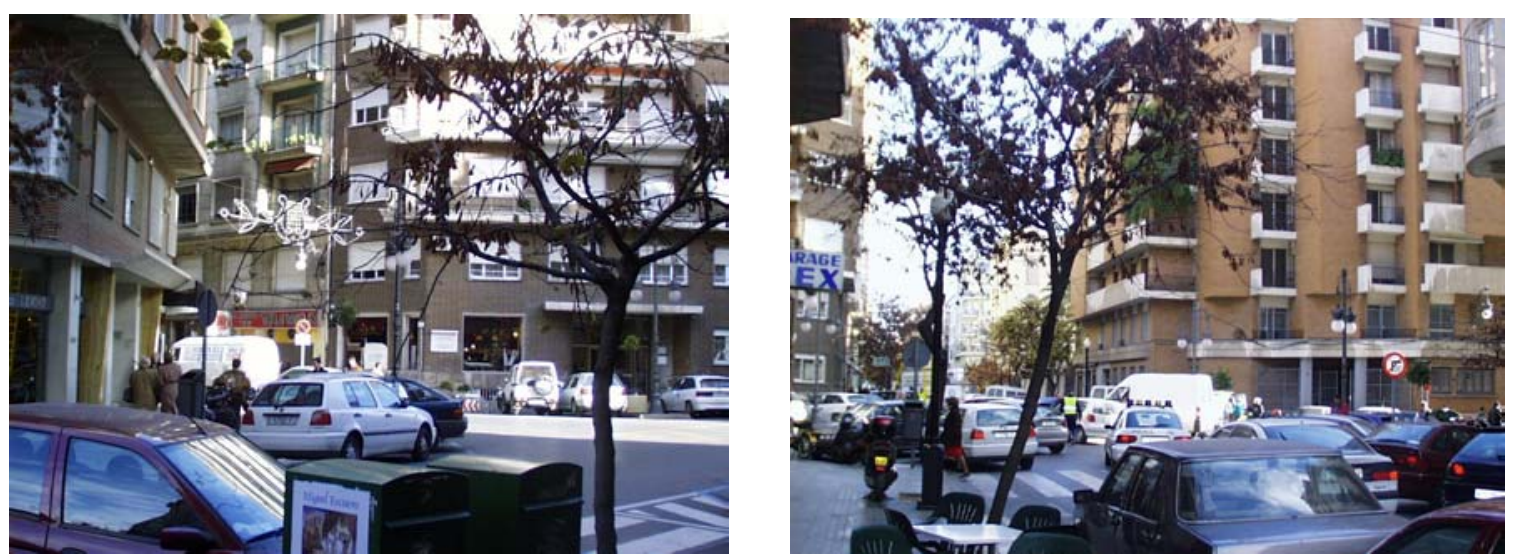

Figura 4.9: Fotos del cruce de cuatro chaflanes entre la calle Isabel la Católica y la calle Ciril Amorós en Valencia.

Estos dos cruces son entornos típicos urbanos. Como se ha observado en la figura 4.7, en las ciudades suele existir una estructura regular, así que estudiando estos dos cruces, se pueden extender las conclusiones a los demás cruces que sean similares. Los dos entornos son planos, rodeados de edificios de 5 o 6 plantas. Los bajos son normalmente de cristal o metálicos, y las paredes construidas con ladrillos. En el entorno también hay farolas, árboles y coches aparcados. En la figura 4.10 se muestran los dos planos correspondientes a los dos cruces donde se han marcado las medidas y las posiciones de los transmisores para cada uno de ellos. 


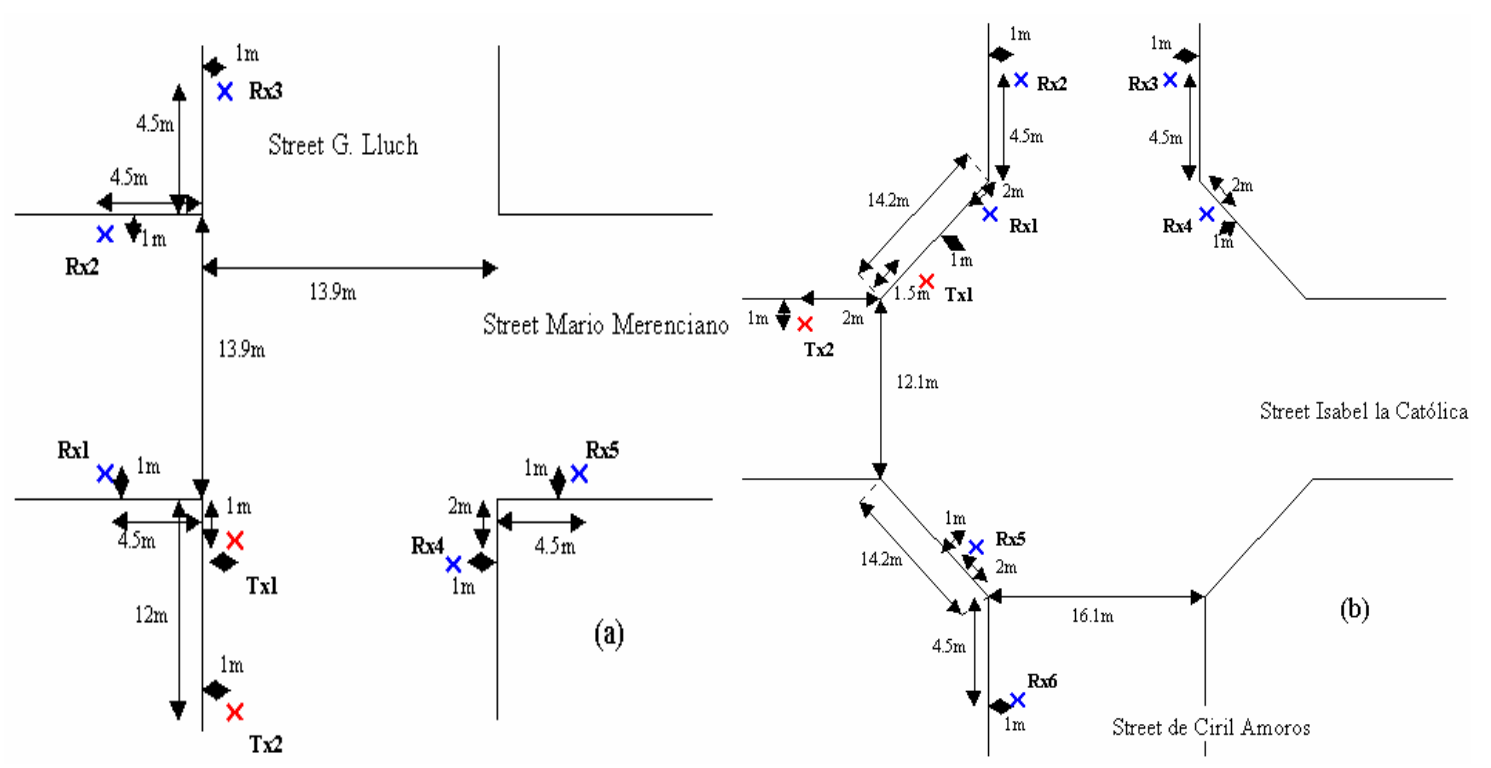

Figura 4.10: Planos de los dos cruces bajo estudio: (a) cruce de cuatro esquinas y (b) cruce de cuatro chaflanes.

\subsubsection{Equipo de medidas}

El equipo de medidas utilizado es el descrito en el apéndice C. El analizador de redes almacena la respuesta del parámetro $S_{21}$ y a partir de su transformada inversa de Fourier se calcula el perfil de retardo (apéndice B).

El equipo de medidas consta de un analizador de redes, un amplificador de banda ancha de $20 \mathrm{~dB}, 4$ pares de dipolos a 450, 900, 1800 y $2400 \mathrm{MHz}$ y varios cables y conectores. Las medidas se tomaron en un ancho de $200 \mathrm{MHz}$ centrado en cada una de las cuatro frecuencias centrales. Mediante la calibración interna del analizador se eliminó el efecto de los cables, conectores y amplificador. Se utilizaron 1601 puntos, que sobre $200 \mathrm{MHz}$ permiten medir un retardo máximo de $8 \mu \mathrm{s}$. Se promedió 32 veces en cada punto de medida y para cada frecuencia, y el nivel máximo de señal se encontraba $80 \mathrm{~dB}$ por encima del ruido.

Para la obtención del perfil de retardo se debe asumir un canal estacionario en sentido amplio con dispersores incorrelados (WSSUS, ver apéndice B). Esta afirmación puede hacerse ya que las medidas fueron tomadas por la noche cuando el tráfico era mínimo y no había movimiento de personas.

\subsubsection{Toma de las medidas}

El transmisor se colocó en un mástil de 3 metros de alto, y el receptor en otro de 1.6 metros. Las posiciones del transmisor se han marcado como Tx1 y Tx2 en cada uno de 
los emplazamientos, y los receptores como Rx1-5 y Rx1-6 para el cruce de cuatro esquinas y de cuatro chaflanes respectivamente (figura 4.10). Para cada posición se tomó una medida por cada una de las cuatro frecuencias. Eso hace 88 medidas si se tienen en cuenta todas las combinaciones. Además, para cada medida, se promedia 32 veces, obteniendo 2816 realizaciones del canal. Para cada una de las respuestas frecuenciales la información es enventanada utilizando una ventana Hanning, se completa con ceros hasta que el número de muestras sea una potencia de 2 , y se calcula su transformada inversa de Fourier para obtener el perfil de retardo.

\subsubsection{Análisis de los datos}

La información se ha clasificado en dos categorías: visión directa $(L o S)$ y no visión directa $(N L o S)$. Hay 5 posiciones para $L o S$ y 7 para $N L o S$ en los chaflanes, y 6 posiciones LoS y $4 N L o S$ en las cuatro esquinas (32 medidas para cada frecuencia y para cada posición). Se ha utilizado un umbral de $25 \mathrm{~dB}$ para eliminar el ruido. El perfil de retardo $P(\tau)$ se obtiene mediante la transformada inversa de Fourier de la respuesta en frecuencia del analizador de redes. Esta función se relaciona con la respuesta del canal $h(t, \tau)$ como (ver apéndice $\mathrm{B})$ :

$$
\left.P(\tau) \approx h(t, \tau)^{2}\right\rangle
$$

donde el promedio se hace sobre las 32 medidas para obtener un perfil de retardo invariante en el tiempo $P(\tau)$. A partir de esta función se han obtenido los siguientes parámetros:

\subsubsection{Dispersión temporal}

El RMS delay spread $(D S)$, definido como la raíz cuadrada del segundo momento central del perfil de retardo, es una medida de las prestaciones de un canal digital de comunicaciones ya que restringe la velocidad máxima sin necesidad de ecualización. Se calcula con la expresión (B.11).

\subsubsection{Correlación en frecuencia}

Este parámetro estudia la correlación entre la respuesta del canal en dos bandas distintas del espectro. Es interesante conocer esta correlación en función de la distancia que las separa. La correlación se puede evaluar mediante [Kiv01]: 


$$
\left.\left.R_{\Delta F}=\operatorname{corr}\left(\overline{P\left(\tau, f_{i}\right.}\right), \overline{P\left(\tau, f_{j}\right.}\right)\right)
$$

donde $\overline{P\left(\tau, f_{i}\right)}$ y $\overline{P\left(\tau, f_{j}\right)}$ son los perfiles de retardo normalizados a las frecuencias $f_{i}$ y $f_{j}$. La normalización se realiza de tal forma que la autocorrelación dé la unidad.

\subsubsection{Líneas de retardo}

La respuesta del canal radio $h(\tau)$ puede ser modelada mediante una línea de retardo [Wep05]:

$$
h(\tau)=\sum_{m=0}^{M} a_{m} \delta\left(\tau-\tau_{m}\right)
$$

donde $M$ representa en número de elementos de la línea, $a_{m}$ la amplitud y $\tau_{m}$ el tiempo de llegada. Todos estos parámetros han sido caracterizados para los dos entornos y las cuatro frecuencias. Asumiendo que un perfil de retardo $P(\tau)$ tiene $N$ muestras uniformemente distribuidas cada $\Delta \tau$, éstas se agrupan en $M$ grupos de $L$ elementos cada uno. Cada coeficiente es representado por una potencia media recibida $\left(P_{m}\right)$, durante esas $L$ muestras, y un retardo medio $\left(\tau_{m}\right)$ que se calculan como:

$$
\begin{gathered}
P_{m}=a_{m}^{2}=\frac{1}{L} \sum_{n=i_{m}}^{i_{m}+L-1} P(n \Delta \tau) \quad 1 \leq m \leq M \\
\tau_{m}=\frac{\sum_{n=i_{m}}^{i_{m}+L-1}(n \Delta \tau) P(n \Delta \tau)}{\sum_{n=i_{m}}^{i_{m}+L-1} P(n \Delta \tau)}
\end{gathered}
$$

Para el sistema UMTS [Rab00], se han propuesto modelos de canal por la ETSI y la ITU-R para diferentes entornos [ETSI98]. Estos modelos asumen 6 coeficientes para todos los entornos, así que en este trabajo se ha seguido el mismo criterio.

\subsubsection{Ancho de banda de coherencia}

El ancho de coherencia mide el rango de frecuencias en el que un canal puede considerarse plano (ver apéndice B). En este ancho de banda, la señal sufre una atenuación constante y un desfase lineal. El ancho de banda se ha calculado a partir de la transformada de Fourier del perfil de retardo $p(\tau)$, y calculando después cuando cae la respuesta hasta un cierto nivel. Este nivel se ha fijado en $-3 \mathrm{~dB}$, ya que es el más común en la literatura [Rap96]. El ancho de banda de coherencia se relaciona con la dispersión temporal inversamente. 


\subsubsection{Resultados}

\subsubsection{Dispersión Temporal}

La tabla 4.1 muestra los valores medios de la dispersión temporal para los dos entornos microcelulares (4 esquinas y 4 chaflanes):

\begin{tabular}{|ccccc|}
\hline & \multicolumn{2}{c}{ LoS } & \multicolumn{2}{c|}{ NLoS } \\
& 4 Esquinas & 4 Chaflanes & 4 Esquinas & 4 Chaflanes \\
$\mathbf{4 5 0} \mathbf{~ M H z}$ & 41.14 & 36.72 & 58.23 & 57.36 \\
$\mathbf{9 0 0} \mathbf{~ M H z}$ & 34.24 & 29.05 & 52.63 & 66.05 \\
$\mathbf{1 8 0 0} \mathbf{~ M H z}$ & 33.85 & 30.77 & 62.90 & 65.64 \\
$\mathbf{2 4 0 0} \mathbf{~ M H z}$ & 31.88 & 27.76 & 61.38 & 56.98 \\
\hline
\end{tabular}

Tabla 4.1: Dispersión temporal media en nanosegundos para $L o S$ y $N L o S$ en cuatro esquinas y cuatro chaflanes a $450 \mathrm{MHz}, 900 \mathrm{MHz}, 1800 \mathrm{MHz}$ y $2400 \mathrm{MHz}$.

Como se puede extraer de la tabla 4.1, para $L o S$ el $D S$ decrece en 10 ns cuando la frecuencia central se incrementa de $450 \mathrm{MHz}$ a $2400 \mathrm{MHz}$, tanto para cruces de cuatro esquinas como para cruces de cuatro chaflanes. También se observa que este parámetro es mayor en los cruces regulares que en los chaflanes considerando la misma frecuencia central. El máximo $D S$ corresponde a $450 \mathrm{MHz}$, y su valor es de 41.14 ns para cruces de cuatro esquinas y 36.72 para chaflanes.

Para $N L o S$, el $D S$ es mayor que para $L o S$ en más de 15 ns para $450 \mathrm{MHz}$ (un $50 \%$ de incremento), y 30 ns para $2400 \mathrm{MHz}$ (un incremento del 100\%). No se saca ninguna conclusión para $N L O S$ en función de la banda de frecuencias, donde el $D S$ está alrededor de 60 ns para ambos entornos y todas las frecuencias.

\subsubsection{Correlación en frecuencia.}

Utilizando (4.2) se ha calculado la correlación en frecuencia entre las distintas bandas. Se ha distinguido entre $L o S$ y $N L o S$. La tabla 4.2 resume los valores de la correlación en frecuencia para cada par de bandas de frecuencias.

\begin{tabular}{|c|c|c|c|c|c|c|c|c|c|c|c|c|}
\hline & \multicolumn{4}{|c|}{$450 \mathrm{MHz}$} & \multicolumn{4}{|c|}{$900 \mathrm{MHz}$} & \multicolumn{4}{|c|}{$1800 \mathrm{MHz}$} \\
\hline & \multicolumn{2}{|c|}{ LOS } & \multicolumn{2}{|c|}{ NLOS } & \multicolumn{2}{|c|}{ LOS } & \multicolumn{2}{|c|}{ NLOS } & \multicolumn{2}{|c|}{ LOS } & \multicolumn{2}{|c|}{ NLOS } \\
\hline & $\mathbf{R}$ & C & $\mathbf{R}$ & C & $\mathbf{R}$ & C & $\mathbf{R}$ & C & $\mathbf{R}$ & C & $\mathbf{R}$ & C \\
\hline $900 \mathrm{MHz}$ & 0.86 & 0.90 & 0.75 & 0.69 & & & & & & & & \\
\hline $1800 \mathrm{MHz}$ & 0.93 & 0.86 & 0.71 & 0.66 & 0.89 & 0.90 & 0.70 & 0.73 & & & & \\
\hline $2400 \mathrm{MHz}$ & 0.84 & 0.83 & 0.65 & 0.70 & 0.86 & 0.90 & 0.78 & 0.70 & 0.88 & 0.90 & 0.70 & 0.73 \\
\hline
\end{tabular}

Tabla 4.2: Correlación en frecuencia para cuatro esquinas $(\mathrm{R})$ y cuatro chaflanes $(\mathrm{C})$ entre las bandas a $450 \mathrm{MHz}, 900 \mathrm{MHz}, 1800 \mathrm{MHz}$ y $2400 \mathrm{MHz}$. 
En los cruces de cuatro esquinas, la correlación media (considerando todos los pares de frecuencias) es de 0.8 para $L o S$ y 0.7 para $N L o S$. Esto significa que la correlación es mayor para $L o S$, ya que el mecanismo fundamental de propagación es el rayo directo. En general, la correlación decrece cuando la distancia en frecuencia aumenta, ya que los distintos mecanismos de propagación son sensibles al cambio de frecuencia. En los chaflanes, la correlación es también más alta en $\operatorname{LoS}$ que en $N L o S$ (valores medios de 0.9 y 0.75 respectivamente). Comparando los cruces de cuatro esquinas y de cuatro chaflanes se puede decir que en media, la correlación en frecuencia es mayor para el caso de los chaflanes en alrededor del $10 \%$ para $L o S$ y del $5 \%$ para $N L o S$.

\subsubsection{Líneas de retardo}

Se han obtenido las líneas de retardo para los dos entornos a las cuatro frecuencias (450, 900, 1800 y $2400 \mathrm{MHz})$. La amplitud de los coeficientes se ha normalizado al mayor valor ( 1 en unidades lineales), y el retardo de la primera componente a 0 ns. Las líneas se han calculado para 6 coeficientes como se sugiere en [ETSI98]. Como las medidas son estáticas, no hay información sobre el Doppler.

La figura 4.11 muestra dibujadas las líneas de retardo para $L o S$ para cada uno de los dos entornos, y la figura 4.12 hace lo mismo pero para el caso de $N L o S$. En las tablas 4.3 y 4.4 se resumen los valores correspondientes a esas líneas. Para $L o S$, el retardo máximo está alrededor de los 200 ns en cruces de cuatro esquinas, y 190 ns para los chaflanes. Para NLoS, el retardo máximo está alrededor de 330 ns para cruces de cuatro esquinas y 350 ns para chaflanes. Además, se observa que para $L o S$, cuando la frecuencia se incrementa, la amplitud de cada coeficiente diminuye. Esto es debido a que la atenuación aumenta con la frecuencia. 

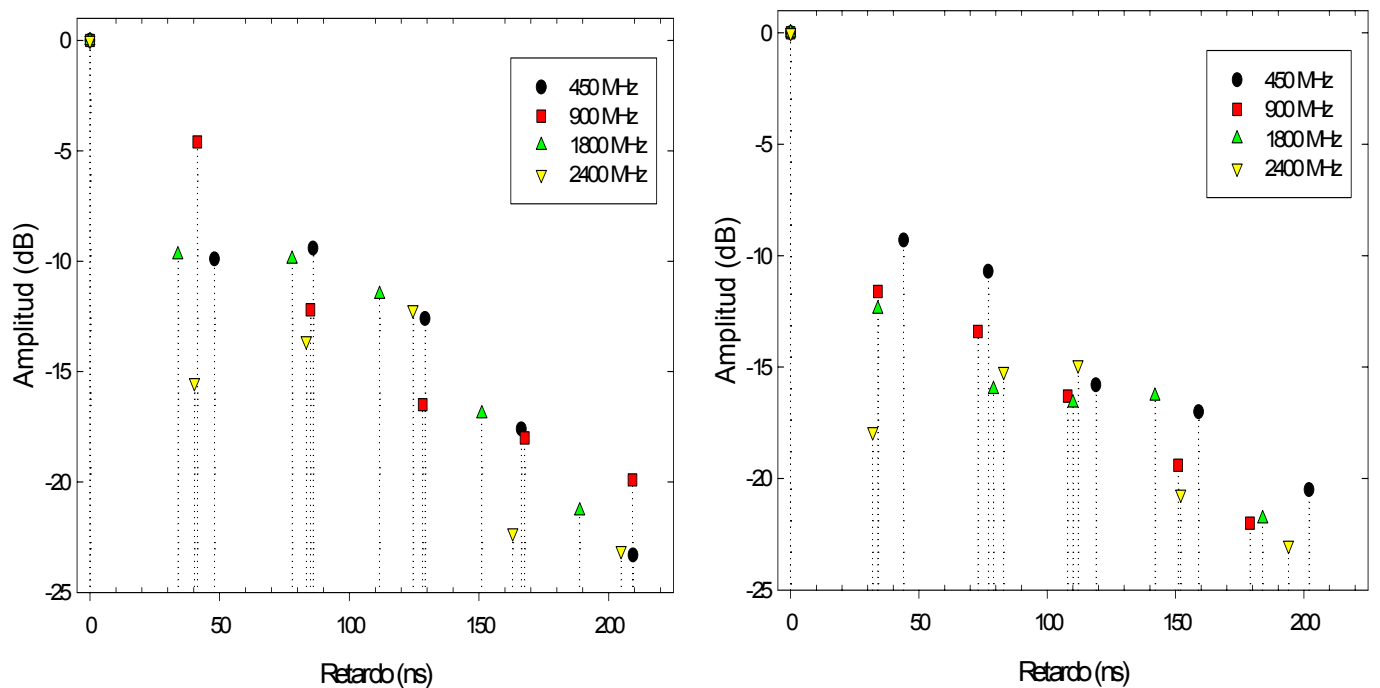

Figura 4.11 Líneas de retardo para cuatro esquinas (a) y cuatro chaflanes (b) en LoS a $450 \mathrm{MHz}$, $900 \mathrm{MHz}, 1800 \mathrm{MHz}$ y $2400 \mathrm{MHz}$.
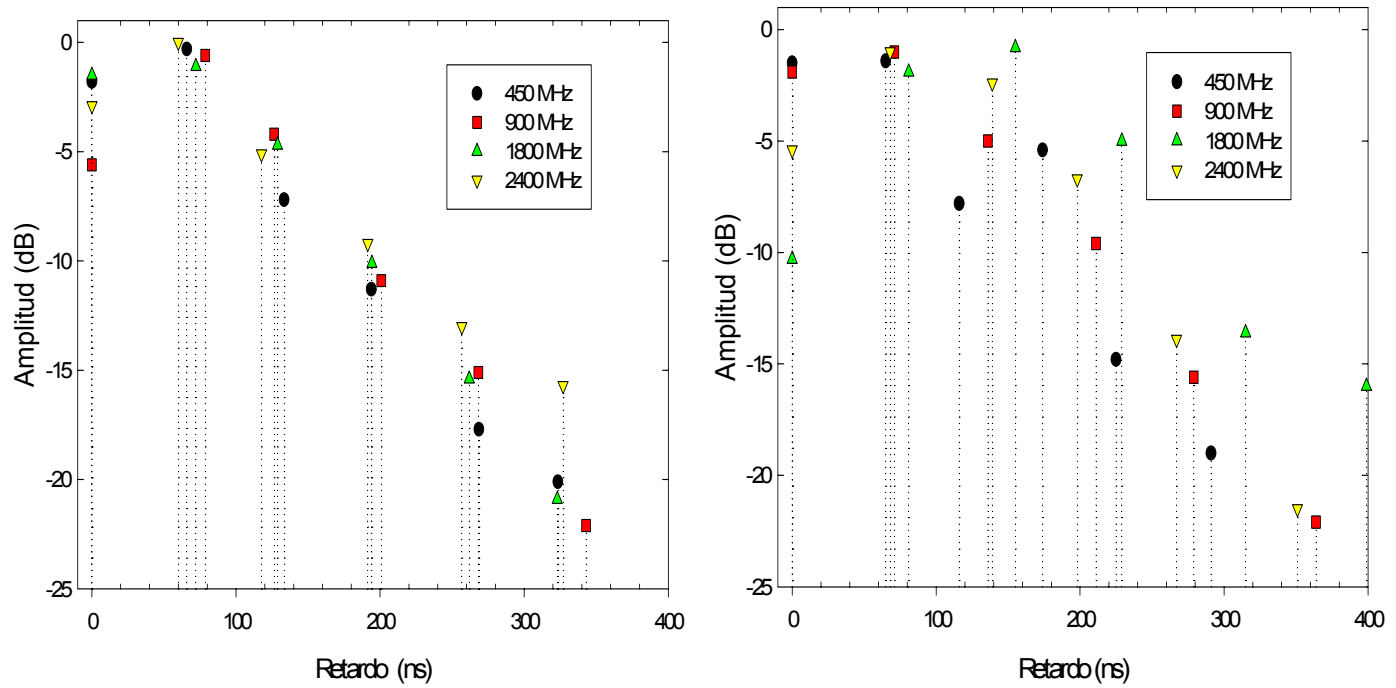

Figura 4.12: Líneas de retardo para cuatro esquinas (a) y cuatro chaflanes (b) en NLoS a $450 \mathrm{MHz}$, $900 \mathrm{MHz}, 1800 \mathrm{MHz}$ y $2400 \mathrm{MHz}$. 


\begin{tabular}{|ccccccccc|}
\hline & \multicolumn{2}{c}{450} & \multicolumn{2}{c}{900} & \multicolumn{2}{c}{ 1800 } & \multicolumn{2}{c|}{ 400 } \\
\hline & R & C & R & C & R & C & R & C \\
\hline Tap 1 Gain & 0 & 0 & 0 & 0 & 0 & 0 & 0 & 0 \\
Tap 2 Gain & -9.9 & -9.3 & -4.6 & -11.6 & -9.7 & -12.4 & -15.5 & -17.9 \\
Tap 3 Gain & -9.4 & -10.7 & -12.2 & -13.4 & -9.9 & -16.0 & -13.6 & -15.2 \\
Tap 4 Gain & -12.6 & -15.8 & -16.5 & -16.3 & -11.5 & -16.6 & -12.2 & -14.9 \\
Tap 5 Gain & -17.6 & -17.0 & -18.0 & -19.4 & -16.9 & -16.3 & -22.3 & -20.7 \\
Tap 6 Gain & -23.3 & -20.5 & -19.9 & -22.0 & -21.3 & -21.8 & -23.1 & -23.0 \\
\hline Time Delay 1 & 0 & 0 & 0 & 0 & 0 & 0 & 0 & 0 \\
Time Delay 2 & 48.0 & 44 & 41.4 & 34 & 33.9 & 34 & 40.3 & 32 \\
Time Delay 3 & 86.0 & 77 & 85.0 & 73 & 77.9 & 79 & 83.4 & 83 \\
Time Delay 4 & 129.2 & 119 & 128.3 & 108 & 111.7 & 110 & 124.5 & 112 \\
Time Delay 5 & 166.3 & 159 & 167.6 & 151 & 151.1 & 142 & 163.0 & 152 \\
Time Delay 6 & 209.4 & 202 & 209.2 & 179 & 188.8 & 184 & 204.8 & 194 \\
\hline
\end{tabular}

Tabla 4.3: Líneas de retardo para 4 esquinas (R) y 4 chaflanes (C) en LoS a $450 \mathrm{MHz}, 900 \mathrm{MHz}$, $1800 \mathrm{MHz}$ y $2400 \mathrm{MHz}$.

\begin{tabular}{|ccccccccc|}
\hline & \multicolumn{2}{c}{450} & \multicolumn{2}{c}{900} & \multicolumn{2}{c}{ 1800 } & \multicolumn{2}{c|}{ 2400 } \\
\hline & $\mathbf{C}$ & $\mathbf{R}$ & $\mathbf{C}$ & $\mathbf{R}$ & $\mathbf{C}$ & $\mathbf{R}$ & $\mathbf{C}$ & $\mathbf{R}$ \\
Tap 1 Gain & -1.5 & -0.1 & -5.0 & -0.9 & -0.5 & -9.5 & -2.9 & -4.4 \\
Tap 2 Gain & 0 & 0 & 0 & 0 & 0 & -1.0 & 0 & 0 \\
Tap 3 Gain & -6.9 & -6.4 & -3.7 & -4.0 & -3.7 & 0 & -5.1 & -1.4 \\
Tap 4 Gain & -11.0 & -4.0 & -10.3 & -8.5 & -9.0 & -4.2 & -9.2 & -5.7 \\
Tap 5 Gain & -17.3 & -13.4 & -14.5 & -14.6 & -14.4 & -12.8 & -13.0 & -12.9 \\
Tap 6 Gain & -19.7 & -17.6 & -21.5 & -21.0 & -19.8 & -15.2 & -15.7 & -20.4 \\
\hline Time Delay 1 & 0 & 0 & 0 & 0 & 0 & 0 & 0 & 0 \\
Time Delay 2 & 65.9 & 65 & 78.6 & 71 & 72.1 & 81 & 59.9 & 68 \\
Time Delay 3 & 133.4 & 116 & 126.5 & 136 & 128.8 & 155 & 117.7 & 139 \\
Time Delay 4 & 193.9 & 174 & 200.8 & 211 & 194.3 & 229 & 191.4 & 198 \\
Time Delay 5 & 268.6 & 225 & 268.2 & 279 & 261.9 & 315 & 256.7 & 267 \\
Time Delay 6 & 323.4 & 291 & 343.0 & 364 & 323.0 & 399 & 327.0 & 351 \\
\hline
\end{tabular}

Tabla 4.4: Líneas de retardo para 4 esquinas (R) y 4 chaflanes (C) en NLoS a $450 \mathrm{MHz}, 900 \mathrm{MHz}$, $1800 \mathrm{MHz}$ y $2400 \mathrm{MHz}$. 


\subsubsection{Ancho de banda de Coherencia}

Finalmente, se estudia el ancho de banda de coherencia. Éste se ha calculado a partir de los perfiles de retardo mediante su transformada de Fourier (incluyendo el umbral). Los resultados se han ordenado separando los casos $L o S$ y $N L o S$ para cada entorno. La tabla 4.5 resume los valores medios en $\mathrm{MHz}$.

\begin{tabular}{|ccccc|}
\hline & \multicolumn{2}{c}{ LOS } & \multicolumn{2}{c|}{ NLOS } \\
& $\begin{array}{c}\text { Cuatro } \\
\text { esquinas }\end{array}$ & $\begin{array}{c}\text { Cuatro } \\
\text { chaflane }\end{array}$ & $\begin{array}{c}\text { Cuatro } \\
\text { esquinas }\end{array}$ & $\begin{array}{c}\text { Cuatro } \\
\text { chaflanes }\end{array}$ \\
$\mathbf{4 5 0} \mathbf{~ M H z}$ & 9.37 & 10.17 & 4.40 & 5.46 \\
$\mathbf{9 0 0} \mathbf{~ M H z}$ & 10.96 & 15.02 & 4.45 & 4.89 \\
$\mathbf{1 8 0 0} \mathbf{~ M H z}$ & 11.32 & 17.05 & 3.38 & 3.40 \\
$\mathbf{2 4 0 0} \mathbf{~ M H z}$ & 12.58 & 18.72 & 3.69 & 4.46 \\
\hline
\end{tabular}

Tabla 4.5: Anchos de banda de coherencia en MHz para cuatro esquinas y cuatro chaflanes en LoS y NLoS a 450 MHz, 900 MHz, 1800 MHz y 2400 MHz.

Para $L o S$, el ancho de banda de coherencia es mayor en el cruce de cuatro chaflanes que en el cruce de cuatro esquinas (el $D S$ era menor). En las cuatro esquinas, el ancho de banda de coherencia es de $9.37 \mathrm{MHz}$ a $405 \mathrm{MHz}$ y aumenta a $12.58 \mathrm{MHz}$ para 2.4 GHz. Por otro lado, vale $10.17 \mathrm{MHz}$ en los chaflanes a $450 \mathrm{MHz}$, y $18.72 \mathrm{MHz}$ para $2400 \mathrm{MHz}$. Esto significa que el ancho de banda de coherencia es mayor en los chaflanes ya que, como se vio anteriormente, el $D S$ es menor. También se observa que cuando la frecuencia aumenta, el ancho de banda aumenta, y este incremento es mayor para chaflanes.

En $N L o S$, el ancho de banda de coherencia para las cuatro esquinas es de $4.4 \mathrm{MHz}$ a $450 \mathrm{MHz}$ y $3.69 \mathrm{MHz}$ a $2.4 \mathrm{GHz}$. Para chaflanes, éste es menos de $1 \mathrm{MHz}$ más ancho. El comportamiento en $N L o S$ es diferente a $L o S$. Aquí, el ancho de banda permanece alrededor de $4 \mathrm{MHz}$, y decrece ligeramente con el aumento de la frecuencia.

\subsubsection{Discusión}

Utilizando un analizador de redes se han tomado medidas para modelar y comparar dos entornos microcelulares: un cruce con cuatro esquinas y un cruce con cuatro chaflanes. Se seleccionaron cuatro frecuencias distintas: $450 \mathrm{MHz}, 900 \mathrm{MHz}, 1800 \mathrm{MHz}$ y 
$2400 \mathrm{MHz}$. También se han distinguido dos situaciones de propagación diferentes para cada entorno y frecuencia: $L o S$ y $N L o S$. La información se ha procesado enventanando la respuesta en frecuencia, se ha completado con ceros hasta que el número de muestras fuese una potencia de 2 y se ha transformado en el dominio del tiempo.

Se ha visto que la dispersión del retardo crecía $10 \mathrm{~ns}$ cuando la frecuencia se incrementa de $450 \mathrm{MHz}$ a $2400 \mathrm{MHz}$ para ambos entornos, y era 5 ns más grande en las cuatro esquinas. En $N L o S$, la dispersión temporal estaba entorno a 60 ns en ambos entornos, y era mayor que en $L o S$ en $15 \mathrm{~ns}$ para $450 \mathrm{MHz}$ y $30 \mathrm{~ns}$ para $2400 \mathrm{MHz}$.

La correlación en frecuencia era mayor en los chaflanes. Para las cuatro esquinas, la correlación era de 0.8 para $L o S$ y 0.7 para $N L o S$. En los chaflanes 0.9 para $L o S$ y 0.95 para $N L o S$. En general, la correlación decrecía cuando la distancia en frecuencia aumentaba.

También se han calculado líneas de retardo para las cuatro frecuencias, en los dos entornos y para $L o S$ y $N L o S$. El retardo máximo para $L o S$ estaba entorno a 200 ns para las cuatro esquinas y 190 para los chaflanes. Para $N L o S$, el retardo máximo era de 330 ns para las cuatro esquinas y 350 para los chaflanes.

Finalmente, se ha calculado el ancho de banda de coherencia. Para $L o S$, el ancho de coherencia era mayor en los chaflanes, y crecía cuando la frecuencia era incrementada. Este incremento era mayor para los chaflanes. Para $N L o S$ el ancho de banda estaba entorno a los $4 \mathrm{MHz}$, e incluso disminuía ligeramente con la frecuencia.

\subsection{Simulaciones MIMO en cruces de cuatro esquinas y cuatro chaflanes}

En este apartado se estudia la capacidad $M I M O$ en dos entornos urbanos microcelulares: cruces de cuatro esquinas y cruces de cuatro chaflanes. Se analizan las diferencias entre ambos entornos, y las orientaciones óptimas de las antenas para maximizar la capacidad [Mol03e]. Por otro lado se estudian los fenómenos que ocurren en un sistema de múltiples antenas cuando se pasa de $L o S$ a $N L o S$.

\subsubsection{Entorno de propagación}

En la figura 4.13 se tienen de nuevo dos entornos microcelulares ideales: un cruce de cuatro esquinas y un cruce con cuatro chaflanes. El ancho de las calles de ambos cruces es de 13.9 metros para facilitar la comparación, y la longitud de los chaflanes es de 10 
metros ( $135^{\circ}$ los ángulos interiores). La altura del transmisor es de 4 metros, y de 1.8 metros la del receptor. Tanto el transmisor como el receptor están formados por 8 elementos alineados uniformemente. Todas las antenas son isótropas y están verticalmente polarizadas.

Para el estudio de la orientación de los arrays, el transmisor se ha situado a 100 metros a la izquierda del cruce, y el receptor recorre 400 metros hacia arriba empezando desde abajo. Se han tenido en cuenta dos configuraciones para los arrays: paralelo y perpendicular al desplazamiento del receptor (figura 4.13). Se utilizará la nomenclatura siguiente para nombrar las distintas orientaciones: $\mathrm{TX}^{\mathrm{V}}, \mathrm{TX}^{\mathrm{H}}, \mathrm{RX}^{\mathrm{V}}$ y $\mathrm{RX}^{\mathrm{V}}$ para el transmisor vertical y horizontal, y el receptor vertical y horizontal. Es decir, dirección paralela (vertical) o perpendicular (horizontal) al desplazamiento del receptor, que se va a centrar en el centro del cruce.

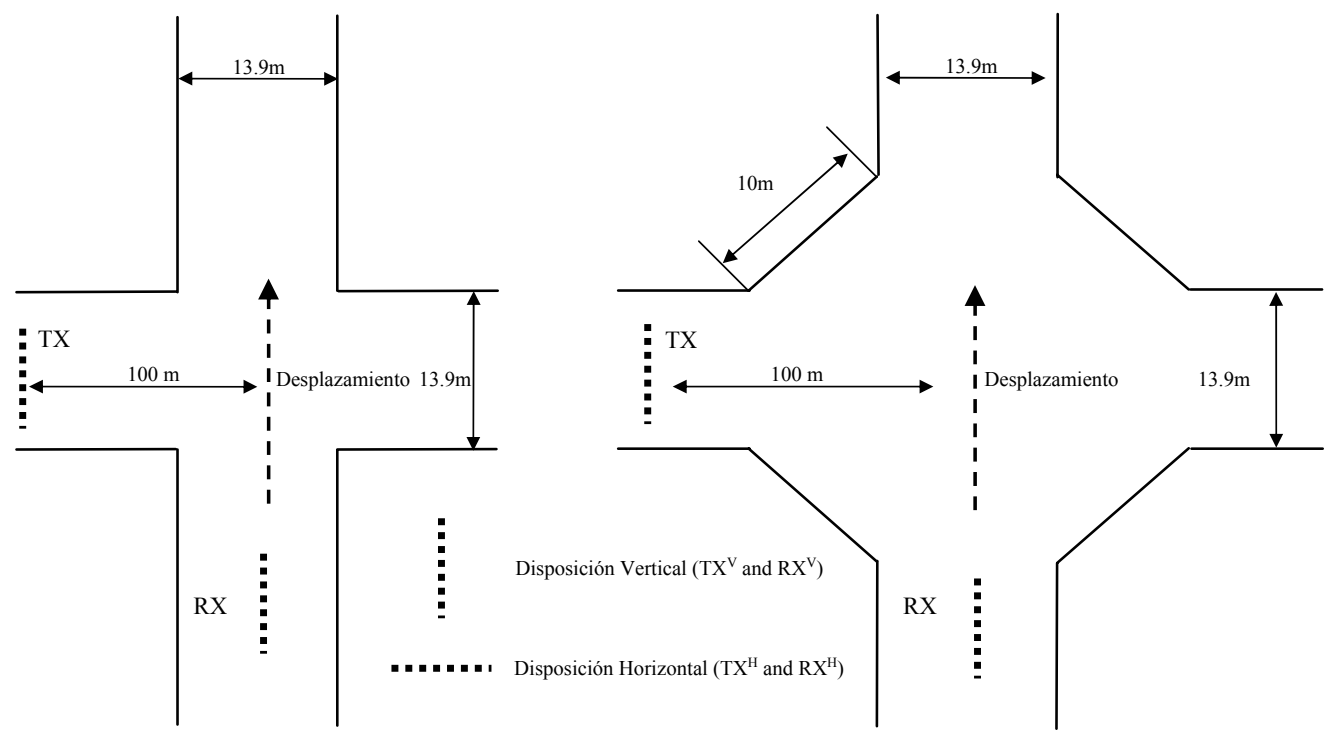

Figura 4.13: Geometría de (a) un cruce de cuatro esquinas y (b) un cruce de cuatro chaflanes para el estudio de la orientación de los arrays.

\subsubsection{Modelo de propagación}

Tal y como se hizo en el capítulo 3, para analizar el canal MIMO se ha utilizado el modelo que se ha desarrollado en la sección 2.2. Se ha tomado un número de antenas transmisoras y receptoras igual a 8. Para obtener la matriz de transferencia $\left(\mathbf{G}_{8 \times 8}\right)$, se han realizado $8 \times 8$ simulaciones en cada posición del receptor (400 posiciones), para cada combinación de arrays. En cada punto, el coeficiente $\mathbf{G}(n, m)$ se obtiene como la suma 
coherente de todos los rayos recibidos en el receptor $m$ cuando la antena $n$ está transmitiendo (banda estrecha).

Se han tenido en cuenta las siguientes contribuciones:

- Rayo directo

- Rayos múltiplemente reflejados

- Rayos difractados

- Rayos difractados/reflejados

A cada una de las contribuciones se le ha añadido la reflexión en el suelo, y las matrices se han normalizado según la norma de Frobenius (apéndice D).

\subsubsection{Capacidad según la orientación de los arrays}

Se ha simulado a $2.1 \mathrm{GHz}$ el escenario de la figura 4.13. Los parámetros eléctricos de las paredes se han fijado en $\sigma=0.01 \mathrm{~S} / \mathrm{m}$ y $\varepsilon_{\mathrm{r}}=5$. Como se ha comentado antes, el transmisor se sitúa a 100 metros a la izquierda de ambos cruces, y el receptor recorre 400 metros de abajo a arriba. La señal a ruido se ha fijado en $20 \mathrm{~dB}$. Se distinguen dos situaciones distintas: $L o S$ y $N L o S$. La primera ocurre cuando el receptor se encuentra en el cruce y hay visión directa, y la segunda cuando el receptor está lejos de esta posición.

La figura 4.14 muestra la capacidad MIMO media cuando transmite $\mathrm{TX}^{\mathrm{V}}$ y recibe $\mathrm{RX}^{\mathrm{V}}$ (ambos orientados verticalmente)

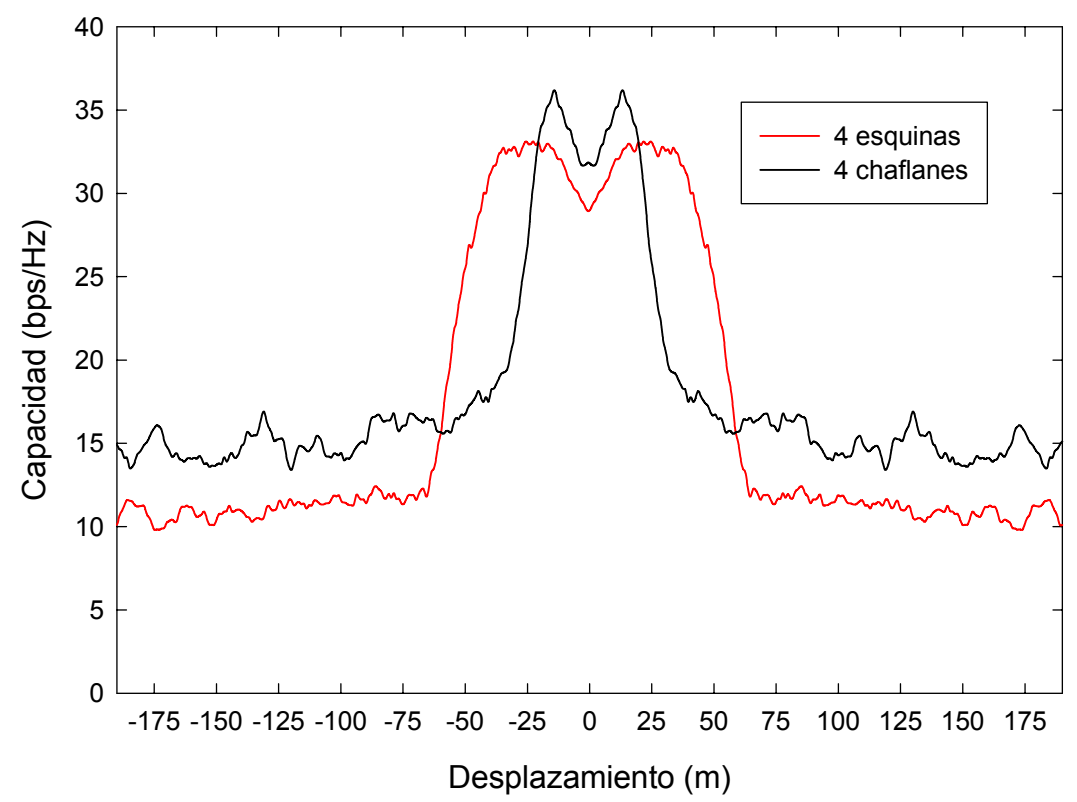

Figura 4.14: Capacidad en un entorno microcelular de cuatro esquinas y cuatro chaflanes para $\mathrm{TX}^{\mathrm{V}}$ $\mathrm{y} \mathrm{RX}^{\mathrm{V}}$. 
Se observa que la capacidad se comporta de forma muy distinta en ambos entornos. En las cuatro esquinas decrece más lentamente que en los chaflanes, aunque en éstos se alcanzan valores más altos en la zona $N L o S$ (alrededor de $14 \mathrm{bps} / \mathrm{Hz}$ para los chaflanes y $11.5 \mathrm{bps} / \mathrm{Hz}$ en el cruce de las cuatro esquinas). La reducción tan drástica de capacidad en la zona $N L o S$ se debe fundamentalmente a dos causas; primeramente la orientación $\mathrm{RX}^{\mathrm{V}}$ no es óptima porque la mayor parte de la energía proviene de la dirección endfire del array, y en segundo lugar porque las dos esquinas hacen de keyhole [Lin01] y disminuyen la capacidad. Para mejorar la capacidad en la zona $N L o S$, el receptor se ha cambiado a $\mathrm{RX}^{\mathrm{H}}$. La figura 4.15 muestra los resultados para $\mathrm{TX}^{\mathrm{V}} \mathrm{y} \mathrm{RX}^{\mathrm{H}}$.

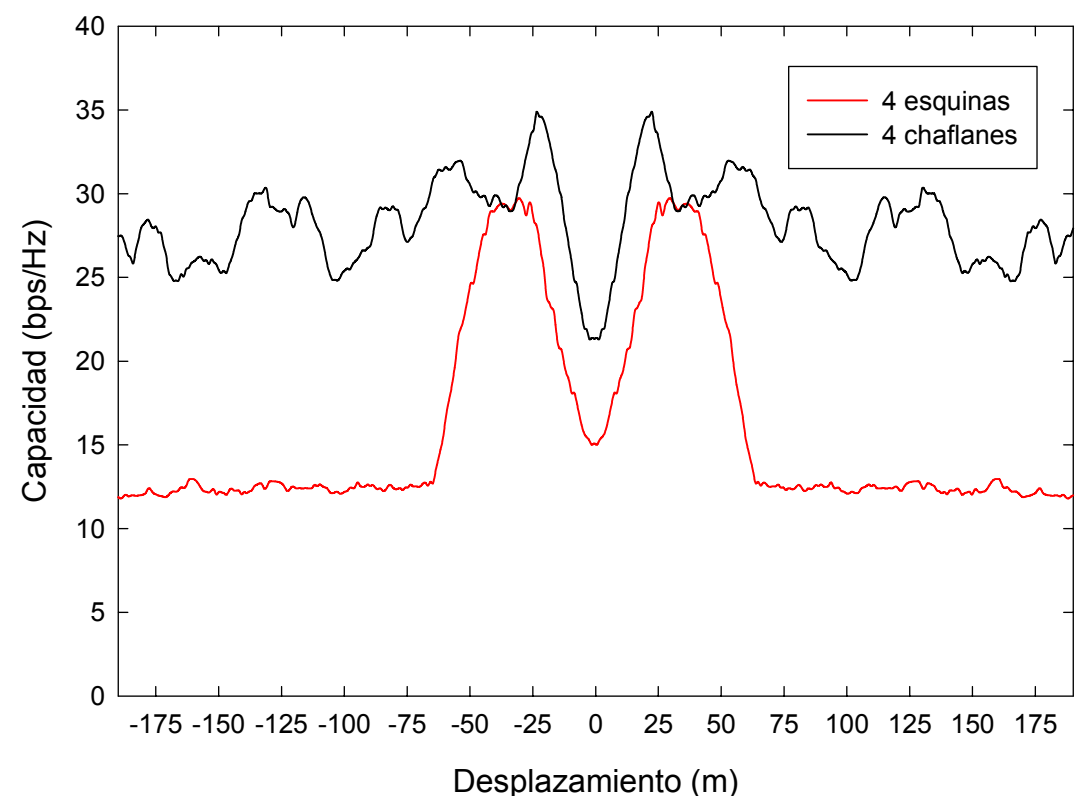

Figura 4.15: Capacidad en un entorno microcelular de cuatro esquinas y cuatro chaflanes para

$$
\mathrm{TX}^{\mathrm{V}} \mathrm{y} \mathrm{RX}^{\mathrm{H}} \text {. }
$$

Se observa en la figura 4.15 que la capacidad máxima se ha reducido en ambos entornos (de 36 a $29 \mathrm{bps} / \mathrm{Hz}$ para el cruce de cuatro esquinas y de 35 a $33 \mathrm{bps} / \mathrm{Hz}$ para chaflanes). En el centro del cruce (desplazamiento cero), se produce una reducción de la capacidad (de 32 a 15 bps/Hz para el cruce de cuatro esquinas y de 28 a 21 bps para chaflanes). Esto se debe a que la orientación del RX recibe toda la energía con la dirección endfire, como ocurría en el caso anterior para $N L o S$. En $N L o S$, la capacidad ha aumentado de 14 a 27 bps/Hz. Para estudiar la influencia de la orientación de la antena transmisora, se han realizado dos simulaciones más, $\mathrm{TX}^{\mathrm{H}} \mathrm{y} \mathrm{RX}^{\mathrm{V}}$ se representan en la figura $4.16, \mathrm{y} \mathrm{TX}^{\mathrm{H}} \mathrm{y}$ $\mathrm{RX}^{\mathrm{H}}$ se representan en la figura 4.17. 


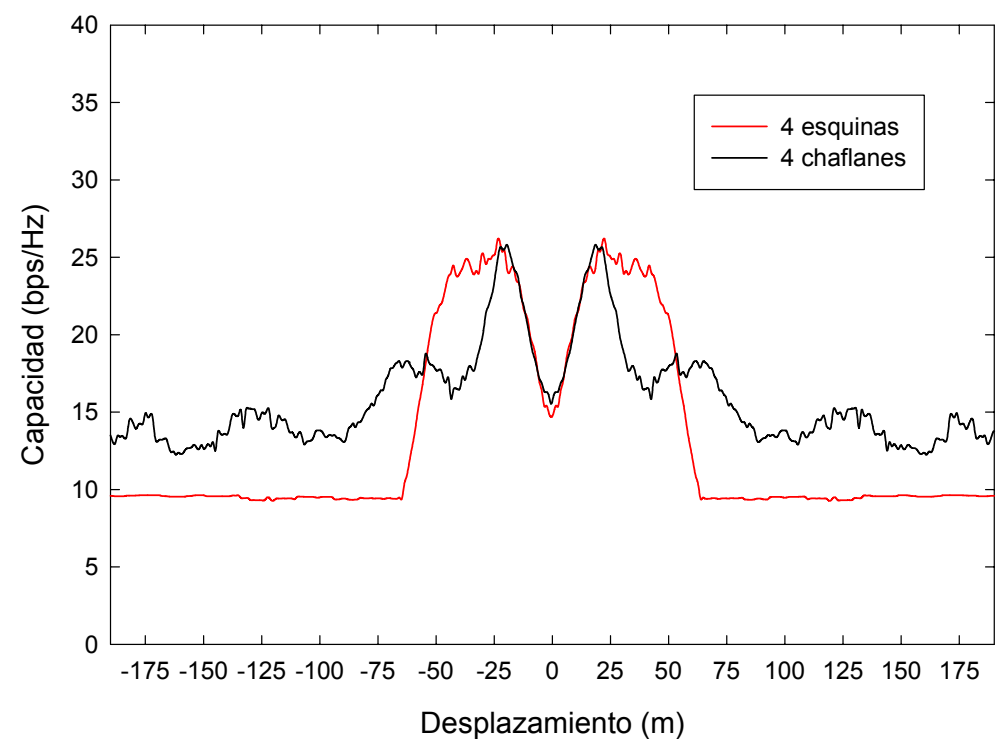

Figura 4.16: Capacidad en un entorno microcelular de cuatro esquinas y cuatro chaflanes para $\mathrm{TX}^{\mathrm{H}}$ y RX $\mathrm{V}^{\mathrm{V}}$.

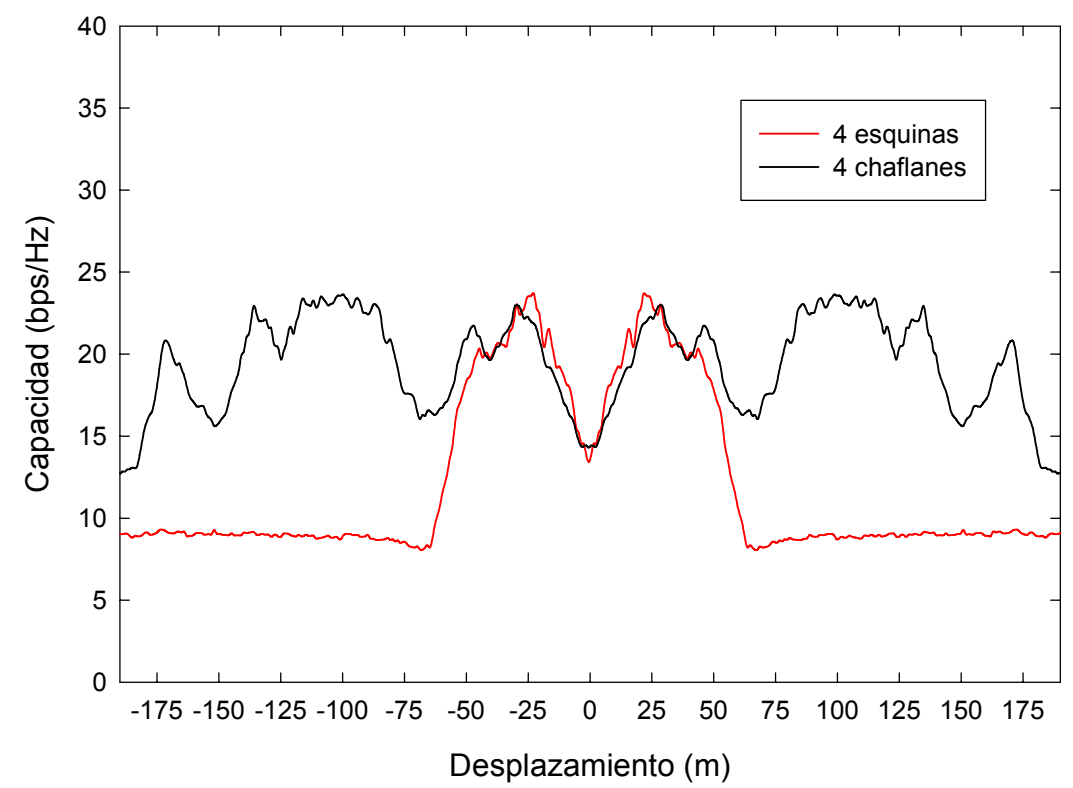

Figura 4.17: Capacidad en un entorno microcelular de cuatro esquinas y cuatro chaflanes para $\mathrm{TX}^{\mathrm{H}}$ y RX ${ }^{\mathrm{H}}$.

En las dos figuras anteriores se observa que la capacidad disminuye en la zona $L o S$ en ambos entornos cuando el transmisor se gira a la posición horizontal. Además, en $N L o S$ existe una reducción de unos $2 \mathrm{~dB}$ en el cruce de las cuatro esquinas y $1 \mathrm{~dB}$ para el de los chaflanes cuando se utiliza $\mathrm{RX}^{\mathrm{V}}$, y $3 \mathrm{~dB}$ en el cruce de las cuatro esquinas y $7 \mathrm{~dB}$ para el de los chaflanes cuando se utiliza $\mathrm{RX}^{\mathrm{H}}$. Se puede decir entonces que la posición $\mathrm{TX}^{\mathrm{H}}$ no es adecuada para maximizar la capacidad en ninguno de los dos entornos anteriores. La tabla 4.6 resume los valores de la capacidad para $L o S$ y $N L o S$ en ambos entornos. 


\begin{tabular}{|l|c|c|c|c|c|c|}
\cline { 2 - 7 } \multicolumn{1}{c|}{} & \multicolumn{2}{|c|}{ NLoS } & \multicolumn{4}{c|}{ LoS } \\
\cline { 2 - 7 } \multicolumn{1}{c|}{} & $\begin{array}{c}\text { Regular } \\
\text { Corner. }\end{array}$ & \multirow{2}{*}{\begin{tabular}{c} 
Chaflane \\
\cline { 4 - 7 } \multicolumn{1}{c|}{}
\end{tabular}} & Corner. & \multicolumn{2}{c|}{ Regular corner } & \multicolumn{2}{c|}{ Chaflane } \\
\cline { 5 - 8 } & 11.5 & 14 & 36 & 32 & 33 & 28 \\
\hline $\mathrm{TX}^{\mathrm{V}}$ and $\mathrm{TR}^{\mathrm{V}}$ & 12 & 27 & 29 & 15 & 35 & 21 \\
\hline $\mathrm{TX}^{\mathrm{V}}$ and $\mathrm{TR}^{\mathrm{H}}$ & 9.5 & 13 & 26 & 15 & 25.5 & 14.5 \\
\hline $\mathrm{TX}^{\mathrm{H}}$ and $\mathrm{TR}^{\mathrm{V}}$ and $\mathrm{TR}^{\mathrm{H}}$ & 9 & 20 & 24 & 14.5 & 23.5 & 14 \\
\hline
\end{tabular}

Tabla 4.6: Capacidades máximas, mínimas y medias en bps/Hz para $N L o S$ y $L o S$ en cruces de cuatro chaflanes y cuatro esquinas.

Se han estudiado las funciones de densidad acumuladas complementarias (Complementary Cumulative Density Functions CCDF) cuando ambos arrays tienen cuatro elementos. Se han obtenido a partir de las simulaciones $8 \times 8$, tomando 5 matrices $4 \times 4$ desplazando un elemento en cada una de ellas (para respetar el espaciado entre antenas). También se ha distinguido entre $L o S$ y $N L o S$, y sólo se ha tenido en cuenta la posición óptima del transmisor como se ha planteado anteriormente $\left(\mathrm{TX}^{\mathrm{V}}\right)$, ya que la horizontal disminuye la capacidad. La figura 4.18 muestra la $C C D F$ 's para $L o S$ tomando $20 \mathrm{~dB}$ de $S N R$.

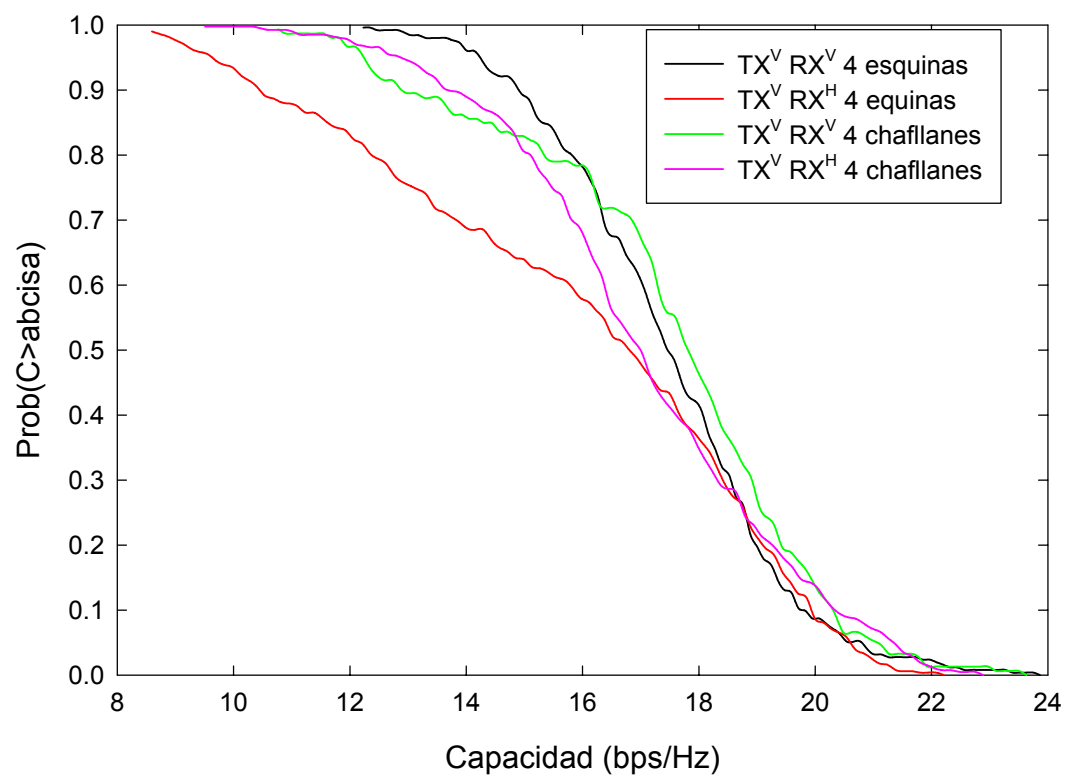

Figura 4.18: Función de densidad cumulativa complementaria de la capacidad para un canal $M I M O 4 \times 4$ en un cruce de cuatro esquinas y cuatro chaflanes para $L o S$. 
Para comparar los resultados de la figura 4.18 se ha utilizado la outage capacity definida en el apéndice D. En concreto se ha utilizado la $\mathrm{C}_{0.1}$ que indica la capacidad durante el 90\% del tiempo (ver D.4). La capacidad máxima corresponde al cruce de las cuatro esquinas y configuración $\mathrm{TX}^{\mathrm{V}}$ y $\mathrm{RX}^{\mathrm{V}}(14.9 \mathrm{bps} / \mathrm{Hz})$, que es cuando ambos arrays están enfrentados. Cuando el receptor ha girado a $\mathrm{RX}^{\mathrm{H}}$ la capacidad ha disminuido a 10.5 bps/Hz. En el caso de los chaflanes, la capacidad en $\operatorname{LoS}$ no varía significativamente debido a que múltiples reflexiones llegan de los cuatro chaflanes. La capacidad para este entorno se encuentra un poco por debajo de los $14 \mathrm{bps} / \mathrm{Hz}$.

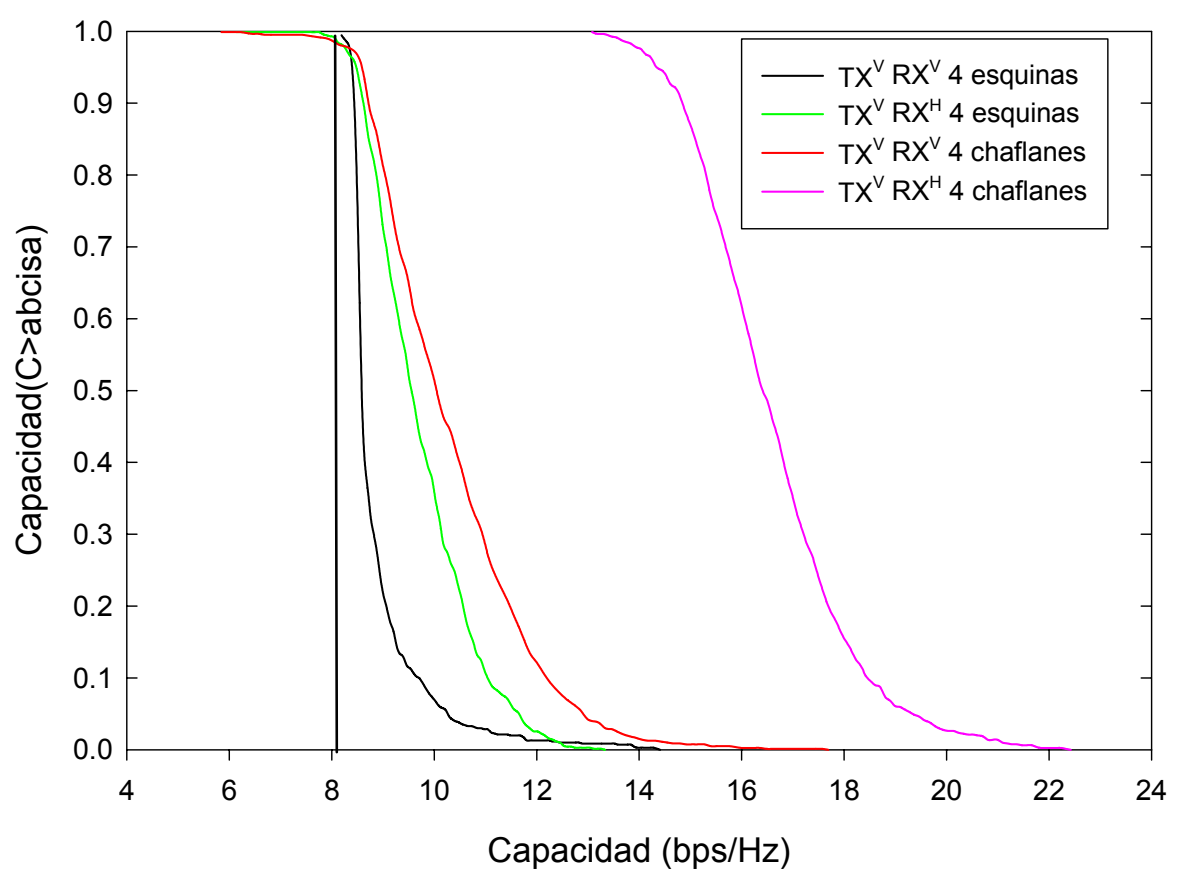

Figura 4.19: Función de densidad cumulativa complementaria de la capacidad para un canal $M I M O 4 \mathrm{x} 4$ en un cruce de cuatro esquinas y cuatro chaflanes para $N L o S$.

La figura 4.19 muestra la $C C D F$ de la capacidad para un sistema $4 \times 4$ en situación $N L o S$ tanto para un cruce de cuatro esquinas como para uno con cuatro chaflanes. La capacidad máxima se consigue en los chaflanes para $\mathrm{TX}^{\mathrm{V}}$ y $\mathrm{RX}^{\mathrm{H}}\left(\mathrm{C}_{0.1}=14.8 \mathrm{~dB}\right)$. Las otras combinaciones ofrecen una capacidad cercana a la de un keyhole [Chi02], la cual para un sistema MIMO 4x4 y con una $S N R$ de $20 \mathrm{~dB}$ es de $8.6 \mathrm{bps} / \mathrm{Hz}$.

\subsubsection{Capacidad en LoS y NLOS}

En este punto se ha estudiado qué ocurre con la capacidad al girar un cruce de cuatro esquinas y otro de cuatro chaflanes. Se ha utilizado el cruce de la figura 4.13, de tal forma que el receptor se desplaza de abajo a arriba, girando a la derecha en el centro del 
cruce. En la figura 4.20 se ha dibujado el mismo cruce de la figura 4.13 indicando el recorrido del receptor para ambos entornos. La anchura de las calles es de 13.9 metros y los chaflanes miden 10 metros. Se ha tomado como referencia el centro de ambos cruces como el centro de coordenadas $(0,0)$.

Las simulaciones se han hecho a $2.1 \mathrm{GHz}$, y de nuevo se han fijado los parámetros eléctricos a $\sigma=0.01 \mathrm{~S} / \mathrm{m}$ (conductividad) y $\varepsilon_{\mathrm{r}}=5$ (permitividad). La señal a ruido en las antenas receptoras es de $20 \mathrm{~dB}$.

El transmisor se ha situado en 6 posiciones distintas:

\begin{tabular}{|c|c|}
\hline Posición $\mathbf{x}$ & Posición y \\
\hline$-100 \mathrm{~m}$ & $0 \mathrm{~m}$ \\
\hline$-20 \mathrm{~m}$ & $5 \mathrm{~m}$ \\
\hline$-30 \mathrm{~m}$ & $4 \mathrm{~m}$ \\
\hline$-25 \mathrm{~m}$ & $0 \mathrm{~m}$ \\
\hline$-30 \mathrm{~m}$ & $-4 \mathrm{~m}$ \\
\hline$-50 \mathrm{~m}$ & $0 \mathrm{~m}$ \\
\hline
\end{tabular}

Tabla 4.7: Posiciones de los transmisores en la figura 4.20.

El receptor recorre dos líneas, desde $(-200 \mathrm{~m}, 0)$ hasta $(0,0)$, y desde $(0,0)$ hasta $(0$, 200m). Para cada posición del transmisor, y para los dos entornos, se han simulado 400 posiciones espaciadas un metro, 200 en vertical y 200 en horizontal. Las orientaciones se han elegido del tal forma que la capacidad sea máxima, esto es, $\mathrm{TX}^{\mathrm{V}}, \mathrm{RX}^{\mathrm{H}}$ en el recorrido vertical $\mathrm{y} \mathrm{RX}^{\mathrm{V}}$ en el recorrido horizontal (ver apartado 4.3.3). El transmisor se ha colocado a una altura de 4 metros, y el receptor a una de 1.8 metros. Ambos arrays están formados por 8 elementos espaciados $\lambda / 2$. Las antenas son isotrópicas y están polarizadas verticalmente.

Para el transmisor situado en $(-30 \mathrm{~m}, 4 \mathrm{~m})$, la figura 4.21 muestra la capacidad en todo el recorrido del receptor. Se distinguen tres zonas en el recorrido: Primero una NLoS desde el principio hasta una cierta distancia al centro del cruce, luego una zona de transición entre $N L o S$ y $L o S$, y por último una clara zona $L o S$. En la zona $N L o S$ la capacidad es mayor en los chaflanes que en el cruce de las cuatro esquinas en unos 5 bps/Hz para un sistema $M I M O$ 8x8. El mismo comportamiento se ha observado para otras posiciones del transmisor. Esto se debe a que en un cruce de cuatro esquinas el mecanismo de propagación fundamental es la difracción, sin embargo en los chaflanes se añaden múltiples reflexiones a las paredes de los chaflanes. 

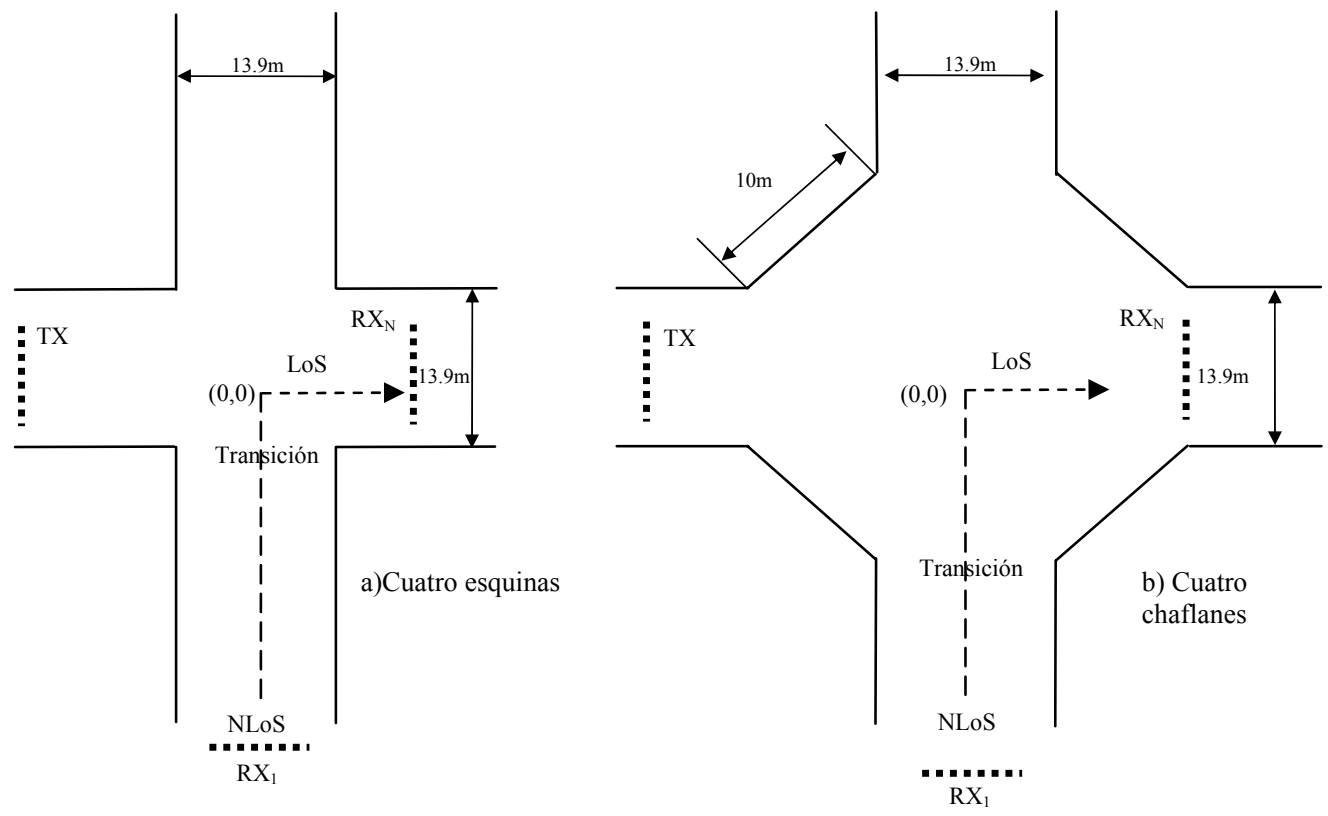

Figura 4.20: Geometría de (a) un cruce de cuatro esquinas y (b) un cruce de cuatro chaflanes para el estudio del paso de LoS a NLoS.

Desde $(-75 \mathrm{~m}, 0)$ a $(0,0)$ se detecta una zona de transición. Esta zona depende de la posición del transmisor y de las dimensiones de cruce. Después de esta zona, cuando el receptor gira $90^{\circ}$, éste se encuentra en una situación clara LoS, la cual no difiere mucho de un entorno a otro.

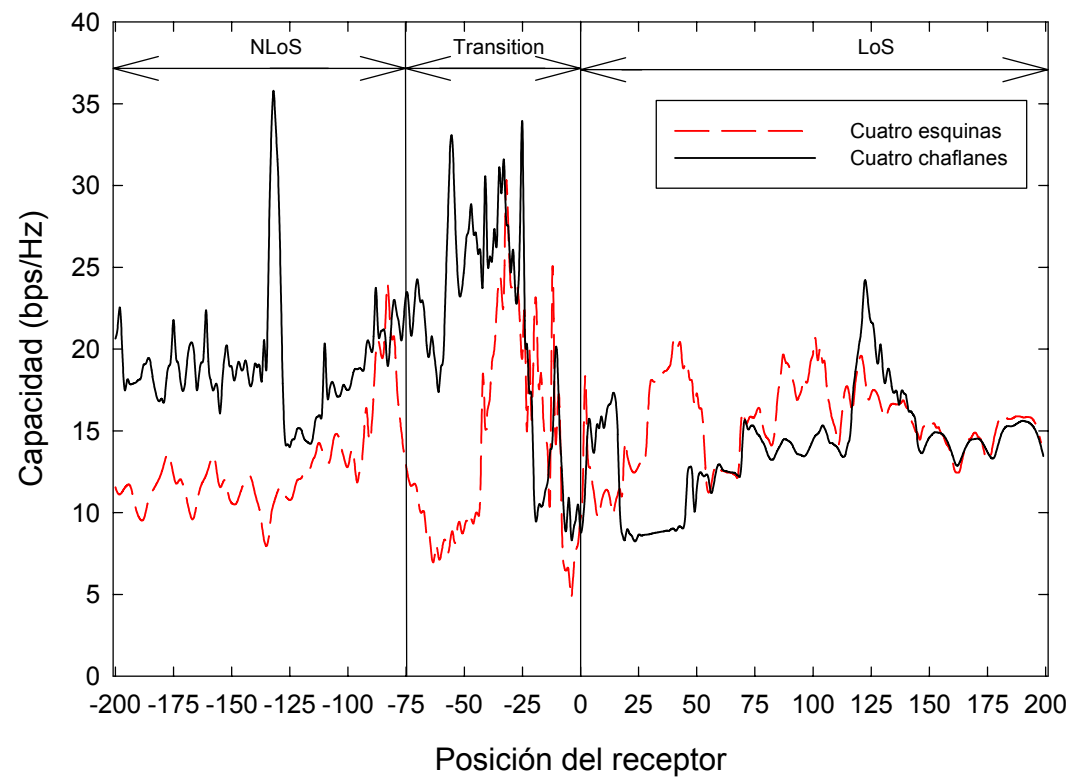

Figura 4.21: Capacidad en un entorno microcelular de cuatro esquinas y cuatro chaflanes para un sistema $8 \times 8$ 
Para las seis posiciones recogidas en la tabla 4.7 se observan resultados similares. Con toda la información se han construido las funciones contrarias de densidad acumuladas de probabilidad de la capacidad CCDF (figura 4.22). No hay mucha diferencia para $L o S$ en ambos entornos, sin embargo, para $N L o S$ la capacidad es unos 4 $\mathrm{bps} / \mathrm{Hz}$ mayor para un entorno de cuatro chaflanes que para otro de cuatro esquinas cuando se utilizan 8 antenas en cada lado del enlace. En la zona de transición, la curva de la $C C F D$ tiene una pendiente más suave para un entorno de cuatro esquinas, y para valores de probabilidad bajos (eje ordenadas de la figura 4.22), la capacidad llega a ser muy elevada en este entorno.

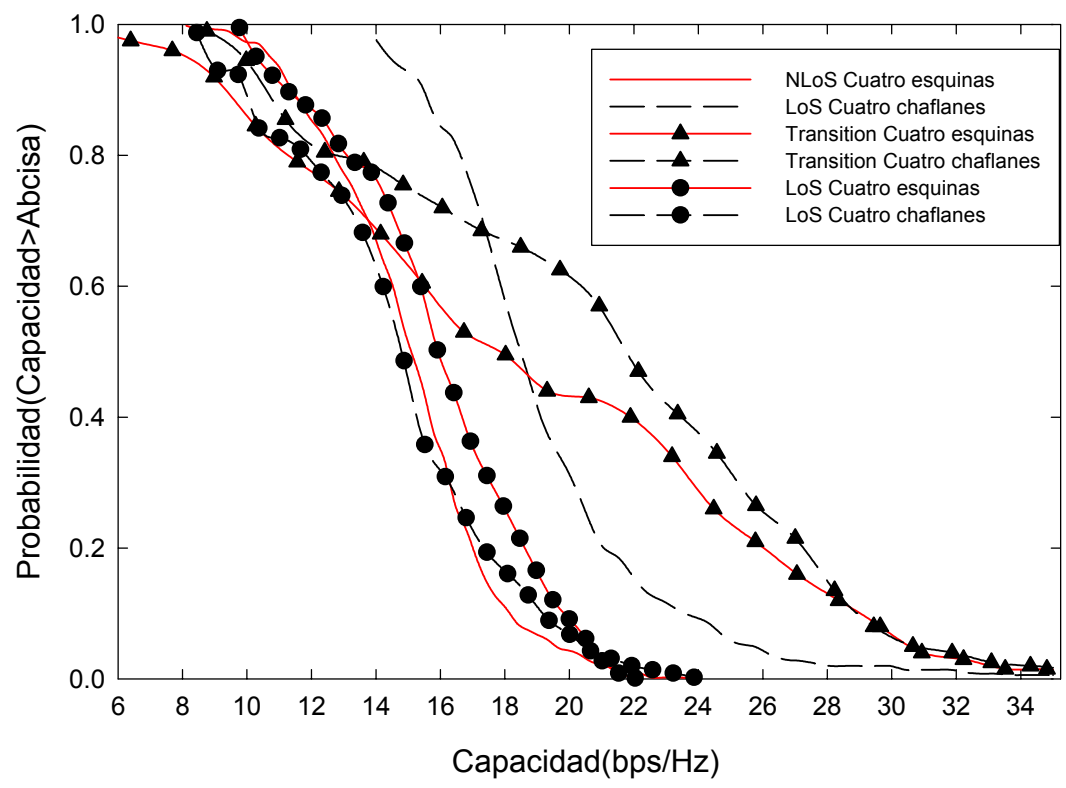

Figura 4.22: Funciones de densidad cumulativa complementaria de la capacidad para un canal $M I M O 8 \times 8$ en un cruce de cuatro esquinas y cuatro chaflanes.

\subsubsection{Discusión}

Se ha estudiado la capacidad de un sistema MIMO 8x8 en dos entornos microcelulares urbanos: un cruce de cuatro esquinas y un cruce de cuatro chaflanes. Primeramente se ha estudiado la disposición de los arrays llegándose a las siguientes conclusiones:

- Para la zona $L o S$, la capacidad no depende demasiado del entorno. Las posiciones óptimas del transmisor y del receptor son $\mathrm{TX}^{\mathrm{V}} \mathrm{y} \mathrm{RX}^{\mathrm{V}}$.

- Para $N L o S$, la posición óptima viene dada por las posiciones del transmisor $\mathrm{TX}^{\mathrm{V}}$ y del receptor $\mathrm{RX}^{\mathrm{V}}$. 
- Para NLoS, los chaflanes proporcionan más capacidad que el cruce de cuatro esquinas, especialmente para $\mathrm{RX}^{\mathrm{H}}$.

De las matrices $8 \times 8$ se calcularon las curvas $C C D F$ para sistemas $4 \mathrm{x} 4$, y se distinguieron los entornos $L o S$ y $N L o S$. Para $L o S$, la máxima capacidad $\mathrm{C}_{0.1}$ se obtuvo para la combinación $\mathrm{TX}^{\mathrm{V}}-\mathrm{RX}^{\mathrm{V}}$. Para $N L o S$ la capacidad disminuyó bastante excepto en el caso de $\mathrm{TX}^{\mathrm{V}}-\mathrm{RX}^{\mathrm{H}}$, donde la capacidad se mantuvo a $14.8 \mathrm{bps} / \mathrm{Hz}$ el $90 \%$ del tiempo.

Por otro lado se estudió el comportamiento de la capacidad al girar una esquina en los dos entornos anteriores. De este estudio se obtuvieron las siguientes conclusiones:

- En LoS la capacidad es similar en ambos entornos (de nuevo).

- En $N L o S$, la capacidad es unos 5 bps/Hz mayor en los chaflanes. Esto se debe a que más reflexiones son guiadas a la zona $N L o S$, y el canal se vuelve más espacialmente dispersivo. De esta forma, la capacidad aumenta.

- Entre las zonas $N L o S$ y $L o S$ se encontró una zona de transición donde la capacidad media $\left(\mathrm{C}_{0.5}\right)$ es mayor que la de $N L o S$.

- Se han presentado curvas CCDFs promediando los resultados de distintas posiciones del transmisor.

\subsection{Modelo paramétrico MIMO}

\subsubsection{Simulaciones de entornos simples}

Para comprobar el funcionamiento y las prestaciones del modelo explicado en el punto 2.4, se ha utilizado un entorno muy sencillo que está representado en la figura 4.21 [Mol04d,Mol04e]. Consiste en un entorno microcelular con dos esquinas separadas 13.9 metros. Para las simulaciones se ha fijado la frecuencia a $2.1 \mathrm{GHz}$, la permitividad a $\varepsilon_{r}=5$ y la conductividad a $\sigma=10^{-2} \mathrm{~S} / \mathrm{m}$. Tanto el transmisor como el receptor están formados por 5 elementos isotrópicos verticalmente polarizados. 


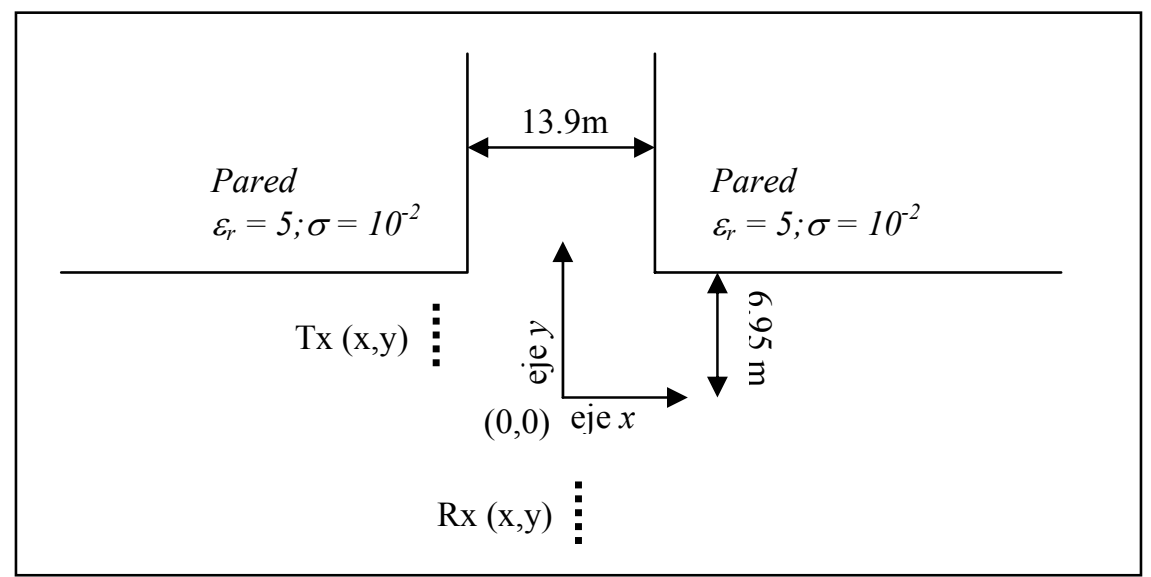

Figura 4.21: Geometría de un entorno sencillo compuesto de dos esquinas para comprobar el modelo paramétrico.

Se han comparado simulaciones completas $M I M O$ con el modelo de ondas planas $(P W)$ (apartado 2.4.1) y con el modelo paramétrico $(P M)$ (apartado 2.4.2). Para ello se ha simulado para cada punto en el plano la matriz completa 5x5 MIMO (25 simulaciones por posición), y una simulación SISO desde el centro del array en transmisión hasta el centro del array en recepción. De esta última simulación se han extraído los parámetros del canal doble-direccional [Ste01] que consisten en: una amplitud compleja ( $\left.E_{\mathrm{SISO}}\right)$, un ángulo de salida $\left(\varphi_{\mathrm{txk}}\right)$, un ángulo de llegada $\left(\varphi_{\mathrm{rxk}}\right)$ y un tiempo de llegada $\left(\tau_{\mathrm{k}}\right)$ para la contribución $\mathrm{k}-$ ésima.

Con estos datos se han utilizado los modelos $P M$ y $P W$ para reconstruir la matriz $\mathbf{G}_{5 \times 5}$, y se han comparado en términos de capacidad con la matriz exacta obtenida con la 25 simulaciones. Para situar las antenas, se ha tomado el eje de coordenadas de la figura 4.21, de tal forma que las esquinas están situadas en $(-6.95 \mathrm{~m}, 6.95 \mathrm{~m})$ y $(6.95 \mathrm{~m}, 6.95 \mathrm{~m})$.

\subsubsection{Rayo directo}

Como primer paso, se ha comprobado la reconstrucción del rayo directo mediante (2.24). El transmisor se ha situado en $(0,0)$ y el receptor realiza un recorrido desde $(1 \mathrm{~m}, 0)$ hasta $(100 \mathrm{~m}, 0)$. Los elementos de ambos arrays se han separado $\lambda / 2$ y su disposición es alineada con el eje y (ambos arrays enfrentados). 


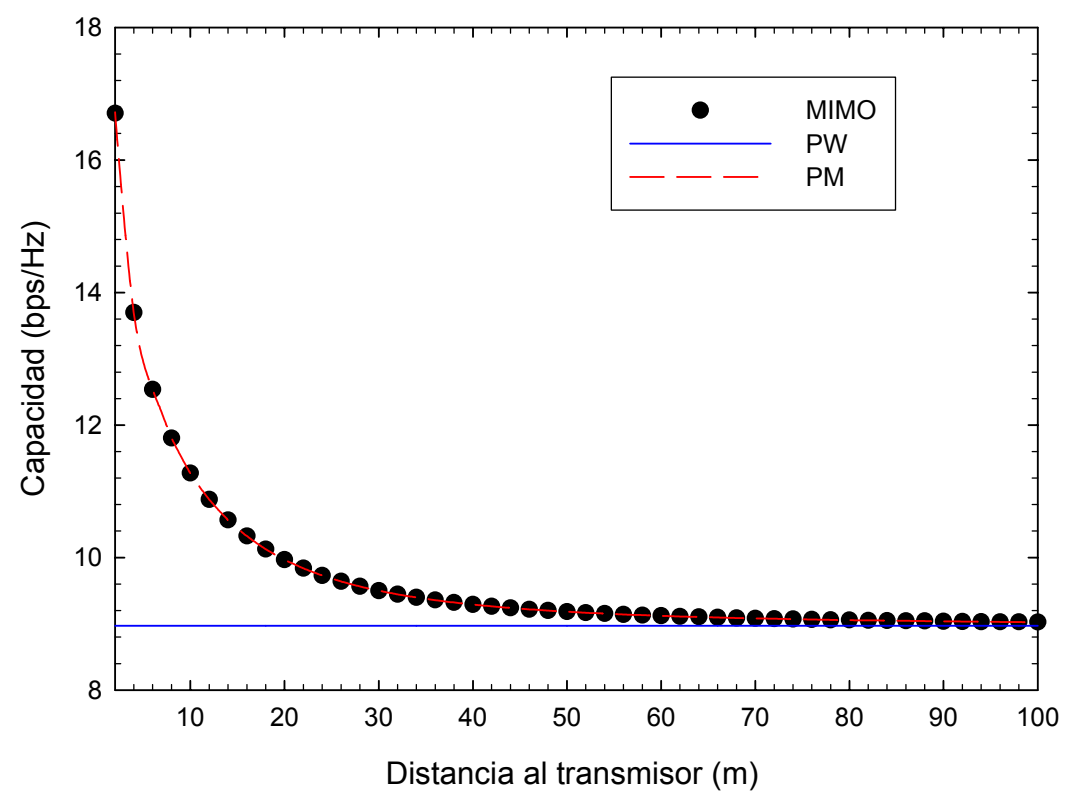

Figura 4.22: Capacidad considerando solamente la contribución $L o S$. El receptor realiza un recorrido por la línea $\mathrm{y}=0$.

La figura 4.22 muestra la capacidad de la componente $L o S$ para el sistema $5 \times 5$ descrito anteriormente. Se ha marcado con un círculo la capacidad exacta, con una línea azul la del modelo $P M$ y con una línea discontinua roja la del modelo $P M$. Se observa que el modelo paramétrico reconstruye perfectamente la capacidad, sin embargo, el modelo $P W$ predice $8.97 \mathrm{bps} / \mathrm{Hz}$ para $20 \mathrm{~dB}$ de SNR sea cual sea la posición del receptor. Esto fue observado en [Jia02], donde se propuso un modelo empírico para determinar la distancia a partir de la cual el error cometido por un modelo $P W$ es del 50\%. Se observa también en la figura que a partir de una cierta distancia, el modelo PW es suficientemente bueno para reconstruir el campo debido a la componente de rayo directo.

\subsubsection{Múltiples reflexiones}

En este punto se ha investigado la reconstrucción de las reflexiones mediante (2.32). Para ello el transmisor se ha situado en $(-10 \mathrm{~m}, 5 \mathrm{~m})$, y el receptor realiza un recorrido lineal desde $(-70 \mathrm{~m}, 0)$ hasta $(0,0)$. Para las simulaciones se han tenido en cuenta la contribución de rayo directo y una reflexión en la pared. Los elementos de los arrays se han espaciado $\lambda, y$ su disposición es vertical. La figura 4.23 muestra la capacidad, donde de nuevo se ha marcado con un círculo la capacidad exacta, con una línea azul el modelo $P M$ y con una línea discontinua roja el modelo $P M$.

El modelo $P M$ reconstruye fielmente la capacidad exacta. El modelo $P W$ es suficientemente bueno para distancias elevadas. El coste computacional del modelo 
paramétrico depende del número de antenas, y consiste en calcular la distancia entre las antenas en el plano imagen (apartado 2.4.2.2). Es importante mencionar que para que el modelo reconstruya perfectamente el canal MIMO el número de contribuciones debe ser igual en todas las antenas.

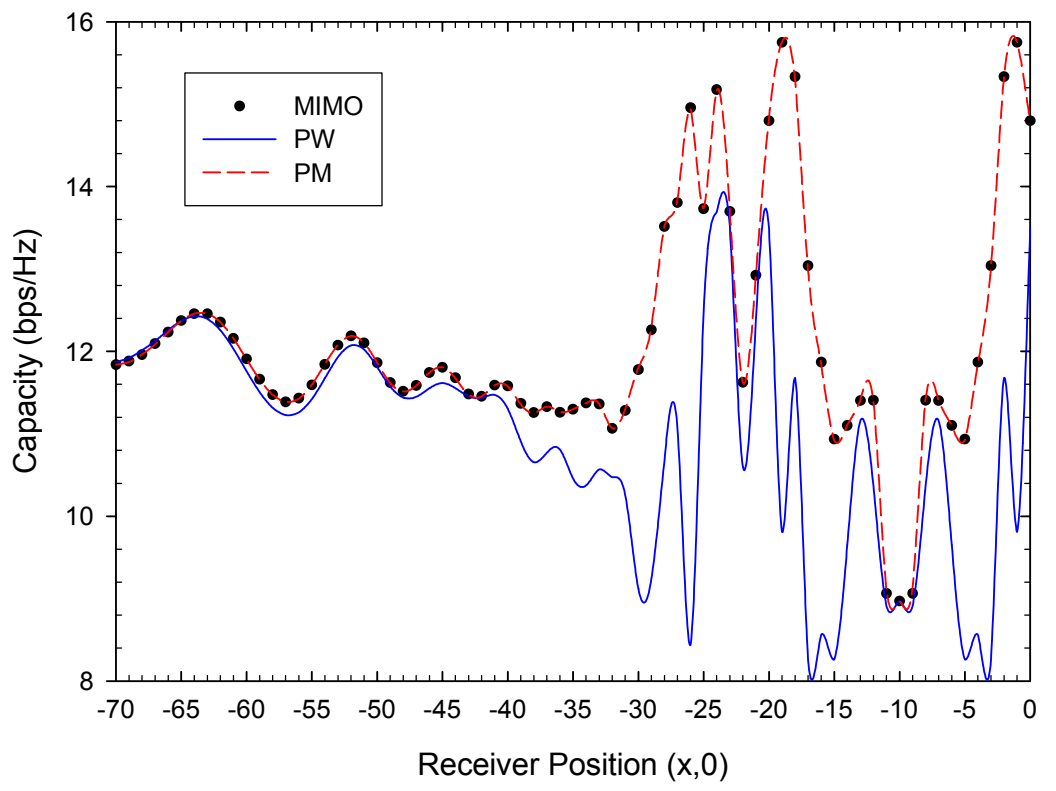

Figura 4.23: Capacidad considerando el rayo directo y una reflexión en la pared para el entorno de la figura 4.21. El receptor realiza un recorrido por la línea $\mathrm{y}=0$.

Como se explicó en el apartado (2.4.2.2) el coeficiente de reflexión depende del ángulo de incidencia. Para el caso soft el impacto es mínimo, sin embargo para polarización hard y sobre el ángulo de Brewster se produce un salto de $180^{\circ}$ en la fase [Bal89]. La simulación anterior se ha realizado con polarización soft. Para comprobar la influencia de la variación del coeficiente de reflexión se ha simulado una situación de caso peor. El transmisor se ha situado en $(-10 \mathrm{~m}, 5 \mathrm{~m})$ radiando de tal manera que su dirección broadside provoca una reflexión que forma un ángulo de $24.1^{\circ}$ con la pared izquierda. Este ángulo se corresponde con el ángulo de Brewster para los parámetros eléctricos $\varepsilon_{r}=5 \mathrm{y} \sigma$ $=10^{-2} \mathrm{~S} / \mathrm{m}$ [Bal89]. El receptor orienta su dirección broadside hacia esta reflexión y realiza un recorrido en línea recta de tal forma que la reflexión del ángulo de Bewster la recibe siempre desde su dirección broadside. 


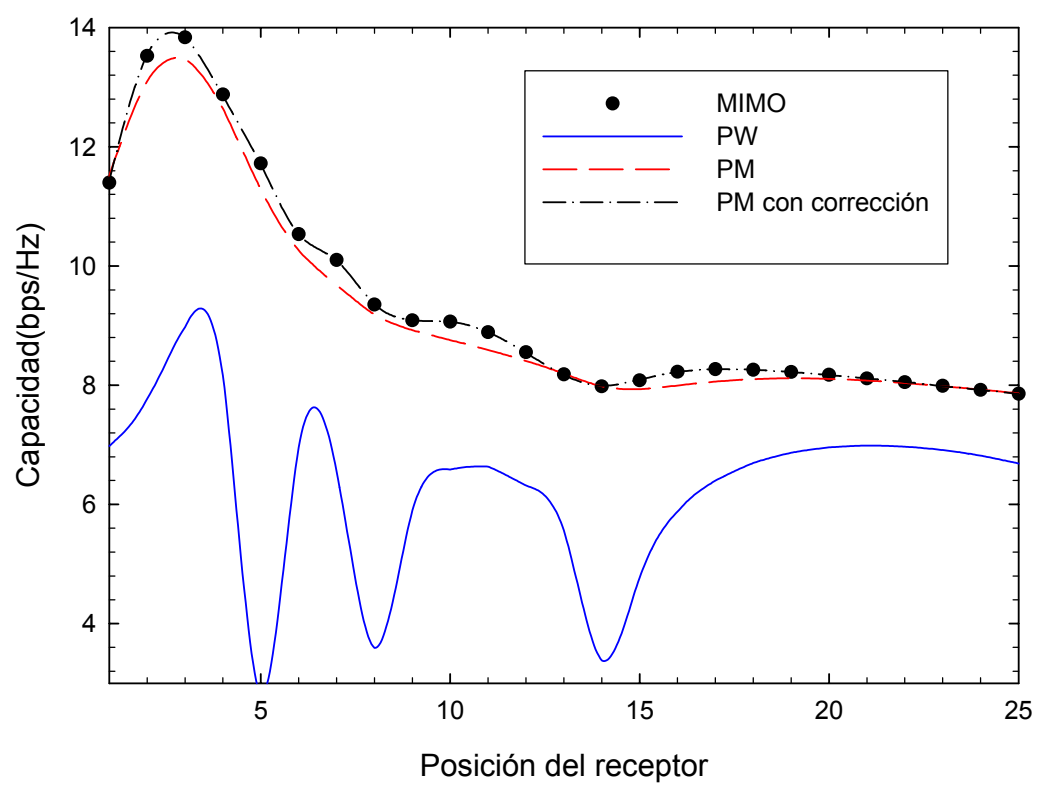

Figura 4.24: Capacidad considerando el rayo directo y una reflexión en la pared para el entorno de la figura 4.21. El receptor se mueve por la línea del ángulo de Brewster.

La figura 4.24 muestra la capacidad producida por el rayo directo y la reflexión en la pared en el ángulo de Brewster según se ha descrito anteriormente. $P M$ junto con la corrección de la fase del coeficiente de reflexión es capaz de reconstruir fielmente el resultado exacto. Sin embargo si no se corrige este ángulo, la solución no es exacta aunque se aproxima bastante. Esto se debe a que en el ángulo Brewster toda la energía es transmitida y no existe reflexión, y cuando un rayo incide con un ángulo ligeramente diferente, el valor de la reflexión es mínimo, y no contribuye demasiado a la capacidad (por eso la línea roja está por debajo de la exacta). Con respecto a $P W$, el resultado no es demasiado bueno. Se puede concluir que incluso cuando el receptor tiene alguna contribución que proviene del ángulo de Brewster, si hay alguna otra como es en el caso de la simulación anterior, es suficiente con reconstruir la propagación esférica debida a la reflexión.

\subsubsection{Difracción}

Finalmente, se ha estudiado la difracción. Debido a que la energía que se produce en la difracción suele ser muy inferior a cualquiera de las que produce otra contribución, se ha estudiado por separado. El transmisor se ha situado en $(-10 \mathrm{~m}, 5 \mathrm{~m})$, y el receptor ha realizado un recorrido desde $(0,-20 \mathrm{~m})$ hasta $(0,20 \mathrm{~m})$. Los elementos se han separado $\lambda / 2$. En la figura 4.25 se observan los resultados de la capacidad teniendo en cuenta la 
simulación $M I M O$ completa, $P W, P M$ sin tener en cuenta las variaciones de coeficiente de reflexión y $P M$ teniéndolas en cuenta.

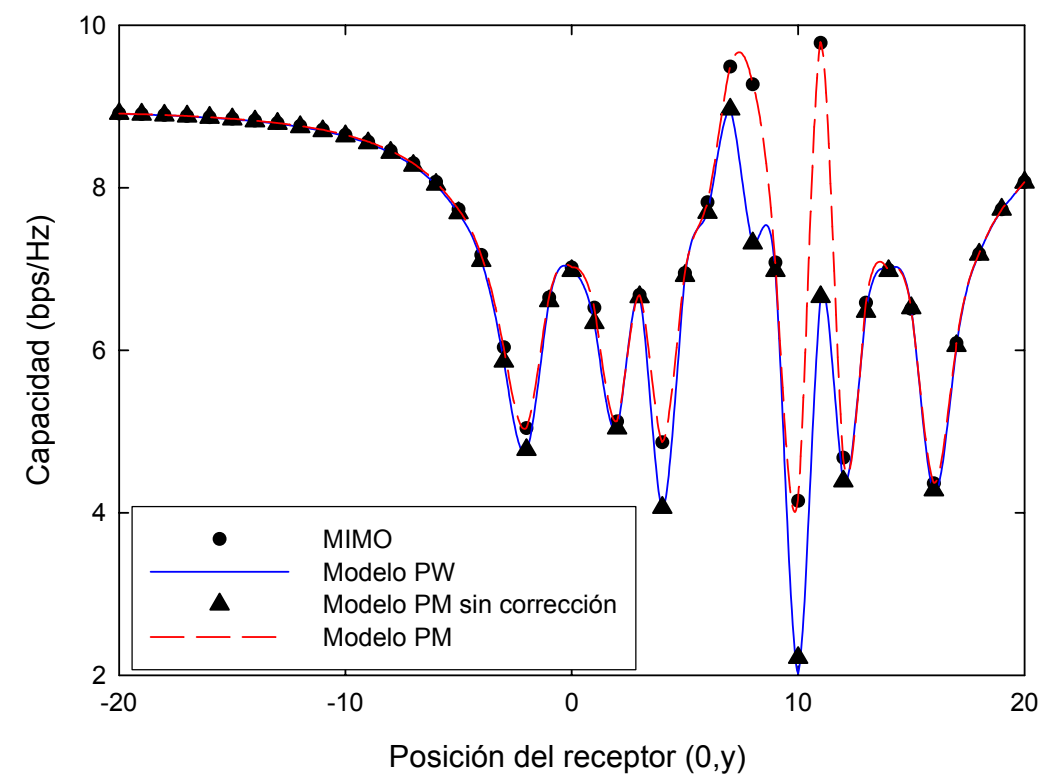

Figura 4.25: Capacidad considerando la difracción de las dos equinas del entorno de la figura 4.21. $\mathrm{El}$ receptor se mueve por la línea $\mathrm{x}=0$.

Se observa que es necesario tener en cuenta las variaciones del coeficiente de difracción para las posiciones cercanas a las esquinas difractoras. En puntos que disten lo suficiente de éstas, no es necesario tener en cuenta esta corrección debido a que se puede asumir constante, e incluso $P W$ funciona correctamente. El incremento en el coste computacional consiste en recalcular el coeficiente de difracción para cada par de antenas utilizando los parámetros $s, s^{\prime}, \phi$ y $\phi^{\prime}$, que son fácilmente obtenibles desde el trazador de rayos.

\subsubsection{Simulaciones en un entorno microcelular real}

Una vez que se han comprobado las distintas contribuciones del modelo $P M$ en un entorno sencillo, se ha simulado un entorno más complejo. Se ha utilizado el plano de la figura 4.26, que se corresponde con unas calles de la ciudad de Murcia. Se han realizado las simulaciones a $2.1 \mathrm{GHz}$, y los parámetros radioeléctricos de las paredes se han tomado como $\varepsilon_{r}=5$ y $\sigma=10^{-2} \mathrm{~S} / \mathrm{m}$. El transmisor es un array lineal de 5 elementos isotrópicos verticalmente polarizados, con separación entre elementos $3 \lambda$. El receptor es otro array de 3 elementos isotrópicos verticalmente polarizados y separados $\lambda$. En las simulaciones, se han considerado hasta diez reflexiones, y dos reflexiones con la de la difracción. 
El transmisor se coloca en dos posiciones, $T X_{1}$ y $T X_{2}$. Desde la primera posición, la distancia mínima es de 45 metros, para la segunda la distancia mínima es de 7.5 metros. El receptor realiza para ambos casos un recorrido de 80 metros de norte a sur. Ambos transmisores están orientados de forma perpendicular al recorrido del móvil, y el receptor está orientado hacia su recorrido.

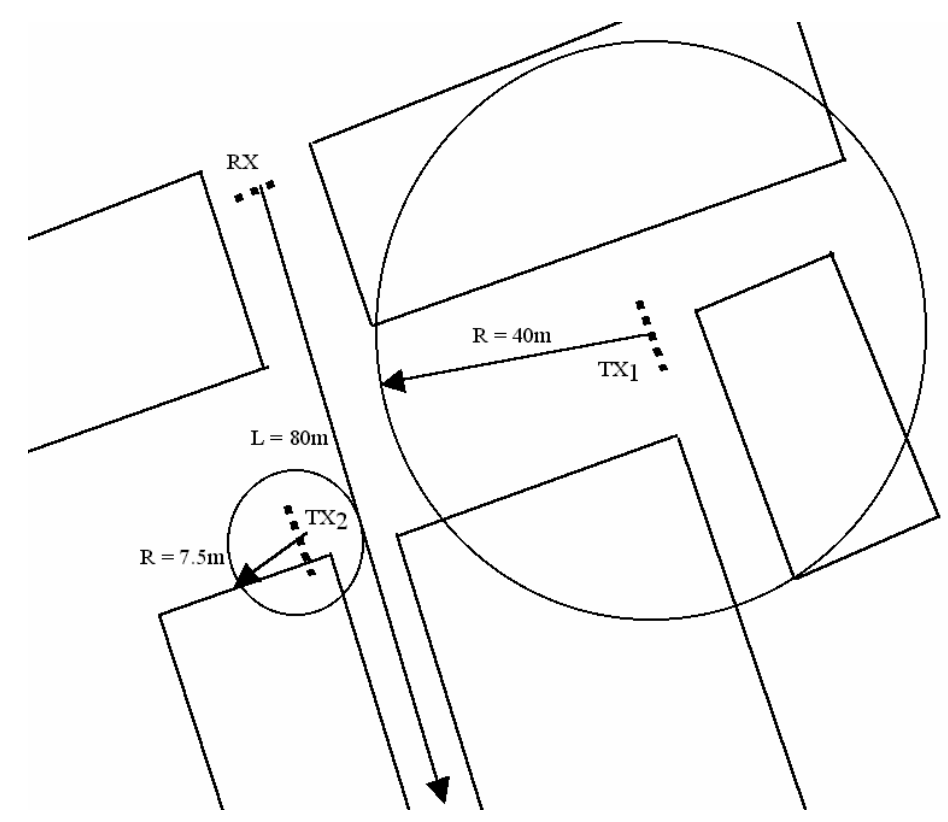

Figura 4.26: Entorno microcelular de la ciudad de Murcia.

La primera simulación es la correspondiente al transmisor $T X_{1}$. El receptor empieza en una zona $N L o S$, a los 17 metros entra en $L o S$ y a los 47 vuelve a $N L o S$ (figura 4.27). Se observa que ambos modelos, $P M$ y $P W$, predicen adecuadamente la capacidad MIMO. El error relativo medio cometido utilizando $P W$ con respecto a la simulación exacta es del $2.28 \%$, y utilizando $P M$ del $2.16 \%$. Se ha observado que el número de contribuciones no es el mismo en cada antena, así que es imposible predecir la capacidad exacta a partir de una sola realización. El error de poco más del $2 \%$ se debe a este inconveniente, de cualquier forma, es un error suficientemente bajo, y el coste computacional es muy inferior al cálculo de la matriz MIMO exacta.

En la primera simulación el transmisor se encontraba bastante alejado del recorrido del receptor, por eso se ha elegido una segunda posición para el transmisor más cercana: $T X_{2}$. El receptor empieza en $L o S$, y a los 49 metros pasa a $N L o S$ (figura 4.28). La distancia mínima entre el transmisor y el receptor se ha reducido bastante. Se observa que $P W$ ya no predice bien la capacidad desde la posición 30 a la 50, ya que está muy cerca del 
transmisor (distancia mínima de 7 metros). El error medio en todos los puntos es del $5.89 \%$ para $P W$ y del $2.41 \%$ para $P M$.

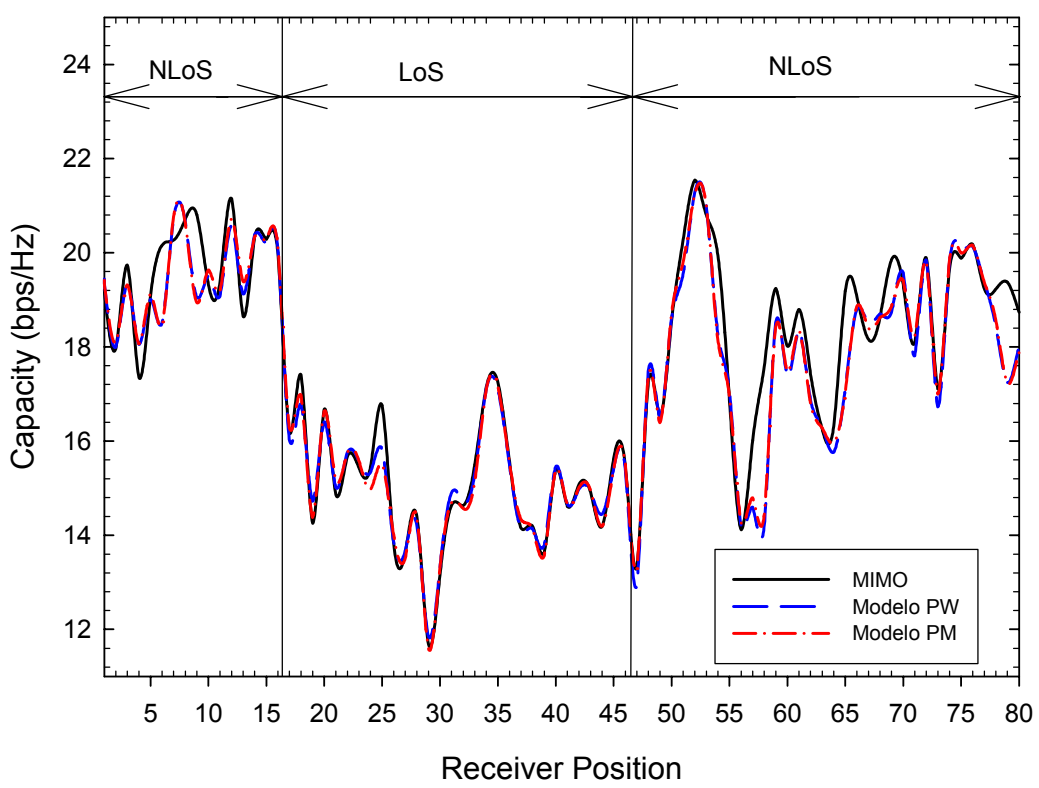

Figura 4.27: Capacidad en el entorno de la figura 4.26 cuando el transmisor se encuentra en $\operatorname{TX}_{1} \mathrm{y}$ el receptor realiza un recorrido de 80 metros.

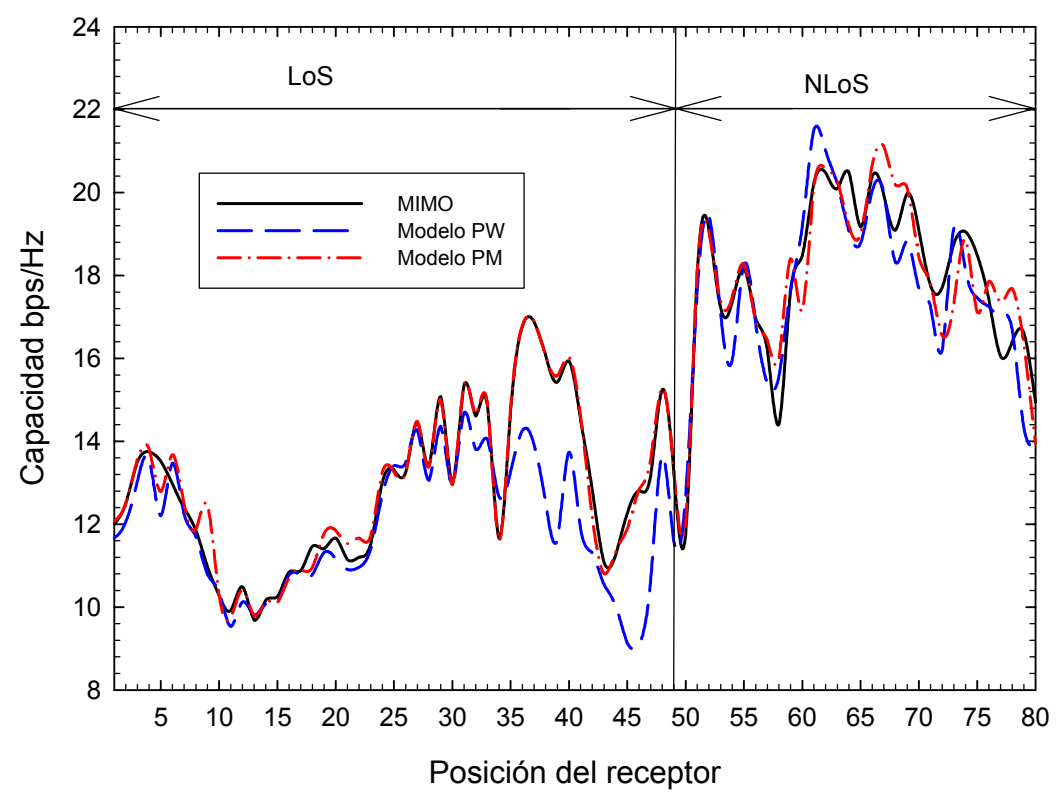

Figura 4.28: Capacidad en el entorno de la figura 4.26 cuando el transmisor se encuentra en $\mathrm{TX}_{2} \mathrm{y}$ el receptor realiza un recorrido de 80 metros. 


\subsubsection{Discusión}

Dos modelos, uno basado en ondas planas y otro paramétrico, que reconstruyen el canal $M I M O$ a partir de una realización, se han comparado con simulaciones exactas del canal $M I M O$. El modelo $P M$ asume que el número de contribuciones no cambia de una antena a otra del mismo array, y que la propagación es esférica. El modelo reconstruye el canal mediante imágenes y tiene en cuenta variaciones tanto en el coeficiente de difracción como en el coeficiente de reflexión.

Primero se han estudiado las diferentes contribuciones por separado en entornos sencillos. Para $L o S, P M$ obtiene el resultado exacto, ya que recalcula todas las distancias entre las antenas, sin embargo, $P W$ sólo es válido para distancias grandes donde se puede asumir que el frente de onda es plano.

En el caso de múltiples reflexiones, de nuevo el modelo $P M$ reproduce fielmente la capacidad, y se ha demostrado que incluso para el caso en que se trabaje con polarización hard sobre el ángulo de Brewster, no es necesario tener en cuenta las variaciones de este coeficiente cuando varía ligeramente el ángulo de incidencia en la pared para cada una de las reflexiones.

Por último, se ha estudiado la difracción. Se ha observado que para puntos cercanos a la arista difractora, es necesario tener en cuenta las variaciones del coeficiente de difracción, ya que éste va a cambiar bastante en función de la posición de cada antena del array. El modelo $P W$ de nuevo es efectivo siempre y cuando la distancia sea grande entre el transmisor y el receptor, o lo que es lo mismo, que la distancia recorrida por la onda sea grande.

Una vez se ha estudiado cada componente en un entorno sencillo, se realizaron simulaciones en un entorno microcelular real de la ciudad de Murcia. Cuando el receptor está alejado del transmisor, ambos modelos $P W$ y $P M$ predicen la capacidad con un error relativo en torno al $2 \%$. Sin embargo, si el receptor se encuentra cerca del transmisor, el error puede llegar a ser bastante elevado, y hace falta suponer propagación esférica y tener en cuenta las variaciones del coeficiente de difracción.

\subsection{Sistemas MIMO distribuidos}

Los sistemas distribuidos han demostrado mejorar las prestaciones del enlace radio frente a los sistemas centralizados [Cla01]. Los primeros están basados en el uso de varias estaciones base simultáneamente dentro de una celda, dotando de macrodiversidad al 
enlace, para aumentando la potencia recibida y la capacidad. En [Roh02] se presenta un estudio teórico donde se estudia tanto el enlace ascendente como el descendente para estos sistemas.

En este apartado se ha estudiado un sistema distribuido donde varias estaciones base comparten las antenas del sistema MIMO. Los resultados se han centrado en un área rural y en un entorno urbano [Mol04f].

\subsubsection{Entorno de propagación}

Se han estudiado dos entornos distintos. El primero es un entorno rural y el segundo un entorno urbano microcelular que se muestra en la figura 4.29.

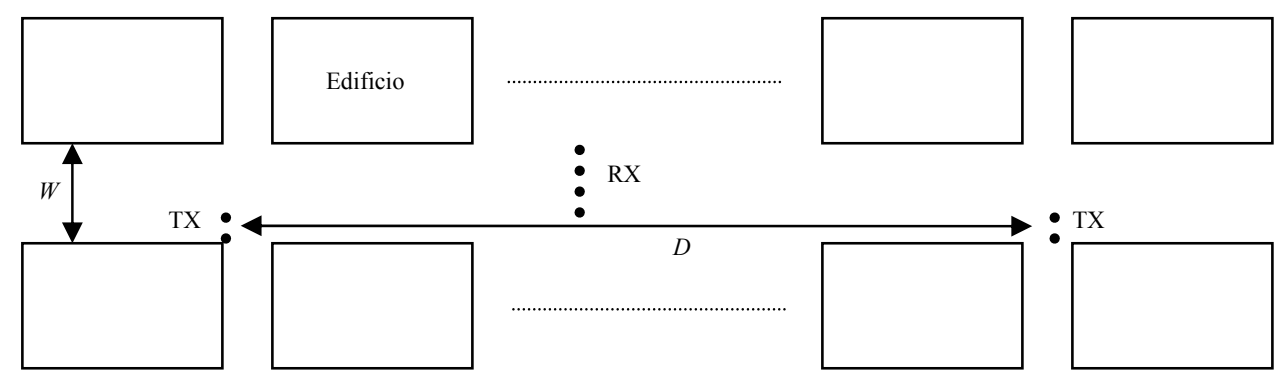

Figura 4.29: Vista en planta de un entorno microcelular formado por edificios regularmente distribuidos a ambos lados de una calle.

La distancia entre los edificios $(W)$ se ha fijado en 18 metros, de los cuales corresponden 8 metros a la carretera ( 2 vías de 4 metros cada una), 2 metros de aparcamiento y 3 metros de acera. La longitud de los edificios es de 60 metros.

Para ambos entornos (rural y urbano), la estación base se ha situado a 15 metros del suelo y por debajo de los tejados en el caso del entorno microcelular. El receptor tiene una altura de 1.5 metros, y recorre una de las vías. Cada receptor está formado por 4 antenas omnidireccionales, espaciadas $\lambda$, y distribuidas perpendicularmente al sentido del desplazamiento. Las estaciones base tienen los elementos espaciados $10 \lambda$.

Se han colocado estaciones cada $D$ metros en cada entorno, y se han tenido en cuenta dos configuraciones: un sistema centralizado y otro distribuido. El centralizado utiliza 4 antenas en cada estación base, y el receptor se conecta a una estación base a la vez. El distribuido utiliza 2 antenas en cada estación base, y el móvil se conecta a dos estaciones base a la vez. 


\subsubsection{Modelos de propagación}

Para el entorno abierto se ha utilizado el modelo de dos rayos propuesto en [Kyr02] para tierra plana. En este modelo se consideran el rayo directo y su reflexión en el suelo. Para analizar el entorno urbano se ha utilizado el trazado de rayos con el modelo que se ha desarrollado en la sección 2.2. Se han tenido en cuenta las siguientes contribuciones:

- Rayo directo

- Rayos múltiplemente reflejados

A cada una de las contribuciones se le ha añadido la reflexión en el suelo, y las matrices se han normalizado según la norma de Frobenius. La capacidad se ha calculado utilizando (D.7). Las simulaciones se han realizado a $2.1 \mathrm{GHz}$ para ambos entornos, y los parámetros eléctricos de las paredes en el entorno urbano han sido $\sigma=0.01 \mathrm{~S} / \mathrm{m}$ y $\varepsilon_{\mathrm{r}}=5$. La señal a ruido en las antenas receptoras se ha fijado en $20 \mathrm{~dB}$.

\subsubsection{Capacidad en entorno abierto con un sistema distribuido}

Se han separado las estaciones base 2 kilómetros. La configuración I utiliza 4 antenas en cada estación base $(B S)$ y 4 antenas en el receptor. El móvil se conecta a la $B S$ más cercana, de tal forma que el receptor realiza un handover a un kilómetro de cada $B S$. Para la configuración II cada $B S$ utiliza 2 antenas y el receptor 4. El sistema funciona transmitiendo por dos $B S$ de tal forma que el número total de antenas transmisoras es de 4. El handover es más suave que en la configuración I, ya que el móvil siempre está conectado al menos a 2 antenas transmisoras durante todo el tiempo (soft handover). 


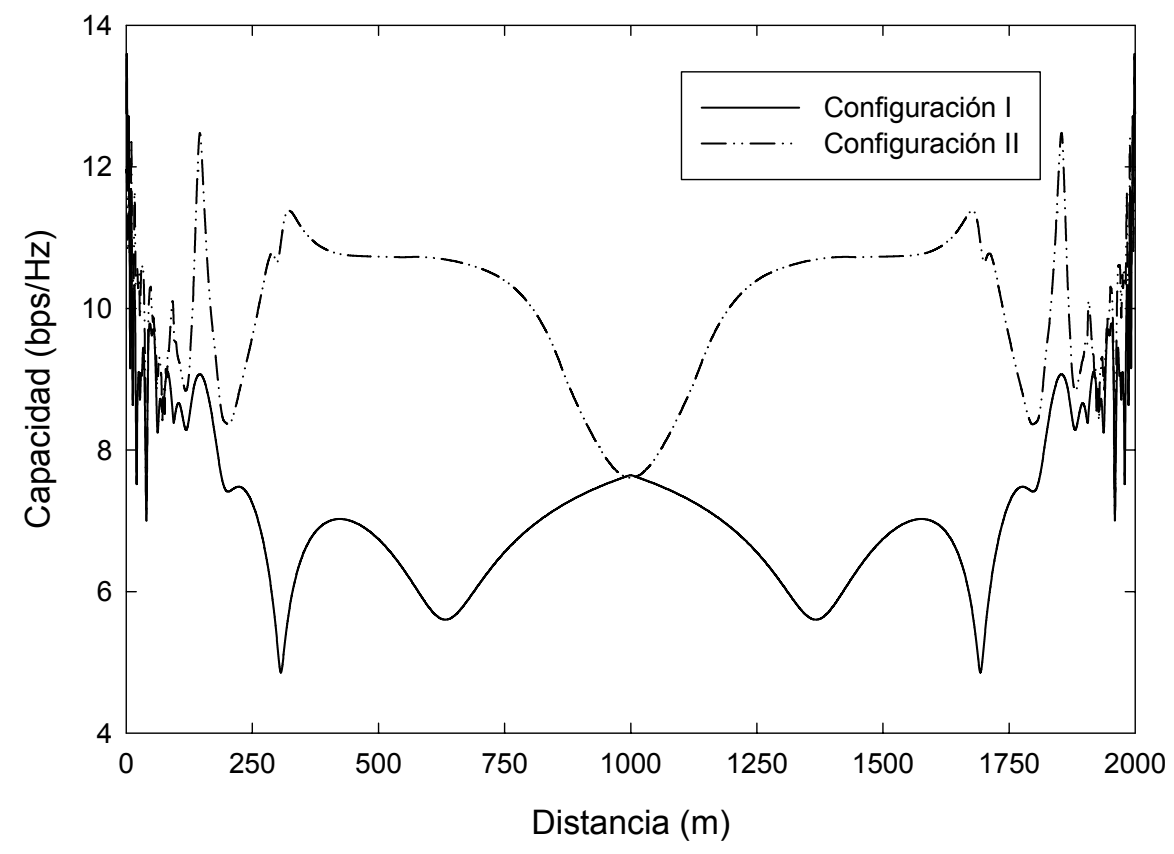

Figura 4.30: Capacidad entre dos estaciones bases separadas 2 kilómetros en un entorno rural abierto.

El primer resultado se muestra en la figura 4.30. En éste, se representa la capacidad en el receptor cuando se mueve desde una estación base a otra contigua, separada 2000 metros, en un entorno rural. Se observa que, con la configuración I, la capacidad decrece fuertemente durante los 200 primeros metros, y luego fluctúa alrededor de $6.5 \mathrm{bps} / \mathrm{Hz}$. Para la configuración II la capacidad permanece sobre los $10 \mathrm{bps} / \mathrm{Hz}$, y decrece a partir de los $750 \mathrm{~m}$. Ambos esquemas tienen una capacidad similar a la distancia $D / 2(1000 \mathrm{~m})$ tal y como se espera debido a la simetría del problema. En la figura 4.31 se presentan curvas CCFD para ambas configuraciones. Para una capacidad outage del 50\%, o capacidad mediana, la capacidad se incrementa de $6.8 \mathrm{bps} / \mathrm{Hz}$ hasta $10.5 \mathrm{bps} / \mathrm{Hz}$ cuando se utiliza la configuración II. Este incremento se debe al aumento de la dispersión angular, ya que la energía procede de dos lugares con azimuts totalmente opuestos. Las siguientes dos figuras (4.32 y 4.33) recogen los valores propios para cada posición entre las dos $B S$ para los dos sistemas respectivamente. 


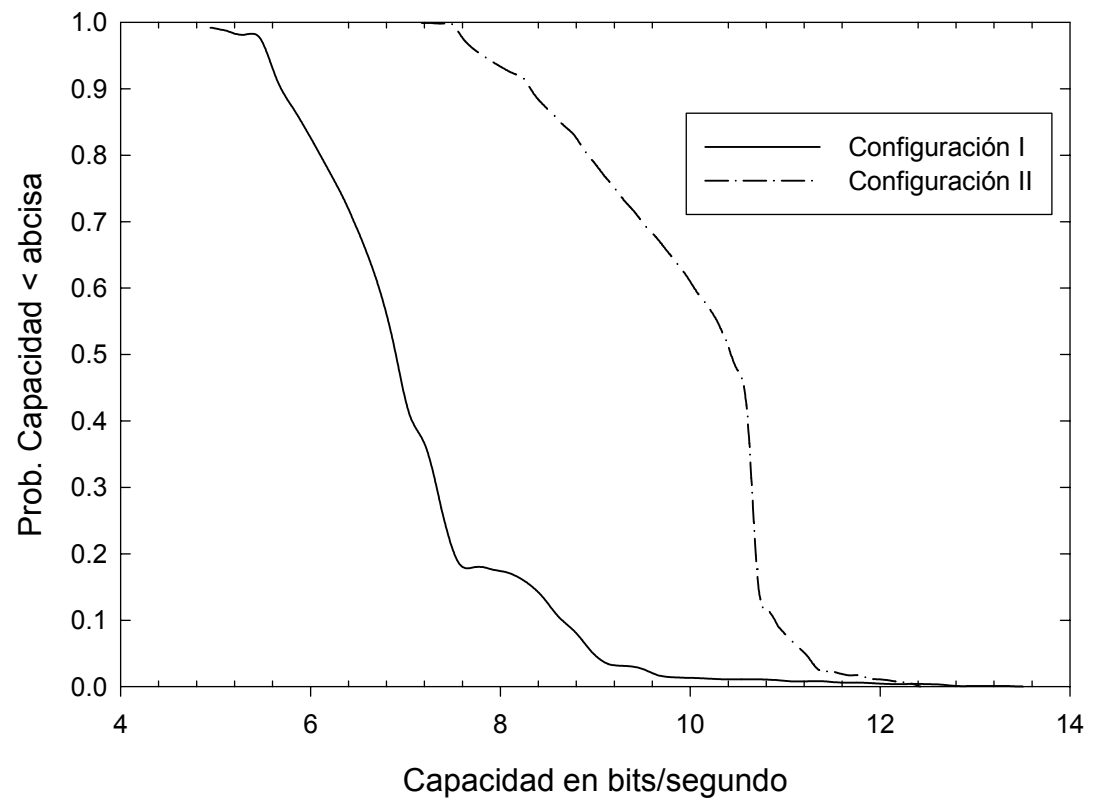

Figura 4.31: Funciones de distribución acumulada de la capacidad entre dos estaciones bases separadas 2 kilómetros en un entorno rural abierto.

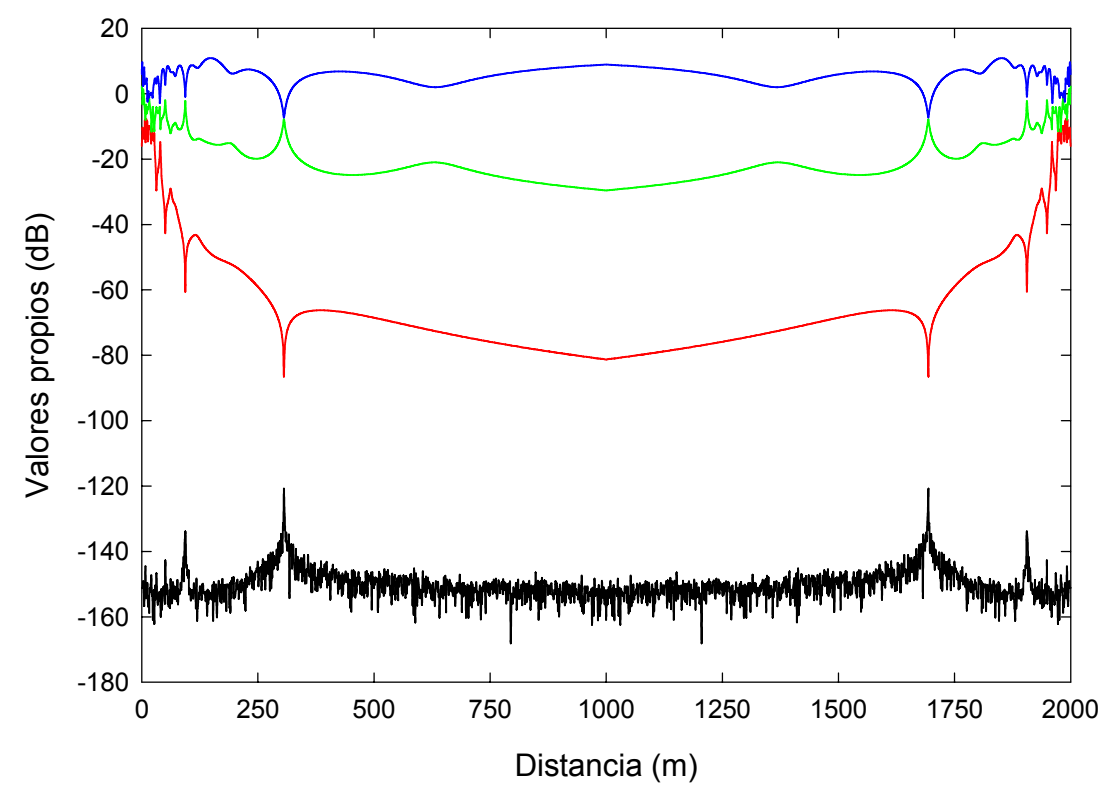

Figura 4.32: Valores propios de la matriz MIMO entre dos estaciones en un entorno rural en función de la posición para la configuración I. 


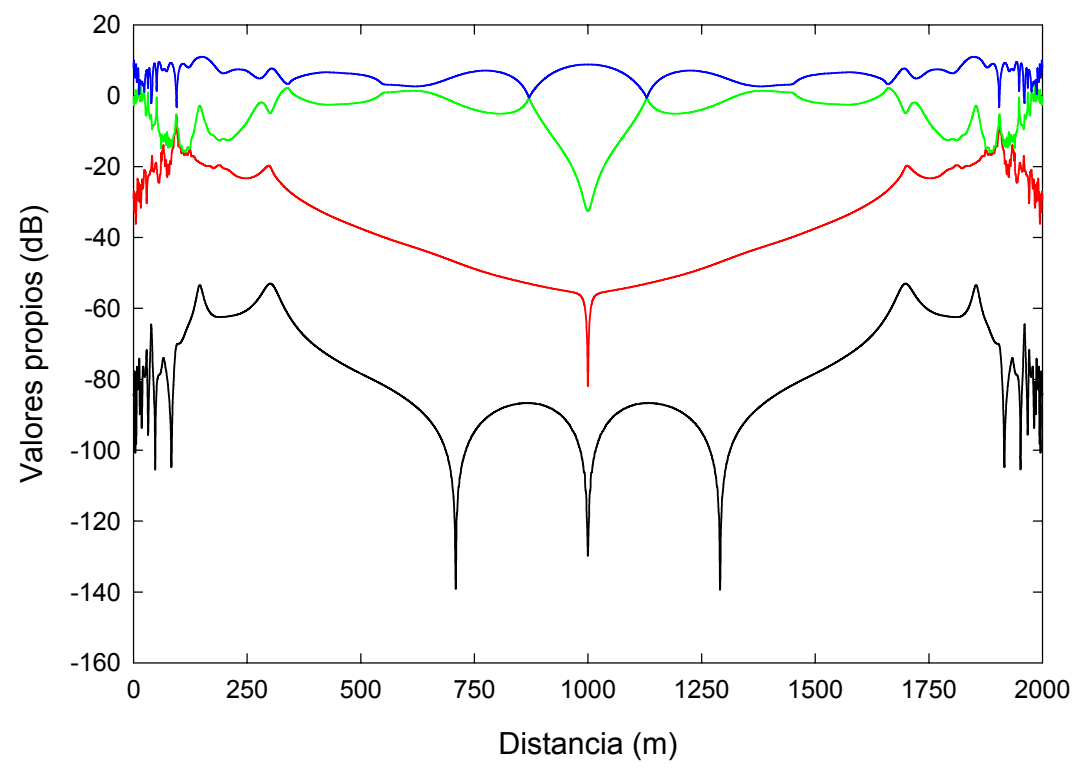

Figura 4.33: Valores propios de la matriz MIMO entre dos estaciones en un entorno rural en función de la posición para la configuración II.

Para la configuración I, se observan dos autovalores elevados, otro $60 \mathrm{~dB}$ menor que ellos y un cuarto que puede considerarse como ruido. Por otro lado, la configuración II tiene dos autovalores parecidos, un tercero $30 \mathrm{~dB}$ inferior a estos y un cuarto que no es tan bajo como el de la configuración I. Se puede concluir que el rango de la matriz $\mathbf{H}$ correspondiente a la configuración I es menor que el de la configuración II, y consecuentemente la capacidad. También se han estudiado las pérdidas básicas de propagación para ambos sistemas. Para la configuración I las pérdidas medias son de 76 $\mathrm{dB}$ con una desviación típica de $6 \mathrm{~dB}$, y para la configuración II, las pérdidas medias son de $82 \mathrm{~dB}$ y la desviación típica de $6 \mathrm{~dB}$.

\subsubsection{Capacidad en entorno urbano con un sistema distribuido}

Para simular el entorno urbano se ha utilizado el plano de la figura 4.29, donde las estaciones se han separado 500 metros, ya que el radio de las microceldas es menor en un entorno urbano. Como antes, se han utilizado 4 antenas en la estación base para la configuración I y dos para la configuración II. Para ambas configuraciones el receptor dispone de 4 antenas. Se ha simulado considerando hasta 50 reflexiones en las paredes y se ha incluido la reflexión en el suelo. No se ha considerado la reflexión sobre los tejados. La figura 4.34 muestra el resultado de la capacidad entre dos $B S$ para los dos sistemas en un entorno urbano, y la figura 4.35 las curvas $C C D F$ para ambas configuraciones. 


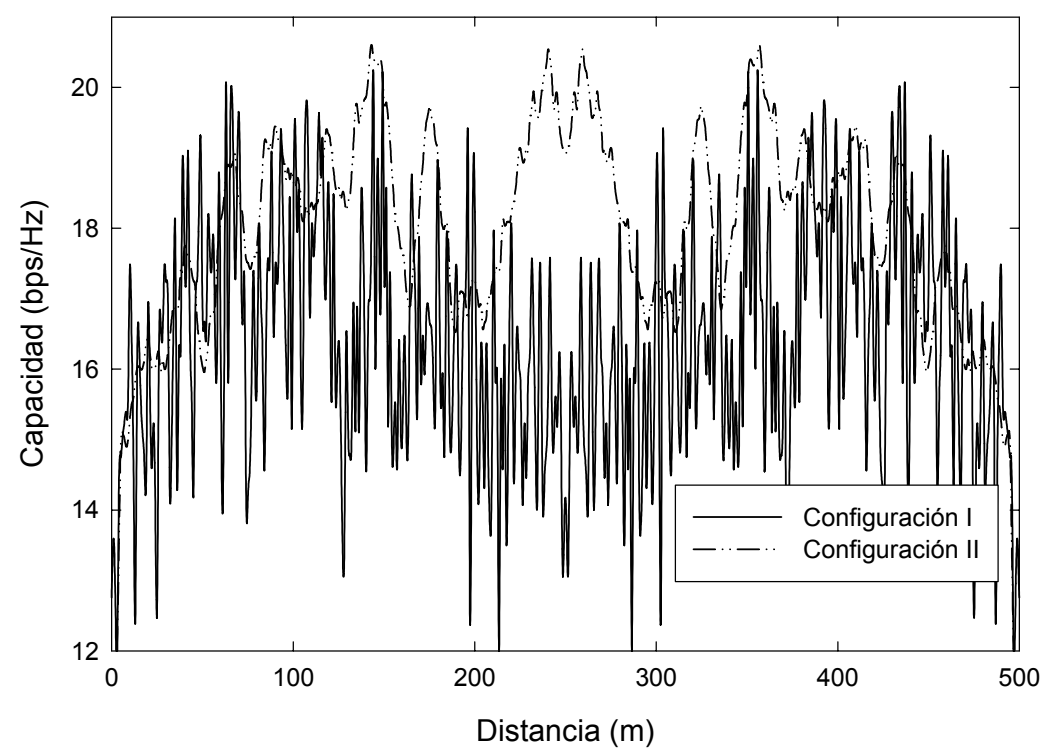

Figura 4.34: Capacidad entre dos estaciones bases separadas 500 metros en un entorno urbano denso.

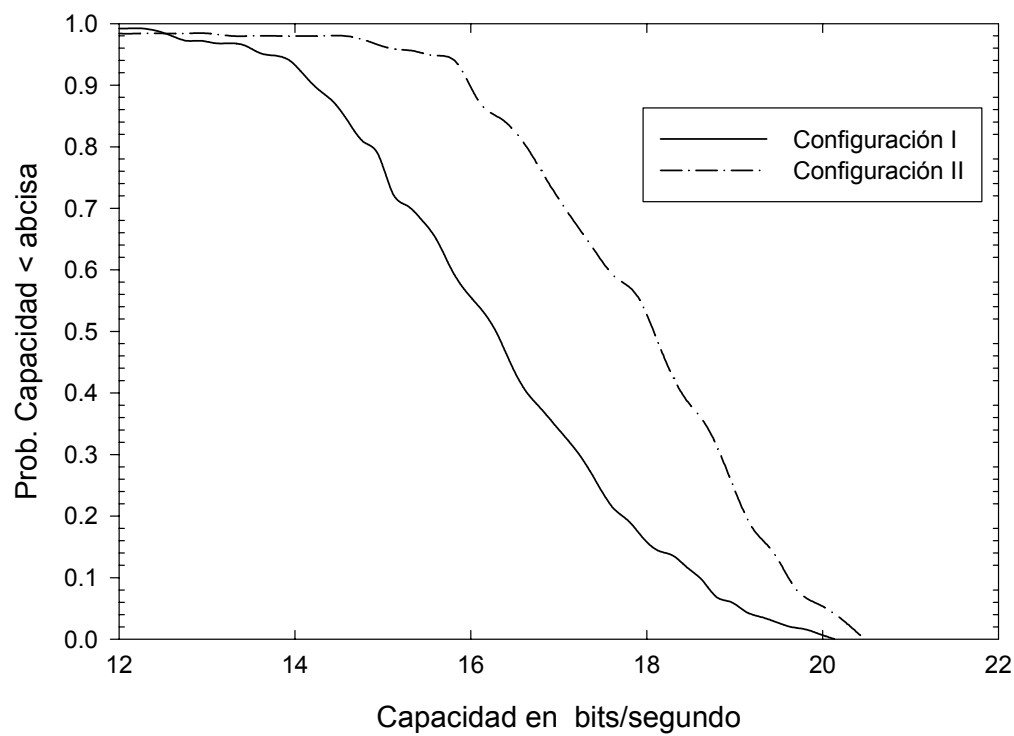

Figura 4.35: Funciones de distribución acumulada de la capacidad entre dos estaciones bases separadas 500 metros en un entorno urbano denso.

Durante los primeros metros no hay mucha diferencia entre la capacidad de ambas configuraciones. Sin embargo, a partir de los 100 metros, con la configuración II se obtiene más capacidad que con la configuración I. La capacidad media para la configuración primera es de 16.3 y para la segunda $18.5 \mathrm{bps} / \mathrm{Hz}$. Si se comparan estas capacidades con las del entorno rural (que eran $6.8 \mathrm{bps} / \mathrm{Hz}$ y $10.5 \mathrm{bps} / \mathrm{Hz}$ respectivamente), la capacidad en un entorno urbano aumenta hasta $10 \mathrm{bps} / \mathrm{Hz}$, ya que la dispersión es mayor (reflexiones laterales). 
Las figuras 4.36 y 4.37 muestran los valores propios para las matrices $M I M O$ en el entorno urbano de la figura 4.29 para ambas configuraciones. Utilizando la primera de ellas, tres de los autovalores tienen bastante potencia, y el cuarto puede ser despreciado. Esto significa que sólo se pueden aprovechar 3 canales virtuales para transmitir la información de forma paralela. Para la segunda configuración, todos los autovalores tienen bastante potencia para poder ser utilizados para transmitir información.

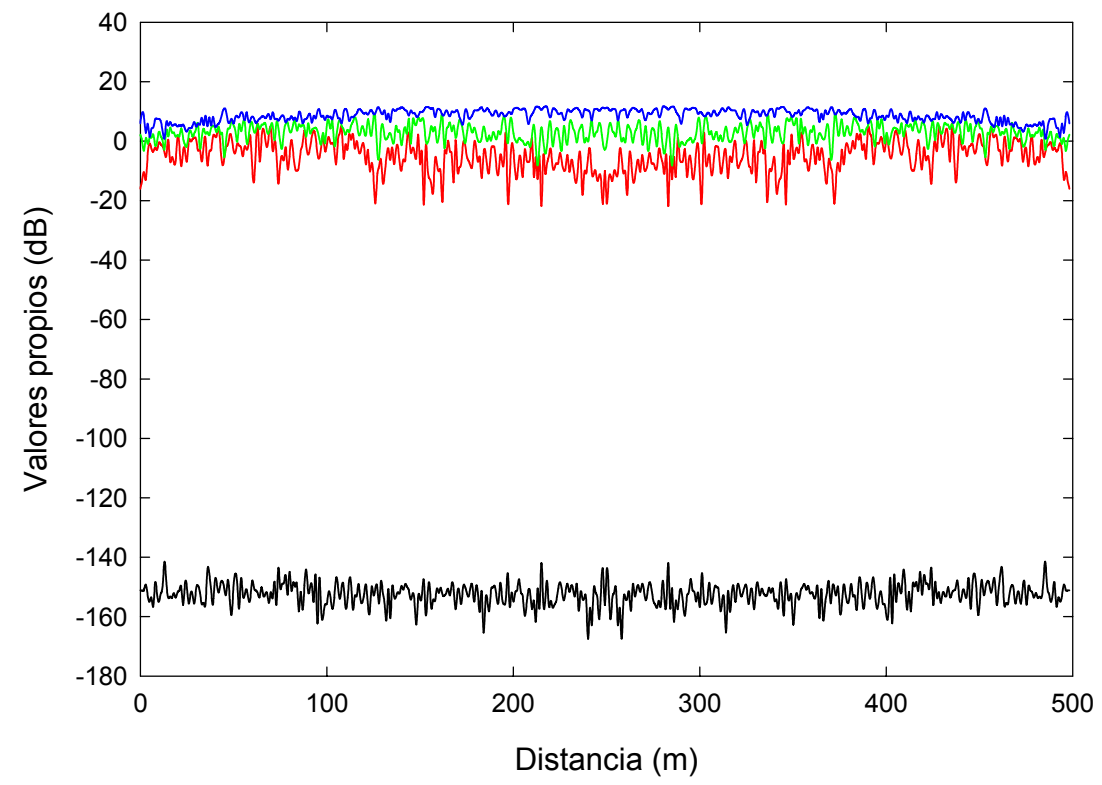

Figura 4.36: Valores propios de la matriz $M I M O$ entre dos estaciones en un entorno urbano en función de la posición para la configuración I.

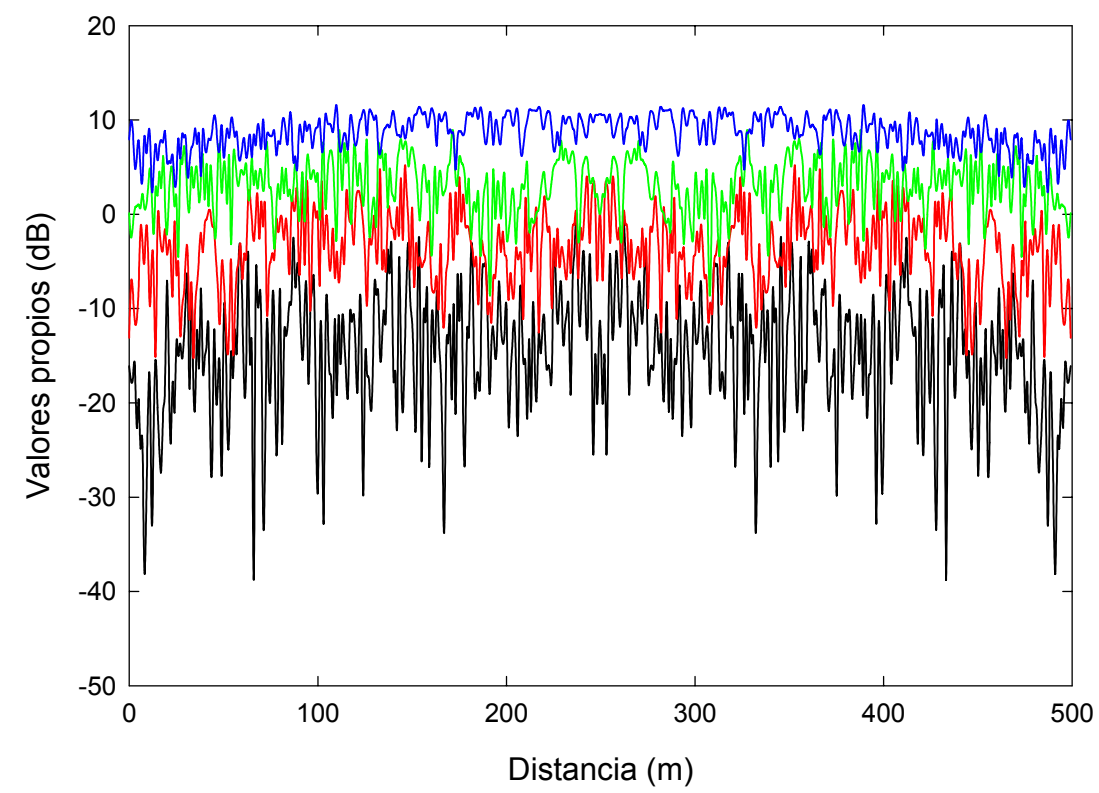

Figura 4.37: Valores propios de la matriz $M I M O$ entre dos estaciones en un entorno urbano en función de la posición para la configuración II. 
El valor medio de las pérdidas en el entorno urbano utilizando la configuración I es de $66 \mathrm{~dB}$ con una desviación típica de $5.6 \mathrm{~dB}$. Para la configuración II, las pérdidas medias son de $71 \mathrm{~dB}$ y la desviación típica de $6 \mathrm{~dB}$.

\subsubsection{Discusión}

En este trabajo se ha utilizado el trazado de rayos para estudiar en una zona rural y en una microcelda el rendimiento de los sistemas distribuidos. Estos consisten en utilizar más de una estación base simultáneamente para incrementar la diversidad. Las ventajas son un aumento de la capacidad, un menor número de antenas en las estaciones base y un handover más suave La contrapartida es un procesado de la señal más complejo, debido a la sincronización y a la macrodiversidad.

Para realizar el análisis se ha utilizado un modelo a dos rayos para el entorno rural y el modelo descrito en el capítulo 2.2 para analizar el entorno urbano.

En el entorno rural la capacidad aumenta de 6.8 a $10.5 \mathrm{bps} / \mathrm{Hz}$ utilizando los sistemas distribuidos (para un canal $4 \times 4$ ). Para un entorno urbano, la capacidad aumenta de 16.3 a 18.5 bps/Hz. Mediante el estudio de los valores propios, se observa que el valor propio más pequeño aumenta de potencia al aumentar la macrodiversidad.

Este trabajo se puede extender aumentando el número de estaciones base, obteniendo una reducción del número de antenas igual a ese número. 



\section{Capítulo 5}

\section{Sistema de Medidas para Canales MIMO}

Los sistemas actuales y futuros necesitan una alta capacidad de transmisión de datos en el enlace radio. A partir de los trabajos realizados por Foschini [Fos96] y Telatar [Te199] se sabe que, aumentando el número de antenas tanto en el lado del transmisor como en el del receptor, se puede aumentar la eficiencia espectral en términos de bps/Hz. Estos sistemas toman el nombre en inglés de Multiple-Input Multiple-Output Systems (MIMO) (ver apéndice D).

Por otro lado, la medida del canal radio es una parte fundamental del estudio del mismo, ya que permite tanto la obtención de datos necesarios para la implementación de 
modelos de propagación como la verificación de los mismos. En [Rap96] se proponen distintas implementaciones para medir la respuesta del canal radio. En concreto, una de ellas consiste en medir la respuesta frecuencial del canal. En el apéndice C se explica el clásico sistema de medidas de banda ancha basado en un analizador de redes, el cual barre el espectro calculando la respuesta en banda estrecha del canal en las frecuencias seleccionadas. Después, transformando la respuesta frecuencial al dominio temporal, se obtiene el perfil de retardo (ver capítulo 2.1.2).

Para realizar medidas $M I M O$ existen diversas implementaciones. En [Lie02] se presenta un sistema de medidas $M I M O$ basado en correladores. En [Med] se presenta el conocido RUSK BRI que mide el canal MIMO mediante un sistema de múltiplexación $R F$ de alta velocidad tanto en el transmisor como en el receptor. Este sistema tiene el inconveniente de ser excesivamente caro (sobre los 600.000€ en el año 2004). En [Bau00] se utiliza un sistema de medidas basado en el barrido de frecuencia. Un sistema de medidas de banda estrecha se presenta en [Chi03]; otro sistema de medidas basado en multitonos en [Sak02]; y en [San04], se presenta un sistema MIMO de banda ancha basado en correladores de señal chirp.

En este capítulo se propone un montaje de medidas de relativo bajo coste, basado en dos analizadores de redes para sistemas de múltiples antenas (MIMO). También se muestran las medidas iniciales tomadas con este equipo de medidas [Mol04g,Cel04].

\subsection{Descripción del equipo de medidas}

El principio de funcionamiento de este sistema de medidas es el mismo que el del equipo de medidas del apéndice $\mathrm{C}$, es decir, se basa en el barrido del espectro utilizando un analizador de redes. La diferencia fundamental se encuentra en la utilización de dos analizadores de redes (en lugar de uno), de tal forma que en cada uno de ellos las señales se mutiplexan en el tiempo para medir la respuesta para cada combinación de antenas. Es decir, se independiza el transmisor del receptor, a diferencia del montaje del apéndice $\mathrm{C}$ donde ambos se encuentran en el mismo analizador de redes. La figura 5.1 recoge el montaje del sistema de medidas. 


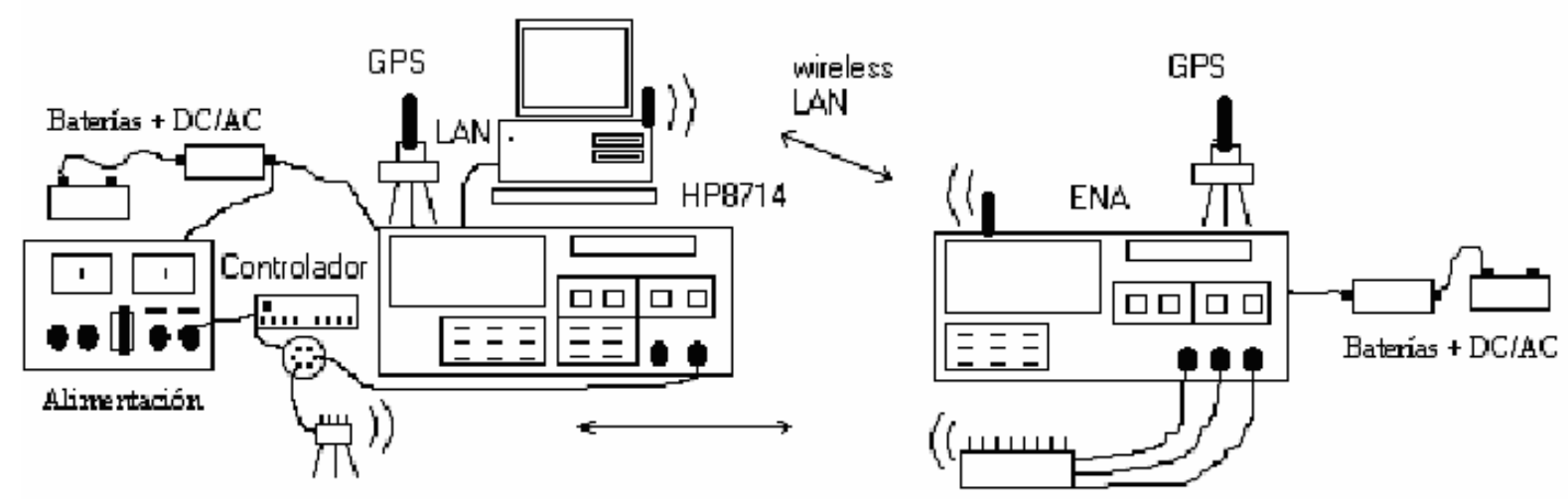

Figura 5.1: Diagrama de bloques del equipo de medidas MIMO.

A continuación, se describen las partes de las que está formado dicho sistema de medidas:

\subsubsection{Analizador de redes multipuerto ENA}

El primer elemento es un analizador de redes multipuerto (figura 5.2). Este analizador se diferencia de los tradicionales en que dispone de más de dos puertos, de tal forma que es capaz de leer simultáneamente la señal de todos los puertos (antenas receptoras) cuando transmite una de las transmisoras. Es el receptor del sistema de medidas, de tal forma que mide las señales de las antenas receptoras y captura los resultados en ficheros de texto de forma ordenada y controlada remotamente por un $P C$. El analizador elegido puede disponer de hasta 16 puertos, aunque el analizador de la figura consta de 7 puertos.

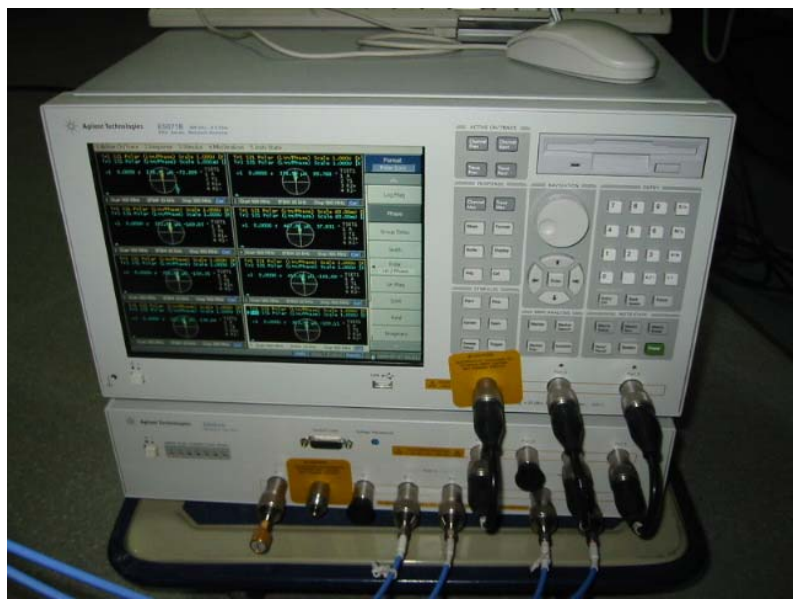

Figura 5.2: Foto del analizador de redes multipuerto. 


\subsubsection{Analizador de redes HP8714}

Este elemento es un analizador de redes tradicional, que va a actuar como transmisor (figura 5.3). Como los analizadores tradicionales, dispone únicamente de dos puertos, aunque el montaje solo necesita uno de ellos. A la salida del puerto se conecta un conmutador de estado sólido que se describe a continuación para dotar al sistema de múltiples antenas en transmisión. Otra opción es la sustitución de este analizador de redes por un generador de señal con barrido, que es el mismo transmisor del que dispone internamente un analizador de redes.

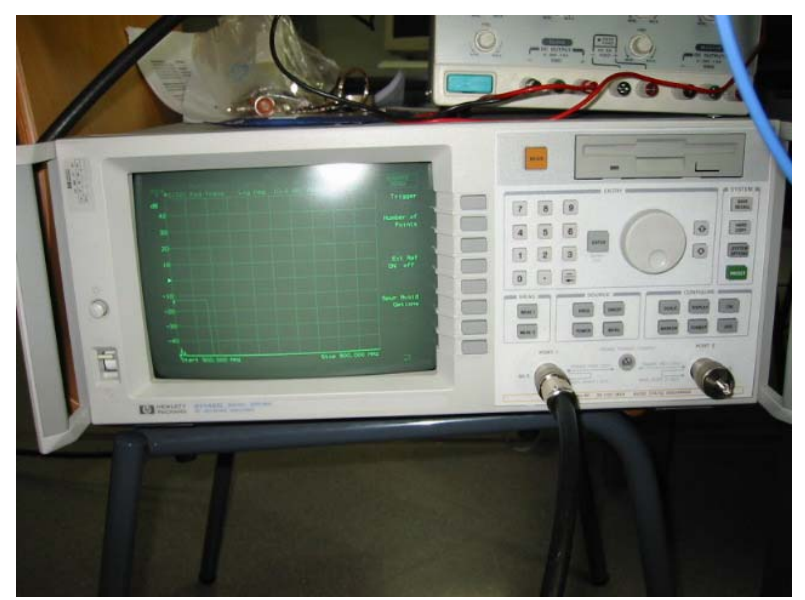

Figura 5.3: Foto del analizador de redes convencional.

\subsubsection{Controlador y conmutador}

En la salida del HP8714 se coloca un conmutador de estado sólido que permite repartir la señal de salida entre tantas antenas como se desee. En concreto, el montaje realizado permite hasta 5 antenas transmisoras. Utilizando más conmutadores se puede aumentar este número configurándolos en cascada. El conmutador elegido es el Agilent $87606 B$, que se controla a partir del controlador Agilent $11713 \mathrm{~A}$ mediante una conexión GPIB (figura 5.4).

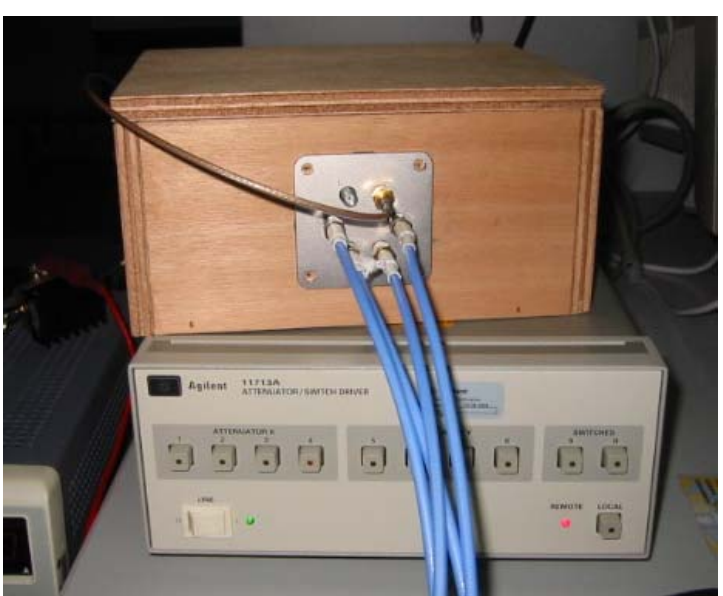

Figura 5.4: Conmutador y controlador de conmutador. 


\subsubsection{GPS Thunderbolt Disciplined Clock Start Kit y antena BULLET III}

Para sincronizar los dos analizadores de redes es necesaria una señal de referencia a $10 \mathrm{MHz}$ muy estable que fije el funcionamiento interno de cada uno de los analizadores. Esta referencia se puede obtener mediante: relojes de rubidio, interconectando los equipos mediante un cable coaxial o mediante una señal de $10 \mathrm{MHz}$ disciplinada por un GPS. Es esta última configuración la que se ha utilizado para la sincronización. De esta forma es posible separar ambos analizadores sin necesidad de cables, ya que quedan perfectamente sincronizados.

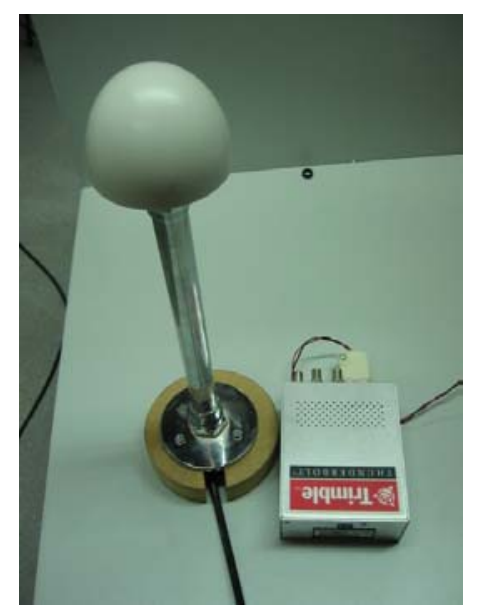

Figura 5.5: Oscilador de $10 \mathrm{MHz}$ disciplinado por un GPS.

\subsubsection{Ordenador portátil}

El control de todo el sistema se realiza a partir de un $P C$. Este permite el control de los dos analizadores junto con el conmutador, de manera que se puedan configurar y calibrar los analizadores así como tomar medidas de manera remota. El $P C$ se conecta al HP8714 mediante una red LAN, al ENA mediante una red WLAN y al conmutador mediante $G P I B$. Los datos obtenidos son almacenados en el $E N A$, ya que éste incorpora un $P C$ interno, y de esta forma no se sobrecarga la red $W L A N$.

\subsubsection{Antenas}

Las antenas utilizadas variarán en función del estudio que se quiera realizar, pudiendo incorporar tantas como acepte el conmutador en transmisión y el ENA en recepción. Además son necesarias dos antenas para la conexión inalámbrica entre el $P C$ 
y el $E N A$, de manera que estos puedan estar separados para la realización de medidas entre lugares distanciados. Estas antenas funcionan bien a $2.4 \mathrm{GHz}$ (IEEE 802.11b) o a $5.5 \mathrm{GHz}($ IEEE 802.11a).

\subsubsection{Cables y transiciones}

Se utilizan cables para conectar los puertos de los analizadores a las antenas, de tal forma que todas las antenas estén conectadas simultáneamente. Será necesario calibrar todos los cables para la toma de las medidas.

\subsubsection{Baterías y convertidores de corriente}

Con el fin de conseguir una autonomía de los equipos que permita la toma de medidas en lugares donde no se pueden alimentar, las baterías ofrecen la potencia necesaria para asegurar el funcionamiento de los mismos mientras dure la campaña de medidas, utilizando convertidores en función de la corriente que necesite cada uno.

\subsection{Proceso de medida}

El proceso de medidas está totalmente controlado por un $P C$, y automatizado mediante un programa en Visual Basic. Inicialmente el proceso se ha programado para la toma de medidas en onda continua ( $\mathrm{CW}$ módulo y fase), y como futura línea de trabajo se extenderá a banda ancha. Esta extensión pasa por sincronizar una señal de disparo en ambos equipos de tal forma que barran el espectro de forma simultánea. El proceso de medida se ha dividido en tres pasos (figura 5.6): el primero es la configuración de los equipos, el segundo la calibración de los cables y conectores del sistema de medida y por último la adquisición propia de las medidas. 


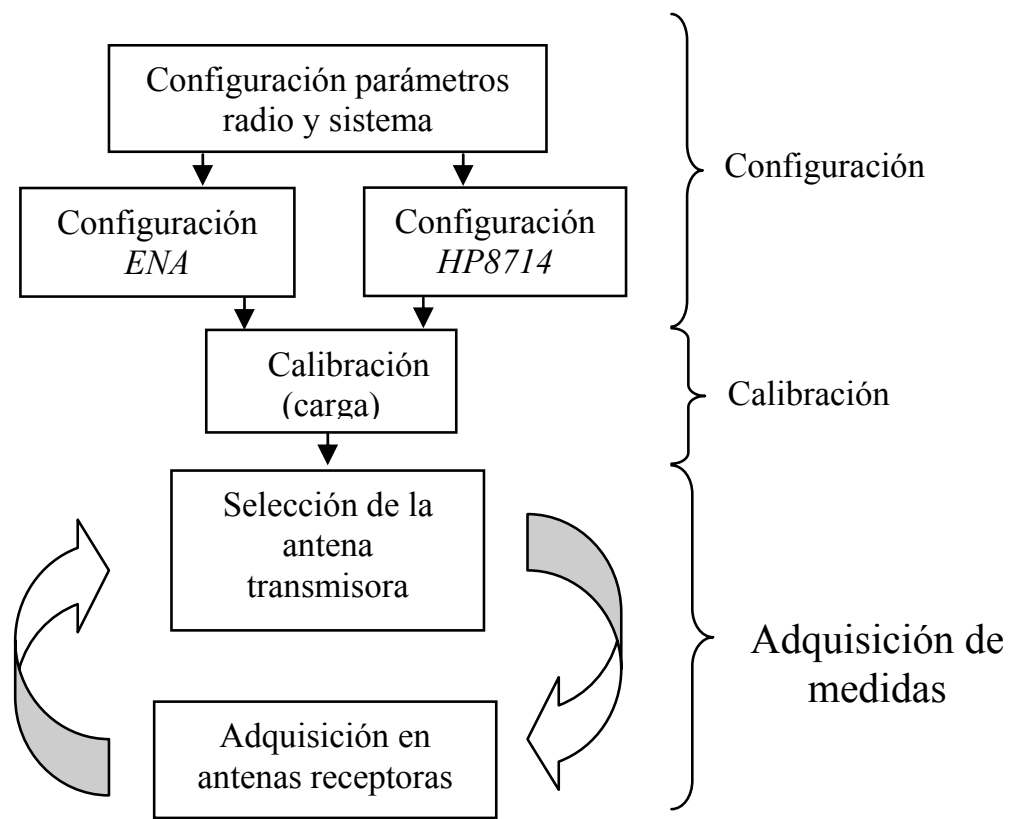

Figure 5.6: Diagrama de bloques del proceso de medida MIMO.

\subsubsection{Configuración del sistema}

La configuración consiste en establecer los parámetros radio y del sistema para el proceso de medidas. Los principales parámetros radio son la frecuencia central, el número de puntos $(N)$ en los que se va a hacer el muestreo y el ancho de banda a medir. En el caso de medidas en $C W$, el ancho de banda es muy pequeño. Otros parámetros radio son: el ancho de banda en la frecuencia intermedia que controla el umbral del ruido y el tiempo de barrido, que controla el tiempo necesario en adquirir los $N$ puntos.

Los parámetros del sistema son básicamente el número de antenas transmisoras y el número de antenas receptoras. Estos parámetros y los anteriores se configuran con el $P C$ bien vía $L A N$ o $W L A N$.

\subsubsection{Calibración}

Durante el proceso de medidas las antenas se conectan a ambos analizadores utilizando cables, amplificadores y conectores. Éstos introducen atenuación y cambios de fase (debidos a la propagación de la señal por el cable).

La calibración se realiza de tal modo que el puerto del ENA que se utiliza como referencia para medir los parámetros $S$, esté configurado con la misma potencia de salida que el puerto que se utiliza en transmisión en el HP8714. De esta forma se podrá calibrar utilizando únicamente el ENA para cada par de cables, uno del transmisor y otro del 
receptor. Después se cambiará el cable del transmisor desde el ENA al HP8714. Evidentemente se tendrá un error de fase constante entre el oscilador de $10 \mathrm{MHz}$ del $E N A$ y el oscilador del HP8714. Este error no es importante ya que todos los canales que se midan van a tener el mismo desfase.

Los archivos de calibración se almacenan en el ENA para la toma posterior de medidas utilizando idéntica configuración. Este proceso se controla automáticamente desde el $P C$.

\subsubsection{Adquisición de medidas}

La adquisición de las medidas empieza con la selección de la primera antena transmisora, a continuación el ENA almacena las señales capturadas por cada una de las antenas receptoras, o dicho de otra forma, las señales capturadas en cada uno de los puertos del equipo receptor. Después de esto, se conmuta a la siguiente antena transmisora y así sucesivamente. La figura 5.7 presenta un esquema temporal de la conmutación del proceso de medida. Este proceso se repite tantas veces como se haya definido en el proceso de medidas. Es importante señalar que el ENA permite leer todos los puertos simultáneamente, haciendo que el proceso de medida sea mucho más rápido. La figura 5.8 muestra una pantalla capturada del ENA en un proceso de medidas.

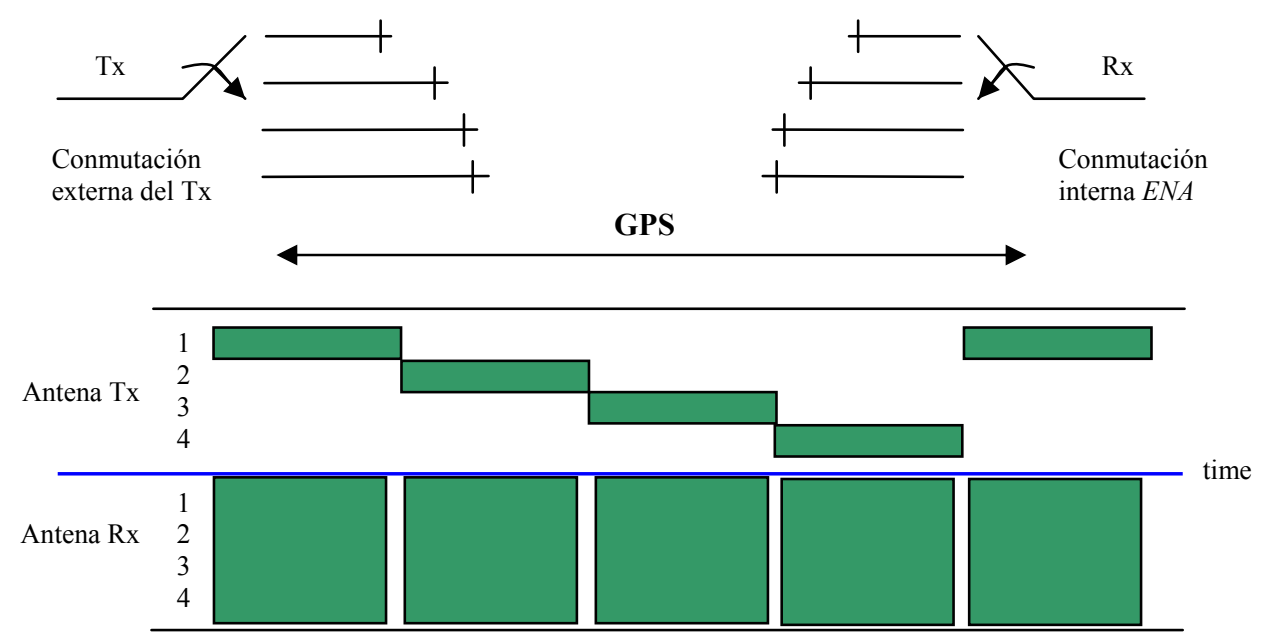

Figura 5.7: Principio básico de medida secuencial del canal MIMO. 


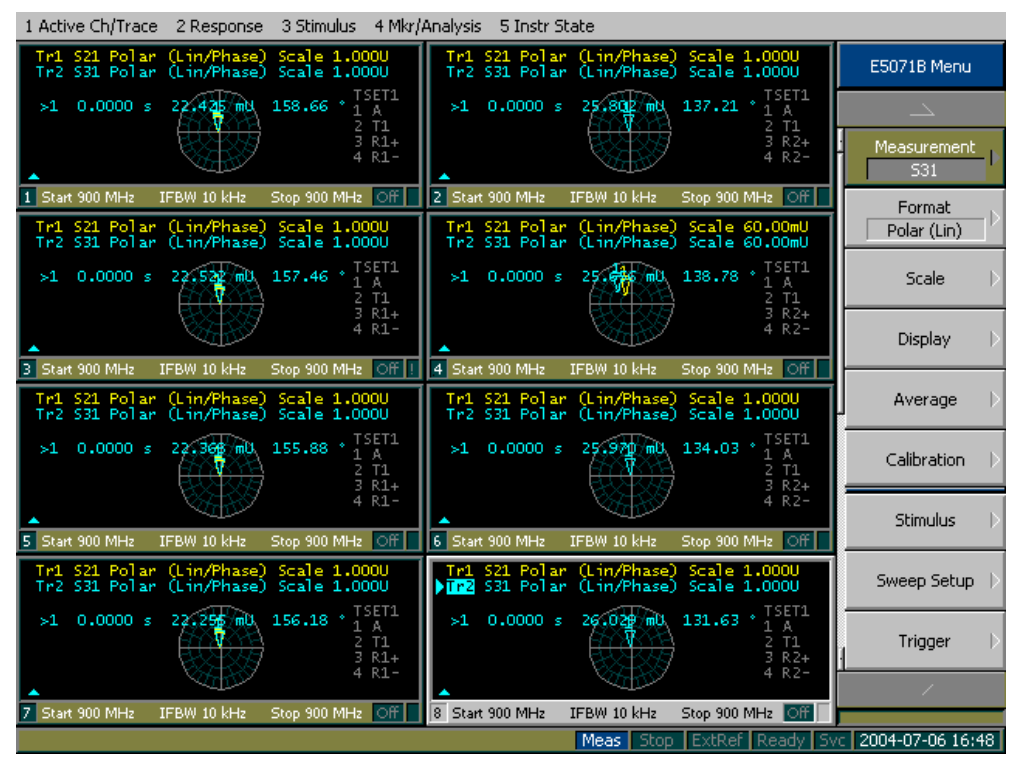

Figura 5.8: Pantalla capturada del analizador de redes multipuesto.

\subsection{Medidas iniciales}

\subsubsection{Medidas en el laboratorio}

Aquí se presentan las primeras medidas que se realizaron para comprobar el funcionamiento del equipo de medidas en uno de los laboratorios de la universidad [Cel04]. Se han utilizado dos antenas en transmisión y otras dos en recepción. Las antenas transmisoras son una antena colineal de UMTS y una antena de panel también de UMTS. En recepción se han utilizado dos antenas bicónicas (apartado C.3.4) de banda ancha, cuyas frecuencias de funcionamiento van desde $500 \mathrm{MHz}$ hasta $3 \mathrm{GHz}$.

Se ha elegido la frecuencia de $2 \mathrm{GHz}$ como portadora $(C W)$, y se han obtenido 201 puntos en cada iteración. Se realizaron hasta 10 iteraciones en las pruebas. La figura 5.9 a) muestra la magnitud medida para cada uno de los elementos de las 201 primeras matrices $\mathbf{G}$, y la figura 5.9 b) la fase. Se observa que hay una cierta oscilación debido a la aleatoriedad del canal, y los saltos bruscos de fase se deben a que la fase es periódica cada $360^{\circ}$.

Con esta información, la figura 5.10 a) muestra la capacidad para las primeras 201 matrices $2 \times 2$ capturadas durante las medidas. Se observa que, aunque las medidas se tomaron en una situación LoS a 2 metros de distancia, la capacidad es bastante elevada debido a la rica dispersión en la sala. En la figura 5.10 b) se ha representado la función CCFD de la capacidad anterior para el sistema 2x2 descrito anteriormente. Los cálculos de capacidad se han realizado para una SNR de $20 \mathrm{~dB}$. 

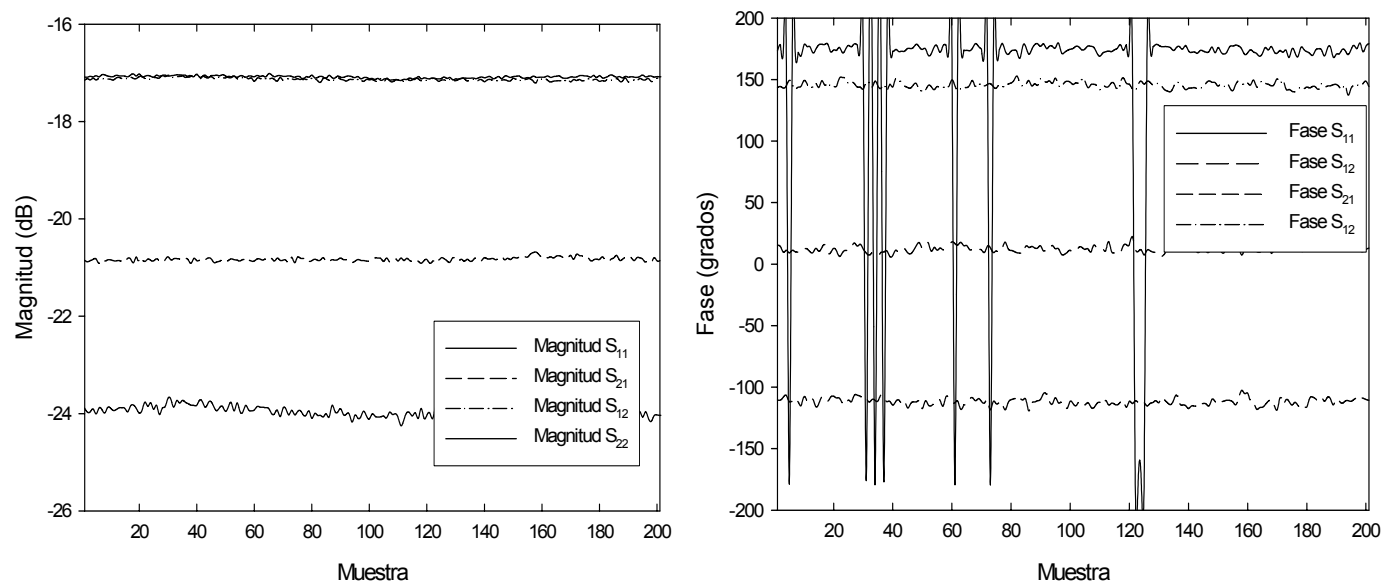

Figura 5.9: a) Magnitud y b) fase de los cuatro elementos de la matriz $\mathbf{G}_{2 \times 2}$ medida en el laboratorio.
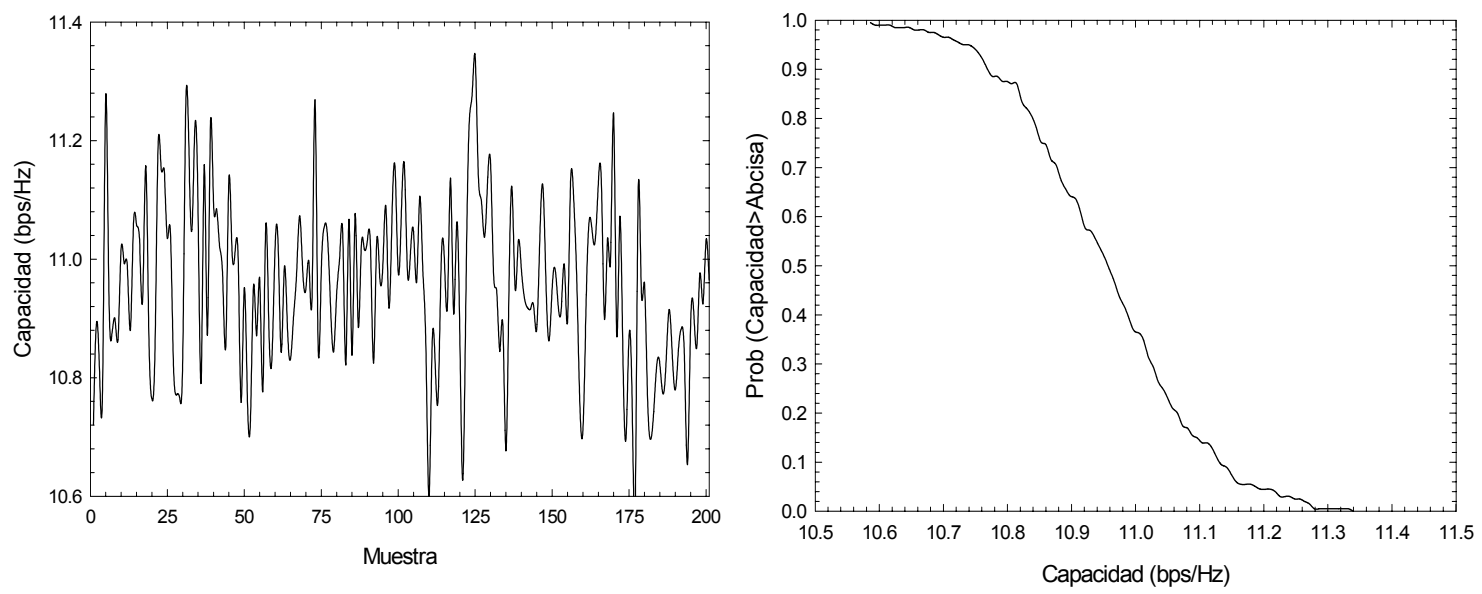

Figura 5.10: a) 201 muestras de la capacidad y b) CCDF de la capacidad de un sistema MIMO $2 \times 2$ medido en una habitación a $2 \mathrm{GHz}$.

\subsubsection{Medidas en el patio de la universidad}

Las siguientes medidas fueron tomadas en uno de los patios de la Universidad Politécnica de Cartagena [Mol04g]. Se construyeron dos arrays con cuatro monopolos (apéndice C), cada uno de ellos sintonizado a $900 \mathrm{MHz}$ sobre un plano de masa, y los elementos se separaron $\lambda / 4$. De las cuatro antenas del transmisor, sólo se utilizaron simultáneamente dos antenas en cada medida, y se consideraron dos espacios entre elementos: $\lambda / 4$ (dos antenas consecutivas) $3 \lambda / 4$ (las dos antenas de los extremos).

La figura 5.11 muestra una foto del patio donde se realizaron las medidas y la figura 5.1 una vista en planta del mismo. El transmisor se colocó en Tx, los receptores en diez posiciones (Rx1-Rx10) y la orientación de todos los arrays según viene indicada en la figura 5.12. 


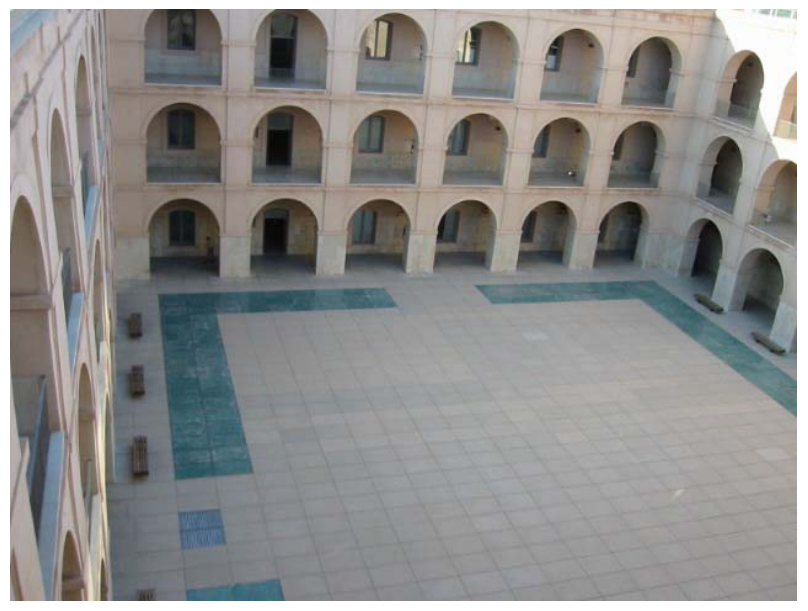

Figura 5.11: Fotografía del patio donde se tomaron las medidas.

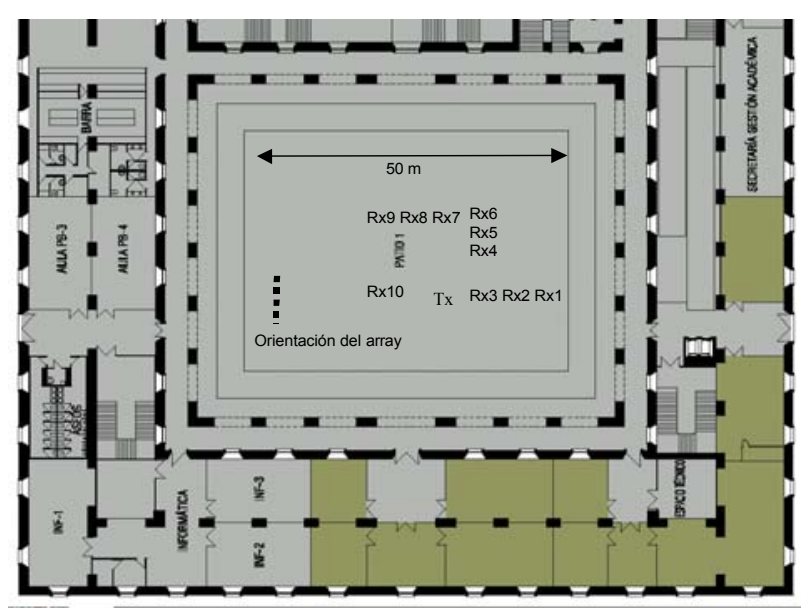

Figura 5.12: Planta del patio donde se tomaron las medidas.

Los parámetros radioeléctricos fueron: frecuencia central $900 \mathrm{MHz}$, ancho de banda intermedia $10 \mathrm{KHz}, 201$ puntos y tiempo de barrido $26 \mathrm{~ms}$. En cada posición se tomaron dos medidas, una con los dos elementos en transmisión separados $\lambda / 4$ y otra medida con los elementos separados $3 \lambda / 4$ (tal y como se ha explicado previamente). El nivel de ruido término se situó a $-95 \mathrm{~dB}$ después de la calibración. En la figura 5.13 se observan sendas fotos de los equipos transmisores y receptores. 

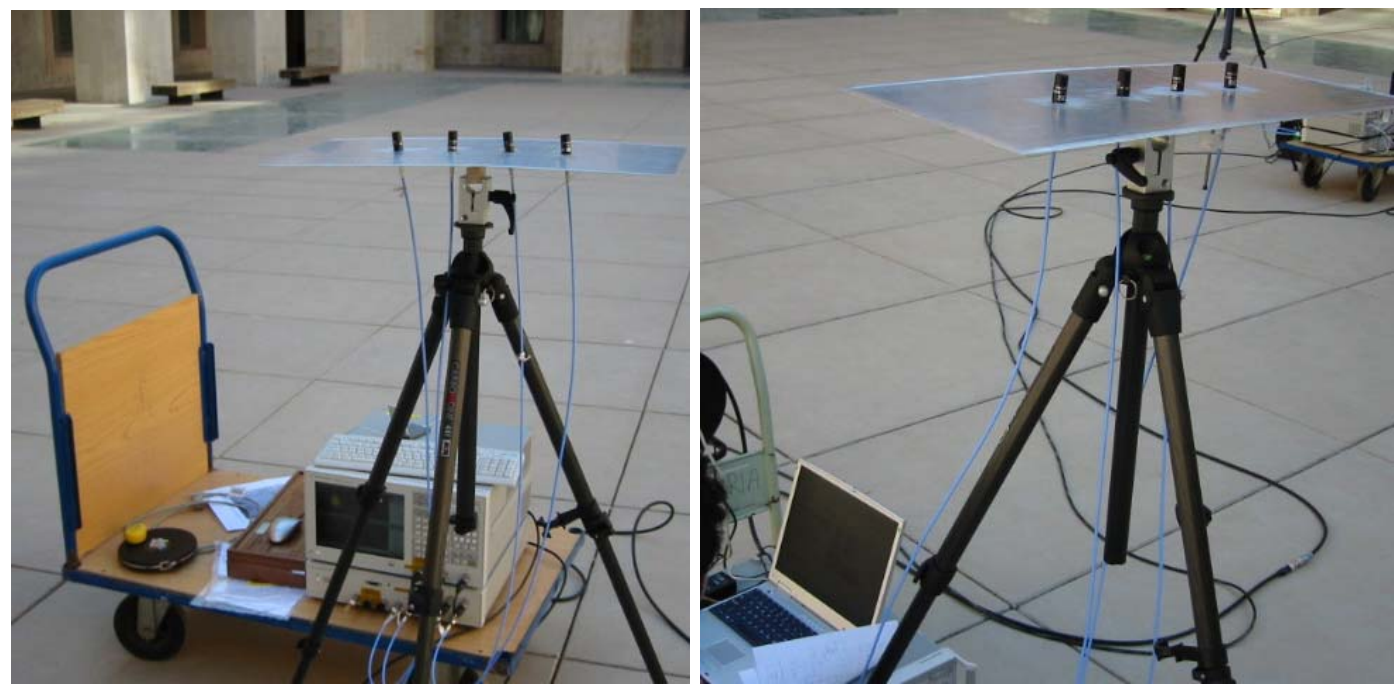

Figura 5.13: a) Receptor y b) transmisor del sistemas de medidas MIMO.
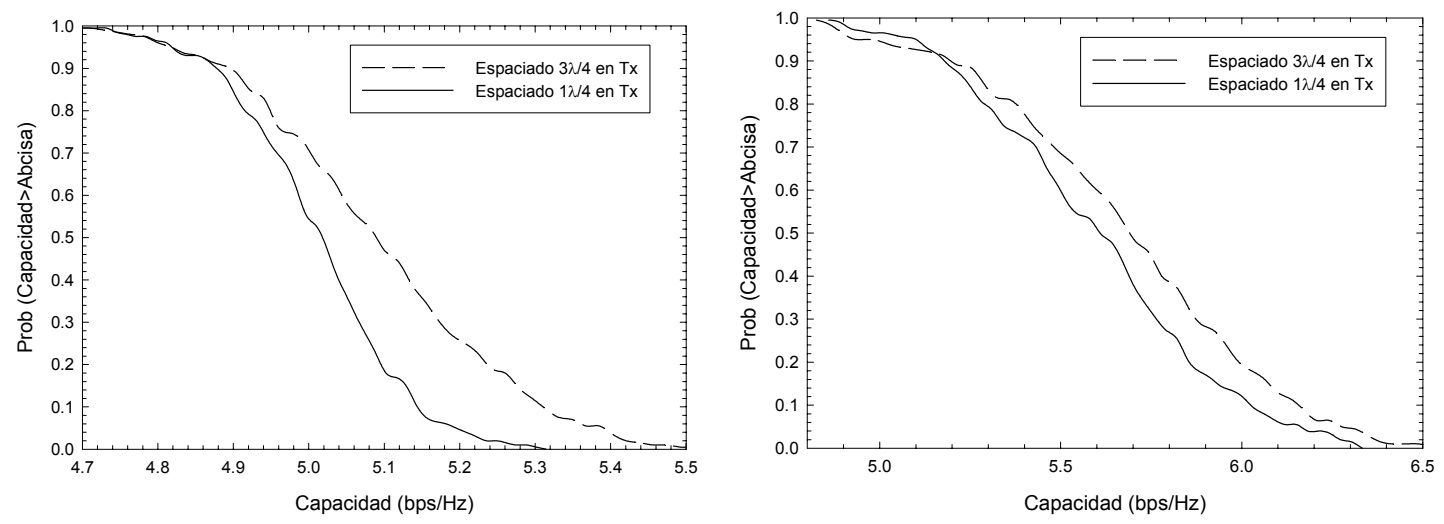

Figure 5.14 Curvas CCDF de la capacidad para el sistema MIMO 4x2 en los puntos a) Rx6 y b) $\mathrm{Rx} 9$.

La figura 5.14 muestra las curvas obtenidas en las posiciones Rx6 y Rx9 del sistema 4x2 MIMO. Las matrices fueron normalizadas en cada posición (Norma de Frobenius sobre las 201 matrices). La SNR se fijó a 10 dB en todos los casos. Se observa que la capacidad en ambos casos está alrededor de los $5 \mathrm{bps} / \mathrm{Hz}$.

\subsubsection{Nuevas medidas en el laboratorio}

Las últimas medidas fueron tomadas a $900 \mathrm{MHz}$ en el mismo laboratorio que las primeras medidas. Se utilizaron los mismos cuatro monopolos en transmisión y los otros cuatro en recepción. Unas fotos del entorno se presentan en la figura $5.15 \mathrm{y}$ un croquis en la figura 5.16 El transmisor fue colocado en $\mathrm{Tx}$, y el receptor en 27 posiciones diferentes (Rx1-Rx27) . El ancho de banda de la frecuencia intermedia fue $10 \mathrm{KHz}$, el número de puntos 201, y el tiempo de barrido a $28 \mathrm{~ms}$. El ruido en el entorno de medidas 
era -110 dB después del proceso de calibración (se utilizo un amplificador de $20 \mathrm{~dB}$ para aumentar el rango dinámico, apéndice C.2.3).
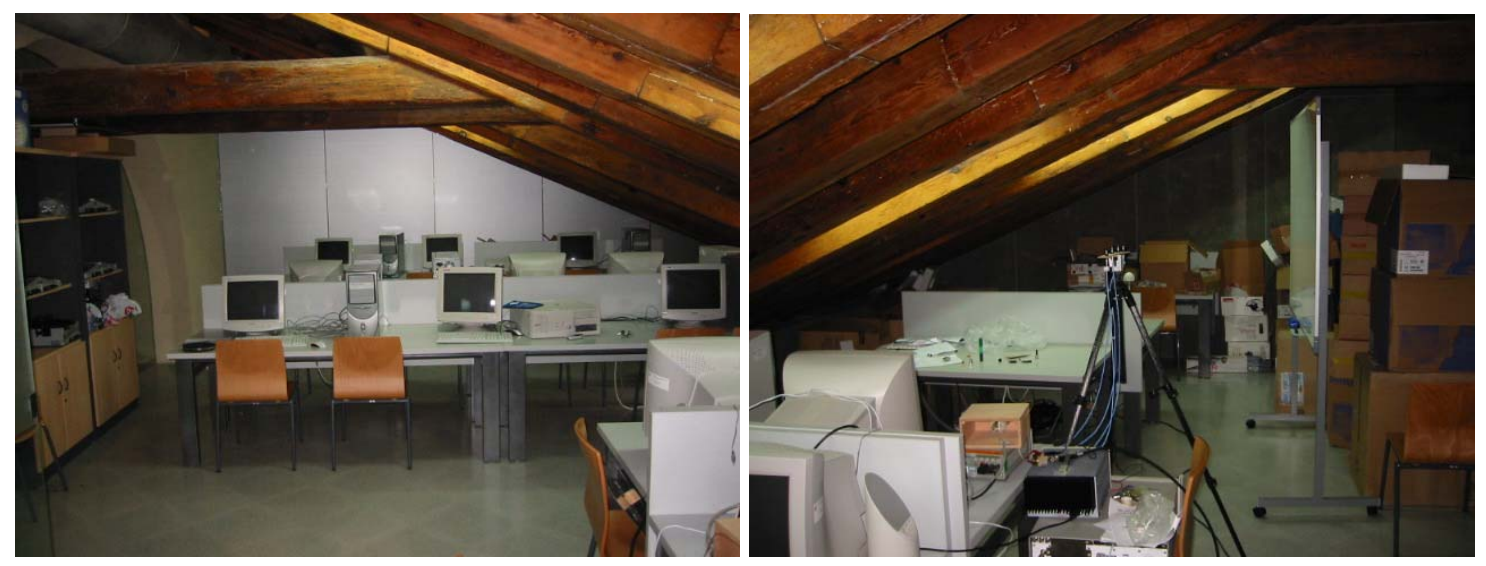

La figura 5.15: Fotos del laboratorio donde se realizaron las medidas.
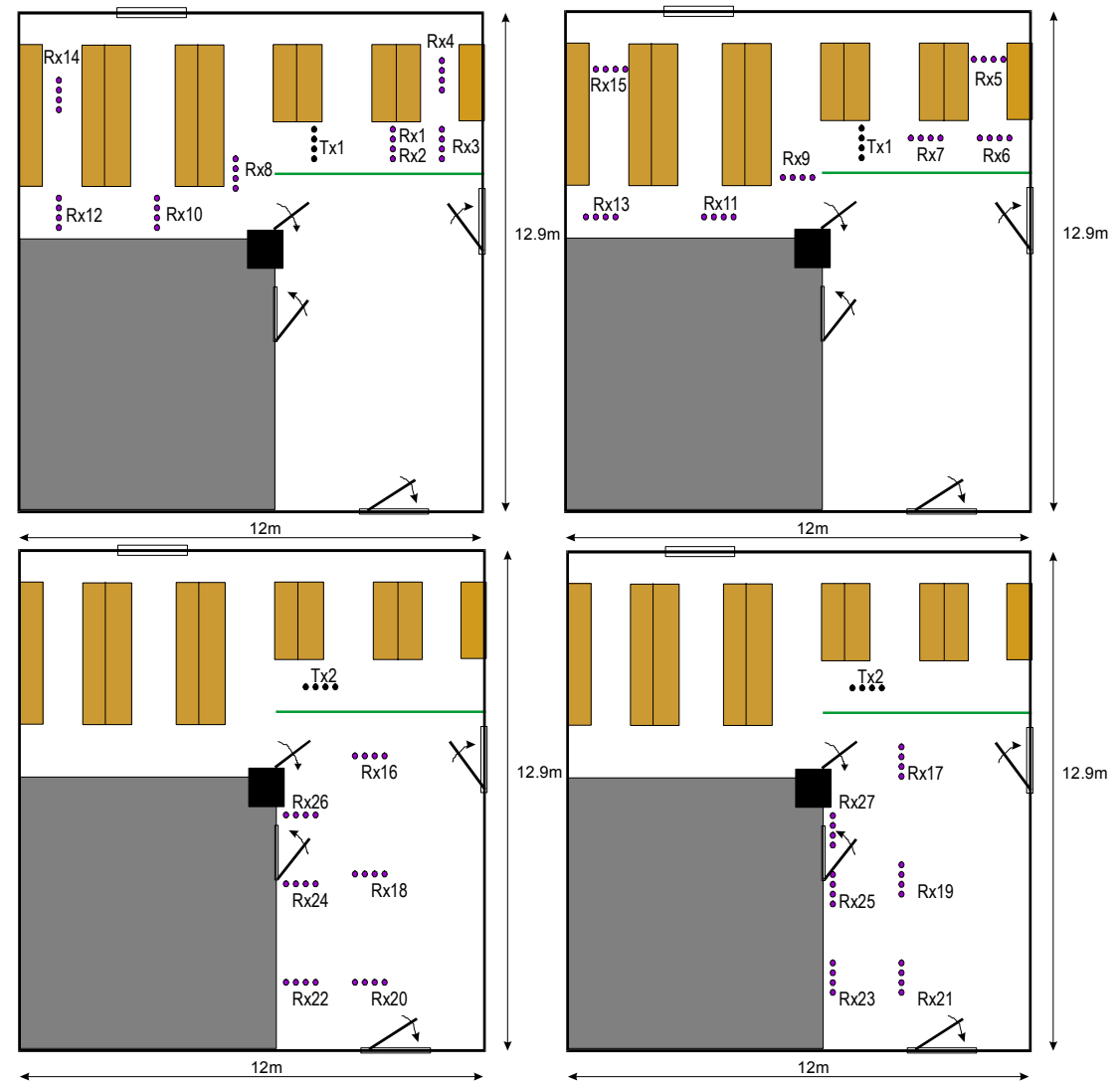

Figura 5.16: Croquis de la planta de la habitación y situación de las antenas.

Los croquis de la figura 5.16 muestran dos disposiciones de los arrays, vertical y horizontal. Los 27 receptores se han distribuido en 4 croquis según sus orientaciones para facilitar la comprensión. Para cada posición del receptor se tomaron medidas con las dos disposiciones. Las medidas desde Rx1 hasta Rx15 fueron tomadas en la misma 
habitación que el transmisor con este orientado verticalmente. Desde Rx16 hasta Rx27 las medidas se tomaron en la habitación contigua, separada por una pared de vidrio, y el array transmisor se colocó en posición horizontal. La medida Rx1 se tomó sin transmitir nada para medir el ruido (en este caso coincide con el rango dinámico), y las medidas $\mathrm{Rx} 22-\mathrm{Rx} 27$ son situaciones $N L o S$ ya que una columna bloquea la contribución directa.

La figura 5.17 muestra la capacidad de las 5427 muestras (27 receptores y 201 muestras por receptor). Se ha fijado la $S N R$ a $20 \mathrm{~dB}$, y se ha normalizado en grupos de 201 muestras, es decir, en cada posición. Se observa que la capacidad del primer punto es muy alta ya que lo único que se mide es ruido. Realmente es una capacidad ficticia, ya que la SNR era muy baja y se tomaron $20 \mathrm{~dB}$. Las capacidades de los últimos puntos son más elevadas que el resto ya que las antenas están en situación $N L o S$, y la dispersión angular es mayor.

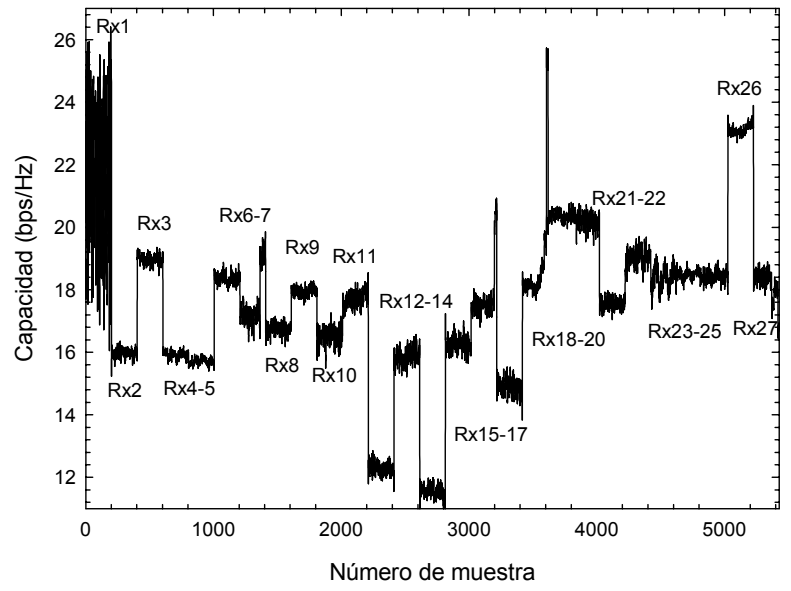

Figura 5.17: Capacidad de los 27 receptores (201 muestras por receptor).

\subsection{Discusión}

Se ha desarrollado un sistema de medidas para medir el canal de comunicaciones de sistemas de múltiples antenas. Está basado en dos analizadores de redes, que controlados mediante un $\mathrm{PC}$, son capaces de tomar medidas MIMO para un número elevado de antenas tanto en transmisión como en recepción. Los elementos principales del sistema son un analizador convencional, un analizador multipuerto, un conmutador de estado sólido y un $P C$. La comunicación entre todos los elementos se centraliza en el PC, que se comunica vía $W L A N$ con el analizador multipuerto, vía $L A N$ con el analizador convencional y vía GPIB con el controlador del conmutador de estado sólido. 
También se han presentado medidas iniciales, tomadas utilizando dicho sistema a $2 \mathrm{GHz}$ en una sala de la universidad, y medidas a $900 \mathrm{MHz}$ en un patio de la universidad y en la misma sala de la universidad. 



\section{Capítulo 6}

\section{Conclusiones}

La calidad de las comunicaciones vía radio depende estrechamente del tipo de entorno de propagación. En este sentido, es necesario el estudio de la propagación en entornos microcelulares y entornos especiales ya que la sociedad demanda cada vez más el uso de las comunicaciones inalámbricas en estos entornos. Por otro lado, la sociedad demanda altas transferencias de información vía radio. Las comunicaciones de banda ancha permiten aumentar la capacidad del enlace de forma proporcional al ancho de banda utilizado, con lo que se necesita estudiar de forma detallada estos sistemas para cada uno de los entornos nombrados anteriormente.

Las prestaciones de una nueva tecnología llamada MIMO (Múltiple-Input Múltiple-Output), auguran aumentos importantes de la eficiencia espectral (bps/Hz) de los sistemas inalámbricos. Este sistema utiliza múltiples antenas a ambos lados de la comunicación, y a partir de una alta decorrelación del canal en ambos extremos del enlace, se puede incrementar de forma lineal con el número de antenas la tasa de transmisión para un ancho de banda dado. 
El objetivo de esta tesis ha sido el estudio tanto teórico como experimental del canal radio en entornos microcelulares y especiales como túneles. Teórico en la medida en que desarrolla modelos eficientes de canal para sistemas de banda ancha y sistemas MIMO. Y experimental ya que se toman de medidas reales en estos entornos y la comparación con los modelos anteriores.

\subsection{Conclusiones}

La primera contribución de la presente tesis ha sido el desarrollo de modelos teóricos para el análisis de sistemas de banda ancha y sistemas MIMO basados en la Óptica Geométrica y la Teoría Uniforme de la Difracción (capítulo 2). Se ha partido de un trazador de rayos capaz de analizar un canal determinista de banda estrecha. El modelo de banda ancha se basa en la discretización de la respuesta frecuencial en $N$ canales de banda estrecha para poder aplicar el trazador original. Esta respuesta frecuencial se transforma en el dominio del tiempo mediante la transformada inversa de Fourier. Por otro lado, se ha extendido el trazador a sistemas MIMO de tal modo que el simulador es capaz de reconstruir la matriz de transferencia MIMO simulando los canales entre las antenas transmisoras y receptoras. Y por último, se ha desarrollado un modelo de canal, que a partir de una simple realización SISO reconstruye el canal MIMO mediante el estudio de los diversos mecanismos de propagación.

Esta tesis también ha contribuido al estudio de la propagación en túneles (capítulo 3). Primeramente desde un punto de vista teórico, se ha estudiado mediante el trazado de rayos la dispersión espacial en la transición de entrada a un túnel ideal. Se concluyó que en esta zona la dispersión angular tiene un máximo al principio de la zona de excitación, a diferencia de la dispersión temporal que la tiene al final de la misma. Se estudió la longitud de esta zona de excitación en diferentes túneles mediante dos métodos: uno matemático y otro físico. El matemático, aproxima las pérdidas de propagación a dos rectas y minimiza el error entre los datos y ambas rectas; y el físico,

aplica la definición de zona de excitación, en la que los rayos reflejados superan a los difractados. Se concluyó que los resultados de ambos métodos son satisfactorios y extremadamente similares.

También se han tomado medidas de banda ancha en un pequeño túnel en el campus de la Universidad Politécnica de Cartagena. Estas medidas se compararon con el modelo de banda ancha de trazado de rayos, dando resultados satisfactorios. Y por 
último, se ha estudiado de forma teórica la capacidad de un sistema $M I M O$ en el interior de un túnel. Se ha observado que la capacidad toma un valor máximo a la entrada, donde la dispersión angular en el receptor es máxima, y a medida que el receptor se separa de la entrada, existe una distancia a partir de la cual esta capacidad disminuye significativamente, y que está relacionada directamente con la zona de excitación del túnel.

La siguiente contribución de la tesis ha sido el estudio de la propagación en los entornos microcelulares. Primeramente, se ha utilizado el trazado de rayos para estudiar el comportamiento radioeléctrico en dos entornos microcelulares: un cruce con cuatro esquinas y otro con cuatro chaflanes. Se ha observado que la dispersión del retardo toma valores mayores en los cuatro chaflanes. Se han tomado medidas utilizando un analizador de redes para modelar y comparar estos dos entornos microcelulares a 450 $\mathrm{MHz}, 900 \mathrm{MHz}, 1800 \mathrm{MHz}$ y $2400 \mathrm{MHz}$. Se han distinguido dos situaciones de propagación diferentes para cada entorno y frecuencia: $L o S$ y $N L o S$. En concreto se ha estudiado la dispersión del retardo, la correlación en frecuencia, líneas de retardo con 6 elementos y el ancho de banda de coherencia.

También se ha estudiado la capacidad teórica $M I M O$ en estos dos entornos microcelulares urbanos. Se ha estudiado la disposición óptima de los arrays y el comportamiento de la capacidad al girar una esquina en los dos entornos anteriores. El siguiente trabajo en esta línea ha sido aplicar el modelo que extiende una realización SISO a una MIMO, explicado en el capítulo 2, en un entorno microcelular real de la ciudad de Murcia. Se ha demostrado que para distancias cortas, este modelo da lugar a resultados más exactos que el modelo clásico de onda plana.

Y por último, para cerrar este capítulo, se han estudiado los sistemas distribuidos. Estos consisten en utilizar más de una estación base simultáneamente para incrementar la diversidad. Para realizar el análisis se ha utilizado un modelo a dos rayos para el entorno rural y el trazado de rayos para analizar el entorno urbano. En ambos entornos la capacidad aumenta de forma importante cuando se utiliza la distribución de las antenas en la estación base, y se observa que los valores propios más pequeños aumentan.

La última aportación de la tesis se recoge en el capítulo 5. En este se ha desarrollado un sistema de medidas para sistemas de múltiples antenas basado en dos analizadores de redes, que controlados mediante un $P C$, son capaces de tomar medidas MIMO para un número elevado de antenas tanto en transmisión como en recepción. Los elementos principales del sistema son un analizador convencional, un analizador 
multipuerto , un conmutador de estado sólido y un PC. La comunicación entre todos los elementos se centraliza en el $P C$, y se comunica vía $W L A N$ con el analizador multipuerto, vía $L A N$ con el analizador convencional y vía GPIB con el controlador del conmutador de estado sólido. También se han presentado medidas iniciales a $900 \mathrm{MHz}$ y $2 \mathrm{GHz}$ tomadas en la universidad.

\subsection{Futuras líneas de investigación}

Una primera futura línea de investigación sería continuar con el desarrollo de modelos de propagación que simplifiquen el análisis del canal radio. En concreto, el desarrollo de modelos $M I M O$ que simulen de una forma eficiente y eficaz los sistemas con múltiples antenas. En esta línea los modelos estocástico-deterministas permiten el análisis con un coste razonable de entornos complejos.

Siguiendo con los sistemas de múltiples antenas, en esta tesis se ha estudiado la capa física para un solo usuario. Se ha supuesto que la interferencia es nula, aunque esto no se cumple en sistemas reales, ya que el sistema se comparte entre muchos usuarios. Es entonces otra posible línea de investigación el estudio del canal radio en presencia de interferencia, para las distintas formas de acceso al medio.

Por otro lado, detrás de la capa física, hay una labor muy importante de procesado de la señal, a partir de la cual se produce la recuperación efectiva de las señales y el aumento real de la capacidad. Sería interesante profundizar en las diversas técnicas de procesado de la señal para sistemas de múltiples antenas, y probarlas tanto en los modelos de canal desarrollados en la presente tesis como en otros existentes en la literatura.

Por último, otra línea de investigación sería la utilización del equipo de medidas desarrollado en el capítulo 5 para la toma de medidas en los diversos entornos. Primeramente se podrían estudiar con medidas los cruces de cuatro esquinas y cuatro chaflanes, y los túneles. Y posteriormente, ampliar estas campañas de medidas a otros entornos. Estas medidas se podrían realizar inicialmente en banda estrecha, y posteriormente ampliarlas a banda ancha. 


\section{Apéndice A}

\section{Trazado de Rayos}

El trazado de rayos es un modelo determinista que se emplea para la predicción de la respuesta del canal de radiocomunicaciones. Se fundamenta en la aplicación de la Óptica Geométrica $(G O)$ y la Teoría Uniforme de la Difracción (UTD). A medida que la frecuencia aumenta, la primera zona de Fresnel, que es la que concentra la mayor parte de la energía [Ber00], tiende a estrecharse y se puede simular como un rayo [Des72,Gla90]. De este modo la propagación de las ondas electromagnéticas se puede seguir de la misma forma que el camino que recorre un rayo óptico, simplificando enormemente el análisis.

Los mecanismos fundamentales de propagación son la reflexión, la difracción y la difusión [Rap96]. La reflexión ocurre cuando una onda electromagnética incide sobre un objeto cuyas dimensiones son superiores a la longitud de onda. $G O$ contempla la reflexión y la trata con la ley de Snell [Bal89]. El fenómeno de la difracción surge cuando un rayo es obstruido por una superficie con irregularidades abruptas (aristas). En este caso se generan ondas secundarias desde esta arista por el principio de Huygens, y 
es la $U T D$ la teoría electromagnética que estudia y resuelve este problema. Por último, la difusión tiene lugar cuando una onda viaja por un medio con objetos de dimensiones similares a la longitud de onda, o cuando el número de objetos por unidad de volumen es alto. La difusión en comunicaciones móviles suele tener un valor muy bajo con respecto a otras contribuciones, y no se suele tener en cuenta en el trazado de rayos.

Existen dos formas de trazar rayos. La primera llamada en inglés Ray Launching, consiste en el lanzado de rayos desde la posición del transmisor con una separación angular constante y en su posterior seguimiento [Zhan98]. La segunda de ellas, Ray Tracing en inglés, se basa en la generación de imágenes a partir de las posibles reflexiones que puedan producirse en un entorno [Mar94]. El trazado de rayos que se ha utilizado en la presente tesis es del primer tipo, y se ha tomado como base el proyecto final de carrera [Rod99].

\section{A.1 Óptica Geométrica}

La Óptica Geométrica $(G O)$ es un método aproximado aplicable a altas frecuencias, en el que los frentes de ondas son tratados como rayos que representan una onda esférica [Bal89]. Se obvia entonces el comportamiento ondulatorio de los campos electromagnéticos para hacer un estudio del problema en forma de teoría de rayos, que incluye la Ley de Snell para la reflexión de un rayo en una superficie. Con la aplicación de la $G O$ se pueden determinar las contribuciones de los campos correspondientes a las ondas incidentes, reflejadas y refractadas de una forma mucho más sencilla que si se aplicase un análisis mediante las ecuaciones de Maxwell. GO contempla las siguientes contribuciones:

\section{A.1.1 Rayo directo}

Las ondas se propagan en medios que van a estar caracterizados por un índice de refracción $n$. Estos medio suelen considerarse homogéneos ( $n$ constante dentro de un mismo medio), lo que quiere decir que el camino que siga cada rayo entre dos determinados puntos será siempre una línea recta (sin obstáculos). De esta forma, el frente de ondas que representa el rayo en cuestión no sufre ningún mecanismo de propagación adicional, y solamente sufrirá la atenuación con la distancia propia de una onda esférica. Es lo que se denomina situación de visión directa entre transmisor y receptor: Line of Sight $(\operatorname{LoS})$. 
El campo electromagnético definido por el rayo directo es:

$$
E_{\mathrm{DIR}}(r)=E_{o} \frac{e^{-j k r}}{r}
$$

donde $E_{0}$ es un factor que depende del transmisor, $r$ es la distancia entre el transmisor y el receptor, y $k$ es el número de onda $\left(k=\frac{2 \pi}{\lambda}\right)$. La expresión se corresponde con el campo propio de una onda esférica, el cual se atenúa inversamente con la distancia entre el transmisor y el receptor. El término exponencial indica la fase de la onda, que depende de la distancia recorrida.

\section{A.1.2 Reflexión}

La reflexión se produce cuando una onda incide sobre la superficie que separa dos medios con diferentes propiedades electromagnéticas, representadas por índices de refracción ( $n_{1}$ y $n_{2}$ ). Parte de la onda incidente es reflejada, y parte es transmitida al segundo medio. $G O$ permite el cálculo de los campos (rayos) que se reflejan de forma especular en una superficie lisa de geometría cualquiera, basándose en las leyes de Snell para la reflexión. Para ello se define un coeficiente de reflexión, $R$, que relaciona la onda incidente y la onda reflejada, y que depende de las características eléctricas de la superficie de reflexión (permitividad y conductividad), de la polarización de la onda incidente, del ángulo de incidencia y de la frecuencia de la onda.

Las propiedades electromagnéticas de una superficie cualquiera se caracterizan mediante la definición de una constante dieléctrica compleja relativa [Bal89]:

$$
\varepsilon_{\mathrm{r}}=\frac{\varepsilon}{\varepsilon_{0}}=\varepsilon_{\mathrm{r}}^{\prime}-j \frac{\sigma}{\omega \varepsilon_{0}}=\varepsilon_{\mathrm{r}}^{\prime}\left(1-\mathrm{j} \tan \delta_{\mathrm{e}}\right) \approx \varepsilon_{\mathrm{r}}^{\prime}-\mathrm{j} 60 \lambda \sigma
$$

donde $\varepsilon_{\mathrm{r}}^{\prime}$ es la permitividad relativa del medio sobre el que incide la onda, $j$ es $\sqrt{-1}, \sigma$ es su conductividad en Siemens/m, $\omega$ es la frecuencia angular, $\varepsilon_{0}$ es la permitividad en el vacío, $\delta$ es la tangente de pérdidas y $\lambda$ es la longitud de onda a la que se propaga la onda en metros.

\section{A.1.2.1 Polarización soft}

También llamada polarización horizontal o TE, se produce cuando el vector campo eléctrico de la onda incidente es perpendicular al plano de incidencia, definido como el plano que contiene al rayo incidente y al reflejado (según las leyes de Snell para 
la reflexión, el rayo incidente y el reflejado están contenidos en el mismo plano) (figura A.1). El campo magnético asociado a la onda estará contenido en dicho plano, ya que, al considerarse campo lejano, $H \perp E$.

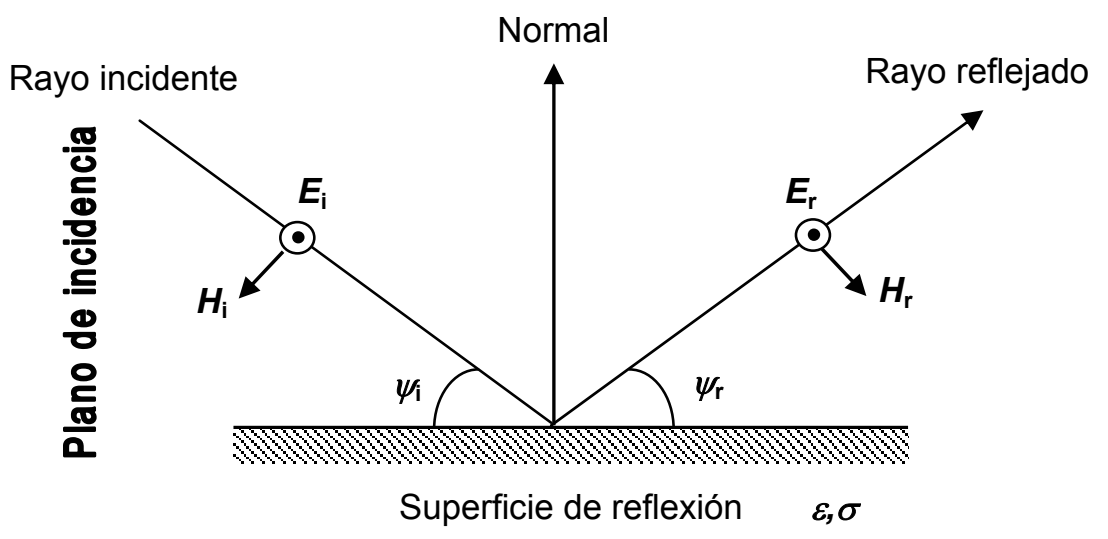

Figura A.1: Incidencia soft. Corte por el plano de incidencia.

El ángulo de incidencia $\psi_{\mathrm{i}}$ coincide con el ángulo de reflexión $\psi_{\mathrm{r}}$, según la ley de Snell $\left(\psi_{\mathrm{i}}=\psi_{\mathrm{r}}=\psi\right)$. El coeficiente de reflexión cuando la incidencia es soft es:

$$
R_{\perp}(\psi)=\frac{\operatorname{sen} \psi-\sqrt{\varepsilon_{r}-\cos ^{2} \psi}}{\operatorname{sen} \psi+\sqrt{\varepsilon_{r}-\cos ^{2} \psi}}
$$

\section{A.1.2.2 Polarización hard}

Tiene lugar cuando el vector campo eléctrico de la onda incidente está contenido en el plano de incidencia (figura A.2). El campo magnético será, pues, perpendicular al mismo. A esta polarización también se le denomina polarización vertical o TM.

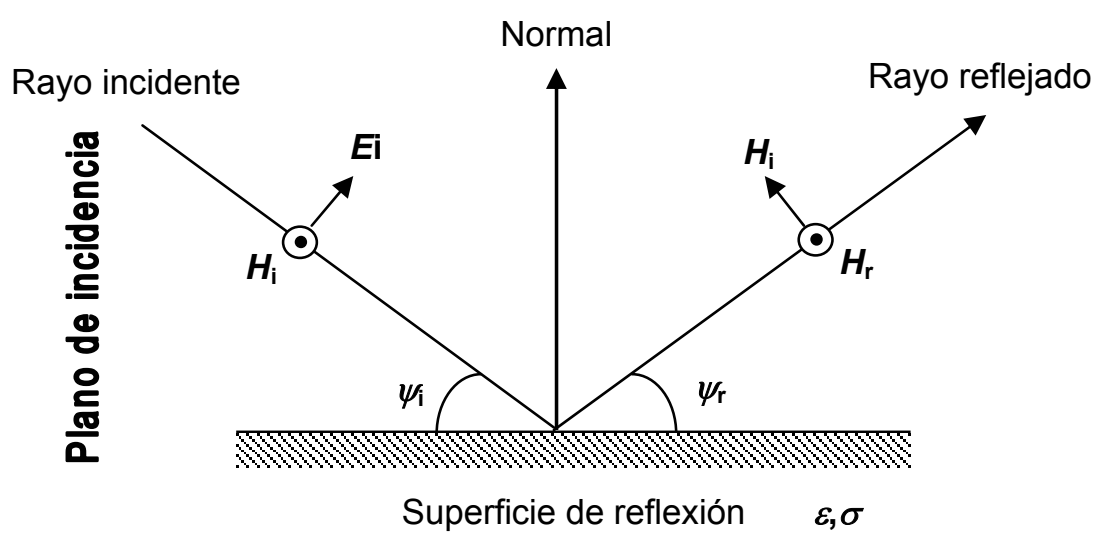

Figura A.2: Incidencia hard. Corte por el plano de incidencia. 
El coeficiente de reflexión para una polarización hard es:

$$
R_{\|}(\psi)=\frac{\varepsilon_{r} \operatorname{sen} \psi-\sqrt{\varepsilon_{r}-\cos ^{2} \psi}}{\varepsilon_{r} \operatorname{sen} \psi+\sqrt{\varepsilon_{r}-\cos ^{2} \psi}}
$$

\section{A.1.2.3 Campo eléctrico definido por un rayo reflejado}

En el caso de que ésta sea una polarización mixta, bastará con descomponer el campo incidente en una componente soft y otra hard, y así utilizar los coeficientes $R_{\perp} \mathrm{y}$ $R||$ según corresponda y por separado, para finalmente sumar vectorialmente las dos soluciones ortogonales obtenidas. La expresión del campo electromagnético asociado a la contribución de una onda reflejada (o rayo reflejado, en $G O$ ) es la siguiente:

$$
E_{R}(r)=E_{o} R \frac{e^{-j k r}}{r}
$$

donde $E_{0}$ es un factor que depende del transmisor, $k$ es el número de onda, $r$ hace referencia a la distancia total recorrida por el rayo reflejado y $R$ es el coeficiente de reflexión, (A.3) o (A.4) dependiendo de si la polarización del campo incidente es soft o hard. Si se produjesen múltiples reflexiones para una misma onda, el valor de $R$ sería el producto acumulado de cada valor $R_{\mathrm{i}}$ correspondiente a la reflexión número $i$ :

$$
R=\prod_{i} R_{\mathrm{i}}
$$

\section{A.2 Teoría Uniforme de la Difracción}

La difracción de un frente de ondas se produce cuando éste se encuentra con algún obstáculo "afilado", como puede ser una esquina en un entorno urbano. La esquina se convierte en un foco emisor secundario (principio de Hyugens), creando un nuevo frente de onda [Ba189].

La óptica geométrica no sirve para calcular los campos producidos por la difracción. Debido a que estos campos tienen una amplitud muy pequeña, no influyen en $L o S$, o en zonas donde los campos reflejados son elevados. Sin embargo, son importantes en las zonas de sombra. 
Para frecuencias altas se puede utilizar un modelo para la difracción, donde éste depende únicamente de la geometría del objeto y de la amplitud, fase, polarización y frecuencia de la onda incidente en el punto de difracción, similarmente a como ocurría con el fenómeno de la reflexión. Se ha desarrollado lo que se conoce como Teoría Uniforme de la Difracción (Uniform Theory of Difraction) (UTD) [Bal89], que deriva de la denominada Teoría Geométrica de la Difracción (Geometrical Theory of Difraction) (GTD) [Kel62].

$G T D$ es una extensión de $G O$ para predecir el campo en una región de sombra causada por una cuña. Sin embargo, GTD no puede aplicarse en la vecindad de las regiones de transición (ver A.2.1). UTD supera estas singularidades para el campo total a lo largo de las llamadas fronteras de transición [Kou74] [Bal89].

\section{A.2.1 Fronteras de Transición}

Existen tres regiones cuyas fronteras dependen de la posición de fuente $\left(\rho^{\prime}, \phi^{\prime}\right)$, del punto de observación $(\rho, \phi)$ y de la posición de la cuña (figura A.3).

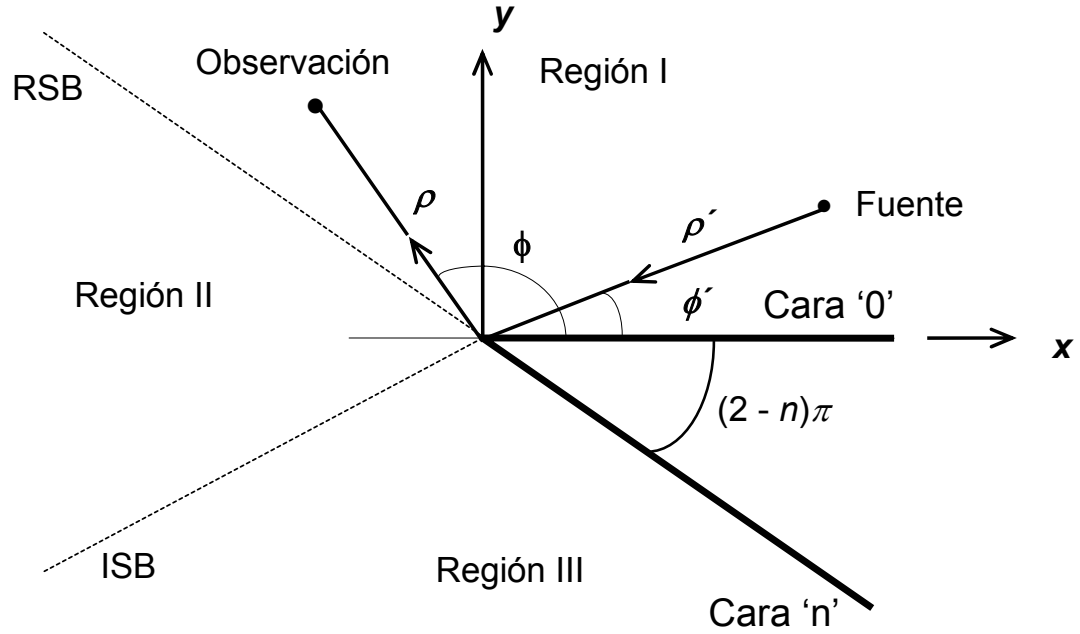

Figura A.3: Regiones de transición y sistema de coordenadas para la cuña.

A la frontera entre las regiones I y II se conoce como Reflected Shadow Boundary $(R S B)$ y a la frontera entre las regiones II y III como Incident Shadow Boundary (ISB). Las contribuciones que han de considerarse para calcular el campo total en cada una de las regiones se muestran en la siguiente tabla: 


\begin{tabular}{||c||c||l||}
\hline \hline Región I & Región II & Región III \\
\hline \hline $0<\phi<\pi-\phi^{\prime}$ & $\pi-\phi^{\prime}<\phi<\pi+\phi^{\prime}$ & $\pi+\phi^{\prime}<\phi<n \pi$ \\
\hline \hline directo & directo & difractado \\
reflejado & difractado & \\
difractado & & \\
\hline
\end{tabular}

Tabla A.1. Regiones frontera de la difracción y las contribuciones asociadas a cada una de ellas.

\section{A.2.2 Campo Difractado}

Se definen dos sistemas de coordenadas (figura A.4): $\left(s^{\prime}, \beta_{0}{ }^{\prime}, \phi^{\prime}\right)$ respecto al rayo incidente desde la fuente en el punto de difracción $Q_{\mathrm{D}} \mathrm{y}\left(s, \beta_{0}, \phi\right)$ respecto al rayo difractado desde $Q_{\mathrm{D}}$ hasta el punto de observación. El campo difractado puede expresarse entonces de la siguiente forma:

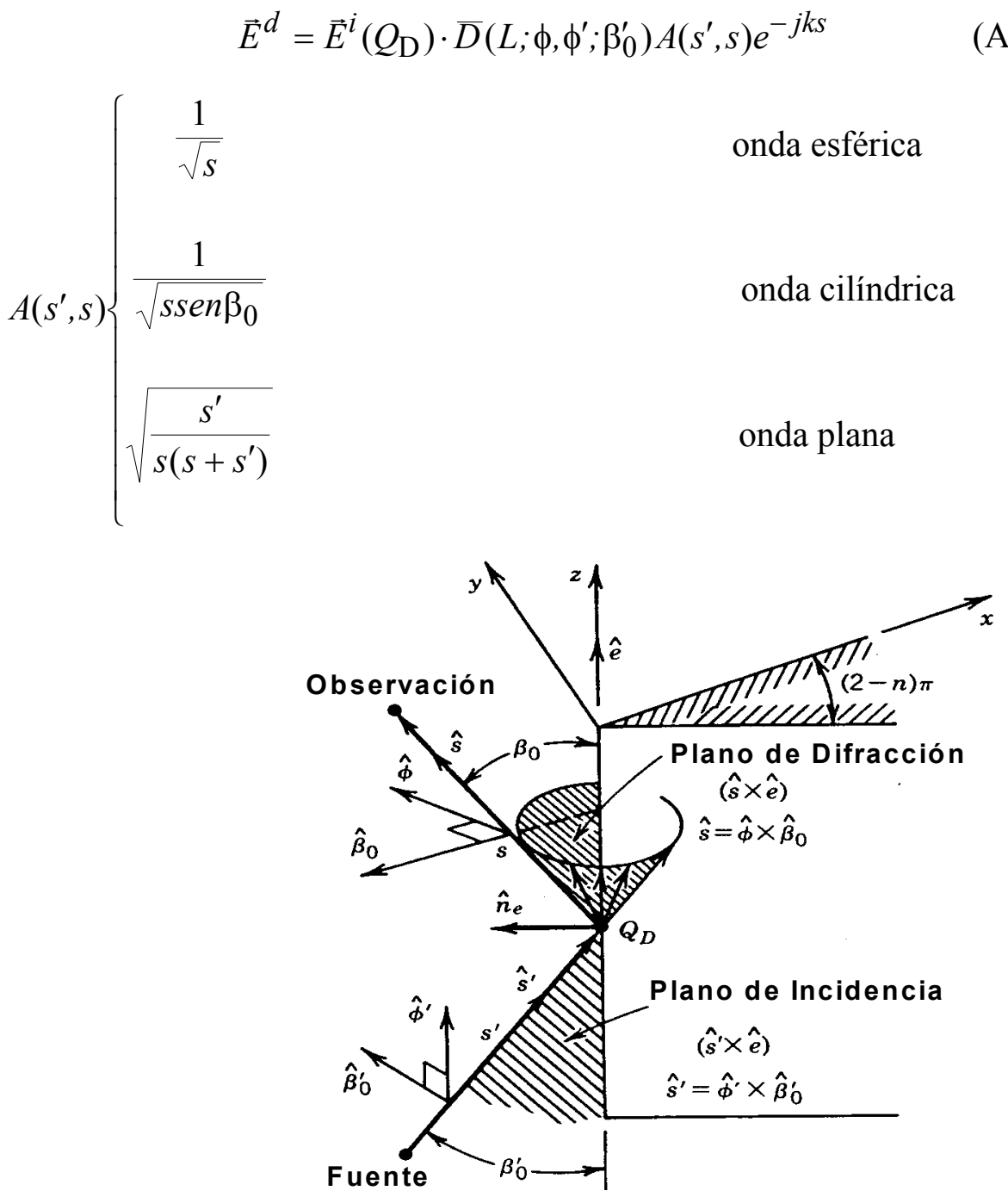

Figura A.4: Incidencia oblicua sobre una cuña de paredes conductoras [Bal89]. 
donde $\vec{E}^{i}\left(Q_{D}\right)$ es el campo incidente en $Q_{\mathrm{D}}, D\left(L ; \phi, \phi^{\prime} ; n ; \beta_{0}^{\prime}\right)$ es el coeficiente diádico de difracción (el cual tiene una expresión matricial para considerar cualquier polarización) y $A\left(s^{\prime}, s\right)$ es un término que tiene en cuenta la variación de la intensidad del campo a lo largo del rayo difractado. Cuando un rayo incide sobre una arista se producen múltiples rayos difractados (figura A.4), cada uno de los cuales lleva asociado un campo, expresado por (A.7).

\section{A.2.3 El Coeficiente Diádico de Difracción}

Siguiendo la geometría de la figura A.4, $\hat{\beta}_{0}^{\prime}$ y $\hat{\phi}^{\prime}$ son dos vectores unitarios paralelo y perpendicular al plano de incidencia (definido por la fuente y la arista de la cuña) y $\hat{\beta}_{0}$ y $\hat{\phi}$ son dos vectores unitarios paralelo y perpendicular al plano de difracción (definido por el punto de observación y la arista de la cuña). Además, estos vectores junto con los vectores $\hat{s}^{\prime}$ y $\hat{s}$ cumplen la siguiente relación:

$$
\begin{aligned}
& \hat{s}^{\prime}=\hat{\phi}^{\prime} \times \hat{\beta}_{0}^{\prime} \\
& \hat{s}=\hat{\phi} \times \hat{\beta}_{0}
\end{aligned}
$$

El coeficiente $\mathrm{D}$ adopta la siguiente expresión:

$$
D=-\hat{\beta}_{0}^{\prime} \hat{\beta}_{0} D_{s}-\hat{\phi}^{\prime} \hat{\phi} D_{h}
$$

donde $D_{\mathrm{s}}$ y $D_{\mathrm{h}}$ son los coeficientes de difracción para el caso de polarización tipo soft o polarización tipo hard respectivamente que son definidos más adelante. Si se descomponen los campos en su componente paralela y perpendicular a los planos de difracción e incidencia queda

$$
\left.\begin{array}{l}
\vec{E}^{i}=E_{\beta_{0}^{\prime}}^{i} \hat{\beta}_{0}^{\prime}+E_{\phi^{\prime}}^{i} \hat{\phi}^{\prime} \\
\vec{E}^{d}=E_{\beta_{0}}^{d} \hat{\beta}_{0}+E_{\phi}^{d} \hat{\phi}
\end{array}\right\}
$$

que permite escribir en forma matricial

$$
\left[\begin{array}{c}
E_{\beta_{0}}^{d}(s) \\
E_{\phi}^{d}(s)
\end{array}\right]=-\left[\begin{array}{cc}
D_{s} & 0 \\
0 & D_{h}
\end{array}\right]\left[\begin{array}{c}
E_{\beta_{0}^{\prime}}^{i}\left(Q_{\mathrm{D}}\right) \\
E_{\phi^{\prime}}^{i}\left(Q_{\mathrm{D}}\right)
\end{array}\right] A\left(s^{\prime}, s\right) \exp (-j k s)
$$

Los coeficientes de Difracción se definen de la siguiente forma:

$$
\left.\begin{array}{l}
D_{s}=D^{i}-D^{r} \\
D_{h}=D^{i}+D^{r}
\end{array}\right\}
$$


donde $D^{i}$ y $D^{r}$ se obtienen imponiendo condiciones de continuidad para el campo total en la $I S B$ y la $R S B$ respectivamente. Las expresiones de estos coeficientes son las siguientes:

$$
\begin{aligned}
& D^{i}=\frac{-\exp (-j \pi / 4)}{2 n \sqrt{2 \pi k \operatorname{sen} \beta_{0}}}\left\{\cot \left[\frac{\pi+\left(\phi-\phi^{\prime}\right)}{2 n}\right] F\left[k L a^{+}\left(\phi-\phi^{\prime}\right)\right]+\right. \\
& \left.\cot \left[\frac{\pi-\left(\phi-\phi^{\prime}\right)}{2 n}\right] F\left[k L a^{-}\left(\phi-\phi^{\prime}\right)\right]\right\} \\
& D^{r}=\frac{-\exp (-j \pi / 4)}{2 n \sqrt{2 \pi k \operatorname{sen} \beta_{0}}}\left\{\cot \left[\frac{\pi+\left(\phi+\phi^{\prime}\right)}{2 n}\right] F\left[k L a^{+}\left(\phi+\phi^{\prime}\right)\right]+\right. \\
& \left.\cot \left[\frac{\pi-\left(\phi+\phi^{\prime}\right)}{2 n}\right] F\left[k L a^{-}\left(\phi+\phi^{\prime}\right)\right]\right\}
\end{aligned}
$$

L es un parámetro de distancia que puede encontrarse satisfaciendo la condición de que el campo total debe ser continuo a lo largo de la $I S B$ y de la $R S B$. Para el caso de onda plana, cilíndrica o esférica incidente en una cuña de paredes planas y arista recta se tiene:

$$
L= \begin{cases}\frac{\operatorname{sen}^{2} \beta_{0}}{s^{\prime} \operatorname{sen} \beta_{0}} & \text { onda plana } \\ s^{\prime}+s & \text { onda cilíndrica } \\ \frac{s^{\prime} \operatorname{sen}^{2} \beta_{0}}{s^{\prime}+s} & \text { onda esférica }\end{cases}
$$

La función $F(\mathrm{x})$ recibe el nombre de Función de Transición de Fresnel y se define en términos de una integral de Fresnel

$$
F(x)=2 j \sqrt{x} \exp (j x) \int_{\sqrt{x}}^{\infty} \exp \left(-j \tau^{2}\right) d \tau
$$

La función $F(x)$ puede calcularse a partir de las integrales del seno y el coseno

$$
\begin{aligned}
& S(x)=\int_{0}^{x} \operatorname{sen}\left(\frac{\pi}{2} \tau^{2}\right) d \tau \\
& C(x)=\int_{0}^{x} \cos \left(\frac{\pi}{2} \tau^{2}\right) d \tau
\end{aligned}
$$

como sigue, 


$$
F(x)=j \sqrt{2 \pi} \sqrt{x} \exp (j x)\left\{\left[\frac{1}{2}-C\left(\sqrt{\frac{2}{\pi}} \sqrt{x}\right)\right]-j\left[\frac{1}{2}-S\left(\sqrt{\frac{2}{\pi}} \sqrt{x}\right)\right]\right\}
$$

En las expresiones el argumento de $F(x)$ contiene a la función $a^{ \pm}(\chi)$ que mide la separación angular entre el punto de observación y la $I S B$ o la $R S B$. Su expresión es:

$$
a^{ \pm}(\chi)=2 \cos ^{2}\left(\frac{2 n \pi N^{ \pm}-\chi}{2}\right), \chi=\phi \pm \phi^{\prime}
$$

siendo $N^{+}$y $N^{-}$los números enteros que más cerca satisfagan las ecuaciones

$$
\begin{aligned}
& 2 \pi n N^{+}-\chi=\pi \\
& 2 \pi n N^{-}-\chi=-\pi
\end{aligned}
$$

\section{A.2.4 Coeficientes de Difracción GTD}

A partir de los coeficientes de difracción definidos por UTD pueden calcularse los coeficientes de difracción definidos por GTD teniendo en cuenta que cuando los campos se evalúan en puntos suficientemente alejados de las fronteras de transición ISB o $R S B$ se cumple

$$
k L a^{ \pm}\left(\phi \pm \phi^{\prime}\right)>10
$$

lo que implica $F(x) \approx 1$. Con esta condición y después de unas transformaciones trigonométricas:

$$
\begin{aligned}
& D^{i}=\frac{\exp (-j \pi / 4)}{n \sqrt{2 \pi k \operatorname{sen} \beta_{0}} \cos \frac{\pi}{n}-\cos \frac{\pi}{n}} \frac{\operatorname{sen}}{n} \\
& D^{r}=\frac{\exp (-j \pi / 4)}{2 \sqrt{2 \pi k} \operatorname{sen} \beta_{0}} \frac{\operatorname{sen} \frac{\pi}{n}}{\cos \frac{\pi}{n}-\cos \frac{\phi+\phi^{\prime}}{n}}
\end{aligned}
$$

Los coeficientes hard o soft se calculan con (A.14). 


\section{A.2.5 Difracción UTD en una cuña de paredes de conductividad finita}

Cuando las paredes de la cuña en la que se produce el fenómeno de la difracción de una onda incidente no son conductoras perfectas, el coeficiente diádico de difracción adopta una nueva forma. Descomponiendo el coeficiente diádico de difracción en sus componentes soft y hard por separado a partir de (A.14), (A.15) y (A.16), y añadiendo los términos $R_{0}^{\perp}$ y $R_{n}^{\perp}$ si la polarización es soft, ó $R_{0}^{\|}$y $R_{n}^{\|}$si es hard, obtenemos el nuevo coeficiente de difracción que ya considera la conductividad finita de las paredes, y que a continuación presentamos en función de la polarización [Lue84]:

$$
\begin{aligned}
& D_{s}=\frac{-\exp (-j \pi / 4)}{2 n \sqrt{2 \pi k \operatorname{sen} \beta_{0}}}\{ \\
& \cot \left[\frac{\pi+\left(\phi-\phi^{\prime}\right)}{2 n}\right] F\left[k L a^{+}\left(\phi-\phi^{\prime}\right)\right]+ \\
& \cot \left[\frac{\pi-\left(\phi-\phi^{\prime}\right)}{2 n}\right] F\left[k L a^{-}\left(\phi-\phi^{\prime}\right)\right]+ \\
& R_{0}^{\perp} \cot \left[\frac{\pi-\left(\phi+\phi^{\prime}\right)}{2 n}\right] F\left[k L a^{-}\left(\phi+\phi^{\prime}\right)\right]+ \\
& \left.R_{n}^{\perp} \cot \left[\frac{\pi+\left(\phi+\phi^{\prime}\right)}{2 n}\right] F\left[k L a^{+}\left(\phi+\phi^{\prime}\right)\right]\right\}
\end{aligned}
$$

si existe incidencia soft; y

$$
\begin{aligned}
& D_{h}=\frac{-\exp (-j \pi / 4)}{2 n \sqrt{2 \pi k \operatorname{sen}} \beta_{0}}\{ \\
& \cot \left[\frac{\pi+\left(\phi-\phi^{\prime}\right)}{2 n}\right] F\left[k L a^{+}\left(\phi-\phi^{\prime}\right)\right]+ \\
& \cot \left[\frac{\pi-\left(\phi-\phi^{\prime}\right)}{2 n}\right] F\left[k L a^{-}\left(\phi-\phi^{\prime}\right)\right]+ \\
& R_{0}^{\|} \cot \left[\frac{\pi-\left(\phi+\phi^{\prime}\right)}{2 n}\right] F\left[k L a^{-}\left(\phi+\phi^{\prime}\right)\right]+ \\
& \left.R_{n}^{\|} \cot \left[\frac{\pi+\left(\phi+\phi^{\prime}\right)}{2 n}\right] F\left[k L a^{+}\left(\phi+\phi^{\prime}\right)\right]\right\}
\end{aligned}
$$

si la incidencia es hard. Si la incidencia tiene una polarización mixta, hay que descomponer el campo incidente en sus componentes soft y hard por separado, para 
luego utilizar $D_{\mathrm{s}}$ o $D_{\mathrm{h}}$ según convenga, al igual que ocurría con el coeficiente de reflexión.

Los parámetros $R_{0}^{\perp, \|}$ y $R_{n}^{\perp, \|}$ que aparecen en (A.28) y en (A.29) representan los coeficientes de reflexión de Fresnel para polarización perpendicular o paralela en la cara ' 0 ' de la cuña (Fig. A.3), con ángulo de incidencia $\phi$ ', y en la cara ' $n$ ' de la cuña, con ángulo de reflexión $(n \pi-\phi)$. Es decir, sus valores se calculan utilizando las (A.3) o (A.4) para el coeficiente de reflexión con los valores de los ángulos adecuados.

La incidencia rasante se produce cuando la onda incidente en una cuña tiene como ángulo de incidencia $\phi{ }^{\prime}=0 \mathrm{o} \phi{ }^{\prime}=n \pi$. En este caso, tanto para paredes conductoras perfectas como con conductividad finita los coeficientes de difracción UTD generales dados por las (A.28) y (A.29) no son los adecuados. Este campo se corrige por un factor de $\frac{1}{2}[\operatorname{Kou} 74]$.

\section{A.2.6 Campo eléctrico definido por un rayo difractado}

El campo definido por un rayo difractado que alcanza el receptor y que no ha sido afectado por otro mecanismo de propagación se puede expresar como:

$$
E_{\mathrm{D}}=\frac{E_{O}}{s^{\prime}} D A\left(s, s^{\prime}\right) \cdot e^{-j k\left(s+s^{\prime}\right)}
$$

Esta expresión es la misma dada por la (A.7). En la figura A.4 se ha definido s', es la distancia que recorre el rayo antes de alcanzar el punto de difracción. De igual forma, s es la distancia que recorre el rayo después del punto de difracción. $D=D\left(n, \beta_{0}\right.$, $\phi ’, \phi, L)$ es el coeficiente de difracción. Este coeficiente puede venir dado por (A.28) si la polarización es soft, o por (A.29) si la polarización es hard. El resto de los parámetros que aparece en estas expresiones ha sido definido en el apartado A.3.2. Cuando el rayo incidente representa una onda esférica el valor del parámetro de distancia $L$, necesario para el cálculo de $D$, viene dado por:

$$
L=\frac{s s^{\prime}}{s+s^{\prime}} \operatorname{sen}^{2} \beta_{0}
$$

tal y como se desprende de (A.17). Por otra parte, de (A.8) se deriva que para ondas esféricas el valor del parámetro $A\left(s, s^{\prime}\right)$ es: 


$$
A\left(s, s^{\prime}\right)=\sqrt{\frac{s^{\prime}}{s\left(s^{\prime}+s\right)}}
$$

Este factor representa la atenuación del campo difractado con la distancia. Habitualmente se le denomina Spreading Factor.

\section{A.3 Resumen de las diferentes contribuciones del trazador}

Si el rayo representa la contribución de la onda directa, el campo que la describe es el siguiente:

$$
E_{D I R}(r)=E_{o} \frac{e^{-j k r}}{r}
$$

Cuando el rayo es reflejado una o varias veces en alguna superficie, el campo de la onda recibida viene dado por:

$$
E_{R}(r)=E_{o} R \frac{e^{-j k r}}{r}
$$

$R$ es el coeficiente de reflexión total, producto de los coeficientes correspondientes a cada una de las reflexiones individuales sufridas por el rayo, y que viene dado por las (A.3) y (A.4) dependiendo de si la polarización del campo incidente es soft o hard. En el caso de que intervengan fenómenos de difracción en una cuña, sea de paredes perfectamente conductoras o no, y considerando ondas esféricas, el campo viene expresado por:

$$
E_{\mathrm{D}}=\frac{E_{O}}{s^{\prime}} D \sqrt{\frac{s^{\prime}}{s\left(s^{\prime}+s\right)}} \cdot e^{-j k\left(s+s^{\prime}\right)}
$$

$s^{\prime}$ es la distancia que recorre el rayo antes de alcanzar el punto de difracción, $s$ es la distancia que recorre después del punto de difracción; y $D=D\left(n, \beta_{0}{ }^{\prime}, \phi{ }^{\prime}, \phi, L\right)$ es el coeficiente de difracción. Este coeficiente puede venir dado por (A.28) si la polarización es soft, o por (A.29) si la polarización es hard.

En el caso de simple difracción combinada con múltiples reflexiones la expresión del campo del rayo correspondiente queda:

$$
E_{\mathrm{R}-\mathrm{D}}=\frac{E_{o}}{s^{\prime}} D R \sqrt{\frac{s^{\prime}}{s\left(s^{\prime}+s\right)}} e^{-j k\left(s+s^{\prime}\right)}
$$


donde $D$ es el coeficiente de difracción calculado en la esquina considerada, y $R$ es el coeficiente de reflexión total (producto del correspondiente a cada reflexión individual). 


\section{Apéndice B}

\section{Caracterización del Canal Radio}

La caracterización del canal radio es fundamental para el diseño de sistemas de comunicaciones móviles. Esta caracterización debe ser realista debido a varios aspectos: el desarrollo de estándares debe reflejar un comportamiento realista del canal, el diseño de sistemas inalámbricos debe estar basado en los parámetros que lo describen, y los prototipos deben ajustarse a modelos realistas del canal.

El canal radio representa la mayor limitación de una comunicación inalámbrica. Su comportamiento es aleatorio y su análisis complicado. El modelado del canal ha sido históricamente una de las partes más difíciles del diseño de un sistema de radiocomunicaciones. En la figura B.1 se representa la potencia recibida por un receptor en unidades logarítmicas $(\mathrm{dBm})$ cuando éste se desplaza a lo largo de un recorrido. Esta potencia $\left(P_{\mathrm{R}}\right)$ es proporcional al cuadrado del voltaje recibido $P_{\mathrm{R}} \alpha \mid V(x)^{2}$ [Ber00]. 


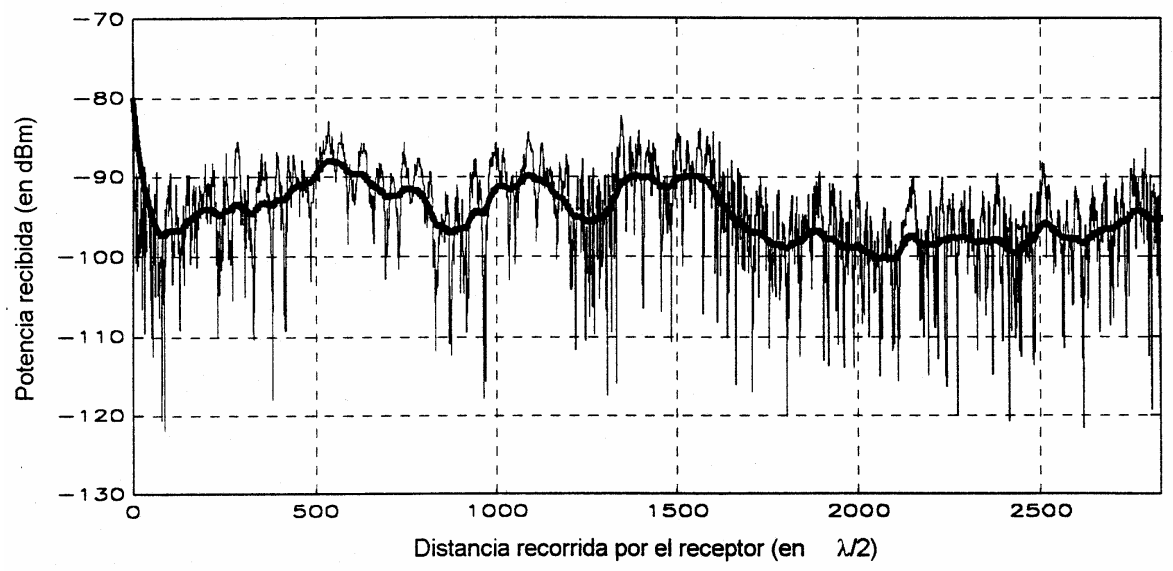

Figura B.1: Potencia recibida en el receptor $(\mathrm{dBm})$ para un recorrido dado en términos de $\lambda$.

Se observan claramente dos comportamientos de la potencia recibida. El primero de ellos es debido a pequeños desplazamientos del receptor que dan lugar a una variación rápida de la potencia recibida, se denomina desvanecimiento rápido de la señal (Small Scale Fading o Fast Fading). Este desvanecimiento es debido a que la señal recibida es la suma de múltiples contribuciones que provienen de diferentes posiciones, y la suma se puede realizar desde en fase hasta en contrafase. Los desvanecimientos de la señal pueden llegar a ser de 3 o 4 órdenes de magnitud (30-40 dB). Por otro lado, si se promedia la potencia recibida en pequeñas áreas, normalmente con ventanas de entre $5 \lambda$ y $40 \lambda$ [Rap96], se observa un comportamiento más suave de la potencia media recibida, y se denomina desvanecimiento lento de la señal (Large-Scale Fading o Slow Fading). Este comportamiento es el resultado del cambio de los elementos del entorno. El hecho de que los nuevos elementos que configuran un entorno cambien, da lugar a una variación del valor medio de la señal.

\section{B.1 Desvanecimiento lento del canal (Large-Scale Fading)}

El comportamiento Large-Scale Fading se puede separar del Small-Scale Fading mediante el promedio de la señal recibida en una ventana centrada en $x$ :

$$
\overline{V(x)}=\frac{1}{2 W} \int_{-W / 2}^{W / 2} V(x+s) \cdot d s
$$

donde $W$ es el tamaño de la ventana, $V(x)$ representa el voltaje recibido en un punto $x$. La variación de señal se hace normalmente en unidades logarítmicas, y se demuestra que 
para áreas que estén a una distancia similar de una estación base, la distribución es del tipo log-normal [Ber00].

$$
\begin{aligned}
& U_{i}=10 \log \left\langle V^{2}\left(x_{i}\right)\right\rangle \\
& p\left(U_{i}-\langle U\rangle\right)=\frac{1}{\sigma \sqrt{2 \pi}} \exp \left[\frac{-\left(U_{i}-\langle U)^{2}\right.}{2 \sigma^{2}}\right]
\end{aligned}
$$

donde $U_{\mathrm{i}}$ es el cuadrado del voltaje promediado en una zona dada en unidades logarítmicas, $\langle U\rangle$ es el valor medio y $\sigma$ la desviación típica.

\section{B.2 Desvanecimiento rápido del canal (Small-Scale fading)}

El Small-Scale fading, describe las fluctuaciones rápidas de la amplitud, fases y retardos de la señal radio durante cortos periodos de tiempo o distancias recorridas. El desvanecimiento lento puede considerarse constante durante recorridos cortos de la señal. Utilizando de nuevo el voltaje de la señal recibida en un punto $x_{i} V\left(x_{\mathrm{i}}\right)$, se puede estudiar el comportamiento del desvanecimiento rápido de la señal normalizando este voltaje con (B.1):

$$
r_{i}=V\left(x_{i}\right) / \overline{V\left(x_{i}\right)}
$$

donde $r_{\mathrm{i}}$ es el voltaje normalizado en el punto $x_{\mathrm{i}}$. La distribución de probabilidad de $p(r)$ en zonas donde no hay visión directa entre transmisor y receptor sigue una distribución de probabilidad del tipo Rayleigh [Par96] (definida para valores positivos de r):

$$
p(r)=\frac{r}{\rho^{2}} e^{-r^{2} / 2 \rho^{2}}
$$

donde $\rho=\sqrt{2 / \pi}$. Para lugares donde existe una contribución dominante a las demás, como por ejemplo en el caso $L o S$, la distribución sigue una distribución del tipo Rice [Par96]:

$$
p(r)=\frac{r}{\rho^{2}} \exp \left(-\frac{r^{2}-r_{0}^{2}}{2 \rho^{2}}\right) I_{0}\left(\frac{r \cdot r_{0}}{\rho^{2}}\right)
$$

donde $I_{0}$ es la función de primera clase y orden cero de Bessel, $r_{0}^{2} / 2$ es proporcional a la potencia de la onda dominante y $\rho^{2}$ es proporcional a la potencia del resto de ondas. La amplitud relativa de la onda dominante con respecto al resto de componentes se mide con el parámetro $K=r_{0}^{2} / 2 \rho^{2}$. Cuando $r_{0}$ es igual a cero, la distribución se convierte en 
Rayleigh, y cuando $r_{0}$ se hace muy grande, la distribución tiende a una distribución Gausiana.

Los factores más importantes que influyen en el desvanecimiento rápido de la señal son los siguientes [Rap96]:

- La propagación multicamino: La presencia de reflectores cambia constantemente. Múltiples señales con amplitudes y fases aleatorias causan fluctuaciones de la potencia de la señal como se ha indicado anteriormente.

- Velocidad del móvil: Cuando el receptor está en movimiento, se produce una modulación en frecuencia denominada efecto Doppler. Esta modulación producirá un ensanchamiento de la señal en frecuencia.

- Los objetos del entorno pueden estar en movimiento, lo que produce una variabilidad de las contribuciones que llegan al receptor.

- El ancho de banda de la señal puede ser superior al ancho de banda del canal. Se define este ancho de banda del canal como la mayor distancia en frecuencia donde dos señales están altamente correladas en amplitud.

Se observa entonces que el canal radio se va a ver afectado por una dispersión temporal debido al multitrayecto, y a una variabilidad temporal debido a que el entorno es variable con el tiempo. Para la caracterización del canal radio, se recurre normalmente a la descripción de éste mediante su equivalente paso bajo $h(t, \tau)$ (Input Delay Spread Function) [Rab01]. En esta definición, $t$ representa la variabilidad temporal, y $\tau$ la dispersividad del canal. La dispersión del retardo $(\tau)$ da lugar a canales selectivos en frecuencia $(f)$ y a la interferencia entre símbolos si este $(\tau)$ es elevado. Por otro lado, los desvanecimientos selectivos en el tiempo $(t)$ dan lugar a la dispersión Doppler (v).

A partir de $h(t, \tau)$ se definen tres funciones de transferencia en los distintos dominios bidimensionales [Rab01]

Time Variable Transfer Function $T(t, f)=\mathfrak{J}\{h(t, \tau)\}_{\tau}$

Delay Doppler Spread Function $s(\mathrm{v}, \tau)=\mathfrak{J}\{h(t, \tau)\}_{t}$

Output Doppler Spread Function $H(v, f)=\mathfrak{J}\left\{\mathfrak{J}\{h(t, \tau)\}_{\tau}\right\}_{t}$ 
donde $\mathfrak{I}\{\}_{x}$ es la transformada de Fourier con respecto a la variable x. Estas funciones son funciones complejas. A partir de estas se definen otras tres funciones reales que representan densidades espectrales de potencia:

Instantaneous Delay Profile Spectral Density $P_{h}(t, \tau)=|h(t, \tau)|^{2}$

Instantaneous Power Delay Profile $P_{S}(v, \tau)=|s(v, \tau)|^{2}$

Delay Doppler Power Spectral Density $P_{H}(v, f)=|H(v, f)|^{2}$

Y a partir de estas densidades, se definen versiones promediadas:

$$
\begin{gathered}
\text { Averaged Delay Profile Spectral Density } P_{h}(\tau)=\left\langle P_{h}(t, \tau)\right\rangle_{t} \\
\text { Averaged Doppler Power Spectral Density } P_{H}(v)=\left\langle P_{H}(v, f)\right\rangle_{f}
\end{gathered}
$$

Los canales reales varían de forma aleatoria, por lo que las funciones del sistema pasan a ser procesos estocásticos. Para describir este comportamiento es necesario utilizar estadísticas descriptivas estables. Se suele suponer que el canal es WSSUS (Wide Sense Stationary with Uncorrelated Scattering) (ver B.4). A partir de funciones correlación tenemos las siguientes funciones correlación:

$P_{h}(u, \tau)$ correlación de Input Delay Spread Function con variación $u=\Delta t$ $R_{T}(u, v)$ correlación de Time Variable Transfer Function con variación $u=\Delta t$ y $v=\Delta f$ $P_{H}(v, v)$ correlación de Output Doppler Spread Function con variación $v=\Delta f$ $P_{S}(\mathrm{v}, \tau)$ correlación de Delay Doppler Spread Function

\section{B.3 Ergodicidad, estacionariedad en sentido amplio y dispersores incorrelados}

El canal radio, tal y como se ha comentado en el apartado anterior, es un proceso aleatorio estocástico. Para que las funciones de transferencia sean manejables, se asume que en pequeños recorridos del móvil (o en intervalos de tiempo pequeños), el canal es estacionario en sentido amplio (con función de correlación invariante) y que los 
dispersores actúan de forma incorrelada entre sí Rab[01]. A continuación se va a desgranar esta definición para aclarar cada una de las suposiciones.

Primeramente se debe tener en cuenta que se está tratando con valores promediados. En un entorno real lo único que se tiene son realizaciones en ciertos instantes de tiempo. Pues bien, la ergodicidad asume que la media estadística se puede sustituir por la media temporal. Esto indica en términos prácticos, que las medidas de la respuesta compleja del canal radio se toman en instantes distintos de tiempo, y luego se calcula su media temporal.

Por otro lado se ha asumido que el canal es estacionario. Estacionariedad en sentido amplio hace referencia a que la correlación entre dos muestras no depende de los instantes en que se toma, sino de la diferencia de tiempos entre ellas. Esto se denomina en inglés Wide-Sense Stationary (WSS).

Por último, se suele asumir dispersores incorrelados (Uncorrelated Scattering $(U S))$. Esta suposición es la dual a WSS, ya que US asume que las contribuciones que llegan con diferentes retardos están incorreladas.

Con todo esto, tenemos la clásica suposición de canal WSSUS (Wide-Sense Stationary Uncorrelated Scattering) de Bello, en el contexto de dispersión atmosférica [Bel63], que es la base para la mayoría de modelos de canal radio de hoy en día.

\section{B.4 Parámetros del canal radioeléctrico}

\section{B.4.1 Perdidas de propagación}

Las pérdidas de propagación son uno de los parámetros fundamentales que caracterizan el canal radio, e influye fuertemente en el comportamiento de un sistema de comunicaciones móviles. Este parámetro indica la atenuación que sufre la señal desde que sale de la antena transmisora hasta que llega a la antena receptora.

Para un sistema de banda estrecha, en el que el ancho de banda de la señal transmitida es mucho menor que la frecuencia central (Apartado B.5.3), se define la inversa de las pérdidas en banda estrecha $L_{N B}$ como:

$$
1 / L_{N B}(t)=\left|\int_{\tau} h(t, \tau) d \tau\right|^{2}=|T(t, 0)|^{2}
$$

donde $h(t, \tau)$ y $T(t, f)$ se definieron en B.2. Las pérdidas en banda estrecha están influenciadas por el Small-Scale Fading (componentes multicamino). Todas estas 
componentes se añaden incoherentemente en el receptor. La estadística de los desvanecimientos es típicamente Rayleigh o Rice.

Para un sistema de banda ancha, donde la señal transmitida es mayor que el ancho de banda de coherencia del canal, se define la inversa de las pérdidas en banda ancha $L_{W B}$ como [Kad95]:

$$
1 / L_{W B}(t)=\int_{\tau}|h(t, \tau)|^{2} d \tau
$$

Esta expresión implica que las componentes se suman en fase. También se puede definir el $L_{W B}$ en frecuencia como:

$$
1 / L_{W B}(t)=\lim _{B \rightarrow \infty} \frac{1}{B} \int_{-B / 2}^{B / 2}|T(t, f)|^{2} d f
$$

Esta última definición se basa en el teorema de Parseval [End89].

\section{B.4.2 Retardo medio y dispersión del retardo}

A partir de función $P_{h}(t, \tau)$, para un instante de tiempo $t$, la función depende únicamente de $\tau$. Esta función se denomina Perfil de Retardo-Potencia, PDP (Power Delay Profile). Indica la potencia en función de la dispersión temporal para un instante dado, y resulta de gran utilidad para calcular la dispersión temporal del canal radio. Se define el retardo medio $\bar{\tau}(t)$ como el momento de primer orden del PDP:

$$
\bar{\tau}(t)=\frac{\int_{\min }^{\tau_{\max }} \xi P_{h}(t, \xi) d \xi}{\int_{\tau_{\min }} P_{h}(t, \xi) d \xi}
$$

donde $\tau_{\min } \mathrm{y} \tau_{\max }$ es el retardo de la primera y última contribución respectivamente. En el caso de tener un perfil de retardo discreto, el retardo medio queda:

$$
\bar{\tau}(t)=\frac{\sum_{i=1}^{N} \tau_{i} P_{h}\left(t, \tau_{i}\right)}{\sum_{i=1}^{N} P_{h}\left(t, \tau_{i}\right)}
$$

donde $N$ es el número de contribuciones, y $\tau_{i}$ es el retardo correspondiente a la contribución $P_{h}\left(t, \tau_{i}\right)$. Se define la dispersión del retardo (RMS Delay Spread) $\sigma_{\tau}(t)$ como el momento de segundo orden del PDP: 


$$
\sigma_{\tau}(t)=\sqrt{\frac{\int_{\min }^{\tau_{\max }} \xi^{2} P_{h}(t, \xi) d \xi}{\tau_{\max } \int_{\tau_{\min }}(t, \xi) d \xi}-\left(\frac{\int_{\max }^{\tau_{\min }} \xi P_{h}(t, \xi) d \xi}{\tau_{\max }} \int^{\tau_{\min } P_{h}(t, \xi) d \xi}\right)^{2}}
$$

y de forma discreta:

$$
\sigma_{\tau}(t)=\sqrt{\frac{\sum_{i=1}^{N}\left(\tau_{i}-\bar{\tau}(t)\right)^{2} P_{h}\left(t, \tau_{i}\right)}{\sum_{i=1}^{N} P_{h}\left(t, \tau_{i}\right)}}
$$

Como se observa en las expresiones anteriores, tanto el retardo medio como la dispersión de retardo dependen del tiempo. Muchas veces los resultados que se obtienen son estos parámetros promediados y su comportamiento estadístico.

\section{B.4.3 Ancho de banda de coherencia}

El ancho de banda de coherencia mide la distancia en frecuencia donde la correlación entre las envolventes complejas de dos portadoras sin modular que se transmiten en un canal dado están altamente correladas [Jak74]. También se puede definir como una medida estadística del rango de frecuencias en el que un canal puede considerarse plano [Rap96]. Este parámetro está ligado inversamente a la dispersión de retardo [Fle96]. En ancho de coherencia se suele definir mediante un umbral a partir del cual la correlación es menor que un cierto valor, normalmente 0.5. La forma de obtenerlo es mediante $\mathfrak{J}\left\{P_{h}(t, \tau)\right\}_{\tau}$, y a partir de esta función medir cuando la correlación disminuye al 0.5 .

\section{B.4.4 Tiempo de coherencia}

Este parámetro mide la separación temporal durante la cual la correlación entre dos respuestas complejas del canal es suficientemente alta. Es el parámetro dual al ancho de banda de coherencia. Al igual que con el ancho de banda de coherencia y la dispersión temporal, existe una relación inversa entre el tiempo de coherencia y el desplazamiento Doppler [Mo199]. Normalmente se define el tiempo de coherencia para una correlación del 50\%. Por otro lado, si se promedia la función $R_{T}(u, v)$ sobre $v$, tendremos la función de coherencia temporal del canal $R_{T}(u)$, y como su nombre indica, 
mide el tiempo de coherencia del canal. Un valor bajo indica que el canal es muy variable, sin embargo, un valor alto, indicaría que el canal es bastante estático.

\section{B.4.5 Doppler medio y dispersión Doppler}

Debido al movimiento del receptor, la señal recibida sufre un efecto llamado Doppler. Este efecto consiste en una modulación en frecuencia de valor [Rap96]:

$$
f_{d}=\frac{v}{\lambda} \cos \theta
$$

donde $v$ es la velocidad del móvil, $\lambda$ la longitud de onda de la señal y $\theta$ el ángulo que forma la trayectoria del móvil con la onda recibida. Se define Doppler medio como el primer momento de $P_{H}(v, f)$ :

$$
\bar{v}(f)=\frac{\int_{-v_{\max }}^{\mathrm{v}_{\max }} P_{H}(\mathrm{v}, f) d \mathrm{v}}{\int_{-\mathrm{v}_{\max }}^{\mathrm{v}_{\max }} P_{H}(\mathrm{v}, f) d \mathrm{v}}
$$

se define la dispersión Doppler como el momento de segundo orden de $P_{H}(v, f)$ :

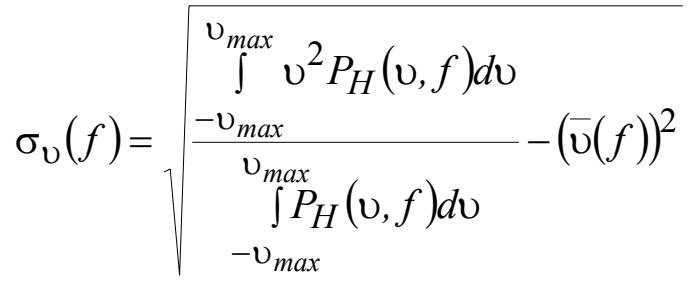

\section{B.4.6 Dispersión angular}

Hasta ahora, las funciones que se han definido no tienen en cuenta variaciones espaciales, es decir, no se ha tenido en cuenta la dirección de salida o llegada de la señal. A partir de la función $P_{h}(t, \tau)$, se puede definir la misma función pero que en lugar de depender del tiempo de retardo $\tau$, dependa de la dirección de llegada de la contribución correspondiente a ese retardo [Ert98]: $P_{h}(t, \varphi)$. De esta forma, para un instante de tiempo $t$, tenemos una función que indica la potencia en función de la dispersión angular para un instante dado. Se define el ángulo medio como el momento de primer orden de $P_{h}(t, \varphi)$ : 


$$
\bar{\varphi}(t)=\frac{\int_{0}^{2 \pi} \xi P_{h}(t, \xi) d \xi}{\int_{0}^{2 \pi} P_{h}(t, \xi) d \xi}
$$

En el caso de tener una función discreta, el ángulo medio de llegada queda:

$$
\bar{\varphi}(t)=\frac{\sum_{i=1}^{N} \varphi_{i} P_{h}\left(t, \varphi_{i}\right)}{\sum_{i=1}^{N} P_{h}\left(t, \varphi_{i}\right)}
$$

donde $N$ es el número de contribuciones, y $\varphi_{i}$ es el ángulo de llegada correspondiente a la contribución $P_{h}\left(t, \tau_{i}\right)$. Se define la dispersión del ángulo de llegada (RMS Angular Spread) como el momento de segundo orden de $P_{h}(t, \varphi)$ :

$$
\sigma_{\varphi}(t)=\sqrt{\frac{\int_{0}^{2 \pi} \xi^{2} P_{h}(t, \xi) d \xi}{\int_{0}^{2 \pi} P_{h}(t, \xi) d \xi}-\left(\frac{\int_{0}^{2 \pi} \xi P_{h}(t, \xi) d \xi}{\int_{0}^{2 \pi} P_{h}(t, \xi) d \xi}\right)^{2}}
$$

y de forma discreta:

$$
\sigma_{\varphi}(t)=\sqrt{\frac{\sum_{i=1}^{N}\left(\varphi_{i}-\bar{\varphi}(t)\right)^{2} P_{h}\left(t, \varphi_{i}\right)}{\sum_{i=1}^{N} P_{h}\left(t, \varphi_{i}\right)}}
$$

Al igual que con los parámetros de la dispersión temporal, tanto el ángulo medio como la dispersión del ángulo medio dependen del tiempo. También aquí los resultados que se obtienen de estos parámetros son analizados estadísticamente. 


\section{Apéndice C}

\section{Equipo de Medidas de Banda Ancha}

La medida del canal radio es una parte esencial del estudio del mismo, ya que permite tanto la obtención de datos necesarios para la implementación de modelos como la verificación de éstos [Cos01]. Para estudiar la respuesta multicamino y el small-scale fading se han desarrollado diversas técnicas para medir la respuesta compleja del canal [Rap96]. Éstas se dividen principalmente en técnicas de medidas mediante la transmisión de pulsos $R F$, técnicas que utilizan la correlación cruzada de secuencias pseudo-aleatorias y técnicas de dominio frecuencial.

Las técnicas de medida mediante la transmisión de pulsos $R F$ [Rap89] tienen el mismo principio de funcionamiento que el del radar. Se transmite un pulso de radiofrecuencia a la frecuencia de interés, de duración $T_{\mathrm{p}}$ y que se repite cada $T_{\mathrm{REP}}$. El receptor está formado por un filtro paso banda de ancho $2 / T_{\mathrm{p}}$ y un detector. Con este sistema se pueden medir respuestas al impulso de duración máxima $T_{\mathrm{REP}}$ y con una 
resolución temporal de $T_{\mathrm{p}}$. Es un sistema que permite la obtención rápida y económica del PDP. Los mayores problemas de estos sistemas son que el sistema es muy sensible al ruido y a la interferencia, y que si la primera componente no es la de mayor amplitud, el sistema tiene problemas de sincronización.

El espectro ensanchado también puede utilizarse para la medida del canal radioeléctrico [Lue89]. Las técnicas que lo utilizan hacen uso de la correlación cruzada de secuencias pseudo-aleatorias $(P N)$. En el transmisor, un código $P N$ se modula a la frecuencia de interés, y en el receptor lo demodula con la misma secuencia $P N$. Ambas secuencias se desincronizan mínimamente para aumentar el tiempo máximo de medida. La ventaja fundamental de estos métodos es que mejoran notablemente la inmunidad al ruido y a la interferencia, y que la sincronización viene dada por la autocorrelación. Sin embargo, no sirven para la realización de medidas a tiempo real por el postprocesado que se necesita hacer de la señal.

El último sistema de medida utiliza el dominio frecuencial y es el que se ha utilizado en los trabajos de esta tesis. Su principio de funcionamiento se explicará en el siguiente punto.

\section{C.1 Técnicas en el dominio de la frecuencia}

Como su nombre indica, estas técnicas hacen uso de la relación entre la respuesta frecuencial y temporal de un canal radioeléctrico (ver apéndice B). El principio de funcionamiento se basa en el análisis mediante barrido en frecuencia del canal radioeléctrico [Rap96]. Un analizador de redes representa un buen ejemplo de aparato para realizar este barrido mediante el parámetro $S_{21}$. El analizador barre un conjunto discreto de $N$ frecuencias $\left(f_{\mathrm{i}}\right)$ espaciadas una cierta frecuencia $(\Delta f)$, con lo que se tendrá caracterizada la función $T\left(t, f_{i}\right)$ para un instante dado, y para el conjunto de frecuencias $f_{\mathrm{i}}$ que utilice el analizador.

Los parámetros de diseño son el número de puntos $N$, el ancho de banda total de medida $(N \Delta f)$, el ancho de banda de frecuencia intermedia y la velocidad de barrido. El máximo retardo medible con este sistema es de $N / \Delta f$, y la resolución temporal de $1 / \Delta f$. El ancho de banda de frecuencia intermedia determina el ruido térmico en el receptor.

Las ventajas de este tipo de medida son que se puede obtener tanto la fase como la amplitud de la respuesta en frecuencia del canal, y que eligiendo un ancho de banda 
de frecuencia intermedia lo suficientemente bajo el ruido del sistema disminuirá considerablemente.

Las desventajas son que necesitamos que el canal sea estático durante el tiempo de medida, la calibración de los elementos del sistema y la sincronización entre el transmisor y el receptor.

\section{C.2 Sistema de medidas basado en un analizador de redes}

El esquema de la figura. C.1 ha sido utilizado en parte de la presente tesis para la realización de campañas de medida. A continuación se describirán los componentes fundamentales del equipo de medida. En la figura C.2 se presentan dos fotografías del equipo de medidas excluidas las antenas.

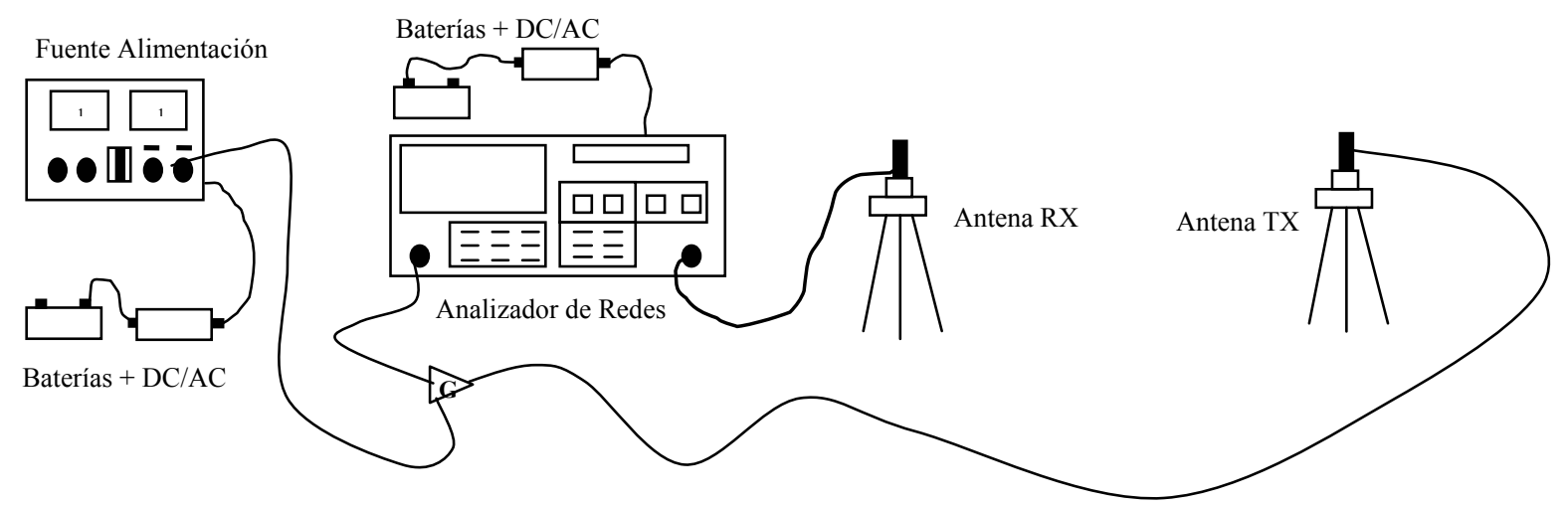

Figura C.1: Diagrama del equipo de medidas basado en la respuesta frecuencial mediante el uso de un analizador de redes.
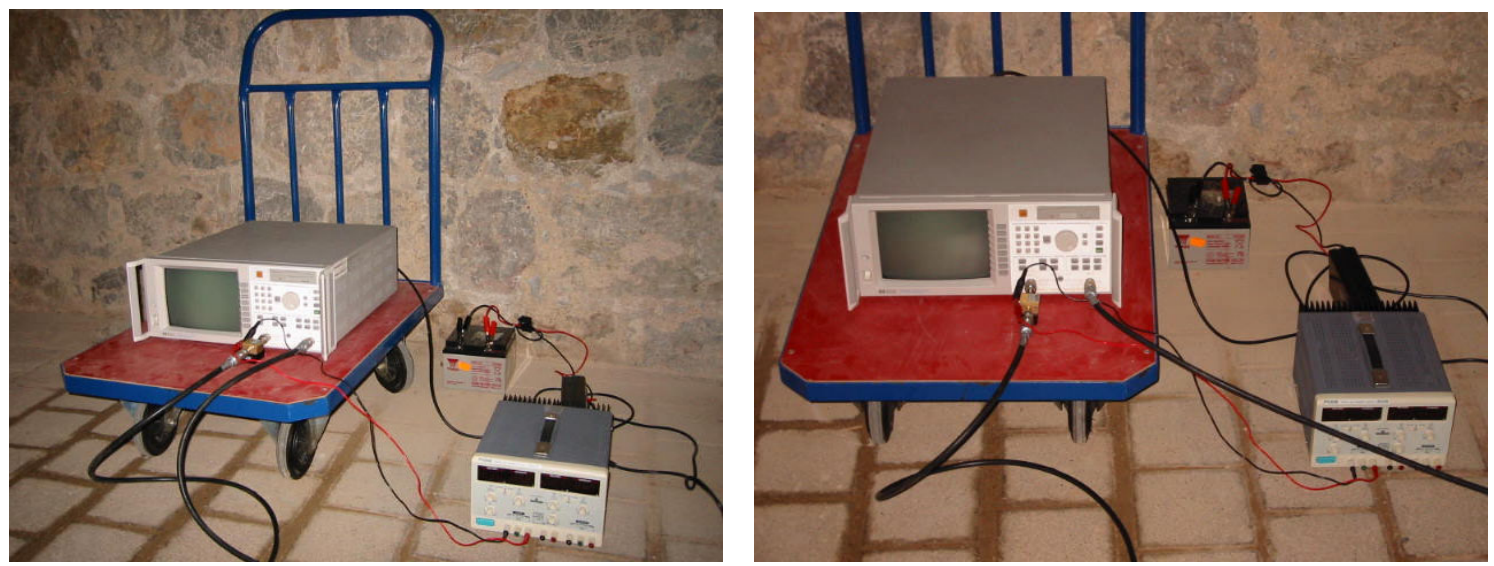

Figura C.2: Fotografías del equipo de medidas. 


\section{C.2.1 Analizador de redes}

Se ha utilizado el analizador HP8714ES (figura C.3). Uno de los puertos del analizador se ha utilizado como transmisor y el otro como receptor. En la siguiente tabla se resumen sus características técnicas:

\begin{tabular}{|c|c|}
\hline Característica & Valor \\
\hline Frecuencia máxima & $3 \mathrm{GHz}$ \\
\hline Impedancia característica del analizador & $50 \Omega$ \\
\hline Potencia máxima de salida & $10 \mathrm{dBm}$ \\
\hline $\begin{array}{c}\text { Ancho de banda mínimo en Frecuencia } \\
\text { Intermedia }\end{array}$ & $10 \mathrm{~Hz}$ \\
\hline Factor de promedio & 32 \\
\hline Número máximo de puntos & 1601 \\
\hline
\end{tabular}

Tabla C.1: Características del analizador de redes HP8714ES.

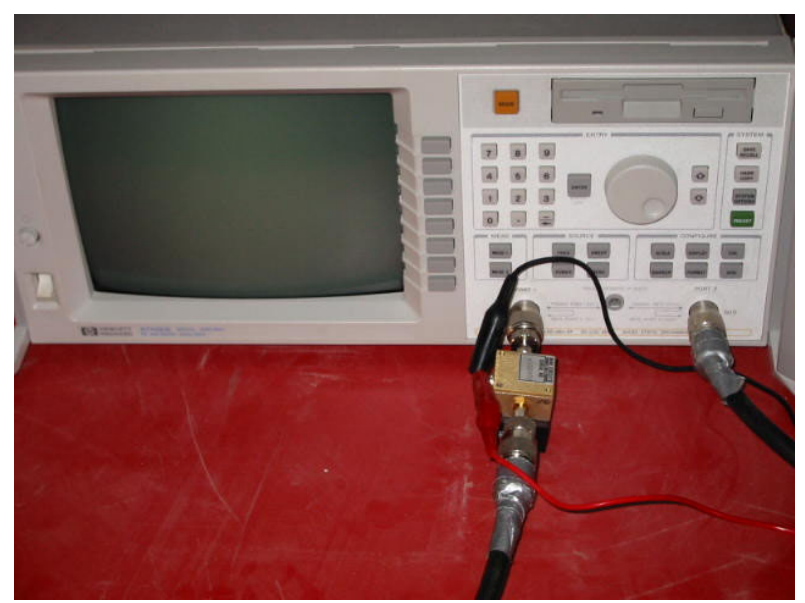

Figura C.3: Analizador de redes HP 8714.

\section{C.2.2 Cables y conectores}

Para las medidas se ha utilizado el cable RG-213/U cuya hoja de características se detalla en la tabla C.1. La frecuencia de corte es de $1 \mathrm{GHz}$, pero con una adecuada calibración se puede utilizar en frecuencias ligeramente superiores como $2 \mathrm{GHz}$. Los cables utilizados se terminaron con conectores tipo $N$ que son los que utiliza el analizador de redes descrito anteriormente. 


\begin{tabular}{|c|c|}
\hline Característica & Valor \\
\hline Conductor & BC (7) $2.26 \mathrm{~mm}$ \\
\hline Dieléctrico & PE $7.24 \mathrm{~mm}$ \\
\hline Apantallamiento & $33 \mathrm{BC} 8.08 \mathrm{~mm}$ \\
\hline Cubierta & PVC-IIA $10.29 \mathrm{~mm}$ \\
\hline Peso & $0.165 \mathrm{Kg} / \mathrm{m}$ \\
\hline Impedancia & $50+/-2$ \\
\hline Velocidad propagación & $66 \%$ \\
\hline Capacidad & $101.1(\mathrm{pF} / \mathrm{m})$ \\
\hline Máximo voltaje & $5000 \mathrm{Vrms}$ \\
\hline Temperatura & $-40{ }^{\circ} \mathrm{C}-+85{ }^{\circ} \mathrm{C}$ \\
\hline Frecuencia (max) & $1 \mathrm{GHz}$ \\
\hline Constantes de Atenuación & $K_{1}=0.162$ \\
& $K_{2}=0.00126$ \\
\hline
\end{tabular}

Tabla C.2. Características del cable RG-213/U.

Para las medidas del capítulo 5, se utilizaron cables AR010 de 1.7 metros de longitud y una frecuencia de trabajo de hasta $3 \mathrm{GHz}$.

\section{C.2.3 Amplificadores}

A las frecuencias de las comunicaciones móviles, la atenuación del cable utilizado es elevada. Su atenuación a $2 \mathrm{GHz}$ es de aproximadamente $0.5 \mathrm{~dB} / \mathrm{m}$, lo que supone una atenuación de $25 \mathrm{~dB}$ para una longitud de $50 \mathrm{~m}$. Por esto, se recurrió al uso de amplificadores que compensasen estas pérdidas. Se seleccionaron los modelos ZFL2500VH y el ZJL-3G de Minicircuits (figura C4) cuyas características se detallan en la tabla C.3.
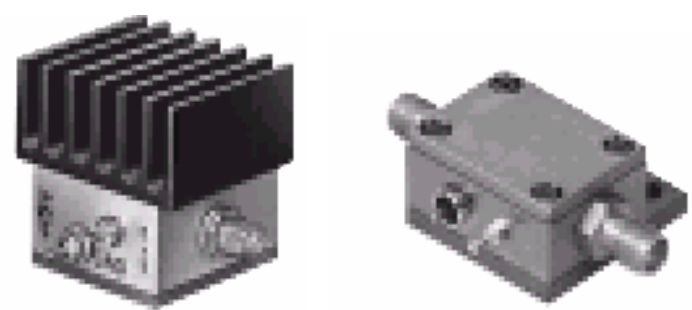

Figura C.4: Amplificadores minicircuits a) ZFL-2500VH y b) ZJL-3G. 


\begin{tabular}{|c|c|c|}
\hline Característica & ZFL-2500VH & ZJL-3G \\
\hline Rango de frecuencias & $10-2500 \mathrm{~Hz}$ & $20-3000 \mathrm{~Hz}$ \\
\hline Ganancia Mínima & $20 \mathrm{~dB}$ & $14 \mathrm{~dB}$ \\
\hline Máxima potencia de salida & $24 \mathrm{dBm}$ & $8 \mathrm{dBm}$ \\
\hline Figura de ruido & $5.5 \mathrm{~dB}$ & $3.80 \mathrm{~dB}$ \\
\hline Intermodulación IP3 & $35 \mathrm{dBm}$ & $22 \mathrm{dBm}$ \\
\hline VSWR & 1.7 & 1.40 \\
\hline Corriente & $300 \mathrm{~mA}$ & $45 \mathrm{~mA}$ \\
\hline Voltaje & $15 \mathrm{~V}$ & $12 \mathrm{~V}$ \\
\hline Conectores & SMA & SMA \\
\hline
\end{tabular}

Tabla C.3: Características de los amplificadores ZFL-2500VH y ZJL-3G.

En el caso del ZFL-2500VH, al ser un amplificador de potencia, se puede poner directamente a la salida del analizador de redes, sin embargo el ZJL-3G satura con la máxima potencia de salida del analizador, así que para que amplifique adecuadamente no debe de ponerse en este punto del montaje (figura C.1).

\section{C.2.3 Antenas}

Las antenas utilizadas para el montaje de la figura C.1 son antenas pequeñas bicónicas de banda ancha cuyo dibujo se detalla en la figura. C.5. En la figura C.6 se presentan dos fotografías de las mismas antenas. Las características técnicas de esta antena se resumen en la tabla C.4.

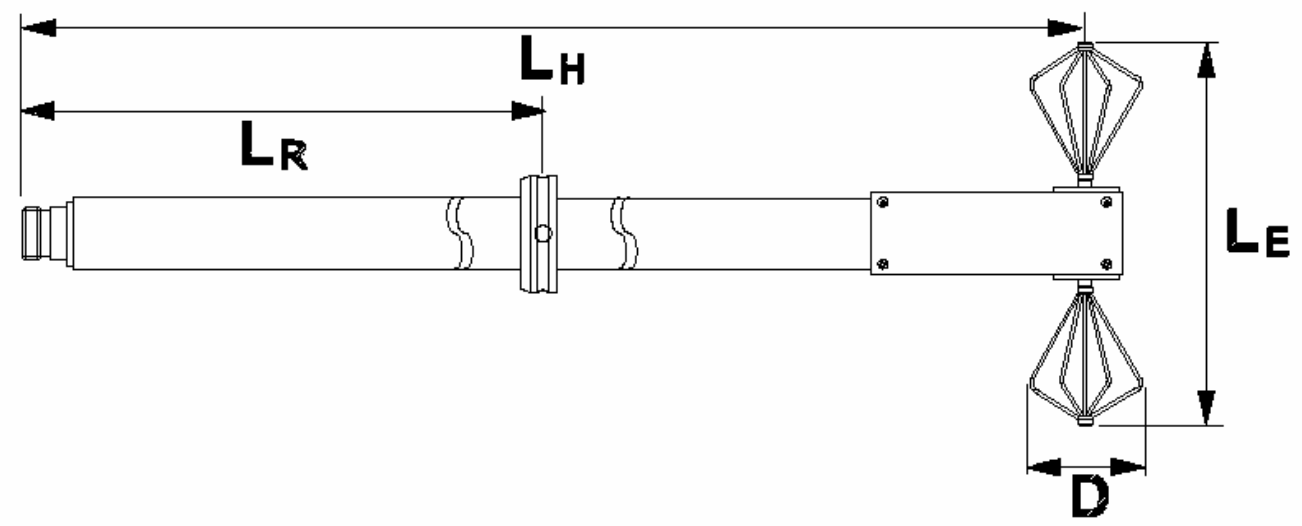

Figura C.5: Antena Microwave Biconical Antenna SBA 9113. 


\begin{tabular}{|c|c|}
\hline Característica & Valor \\
\hline Polarización & Lineal \\
\hline Frecuencias de funcionamiento & $500 \mathrm{MHz}$ a $3 \mathrm{GHz}$ \\
\hline Impedancia de entrada & $50 \Omega$ \\
\hline $\mathrm{L}_{\mathrm{E}}$ & $140 \mathrm{~mm}$ \\
\hline $\mathrm{D}$ & $49 \mathrm{~mm}$ \\
\hline Tubo & $22 \mathrm{~mm}$ \\
\hline Ganancia & $-1.5 \mathrm{dBi}$ a $1.5 \mathrm{dBi}$ \\
\hline Factor de antena & $25 \ldots 41 \mathrm{~dB} / \mathrm{m}$ \\
\hline Máxima potencia de entrada & 20 \\
\hline Peso & $750 \mathrm{~g}$ \\
\hline Inversión de simetría & $<0.2 \mathrm{~dB}$ \\
\hline
\end{tabular}

Tabla C.4: Características de la antena $S B A 9113$.
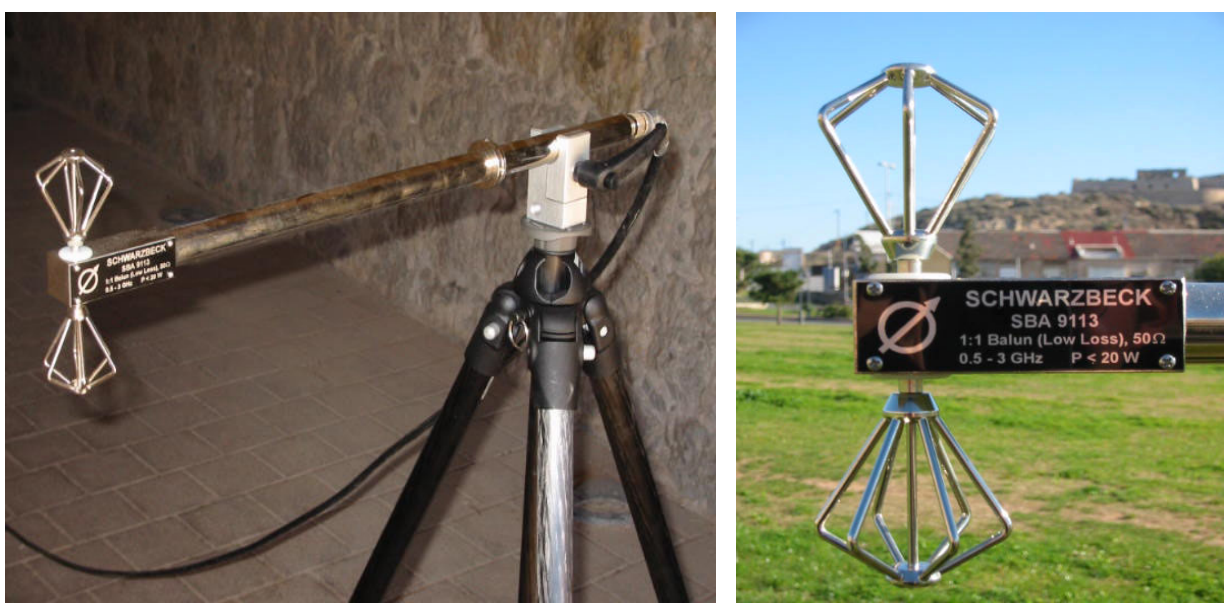

Figura C.6: Fotografías de las antenas SBA 9113.

También se utilizaron en la realización de la tesis (capítulo 5):

- Varios monopolos sintonizados a $900 \mathrm{MHz}$ (Ref-SCH32).

- Una antena de panel KATREIN (742-149) con ancho de haz 90', ganancia 7dBi y frecuencias de funcionamiento 824-960/1710-2170 MHz.

- Una antena colineal KATREIN (738-449) Omnidireccional, ganancia 2dBi y frecuencias de funcionamiento 824-960/1710-2170 MHz. 



\section{Apéndice D}

\section{Multiple-Input Multiple-Output}

El incremento de la demanda de espectro radioeléctrico ha motivado el estudio de nuevas técnicas que aumenten eficientemente el uso del mismo. Los sistemas tradicionales están formados por una antena transmisora y otra receptora (sistemas Single-Input Single-Output (SISO)). La capacidad máxima teórica que se puede obtener con un sistema de este tipo fue predicha por Shannon en 1948 [Sha48]. En algunos casos, esta configuración se modifica aumentando el número de antenas transmisoras o receptoras para dotar de diversidad en transmisión o en recepción respectivamente [Rab97], pero con esto no se aumenta la capacidad del sistema.

Los trabajos pioneros de Winter [Win87], y sobre todo los de Foschini [Fos96] y Telatar [Te199] demuestran que aumentando el número de antenas a ambos lados del canal, se aumenta sustancialmente el número de bits transmitidos por hercio, cosa impensable en sistemas SISO. Los sistemas MIMO, utilizan múltiples antenas en transmisión, y múltiples antenas en recepción; y garantizando que el entorno ofrezca una rica dispersión angular, se podrá procesar la información en recepción y aumentar 
enormemente la capacidad [Fos96]. Este aumento de la capacidad espectral está asociado a una riqueza de dispersión en el entorno, la cual permite la transmisión de información por caminos independientes. Para un sistema con $M$ antenas transmisoras, y $N$ antenas receptoras, ese incremento de capacidad puede llegar hasta ser del orden $\operatorname{del} \min (N, M)$.

\section{D.1 Nociones básicas de Teoría de la Información}

Para un sistema sin memoria con una antena transmisora y otra receptora (Single-Input Single-Output) (figura D.1.a), la capacidad máxima del sistema viene dada por [Sha48]:

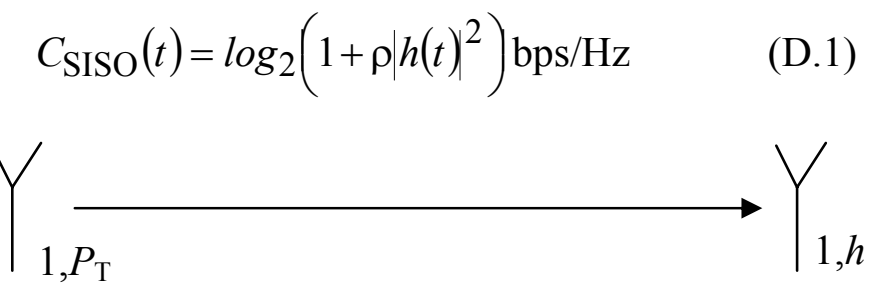

Figura D.1: Esquema de un sistema SISO.

donde $h(t)$ es la respuesta instantánea compleja normalizada del canal, y $\rho$ es la relación señal a ruido $(S N R)$ en el receptor. En el caso que se aumente el número de antenas en recepción (Single-Input Multiple-Output SIMO) (Diversidad en recepción, figura D.2.b), la capacidad máxima viene dada por [Ges03]:

$$
C_{\mathrm{SIMO}}(t)=\log _{2}\left(1+\rho \sum_{i=1}^{N} \mid h_{i}(t)^{2}\right) \mathrm{bps} / \mathrm{Hz}
$$
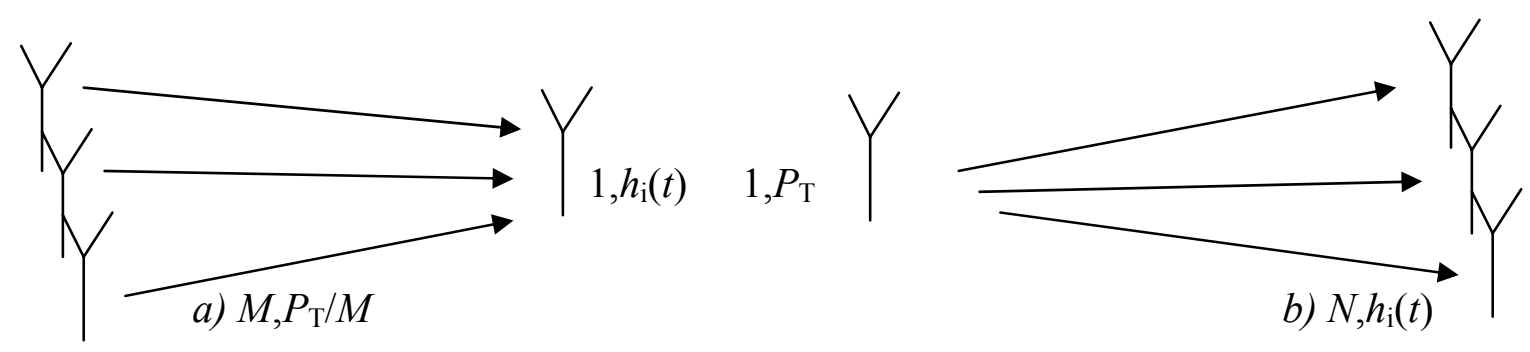

Figura D.2: Esquema de un sistema a) MISO y b) $S I M O$.

donde $N$ es el número de antenas receptoras, y $h_{i}(t)$ es la respuesta compleja normalizada del canal cuando se recibe por la antena $i$-ésima. La capacidad cuando se 
utiliza diversidad en recepción tiene un aumento logarítmico con el número de antenas, similar a un aumento de $\rho$. El caso dual sería aumentar el número de antenas transmisoras dotando de diversidad de transmisión al sistema (Multiple-Input SingleOutput MISO) (Fig. D.2.a). La capacidad resultante es [Ges03]:

$$
C_{\mathrm{MISO}}(t)=\log _{2}\left(1+\frac{\rho}{M} \sum_{i=1}^{M} \mid h_{i}(t)^{2}\right) \mathrm{bps} / \mathrm{Hz}
$$

donde $M$ es el número de antenas transmisoras y $h_{i}(t)$ es la respuesta compleja normalizada del canal cuando se transmite por la antena $i$-ésima. La normalización de la señal a ruido con el número de antenas transmisoras se debe a la restricción de que la potencia total transmitida debe ser constante para que todos los casos sean comparables, es decir, que la suma de las potencias de cada antena transmisora es constante y de valor $P_{\mathrm{T}}$.

\section{D.2 Capacidad MIMO}

En el apartado anterior se ha repasado la capacidad máxima teórica de los sistemas SISO, SIMO y MISO. Como extensión de estos, si se aumenta el número de antenas tanto en transmisión como en recepción tendremos un sistema MIMO (Multiple-Input Multiple-Output). El modelo más sencillo (banda estrecha) de un canal MIMO es:

$$
r=\mathbf{G} s+n
$$

donde $r$ es un vector complejo de dimensiones $N \mathrm{x} 1 \mathrm{y}$ representa la señal recibida en las $N$ antenas receptoras, $\mathbf{G}$ es una matriz de dimensiones $N \mathrm{x} M$, donde cada elemento $\mathbf{G}_{i, j}$ es la respuesta del canal cuando transmite la antena $j$ y recibe la antena $i, s$ es un vector $M \times 1$ que representa las señales transmitidas por las $M$ antenas transmisoras y $n$ es un vector ruido de las mismas dimensiones que $r$. La capacidad máxima viene dada por [Fos96] :

$$
C_{\mathrm{MIMO}}(t)=\log _{2}\left(\operatorname{det}\left[\mathbf{I}_{N}+\frac{\rho}{M} \mathbf{H}(t) \mathbf{H}^{H}(t)\right]\right) \mathrm{bps} / \mathrm{Hz}
$$




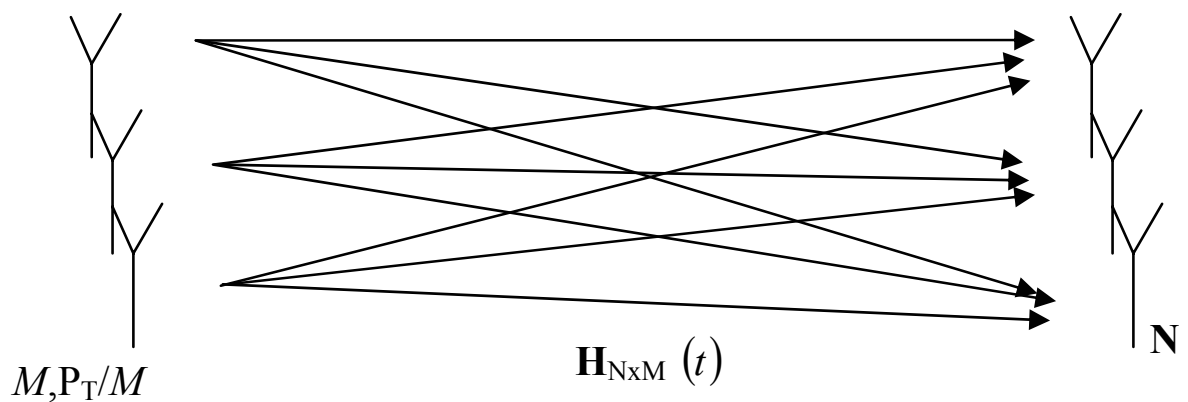

Figura D.3: Esquema de un sistema MIMO.

donde $\left({ }^{\mathrm{H}}\right)$ indica transpuesto-conjugado, $\mathbf{I}_{\mathrm{N}}$ es la matriz identidad de dimensiones $N \mathrm{x} N$ y $\mathbf{H}$ es la matriz $\mathbf{G}$ normalizada de tal forma que el valor medio de $\left|\mathbf{H}_{i j}\right|, E\left\langle\mathbf{H}_{i j}\right\rangle=1$. También puede expresarse mediante la norma de Frobenius como $E\left\langle\mathbf{H}_{F}^{2}\right\rangle=N M[$ Alm03]. $\mathbf{H}$ debe conocerse en el receptor para demodular adecuadamente la señal. Se demuestra en [Te199] y [Fos96] que el aumento de la capacidad máxima teórica para un sistema de estas características tiene un incremento lineal con el número de antenas.

La expresión (D.5) indica cuál es la capacidad máxima para un sistema de múltiples antenas cuando el transmisor no conoce la respuesta del canal $\mathbf{H}$. En este caso el transmisor reparte la potencia de forma igual entre todas las antenas. Cuando el transmisor conoce la respuesta del canal, éste puede optimizar la transmisión de la información repartiendo la potencia de forma que la capacidad sea máxima (inyectando más potencia en los canales más favorables). Cuando el transmisor conoce la respuesta del canal, y adecúa la potencia a éste toma el nombre de Water-Filling. La expresión que define esta capacidad para un sistema $M I M O$ con conocimiento del canal en el transmisor viene dada por [Te199]:

$$
C_{\mathrm{MIMO}_{-} \mathrm{WF}}(t)=\log _{2}\left(\operatorname{det}\left[\mathbf{I}_{\mathrm{N}}+\mathbf{H}(t) \mathbf{Q} \mathbf{H}^{\mathrm{H}}(t)\right]\right) \mathrm{bps} / \mathrm{Hz}
$$

donde $\mathbf{Q}$ es la matriz de covarianza del vector $s$. La traza de $\mathbf{Q}$ debe de ser menor que $\rho$ para asegurar la restricción de limitar la potencia transmitida en el transmisor. Por otro lado, para el caso en que $\mathbf{Q}=(\rho / N) \mathbf{I}_{\mathrm{N}}$, es decir cuando la potencia se distribuya de forma uniforme, (D.6) se convierte en (D.5). La expresión (D.5) se puede rescribir mediante [Te199]: 


$$
C_{\mathrm{MIMO}}(t)=\sum_{i=1}^{m} \log _{2}\left(1+\frac{\rho}{N} \lambda_{i}(t)\right) \mathrm{bps} / \mathrm{Hz}
$$

donde $\lambda_{\mathrm{i}}(t)$ son los valores propios de $\mathbf{W}(t), m$ el mínimo de $M$ y $N, \mathrm{y} \mathbf{W}(t)$ :

$$
\mathbf{W}(t)=\left\{\begin{array}{l}
\mathbf{H}(t) \mathbf{H}^{\mathrm{H}}(t)=\mathbf{U}(t) \boldsymbol{\Lambda}(t) \mathbf{U}^{\mathrm{H}}(t), M \leq N \\
\mathbf{H}^{\mathrm{H}}(t) \mathbf{H}(t)=\mathbf{V}(t) \boldsymbol{\Lambda}(t) \mathbf{V}^{\mathrm{H}}(t), M>N
\end{array}\right.
$$

donde $\mathbf{U}(t)$ y $\mathbf{V}(t)$ son matrices unidad, y $\Lambda(t)$ contiene los $m$ valores propios $\lambda_{\mathrm{i}}$. Para el caso de Water-Filling [Te199]:

$$
C_{\mathrm{MIMO}_{-} \mathrm{WF}}(t)=\sum_{i=1}^{m} \log _{2}\left(\mu \lambda_{i}(t)\right)^{+}
$$

donde se satisface la ecuación siguiente:

$$
\rho(t)=\sum_{i=1}^{m}\left(\mu-\lambda_{i}^{-1}(t)\right)^{+}
$$

y "+" significa que sólo se toman los valores positivos de esta expresión y $\mu$ se denomina nivel de llenado. Se demuestra que el Water-Filling mejora al uniforme cuando la señal a ruido es baja [Smi02]. Por ejemplo, para una $\rho$ de $-10 \mathrm{~dB}$ se produce una mejora del 200\% [Chu02]. Sin embargo, para entornos donde la potencia recibida es muy superior al ruido ambas estrategias convergen [Ges03].

\section{D.3 Ganancia de Array, de diversidad y de multiplexado}

La ganancia de array es un aumento de la $S N R$ en el receptor debido a un procesado de la señal en el transmisor o en el receptor. Este procesado consiste en combinar varias señales. Para obtener esta ganancia bien el transmisor o el receptor deben conocer el canal, y dado que es más sencillo que el receptor conozca la respuesta del canal, la ganancia de array se suele implementar en el receptor.

La diversidad consiste en obtener réplicas de la misma señal transmitida que se hayan propagado por canales cuyos desvanecimientos sean independientes. Esto garantiza en cierta medida que aunque una de ellas se desvanezca fuertemente, alguna de las otras nos dé nivel suficientemente alto como para poder recuperar la señal. La diversidad puede hacerse en frecuencia, tiempo, espacio, polarización, etc. Se suele preferir la diversidad espacial ya que no repercute en la eficiencia espectral de un sistema. 
La ganancia por multiplexado espacial es el incremento lineal que se produce en un sistema $M I M O$ cuando aumenta el número de antenas sin coste extra alguno de potencia o ancho de banda [Fos96]. Esta ganancia se consigue mediante la transmisión de flujos de datos independientes en cada uno de los autovalores significativos de la matriz de transferencia.

\section{D.4 Capacidad Ergódica y Outage}

La capacidad, según Shanon, para un usuario en un canal invariante en el tiempo, es la máxima información mutua entre transmisor y receptor. También la podemos definir como la máxima tasa de transferencia de información que se puede transmitir por el canal con una probabilidad de error arbitrariamente baja [Sha48].

Cuando el canal es variante y aleatorio, la capacidad se vuelve una variable aleatoria. Se utilizan generalmente dos criterios para la medida de la misma: la capacidad media o ergódica (Ergodic capacity) y capacidad Outage (Outage Capacity). La capacidad ergódica es la máxima transferencia de información mutua promediada entre todos los estados del canal [Te195][Te199].

La Outage Capacity viene expresada por un \%, el cual indica el porcentaje de tiempo en el cual la capacidad es superior a ese valor $C_{100-X \%}$ [Dri99][Loz01]. Así por ejemplo, una capacidad $C_{0.01}=12 \mathrm{bps} / \mathrm{Hz}$ indicaría que durante el 99\% del tiempo, la capacidad es superior a $12 \mathrm{bps} / \mathrm{Hz}$.

\section{D.5 Técnicas MIMO}

Se han desarrollado diversas técnicas que aprovechan la diversidad espacial de los canales MIMO. Estas técnicas se dividen en dos grupos: Space-Time Coding y Spatial Multiplexing. La primera aprovecha la diversidad espacial para, manteniendo el régimen binario, disminuir la probabilidad de error [Ala98][Tar99]. La segunda aumenta la capacidad del canal para una $S N R$ dada mediante la múltiplexación espacial de la información a transmitir.

En las técnicas Space-Time Coding, las señales que se entregan a las antenas son tratadas como vectores de símbolos que representan un cierto código. El objetivo de estas técnicas es diseñar un código óptimo para que la señal sea demodulada de una forma eficiente en el receptor, y se pueda recuperar la señal con una $S N R$ más baja 
[Tar99]. En la figura D.4 se muestra el esquema de bloque de una codificación SpaceTime Coding obtenido de [Ges03]. Se observa en la figura que cada símbolo $s(k)$ se codifica en un vector del tamaño del número de antenas, de tal forma que la detención en el receptor se haga de una forma más eficiente.

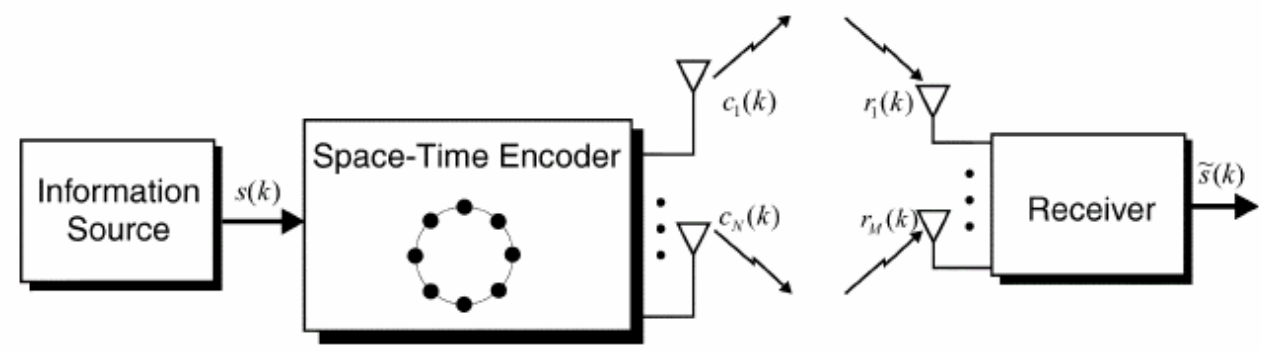

Figura D.4: Esquema de codificación Space-Time Coding obtenido de [Ges03].

El principio básico el Spatial Multiplexing es transmitir la información de forma independiente en cada antena. A la técnica original se le llamó BLAST (Bell Laboratories Layered Sapce Time), aunque ahora se la conoce como Diagonal D$B L A S T$ [Fos96b] y Vertical $V$-BLAST [Wo198]. En estas técnicas el receptor recupera la señal y la combina mediante procesado de señal. Este procesado conlleva combinaciones lineales de decorrelaciones/MMSE, detenciones y cancelación de interferencias no lineales [Ala98]. La figura D.5 muestra un esquema de Spatial Multiplexing para un sistema de 3 antenas transmisoras y tres antenas receptoras obtenido de la referencia [Ges03]. La figura ilustra claramente cómo se realiza el proceso de ganancia de multiplexado. La información se transmite por cada antena independientemente, y se reconstruye en el receptor para formar el código transmitido.

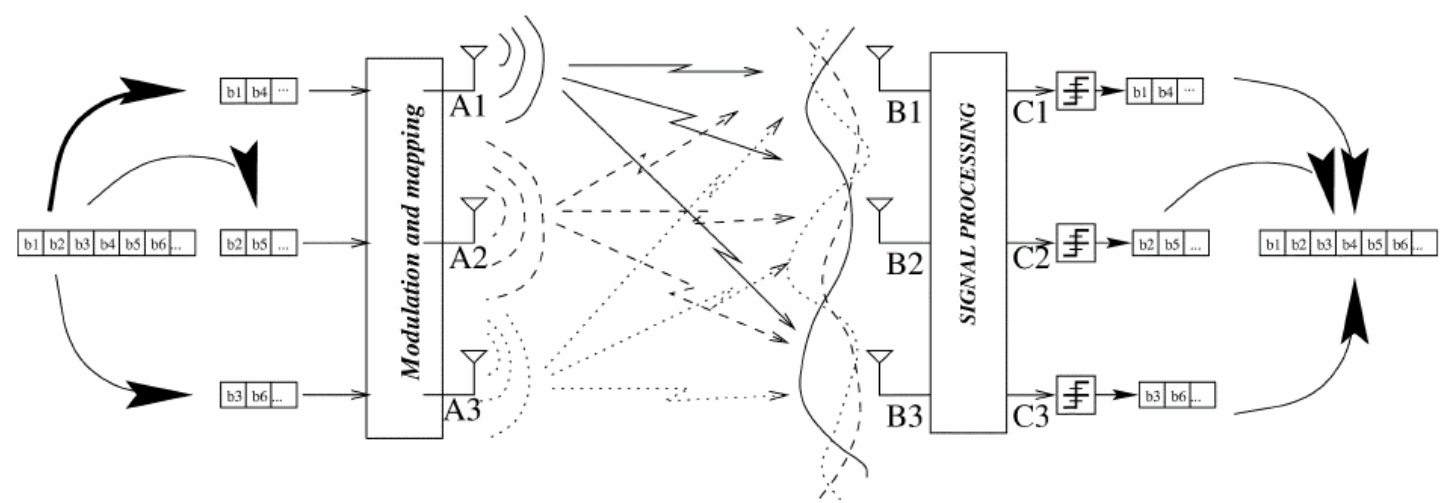

Figura D.5 Esquema de codificación Spatial Multiplexing obtenido de [Ges03] con tres antenas en transmisión y tres antenas en recepción. 



\section{Appendix E}

\section{Summary in English}

Wireless communications are nowadays an essential part of the everyday life of the society we live in. Being able to communicate at any time and from anywhere has become a requirement as well as a sign of quality of the communications. In addition, the demand for data exchange has increased considerably: what used to be simple voiced conversations are now data communications where information is transmitted at high speed. This implies developing advanced communications systems that are capable of meeting these requirements and needs.

The demand for transmitting great amounts of data via radio causes a focus on the search for possible ways of increasing the transmission capacity using the scant radio resources available. Communicating from inside tunnels, shopping malls and means of transport among other places is a new requirement of every modern telecommunication system.

One of the technologies used for increasing the capacity in the wireless interface is that of wideband communications, which capacity is proportional to the bandwidth 
used. The analysis of these systems is complicated because new parameters come up, which characterise their behaviour (appendix B).

Another possible way of increasing the capacity is the use of multiple antennas at both sides of the communication link. Placing these antennas enables reaching high spectral efficiencies (bits/sg/Hz), which would be impossible with conventional systems. Signals that arrive and depart from the various radiant elements must be sufficiently decorrelated. This new technology is the so-called MIMO (Multiple-Input Multiple-Output) (appendix D).

For the development of these mobile communication systems it becomes necessary to create theoretical models that characterise the main propagation mechanisms for the different kinds of environments. These models may originate either from the analysis of data obtained by measurements or from other more complex models that solve the electromagnetic problem theoretically. These usually offer approximate and easy to implement solutions, giving results that are a trade between computational cost and accuracy. In this thesis a ray-launching model has been used, which is based on Geometric Optics (GO) and Uniform Theory of Diffraction (UTD) (appendix A).

Measuring the radio channel is essential for its study, since it allows us both to obtain the data required for the implementation of the models and to verify these data.

The main aim of this thesis is the theoretical and experimental study of the radio channel in micro cellular and special environments such as tunnels. On the one hand it is a theoretical study because it develops efficient channel models for wideband systems and MIMO systems. On the other hand it is experimental, since it takes real measures in special environments and compares with theoretical models.

The first contribution of this thesis is the development of theoretical models for the analysis of wideband systems and MIMO systems based on Geometric Optics (GO) and Uniform Theory of Diffraction (UTD). The starting point was a ray-launching engine capable of analysing a narrowband deterministic channel. The wideband model is based on the modelling of the channel into $\mathrm{N}$ narrowband channels, in order to apply to the original ray-launching engine at each one. This frequency channel response is transformed into time domain by using the Inverse Fourier Transform. The raylaunching engine has been extended to MIMO systems for the simulator to be able to reconstruct the MIMO transfer matrix simulating the channels between the transmitting and receiving antennas. A channel model has also been developed, which from a simple 
SISO realisation reconstructs the MIMO channel by means of the study of the various propagation mechanisms.

This thesis also contributes to the study of the propagation in tunnels. First of all, from a theoretical point of view, the angular spread in the transition to an ideal tunnel has been studied by using the ray launching. It was concluded that the angular spread in this zone has a maximum at the beginning of the excitation zone, unlike the delay spread, where the maximum is found at the end. The length of this excitation zone in different tunnels was studied using two methods: a mathematical method and a physical one. The first one calculates the mean square error between the path loss and its two regression lines. The second one uses the definition of excitation zone, where the energy of the reflected rays is greater than the energy of the diffracted rays. Both methods show similar and satisfactory results.

Wideband measures were also taken in a small tunnel located at the university campus of the Technical University of Cartagena. These measurements were compared to the wideband ray-launching model and the results were satisfactory too. In a theoretical way, the capacity of a MIMO system inside a tunnel was studied. It was observed that the capacity takes its highest value at the entrance, where the angular spread in the receptor reaches its maximum, and there exists a distance from the entrance of the tunnel where the capacity drops sharply. This distance is related to the excitation zone of the tunnel.

Another contribution of this thesis is the study of propagation in micro cellular environments. The ray-launching engine has been used to study the radio propagation behaviour in two micro cellular environments: a regular street corner and a chaflane street corner. It was observed that the delay spread takes higher values in the chaflane street corner. Measures have been taken using a network analyser for modelling and comparing these two environments at $450 \mathrm{MHz}, 900 \mathrm{MHz}, 1800 \mathrm{MHz}$, and $2400 \mathrm{MHz}$. Two different propagation situations have been distinguished for each environment and frequency: LoS and NLoS. The delay spread, frequency correlation, tapped delay lines and coherence bandwidth have been studied.

The theoretical MIMO capacity has also been studied in these two micro cellular environments. The optimal configuration of the arrays was analysed and the capacity behaviour on corners in the two previous environments was studied too. The following task was the application of the model extending a SISO realisation to a MIMO one in a real micro cellular environment in the city of Murcia. It was shown 
that, for short distances, this model gives more accurate results than the classical planar wave model.

Finally, distributed systems have been studied. These systems simultaneously use more than one base station in order to increase the diversity. For the analysis a tworay model was used for the rural environment and the ray tracing was used for the urban environment. In both of them capacity increased significantly when distribution of the antennas at the base station was used and it was observed that the smaller eigenvalues increased.

The last contribution of the thesis is registered in chapter 5. In this chapter a measurement system for multiple antenna systems is developed, which is based on two network analysers that are PC controlled and capable of taking MIMO measures for a high amount of antennas both in transmission and in reception. The main elements of the system are a conventional analyser, a multiport analyser, a fast switcher and a PC. The communication among all of these elements is centred on the PC and it takes place via WLAN with the multiport analyser, via LAN with the conventional analyser, and via GPIB with the fast switcher. Initial measures at $900 \mathrm{MHz}$ and $2 \mathrm{MHz}$ taken at the university have also been presented.

As for future research lines the first one would be to carry on with the development of propagation models that simplify the radio channel analysis, more precisely MIMO models that simulate in an efficient way multiple antenna systems. Following this line stochastic-deterministic models allow the analysis at a reasonable cost in complex environments.

Regarding multiple antenna systems, in this thesis the physical layer for one single user has been studied. It is assumed that the interference is zero, though this is not so in real systems, since the system is shared among many different users. Thus, another possible research line is the study of the radio channel in presence of interferences for the different radio access techniques.

On the other hand, behind the physical layer there is a remarkable task of signal processing. From this task, the effective recovery of the signals and the real increase of capacity are produced. It would be interesting to go into detail with the various signal processing techniques for MIMO systems, and to test them both in the channel models developed in the present thesis and in the models of the literature.

Finally, another future research line would be the use of the measurement equipment developed in chapter 5 for measurement campaigns in the different 
environments. Firstly, regular street corners, chaflanes and tunnels could be measured. Secondly, these campaigns could be taken to other environments. All these measurements could be performed initially in narrowband, and they could be later performed in wideband.

Some of the materials of this thesis have been published elsewhere as listed below:

One work of chapter 2 has been published in:

Rubén Hibernón Fernández, José María Molina García-Pardo, y Leandro Juan-Llácer, "Herramienta para Análisis de Canales MIMO en Microceldas Basada en GIS", XIX Simposium Nacional de la Unión Cientifica Internacional de Radio, Barcelona, Septiembre 2004.

Seven works of chapter 3 has been published in:

José María Molina Garcia-Pardo and Leandro Juan-Llácer, "Path Loss, Delay Spread and Angular Spread at 2.1 GHz while entering Tunnels", COST 273 TD(02) 043, Espoo, Finland 2002/May/30-31.

José María Molina Garcia-Pardo, José Victor Rodríguez Rodríguez, and Leandro Juan-Llácer, "Angular Spread at 2.1 GHz while entering Tunnels", Microwave and Optical Technology Letters, vol. 37, no. 3, May 2003.

José María Molina García-Pardo, José Victor Rodríguez Rodríguez y Leandro Juan-Llácer, "Cálculo de la Zona de Excitación para diversos túneles a la frecuencia de 2.1 GHz", XVII Simposium Nacional de la Unión Cientifica Internacional de Radio, Alcalá de Henáres, Madrid, Septiembre 2002.

José María Molina Garcia-Pardo, Jose Victor Rodriguez and Leandro Juan-Llácer, "Measurements and Characterization of the Wide Band Complex Channel Transfer Function in a Small Tunnel”, COST 273 TD(03)016 Barcelona, Spain 2003/January.

Jose-Maria Molina-García-Pardo, Jose-Victor Rodríguez, and Leandro Juan-Llacer, "Wide-Band Measurements and Characterization at $2.1 \mathrm{GHz}$ While Entering in a Small Tunnel", IEEE Transaction on Vehicular Technology, vol. 53, no. 6, November 2004.

José María Molina García-Pardo, José Victor Rodríguez Rodríguez y Leandro Juan-Llácer, "Capacidad MIMO en la Transición de entrada a un Túnel”, XVIII Simposium Nacional de la Unión Científica Internacional de Radio, A Coruña, 10-12 Septiembre 2003.

José-María Molina-García-Pardo, José-Víctor Rodríguez and Leandro Juan-Llácer, "MIMO Capacity at $2.1 \mathrm{GHz}$ While Entering Tunnels", IEEE Vehicular Technology Conference Fall, Los Ángeles, September, 2004. 
Seven works of chapter 4 has been published in:

Jose-Maria Molina-García-Pardo and Leandro Juan-Llácer, "Time Delay Spread at $2.1 \mathrm{GHz}$ around Regular and Chaflane Street Corners for Microcellular Communications", The 13th IEEE International Symposium on Personal, Indoor and Mobile Radio Communications, vol. 3, pp. 12001202, Lisbon, 15-18 September 2002.

Jose-Maria Molina-Garcia-Pardo, Vicent-Miquel Rodrigo-Peñarrocha and Leandro Juan-Llacer "Wideband Radio Communication Measurements at 450, 900, 1800 and $2400 \mathrm{MHz}$ at Regular and Chaflane Street Corners", IEEE Antennas and Propagation Conference, Ohio, June 2003.

Jose-Maria Molina-Garcia-Pardo, Vicent-Miquel Rodrigo-Peñarrocha and Leandro Juan-Llacer "Characterization at 450, 900, 1800 and $2400 \mathrm{MHz}$ of Regular and Chaflane Street Corners by Measurements", accepted for publication in IEEE Transactions on Antennas and Propagation.

Jose-Maria Molina-Garcia-Pardo, Jose-Victor Rodriguez, Leandro JuanLlacer, "Evaluation of MIMO capacity in regular and chaflane street corners for microcellular communications", The 14th IEEE International Symposium on Personal, Indoor and Mobile Radio Communications, 2003. PIMRC 2003, vol. 2, pp 1511-1515, Beijing, China, September 2003.

José-María Molina-García-Pardo, José-Víctor Rodríguez and Leandro Juan-Llácer, "Modelo MIMO Paramétrico para Simulaciones utilizando el Trazado de Rayos", XIX Simposium Nacional de la Unión Científica Internacional de Radio, Barcelona, Septiembre 2004.

José-María Molina-García-Pardo, José-Víctor Rodríguez and Leandro Juan-Llácer, "Parametric MIMO Model for Ray Tracing/Launching Simulations", IEEE Vehicular Technology Conference Fall, Los Ángeles, September 2004.

José-María Molina-García-Pardo, Domingo Pardo-Quiles, José Victor Rodríguez and Leandro Juan-Llácer, "A Distributed MIMO Scheme for Urban Street Microcells", 15th IEEE International Symposium on Personal, Indoor and Mobile Radio Communications, Barcelona, September 2004.

Two works of chapter 5 has been published in:

Javier Celdrán-Blaya, José María Molina García-Pardo, y Leandro JuanLlácer, "Sistema de medidas MIMO basado en dos analizadores de redes", XIX Simposium Nacional de la Unión Científica Internacional de Radio, Barcelona, Septiembre 2004.

Jose-María Molina-Garcia-Pardo, Javier Celdrán-Blaya, Jose-Victor Rodríguez y Leandro Juan-Llácer, "A MIMO Measurement System Based on Two Network Analyzers”, COST 273 TD(04)106, Gothenburg, Sweden, 2004/June/09-10. 


\section{Bibliografía}

[Ala98] S. M. Alamouti, “A Simple Transmit Diversity Technique for Wireless Communications", IEEE Journal on Selected Areas in Communications, vol. 16, no. 8, pp. 1451-1458, 1998.

[Alm03] P. Almers, F. Tufvesson, P. Karlsson and A. Molish, "The Effect of Horizontal Array Orientation on MIMO Channel Capacity", Mitsubishi, TR-2003-39, July 2003.

[Bal89] C. A. Balanis, Advance Engineering Electromagnetics, New York, 1989.

[Bar02] M.Barbiroli, C.Carciofi, G.Falciasecca, M.Frullone, P.Grazcioso and Alessandro Varini, “A New Statistical Approach for Urban Environment Propagation Modelling”, IEEE Transactions on Vehicular Technology, vol. 51, no. 5, pp. 1234-1241, September 2002 .

[Bau00] D. S. Baum, D. Gore, R. Nabar, S. Panchanathan et al., "Measurements and Characterization of Broadband MIMO Fixed Wireless Channels at $2.5 \mathrm{GHz}$, Proceedings of ICPWC'00, Hyderabad, December 2000. 
[Bel63] P. Bello, "Characterization of randomly time-variant linear channels", IEEE Transactions on Communication Systems, CS-11:360-393, December 1963.

[Ber94] H. L. Bertoni, W. Honcharenko, L. R. Maciel and H. H. Xia, "UHF Propagation Predictions for Wireless Personal Communications", Proceedings of the IEEW, vol. 82, no. 9, pp. 1333-1359, September 1994.

[Ber00] H. L. Bertoni, Radio Propagation for Modern Wireless Systems, New Jersey: Prentice Hall, 2000.

[Bur01] A. Burr, "MIMO wireless systems: principles, potential, problems and prospects", COST 273 Helsinki, 2001.

[Bur02] A. Burr, "Evaluation of the Capacity of the MIMO channel in a Corridor using ray tracing techniques", 2002 International Zurich Seminar on Broadband Communications, vol. 47, no. 2, pp 173-176, February 2002.

[Cal02] M. Calvo Ramón, Sistemas de Comunicaciones Móviles de Tercera Generación IMT-2000 (UMTS), Fundación Airtel, 2002.

[Cat99] M. F. Cátedra and J. Pérez-Arriaga, Cell Planning for wireless Communications, Artech House, 1999.

[Ce104] Javier Celdrán-Blaya, José María Molina García-Pardo, y Leandro Juan-Llácer, "Sistema de medidas MIMO basado en dos analizadores de redes", XIX Simposium Nacional de la Unión Científica Internacional de Radio, Barcelona, Septiembre 2004.

[Chi78] J.Chiba, T. Inaba, Y. Kuwamoto, O. Banno, and R. Sato, "Radio communication in tunnels", IEEE Transactions on Microwave Theory Technology, vol. 26, no. 6, pp. 439-443, 1978.

[Chi82] J. Chiba and K. Sugiyama, "Effects of trains on cut-off frequency and field in rectangular tunnel as waveguide", IEEE Transactions on Microwave Theory Technology, vol. 30, no. 5, pp 757-759, May 1982.

[Chi02] D. Chizhik, G. J. Focshini, M. J. Gans and R. A. Valenzuela, "Keyholes, Correlations, and Capacities of Multielement Transmit and Receive Antennas", IEEE Transactions on Wireless Communications, vol. 1, no. 2, pp 361-368, April 2002. 
[Chi03] D. Chizhik, J. Ling, P. Wolniansky, R. Valenzuela, N. Costa and K. Huber, "Miltiple-Input-Multiple-Output Measurements and Modeling in Manhattan", IEEE Journal on Selected Areas in Communications, vol. 21, no. 3, April 2003.

[Chu00] C. N. Chuan, G. J. Foschini, R. A. Valenzuela, D. Chizhik, J. Ling and J. M. Kahn, "Capacity Growth of Multi-element Arrays in Indoor Outdoor Wireless Channels", IEEE Wireless Communication and Networking Conference, 2000.

[Chu02] C. N. Chuah, D. Tse, J. M. Kahn and R. Valenzuela, "Capacity Scaling in MIMO wireless systems under correlation fading", IEEE Transaction on Information Theory, vol. 48, pp. 637-650, March 2002.

[Cla01] M. V. Clark, Thomas. M. Willis III, L. J. Greenstein, A. J. Rustako, V. Erceg and R. S. Roman, "Distributed vs Centralized Antenna Arrays in Broadband Wireless Networks," IEEE Vehicular Technology Conference, pp. 33-37, 2001.

[Con03] Jean-Marc Conrat and Patrice Pajusco, "A Versatile Propagation Channel Simulator for MIMO Link Level Simulation", COST 273 TD(03)120, Paris, France, May 2003 .

[Cos91] COST 231, "Urban Transmission Loss Models for Small-Cell and Micro-Cell Mobile Radio in the 900 and $1800 \mathrm{MHz}$ Bands," Propagation Models Report, no. COST231 TD(90) 119, revision 1, September 1991.

[Cos99] COST 231: European Co-operation in the Field of Scientific and Technical Resarch: Digital Mobile Radio Towards Future Generation System", Final Report, ISBN 92-828-5416-7, Belgium 1999.

[Cos01] COST 259: European Co-operation in Mobile Radio Reserach, Ed. Luis M. Correia, Wireless Flexible Personalized Communications, John Wiley\&Sons, 2001

[Cox77] D. C. Cox, "Multipath Delay Spread and Path Loss Correlation for $910 \mathrm{MHz}$ Urban Mobile Radio Propagation", IEEE Transactions on Vehicular Technology, vol. 26, no. 4, pp. 340-344, November 1977.

[Cre95] P. M. Crespo and J. Jiménez, "Computer Simulation of Radio Channels Using a Harmonic Decomposition Technique", IEEE Transactions on Vehicular Technology, vol. 44, no. 3, pp. 414-419, August 1995.

[De191] P. Delogne, "EM Propagation in Tunnels", IEEE Transactions on Antennas and Propagation, vol. 39, no. 3, pp. 401-406, 1991. 
[Der78] L. Deryck, "Natural propagation of electromagnetic waves in tunnels", IEEE Transactions on Vehicular Technologies, vol. 27, no. 3, pp. 145-150, 1978.

[Des72] G. A. Deschamps, "Ray techniques in electromagnetics", Proceedings of the IEEE, vol. 60, no. 9, pp. 1022-1035, 1972.

[Dev86] D. M. J. Devasirvatham, “Time Delay Spread and Signal Level Measurements of $850 \mathrm{MHz}$ Radio Waves in Building Environments", IEEE Transactions on Antennas and Propagations, vol. 34, no. 11, pp. 1300-1305, November 1986.

[Dri99] Driessen and G. J. Foschini, "On the capacity Formula for Multiple InputMultiple Output Wireless Channels: A Geometric Interpretation", IEEE Transaction on communications, pp 173-176, February 1999.

[Ems75] A. G. Emslie, R. L. Lagace, and P. F. Strong, "Theory of the propagation of UHF radio waves in coal mine tunnels", IEEE Transactions on Antennas Propagation, vol. 23, no. 2, pp. 192-205, 1975.

[End89] A. W. M. van den Enden and N. A. M. Verhoeckx, Discrete-time Signal Processing, Number ISBN 0-13-216755-7, Prentice Hall, New York, 1989.

[Erc92] V. Erceg, S. Ghassemzadeh, M. Taylor, D. Li and D. L. Schiling, "Urban/Suburban Out-of-Sight Propagation Modelling", IEEE Communication Magazine, pp. 56-61, June 1992.

[Erc94] V. Erceg, A. J. Rustako and R. S. Roman, "Diffraction Around Corners and Its Effects on the Microcell Coverage Area in Urban and Suburban Environments at 900 MHz”, IEEE Transactions on Vehicular Technology, vol. 43, no. 11, pp. 762-766, August 1994.

[Ert98] R. B. Erter and P. Cardieri, "Overview of Spatial Channel Models for Antenna Array Communication Systems", IEEE Personal Communications, pp. 10-22, February 1998.

[ETSI98] ETSI TR 101112 V 3.2.0), "Selection procedures for the choice of radio transmission technologies for UMTS", ETSI Technical Report, 04-1998.

[Fle96] B. H. Fleury, "An uncertainty relation for WSS processes and its application to WSSUS systems", IEEE Transactions on Communications, vol. 44, pp. 1632-1634, 1996. 
[For95] S. J. Fortune, D. H. Gay, B. W. Kernighan, O. Landron, R. A. Valenzuela and M. H. Wright, "WiSE Design of Indoor Wireless Systems: Practical Computation and Optimization”, IEEE Computational Science and Engineering, March 1995.

[Fos96] G. J. Foschini and J. Gans, "On Limits of Wireless Communications in a Fading Environment when Using Multiple Antennas ”, Bell Labs Technical Journal, vol. 1, no. 2, Lucent Technologies, pp 41-59, Autumn 1996.

[Fos96b] G. J. Foschini, "Layered Space-Time Architecture for Wireless Communication in a Fading Environment When Using Milti-Element Antennas", Bell Laboratories, Lucent Technologies, Crawford Hill Laboratory, 1996.

[Ful98] J. Fuhl, A. Molish, E. Bonek, "Unified Channel Model for Mobile Radio Systems with Smart Antennas", IEE Proceedings of Radar, Sonar Navigation, 145, pp. 32-41, 1998.

[Ful02 $\left.{ }^{\circ}\right]$ T. L. Fulgum, K.J. Molnar and A.Duel-Hallen, “The Jakes Fading Model for Antenna Arrays Incorporating Azimut Spread", IEEE Transactions on Vehicular Technology, vol. 51, no. 5, pp. 968-977, September 2002.

[Fur89] T. Furuno and T Taga "Time Delay in Microcellular for Personal Communication Systems", IEICE Transactions on Communications, vol. E79-B, no. 9, pp. 1199-1204, September 1996.

[Gal03] Giovanni del Galdo, "IlmProp: a Flexible Geometry-Based Simulation Environment for MultiUser MIMO Communications", COST 273 TD(03)188, Prague, Czech Republic, September, 2003.

[Ge00] D. Gesbert, H. Bolcskei, D. Gore and A. Paulraj, "MIMO wireless channels: Capacity and performance predictions", in proceedings CT10-5, IEEE Globecom 2000, San Francisco, CA, November 27 - December 1, 2000.

[Ges03] D. Gesbert, M. Shafi, D-S Shiu, P. Smith and A. Naguib, "From Theory to Practice: An Overview of MIMO Space-Time Coded Wireless Systems", IEEE Journal on Selected Areas in Communications, vol. 21, no. 3, April 2003

[Ger01] G. German, Q. Spencer, L. Swindlehurst and R. Valenzuela, "Wireless Indoor Channel Modeling: Statistical Agreement of Ray Tracing Simulations and Channel Sounding Measurements", Proc. IEEE ICASSP, Salt Lake city, UT, May 2001. 
[Gla90] GLASSNER, ANDREW S, An introduction to Ray Tracing, Academic Press, Harcourt Brace Jovanovich Publishers, New York, Tercera edición 1990.

[Goo00] Alan Gooding, "The Characterisation of Mobile Radio Communications Channels in the 450, 900, 1800 and $2400 \mathrm{MHz}$ Frequency Bands in a Microcellular Environment", Final Project, Valencia April 2000.

[Ham02] D. Hampicke, M. Landmann, C. Scheider, G. Sommerkorn, R. Thoma, T. Fugen, J. Maurer and W. Wiesbeck, "MIMO Capacities for Different Antenna Array Structures Based on Double Directional Wideband Channel Measurements", IEEE VTC 2002 Fall, Vancouver Canada, 24-28 September 2002.

[Hat80] M. Hata, "Empirical Formula for Propagation Loss in Land Mobile Radio Services", IEEE Transactions on Vehicular Technology, vol. 29, no. 3, August 1980.

[Hib03] Rubén Hibernón Fernández, José María Molina García-Pardo, y Leandro JuanLlácer, "Herramienta para Análisis de Canales MIMO en Microceldas Basada en GIS", XIX Simposium Nacional de la Unión Científica Internacional de Radio, Barcelona, Septiembre 2004.

[Hoe92] P. Hoeher, “A Statistical Discrete-Time Model for the WSSUS Multipath Channel", IEEE Transactions on Vehicular Technology, vol. 41, no. 4, pp. 461-468, November 1992.

[Hol00] C. L. Holloway, D. A. Hill, R. A. Dalke and G. H. Hufford, "Radio Wave propagation Characteristics in Lossy Circular Waveguides Such as Tunnels, Mine Shafts, and Boreholes", IEEE Transactions on Antennas and Propagation, vol. 48, no. 9, pp. 1354-1366, September 2000.

[Hum03] G. Humer, R. Kloibhofer, G. Pfeiffer, G. Steinboeck, "COST 259 Channel Model Implementation for Real-Time Simulations", COST 273 TD (03)202, 2003.

[Hwa98] Y. Hwang, Y. P. Zhang and R. G. Kouyomjian, "Ray-Optical Prediction of Radio-Wave Propagation Characteristics in Tunnel Environments- Part 1: Theory", IEEE Trans. on Antennas and Propagation., vol. 46, no. 9, pp. 1328-1336. September 1998.

[Ike84] F. Ikegami, S. Yoshoida, T. Takeuchi and M. Umehira, "Propagation Factors Controlling Mean Field Strength on Urban Streets", IEEE Transactions on Antennas and Propagation, vol. 32, pp. 822-829, December 1984. 
[Jak74] W. C. Jakes, Microwave Mobile Communications, John Wiley and Sons, New York, 1974.

[Jia02] J-S. Jiang and M. Ingram, "Path Model and MIMO capacity for measured indoor channels at $5.8 \mathrm{GHz}$ ", IEEE International Symposium on Antenna Technology and Applied Electromagnetics, August 2002.

[Jia02b] J-S. Jiang and M.A. Ingram, "Distributed Sorce Model for Short-Range MIMO", International Symposium on Vehicular Technology Conference, October 2002

[Kad95] G. Kadel and R. Lorenz "Impact of the radio channel on the performance of digital mobile communication systems", In Sixth IEEE Int. Symposium on Personal, Indoor and Mobile Radio Communications PIMRC'95, pp. 419-423, 1995.

[Kel62] J.B. Keller, "Geometrical theory of diffraction", Journal Optical Society American, vol. 52, no. 2, pp. 116-130, 1962.

[Kiv99] J. Kivinen, T. O. Korhonen, P. Aikio, R. Gruber, P. Vainikainen and S. G. Häggman, "Wideband Radio Channel Measurement System at 2 GHz", IEEE Transactions on Instrumentation and Measurement, vol. 48, no. 1, pp 39-44, February 1999.

[Kiv01] J. Kivinen, X. Zhao and P. Vainikainen, "Empirical Characterisation of Wideband Indoor Radio Channel at 5.3 GHz", IEEE Transactions on Antennas and Propagation., vol. 49, no. 8, pp. 1192-1203, August 2001.

[Kou74] R. G. Kouyaumijan and P. H. Pathak, "A Uniform Geometrical Theory of Diffraction for an Edge in a Perfectly Conducting Surface", Proceedings of the IEEE, vol. 62, no. 11, pp. 1448-1461, November 1974.

[Kyr02] P. Kyritsi, "MIMO Capacity in Free Space and Above Ground: Theory and Experimental results”, IEEE PIMRC '02. September 2002.

[Laa76] K. D. Laakmann and William H. Steier, "Waveguides: characteristic modes of hollow rectangular dielectric waveguides", Applied Optics, vol. 14, no. 5, pp 1134-40, 1976.

[Lam98] J. S. Lamminmäki and J.J.A. Lempiäinen, "Radio Propagation characteristics in curved tunnels", IEEE Proceedings of Microwave Antennas Propagation, vol. 45, no. 4, pp. 327-331, August 1998. 
[Law94] M. C. Lawton and J. P. McGeehan, "The Application of a Deterministic Ray Launching Algorithm for the Prediction of Radio Channel Characteristics in Small-Cell Environments", IEEE Transactions on Vehicular and Technology, vol. 43, no. 4, pp. 955-969, November 1994.

[Lee01] B. S. Lee, A. R. Nix and J. P. McGreehan, “A Spatio-Temporal Ray Launching Propagation Model for UMTS Pico and Microcellular Environments", Vehicular Technology Conference, vol. 1, pp. 367-371, 2001.

[Lie98] M. Lienard and P. Degauque, "Propagation in Wide Tunnels at 2GHz: A Statistical Analysis", IEEE Transactions on Vehicular Technology, vol. 47, no. 1, pp. 283-296. February 1998.

[Lie99] M. Liénard and P. Degauque, "Wideband analysis of propagation along radiating cables in tunnels", Radio Science, vol. 34, no. 1, pp. 113-122, 1999

[Lie00] M. Liénard, S. Betrecourt and P. Degauque, "Propagation in Road Tunnels/Influence of the Traffic Conditions and Channel Characterisation for Adaptive Antennas", COST 259 TD(00) 001, January 2000.

[Lie02] Liénard, J Baudet, D. Degardin and Pierre Degauque, "Characterisation of MIMO Channels in Subway Tunnels ," COST 273 TD(02) 011, Guildford 2002.

[Lin01] J. Ling, D. Chizhik, R. Valenzuela, "Predicting Multi-Element Receive \& Transmit Array Capacity Outdoors with Ray Tracing”, IEEE VTC Rhodes, 2001.

[Loz01] A. Lozano, F. R. Farrokhi and R. Valenzuela, "Lifting the limits on high-speed wireless data access using antenna arrays", IEEE Communications Magazine, vol. 39, pp. 156-162, September 2001.

[Lue89] R. J. Luebbers, W. A. Foose and G. Reyner, "Comparison of GTD Propagation Model Wide-Band Path Loss Simulation with Measurements", IEEE Trans. on Antennas and Propagat., vol. 37, no. 4, pp. 499-505, April 1989.

[Lue84] Luebbers, R. J. "Finite conductivity uniform GTD versus knife edge diffraction in prediction of propagation path loss, " IEEE Trans. Antennas and Propagation, vol. 32, no. 1, pp. 70-76, January 1984.

[Mah74] S. F. Mahmoud and J.R. Wait, "Geometrical optical approach for electromagnetic wave propagation in rectangular mine tunnels", Radio Science, vol. 9 no. 12 , pp. 1147-1158, 1974. 
[Mar94] P. Mariage, M. Lienard, and P. Degauque, "Theoretical and experimental approach of the propagation of high frequency waves in road tunnels", IEEE Transactions on Antennas and Propagation, vol. 42, no. 1, pp. 75-81, 1994.

[Mar01] F. Martí Pallarés, F. J. Ponce Juan y L. Juan-Llácer, “Analysis of Path Loss and Delay Spread at $900 \mathrm{MHz}$ ans $2.1 \mathrm{GHz}$ While Entering Tunnels," IEEE Transactions on Vehicular Technology, vol. 50, no. 3, pp. 767-776. May 2001.

$[\mathrm{Med}] \underline{\text { www.medav.de }}$

[Mo199] A. F. Molisch and M. Steinbauer, "Condensed parameters for characterizing wideband mobile radio channels", IEE International Journal of Wireless Information Networks, (IJWIN), vol. 6, pp. 133-154, July 1999.

[Mol02] A.F. Molish, M. Steinbauer. M. Toreltsch, E. Bonek, R.S. Thoma, "Capacity of MIMO Systems Based on Measured Wireless Channels", IEEE Journal on Selected Areas in Comm, vol. 20, no. 3, pp. 561-569, April 2002.

[Mol02a] José María Molina Garcia-Pardo and Leandro Juan-Llácer, "Path Loss, Delay Spread and Angular Spread at 2.1 GHz while entering Tunnels", COST 273 TD(02) 043, Espoo, Finland 2002/May/30-31.

[Mo102b] José María Molina García-Pardo, José Victor Rodríguez Rodríguez y Leandro Juan-Llácer, "Cálculo de la Zona de Excitación para diversos túneles a la frecuencia de 2.1 GHz”, XVII Simposium Nacional de la Unión Científica Internacional de Radio, Alcalá de Henáres, Madrid, Septiembre 2002.

[Mol02c] Jose-Maria Molina-García-Pardo and Leandro Juan-Llácer, "Time Delay Spread at 2.1 GHz around Regular and Chaflane Street Corners for Microcellular Communications", The 13th IEEE International Symposium on Personal, Indoor and Mobile Radio Communications, vol. 3, pp. 1200-1202, Lisbon, 15-18 September, 2002.

[Mol03a] José María Molina García-Pardo, José Victor Rodríguez Rodríguez, and Leandro Juan-Llácer, "Angular Spread at 2.1 GHz while entering Tunnels”, Microwave and Optical Technology Letters, vol. 37, no. 3, May 2003.

[Mol03b] José María Molina Garcia-Pardo, Jose Victor Rodriguez and Leandro JuanLlácer, "Measurements and Characterization of the Wide Band Complex Channel Transfer Function in a Small Tunnel", COST 273 TD(03)016, Barcelona, Spain 2003/January. 
[Mol03c] José María Molina García-Pardo, José Victor Rodríguez Rodríguez y Leandro Juan-Llácer, "Capacidad MIMO en la Transición de entrada a un Túnel", XVIII Simposium Nacional de la Unión Cientifica Internacional de Radio, A Coruña, 10-12 Septiembre 2003.

[Mol03d] Jose-Maria Molina-Garcia-Pardo, Vicent-Miquel Rodrigo-Peñarrocha and Leandro Juan-Llacer "Wideband Radio Communication Measurements at 450, 900, 1800 and $2400 \mathrm{MHz}$ at Regular and Chaflane Street Corners", IEEE Antennas and Propagation Conference, Ohio, June, 2003.

[Mol03e] Jose-Maria Molina-Garcia-Pardo, Jose-Victor Rodriguez, Leandro JuanLlacer, "Evaluation of MIMO capacity in regular and chaflane street corners for microcellular communications", The 14th IEEE International Symposium on Personal, Indoor and Mobile Radio Communications, 2003. PIMRC 2003, vol. 2, pp 1511-1515, Beijing, China, September, 2003.

[Mol04a] Jose-Maria Molina-García-Pardo, Jose-Victor Rodríguez, and Leandro JuanLlacer, "Wide-Band Measurements and Characterization at $2.1 \mathrm{GHz}$ While Entering in a Small Tunnel", IEEE Transaction on Vehicular Technology, vol. 53, no. 6, November 2004.

[Mol04b] José-María Molina-García-Pardo, José-Víctor Rodríguez and Leandro JuanLlácer, "MIMO Capacity at $2.1 \mathrm{GHz}$ While Entering Tunnels", IEEE Vehicular Technology Conference Fall, Los Ángeles, September, 2004.

[Mol04c] Jose-Maria Molina-Garcia-Pardo, Vicent-Miquel Rodrigo-Peñarrocha and Leandro Juan-Llacer "Characterization at 450, 900, 1800 and $2400 \mathrm{MHz}$ of Regular and Chaflane Street Corners by Measurements", accepted for publication in IEEE Transactions on Antennas and Propagation, December 2004.

[Mol04d] José-María Molina-García-Pardo, José-Víctor Rodríguez and Leandro JuanLlácer, "Modelo MIMO Paramétrico para Simulaciones utilizando el Trazado de Rayos", XIX Simposium Nacional de la Unión Científica Internacional de Radio, Barcelona, Septiembre 2004.

[Mol04e] José-María Molina-García-Pardo, José-Víctor Rodríguez and Leandro JuanLlácer, "Parametric MIMO Model for Ray Tracing/Launching Simulations", IEEE Vehicular Technology Conference Fall, Los Ángeles, September, 2004. 
[Mol04f] José-María Molina-García-Pardo, Domingo Pardo-Quiles, José Víctor Rodríguez and Leandro Juan-Llácer, "A Distributed MIMO Scheme for Urban Street Microcells", 15th IEEE International Symposium on Personal, Indoor and Mobile Radio Communications, Barcelona, September 2004.

[Mol04g] Jose-María Molina-García-Pardo, Javier Celdrán-Blaya, Jose-Victor Rodríguez y Leandro Juan-Llácer“, A MIMO Measurement System Based on Two Network Analyzers", COST 273 TD(04)106, Gothenburg, Sweden, 2004/June/09-10.

[Oes02] C. Oestges, B. Clerckx, L. Raynaud and D- Vanhoenacker-Janvier, "Deterministic Channel Modeling and Performance Simulation of Microcellular WideBand Communication Systems ," IEEE Transactions on Vehicular Technology, vol. 51, no. 6, pp. 1422-1429, November 2002.

[Par96] D. Parsons, The Mobile Radio Propagation Channel, Wiley, Chichester, West Sussex, England, 1996.

[Pap98] N. Papadakis, A. G. Kanatas and P. Costantinou, "Microcellular Propagation Measurements and Simulation at $1.8 \mathrm{GHz}$ in Urban Radio Environment", IEEE Transactions on Vehicular Technology, vol. 47, no. 3, pp. 1012-1026, August 1998.

[Rab 97] J. M. Hernández Rábanos, Comunicaciones Móviles, Madrid, Centro de Estudios Ramón Areces, 1997.

[Rab01] J.M. Hernándo Rábanos, Comunicaciones móviles de tercera generación, Telefonica Móviles España S.A., Madrid 2001.

[Rap89] T. S. Rappaport, "Characterization of UHF Multipath Radio Channels in Factory Buildings", IEEE Transaction in Antennas and Propagation, vol. 40, no. 2, pp. 323-331, August 1989.

[Rap90] T. S. Rappaport, S. Y. Seidel and R. Singh, “900-MHz Multipath Propagation Measurements for U.S. Digital Cellular Radiotelephone", IEEE Transactions on Vehicular Technology, vol. 39, no. 2, pp. 132-139, May 1990.

[Rap96] T. S. Rappaport, Wireless Communications, New York, Prentice Hall, 1996.

[Riz97] K. Rizk, J. F. Wagen and F. Gardiol, "Two dimensional Ray-Tracing Modeling for Propagation Prediction in Microcellular Environments", IEEE Transactions on Vehicular Technology, vol. 46, no 2, pp. 508- 518, May 1997. 
[Roh] W. Roh and A. Paulraj, "MIMO Channel Capacity for Distributed Antenna Systems”, IEEE 56th Vehicular Technology Conference Fall, pp. 706-708, 2002.

[Rod99] Rodríguez, Jorge Luis, Predicción de parámetros básicos de propagación en entornos microcelulares mediante técnicas de trazado de rayos, Proyecto Fin de Carrera, Escuela Técnica Superior de Ingenieros de Telecomunicación de la Universidad Politécnica de Valencia. Julio 1999.

[Rod01] J. L. Rodriguez and L. Juan-Llácer, "Comparison of path loss and time delay spread in regular and chaflanes street corners for microcellular communications", Microwave and optical technology letters, vol. 29, pp. 139-142, 2001.

[Rus91] A. J. Rustako, N. Amitay, G. J. Owens and R.S. Roman, "Radio Propagation at Microwave Frequencies for Line-of-Sight Microcellular Mobile and Personal Communications", IEEE Transactions on Vehicular Technology, vol. 40, no. 1, pp. 203 210, February 1991.

[Sak02] K. Sakaguchi, J. Takada and K. Araki, "A Novel Architecture for MIMO Spatio-Temporal Channel Sounder", IEICE Transactions on Electronics, vol. E02-C, no. 3, March 2002.

[Sa199] S. Salous, "Measurement of multipath delay statistic over a 72 to $90 \mathrm{MHz}$ bandwidth at $1.8 \mathrm{GHz}$ in two European cities", Radio Science, vol. 34, no. 4, pp. 797816, July-August 1999.

[San04] S. Salous and N. Razavi-Ghods, "Semi-Sequential MIMO Channel Measurement in Indoor Environments", COST 273 TD(04)079, Gothenburg, Sweden, June 2004.

[Sha48] C. E. Shannon, "A mathematical theory of communication", Bell System Technical Journal, vol. 27, pp. 379-423 and 623-656, July and October, 1948.

[Smi02] P. J. Smith and M. Shafi "On a Gaussian Approximation to the capacity of Wireless MIMO Systems”, Int. Conf. Communications, ICC, pp. 406-410, 2002.

[Ste01] M. Steinbauer, "The Radio Propagation Channel - A Non-Directional, Directional and Double-Directional Point-of-View", PhD Thesis, Technische Universität Wien, November 2001.

[Tar99] V. Tarokh, H. Jafarkhani, and A. R. Calderbank "Space-time block codes from orthogonal designs", IEEE Transactions on Information Theory, vol. 45 no 5, pp. 1456- 
1467, July 1999.

[Te195] I. E. Telatar, "Capacity of Multi-Antenna Gaussian Channel", European Transaction on Telecommunications, AT\&T Bell Laboratories, Tech. Memo., June 1995

[Te199] Telatar, I.E., "Capacity of Multi-Antenna Gaussian Channel”, European Transactions on Telecommunications, vol. 10, no. 6, pp. 585-595, 1999.

[Tho01] R. S. Thomä, D. Hampicke, A. Richter, G. Sommerkorn, "MIMO Vector Channel Sounder Measurements for Smart Antenna System Evaluation”, European Transaction on Telecommunications, ETT, vol. 12, no. 5, pp. 427-438, September/October 2001.

[Wal88] J. Walfisch and H. L. Bertoni, "A Theoretical Model of UHF Propagation in Urban Environments", IEEE Transaction Antennas and Propagation, vol. 36, pp. 17881796, December 1998.

[Wep95] J. A. Wepman, J. R. Hoffman and L. H. Loew, “Analysis if Impulse Response Measurements for PCS Channel Modelling Applications", IEEE Transactions on Vehicular Technology, vol. 44, no. 3, pp. 613-620, August 1995.

[Win87] Winters, "On the Capacity of Radio Communications Systems with Diversity in a Rayleigh Fading Environment", IEEE Journal on Selected Areas of Communications, vol. 5, pp. 871-878, June 1987.

[Wo198] P.W. Wolniansky, G. J. Foschini, G.D. Golden and R.A. Valenzuela, "VBLAST: An Architecture for realizing Very High Data Rates Over the Rich-Scattering Wireless Channel", Bell Laboratories, Lucent Technologies, Crawford Hill Laboratory, 1998.

[Yam85] Y. Yamaguchi, T. Abe, T. Sekiguchi and J. Chiba, "Attenuation constants of UHF radio waves in arched tunnels", IEEE Transactions on Microwave Theory Technology, vol. 33, no. 8, pp. 714-718, August 1985.

[Zha97] Wei Zhang, "A Wide-Band Propagation Model Based on UTD for Cellular Mobile Radio Communications", IEEE Transactions on Antennas and Propagation, vol. 45, no. 11, pp. 1669-1678, November 1997.

[Zha98] Y. P. Zhang and Y. Hwang, "Measurements and statistical modeling of 900 $\mathrm{MHz}$ radio propagation channels for microcellular and personal communications in tunnels”, Wireless Personal Communications, vol. 7, no. 1, pp. 25-39, 1998. 
[Zha98b] Y. P. Zhang and Y. Hwang, "Theory of the Radio-Wave Propagation in Railway Tunnels", IEEE Transactions on Vehicular Technologies, vol. 47, no. 3, pp. 1027-1036, 1998.

[Zha98c] Y. P. Zhang, Y. Hwang and R. G. Kouyomjian, "Ray-Optical Prediction of Radio-Wave Propagation Characteristics in Tunnel Environments- Part 2: Analysis and Measurements", IEEE Transactions on Antennas and Propagation, vol. 46, no. 9, pp. 1337-1345, September 1998.

[Zha01] Y. P. Zhang, G. X. Zheng and J. H. Sheng, "Radio Propagation at $900 \mathrm{MHz}$ in Underground Coal Mines", IEEE Transactions on Vehicular Technology, vol. 49, no. 5, pp. 757-762, May 2001.

[Zhe99] G. X. Zheng, J. H. Sheng and Y. P. Zhang, "Propagation of UHF radio waves in trapezoidal tunnels", Microwave and Optical Technology Letters, vol. 20, no. 5, pp. 295 297. March 1999. 


\section{Acrónimos}

Español

AS

$\mathrm{CCDF}$

CW

GIS

GO

GPS

GTD

DS

ETSI

IDFT
Dispersión Angular

Función de Densidad Acumulada

Complementaria

Onda continua

Sistemas de información geográfica

Óptica Geométrica

Sistema de Posicionamiento Global Global Position System

Teoría Geométrica de la Difracción Geometrical Theory of Difraction

Dispersión Temporal

Delay Spread

Instituto Europeo de estandarización European Telecommunications

de las Telecomunicaciones

Stadards Institute

Transformada Inversa de Fourier
Angular Spread

Complementary Cumulative Density

Functions

Continuous Wave

Geometric Optics 
Discreta

ISB

ITU

LoS

MIMO

MISO Múltiples entradas y una salida

NLoS No visión directa

PDP Perfil de Retardo

$\mathrm{PF}$

PM

PW

RSB

SIMO

SNR

US

UTD

UTM

WSS

WSSUS
Frontera de sombra incidente

Unión Internacional de las

Telecomunicaciones

Visión directa

Múltiples entradas y salidas

Factor de propagación

Modelo Paramétrico

Modelo onda Plana

Frontera de sombra reflejada

Una entrada y múltiples salidas

Relación Señal a Ruido

Dispersores incorrelados

Teoría Uniforme de la Difracción

Estacionario en sentido amplio

Estacionario en sentido amplio

Con dispersores incorrelados
Incident Shadow Boundary

International Telecommunication

Union

Line of Sight

Multiple-Input Multiple-Output

Multiple-Input Single-Output

Non Line of Sight

Power Delay Profile

Propagation Factor

Parametric Model

Planar Wave Model

Reflected Shadow Boundary

Single-Input Multiple-Output

Signal to Noise Rate

Uncorrelated Scattering

Uniform Theory of Diffraction

Universal Transverse Mercator

Wide-Sense Stationary

Wide-Sense Stationary Uncorrelated

Scattering 


\section{Notación}

\section{Símbolo}
A
Factor de dispersión.
$\mathrm{D}$
Coeficiente de difracción.
$\mathrm{D}_{\mathrm{s}} \quad$ Coeficiente de difracción soft.
$\mathrm{D}_{\mathrm{h}} \quad$ Coeficiente de difracción hard.
$\delta \quad$ Tangente de pérdidas.
$\mathrm{E}_{\mathrm{DIR}} \quad$ Campo eléctrico recibido por la componente de rayo directo.
$\mathrm{E}_{\mathrm{D}} \quad$ Campo eléctrico recibido por la componente de rayo difractado.
$\mathrm{E}_{\mathrm{R}} \quad$ Campo eléctrico recibido por la componente de rayo reflejado.
$\mathrm{E}_{\mathrm{o}} \quad$ Factor que depende del transmisor.
$\varepsilon \quad$ Permitividad.
$\varepsilon_{\mathrm{r}} \quad$ Permitividad relativa. 
$\varepsilon_{0} \quad$ Permitividad en el vacío.

$f \quad$ Frecuencia.

$\bar{\varphi}(t) \quad$ Dispersión angular media.

$\sigma$

Conductividad.

$\sigma_{\tau}(t) \quad$ Varianza de la dispersión temporal.

$\sigma_{v}(f) \quad$ Varianza de la dispersión de la dispersión Doppler.

$\sigma_{\varphi}(t) \quad$ Varianza del a dispersión de la dispersión angular.

$h(t, \tau) \quad$ Función de transferencia del canal radio.

k Número de onda.

K Factor K.

$L_{N B} \quad$ Pérdidas de banda estrecha.

$L_{W B} \quad$ Pérdidas de banda ancha.

$\lambda \quad$ Longitud de onda.

$\mathrm{n} \quad$ Índice de refracción.

$\rho \quad$ Señal a Ruido.

r Distancia recorrida por el rayo.

R Coeficiente de reflexión.

$\mathrm{R}_{\perp} \quad$ Coeficiente de reflexión para polarización soft.

$\mathrm{R}_{\|} \quad$ Coeficiente de reflexión para polarización hard.

$\mathrm{t} \quad$ Variable que indica la variabilidad temporal del canal.

$\tau \quad$ Variable que indica la dispersión temporal del canal.

$\bar{\tau}(t) \quad$ Retardo medio.

$V\left(x_{\mathrm{i}}\right) \quad$ Voltaje instantáneo recibido en la posición $x_{\mathrm{i}}$.

৩ Dispersión Doppler.

$\bar{v}(f) \quad$ Dispersión Doppler media.

$\omega$

Frecuencia Angular. 